Florida International University FIU Digital Commons

3-23-2015

\title{
Time, Cost, and Environmental Impact Analysis for Sustainable Design at Multiple Building Levels
}

Peeraya Inyim

pinyi001@fiu.edu

DOI: $10.25148 /$ etd.FI15032171

Follow this and additional works at: https://digitalcommons.fiu.edu/etd

Part of the Civil Engineering Commons, and the Construction Engineering and Management Commons

\section{Recommended Citation}

Inyim, Peeraya, "Time, Cost, and Environmental Impact Analysis for Sustainable Design at Multiple Building Levels" (2015). FIU Electronic Theses and Dissertations. 1800.

https://digitalcommons.fiu.edu/etd/1800 


\section{FLORIDA INTERNATIONAL UNIVERSITY}

Miami, Florida

TIME, COST, AND ENVIRONMENTAL IMPACT ANALYSIS FOR SUSTAINABLE DESIGN AT MULTIPLE BUILDING LEVELS

A dissertation submitted in partial fulfillment of

the requirements for the degree of

DOCTOR OF PHILOSOPHY

in

CIVIL ENGINEERING

by

Peeraya Inyim 
To: Dean Amir Mirmiran

College of Engineering and Computing

This dissertation, written by Peeraya Inyim, and entitled Time, Cost, and Environmental Impact Analysis for Sustainable Design at Multiple Building Levels, having been approved in respect to style and intellectual content, is referred to you for judgment.

We have read this dissertation and recommend that it be approved.

Berrin Tansel

Ton-Lo Wang

$\begin{array}{r}\hline \text { Yimin Zhu } \\ \hline \text { Arindam Gan Chowdhury,Co-Major Professor } \\ \hline \text { Wallied Orabi,Co-Major Professor }\end{array}$

Date of Defense: March 23, 2015

The dissertation of Peeraya Inyim is approved.

Dean Amir Mirmiran

College of Engineering and Computing

Dean Lakshmi N. Reddi

University Graduate School

Florida International University, 2015 
(C) Copyright 2015 by Peeraya Inyim

All rights reserved. 


\section{DEDICATION}

This dissertation is dedicated to my parents, who have been a great support to me. 


\section{ACKNOWLEDGMENTS}

First, I would like to express my deepest gratitude to Dr. Yimin Zhu for his constant guidance and endless encouragement. He has guided and supported me throughout my research. Without him, I would not have experienced a lot of great opportunities in my Ph.D. life. I am extremely proud to be one of his students. I always admire his work and perseverance to provide profound knowledge to students and research.

I would like to thank Dr. Wallied Orabi, a co-major advisor, who greatly supports my Ph.D. journey. His mentorship, thoughtful suggestions, and helpful efforts have encouraged me to grow my knowledge in achieving this dissertation and research. I would also like to thank Dr. Arindam Gan Chowdhury for serving as a co-major advisor. His considerate guidance and suggestion have been beneficial help to this dissertation.

My grateful thanks are to my Ph.D. committee members, Dr. Berrin Tansel and Dr. Ton-Lo Wang, for their wonderful recommendations in improving my dissertation. I also would like to thank Dr. Junghyon Mun and Dr.Guangyuan Xiong from the University of North Texas for providing significant and useful material to this research.

Next, I would like to express gratefully appreciation to the OHL School of Construction and the Department of Civil and Environmental Engineering, for providing me with the invaluable opportunity to pursue my Ph.D. at Florida International University. My sincere thanks are also to all faculty, staff, and students at the OHL School of Construction. 
My Ph.D. studies and dissertation were financially supported in part by the National Science Foundation Grant No. 1000136, as well as the Dissertation Year Fellowship from the University Graduate School, Florida International University.

Finally, my forever and important gratitude goes to my parents, Phimsiri Inyim and Ranas Inyim, and my brother, Kittichon Inyim, for their great support, understanding, and unconditional love. I would like to offer special thanks to David Palm for his consistent patience and support in all situations. 


\title{
ABSTRACT OF THE DISSERTATION \\ TIME, COST AND ENVIRONMENTAL IMPACT ANALYSIS FOR \\ SUSTAINABLE DESIGN AT MUTIPLE BUILDING LEVELS
}

\author{
by
}

Peeraya Inyim

Florida International University, 2015

Miami, Florida

\section{Professor Wallied Orabi, Co-Major Professor}

Professor Arindam Gan Chowdhury, Co-Major Professor

Construction projects are complex endeavors that require the involvement of different professional disciplines in order to meet various project objectives that are often conflicting. The level of complexity and the multi-objective nature of construction projects lend themselves to collaborative design and construction such as integrated project delivery (IPD), in which relevant disciplines work together during project conception, design and construction. Traditionally, the main objectives of construction projects have been to build in the least amount of time with the lowest cost possible, thus the inherent and well-established relationship between cost and time has been the focus of many studies. The importance of being able to effectively model relationships among multiple objectives in building construction has been emphasized in a wide range of research. In general, the trade-off relationship between time and cost is well understood and there is ample research on the subject. However, despite sustainable building designs, relationships between time and environmental impact, as well as cost and environmental impact, have not been fully investigated. 
The objectives of this research were mainly to analyze and identify relationships of time, cost, and environmental impact, in terms of $\mathrm{CO}_{2}$ emissions, at different levels of a building: material level, component level, and building level, at the pre-use phase, including manufacturing and construction, and the relationships of life cycle cost and life cycle $\mathrm{CO}_{2}$ emissions at the usage phase. Additionally, this research aimed to develop a robust simulation-based multi-objective decision-support tool, called SimulEICon, which took construction data uncertainty into account, and was capable of incorporating life cycle assessment information to the decision-making process. The findings of this research supported the trade-off relationship between time and cost at different building levels. Moreover, the time and $\mathrm{CO}_{2}$ emissions relationship presented trade-off behavior at the pre-use phase. The results of the relationship between cost and $\mathrm{CO}_{2}$ emissions were interestingly proportional at the pre-use phase. The same pattern continually presented after the construction to the usage phase. Understanding the relationships between those objectives is a key in successfully planning and designing environmentally sustainable construction projects. 


\section{TABLE OF CONTENTS}

CHAPTER

PAGE

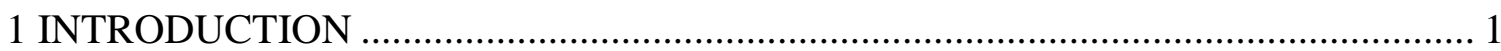

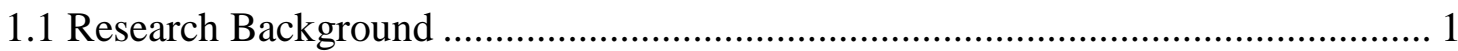

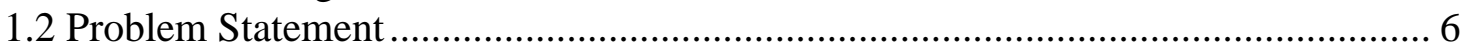

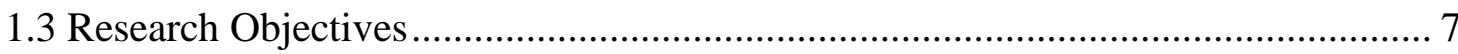

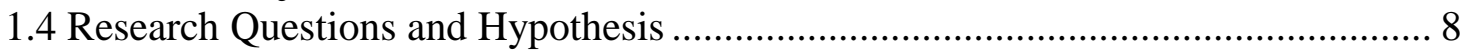

1.5 Research Significance and Methodology ............................................................ 9

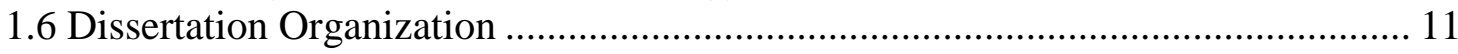

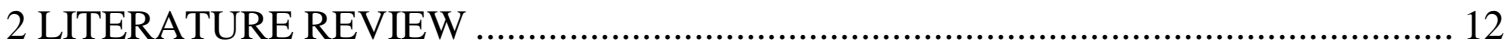

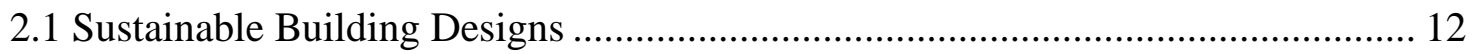

2.2 Trade-off Problems in Multiple Objectives Optimization ...................................... 17

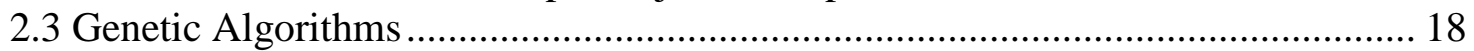

2.4 Monte Carlo Simulation............................................................................... 20

2.5 Building Life Cycle Assessment Tools............................................................... 21

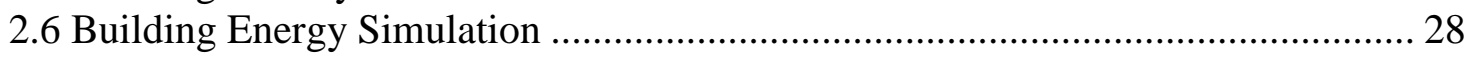

3 AN INTEGRATED SIMULATION FRAMEWORK FOR SUSTAINABLE

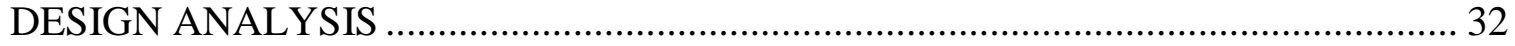



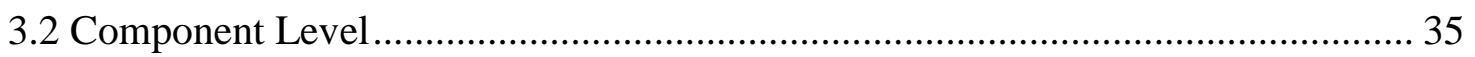

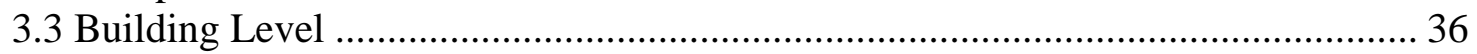

4 ANALYSIS OF TIME, COST AND ENVIRONMENTAL IMPACT RELATIONSHIPS AT BUILDING MATERIAL LEVEL_............................................ 41

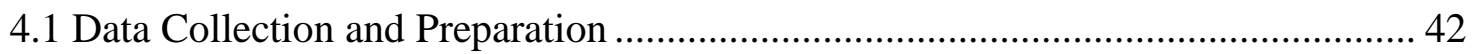

4.1.1 Data Scope and Sources .......................................................................... 42

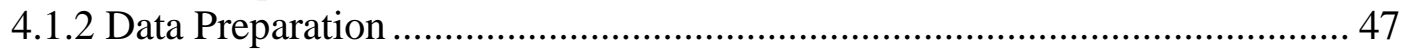

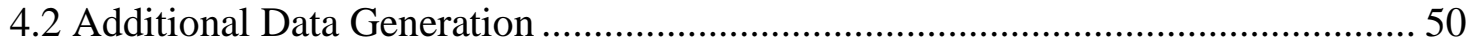

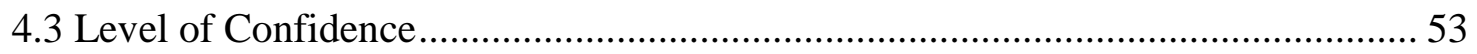

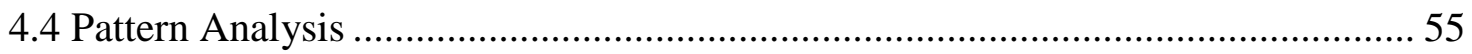

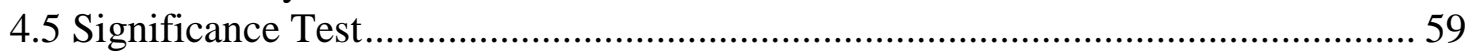

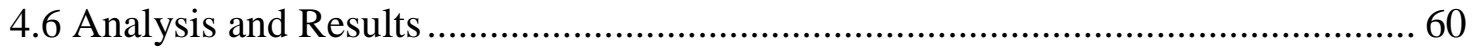

5 ANALYSIS OF CONSTRUCTION TIME, INITIAL CONSTRUCTION COST, AND ENVIRONMENTAL IMPACT RELATIONSHIP AT COMPONENT AND

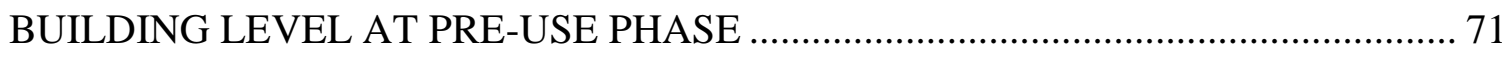

5.1 Data Collection and Case Study Descriptions ................................................... 72

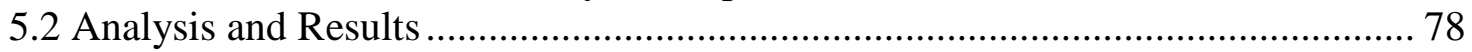




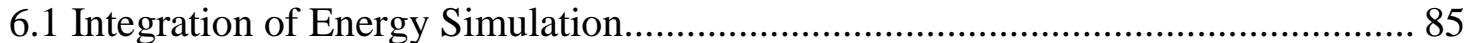

6.2 Data Collection and Case Study Description.................................................. 87

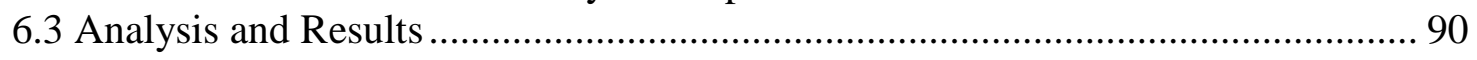

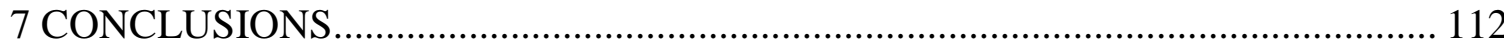

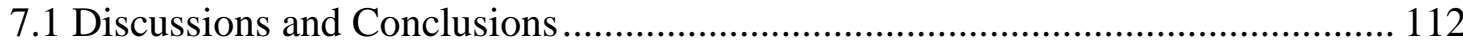

7.2 Limitation and Future Studies...................................................................... 117

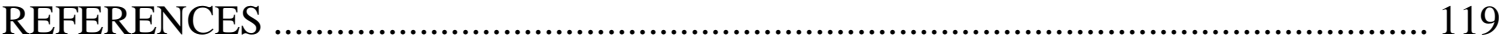

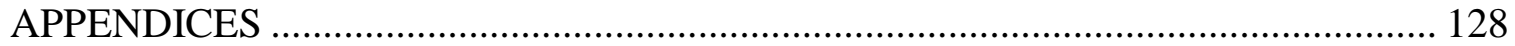

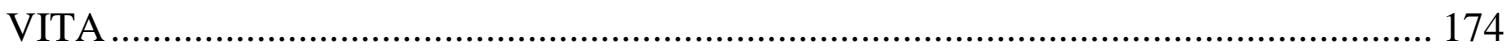




\section{LIST OF TABLES}

TABLE

PAGE

Table 1 Example of Environmental Building Performance Assessment Methods.......... 23

Table 2 Review of Building Environmental Assessment Tools .................................. 27

Table 3 Examples of Building Energy Simulation Programs ...................................... 29

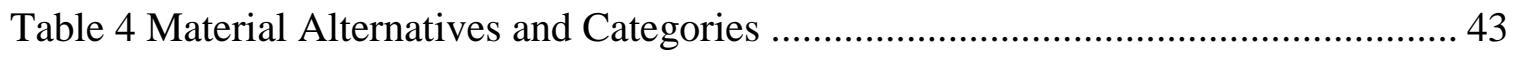

Table 5 Summary of the Two Scenarios .............................................................. 48

Table 6 Summary Functions Representing Variables' Distribution ............................... 52

Table 7 Summary of Dominant Alternatives and Probability in Percentage ................... 63

Table 8 Alternative Pairwise Analysis in Structural Component Category .................... 66

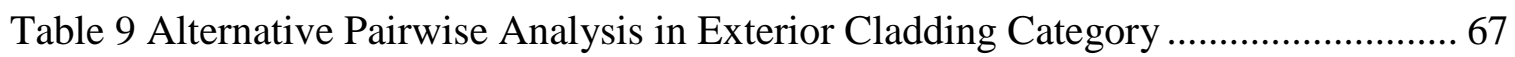

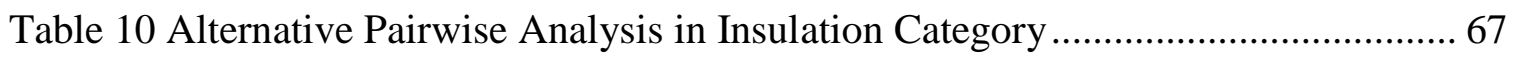

Table 11 Alternative Pairwise Analysis in Roofing Category ..................................... 67

Table 12 Alternative Pairwise Analysis in Concrete Footing 3000 psi Category ............ 68

Table 13 Alternative Pairwise Analysis in Concrete Footing 4000 psi Category ............ 68

Table 14 Alternative Pairwise Analysis in Concrete Slab 4 inches 3000 psi Category ... 68

Table 15 Alternative Pairwise Analysis in Concrete Slab 4 inches 4000 psi Category ... 69

Table 16 Alternative Pairwise Analysis in Concrete Slab 8 inches 3000 psi Category ... 69

Table 17 Alternative Pairwise Analysis in Concrete Slab 8 inches 4000 psi Category ... 69

Table 18 Examples of the Zero Energy Research Laboratory Activities and Theirs

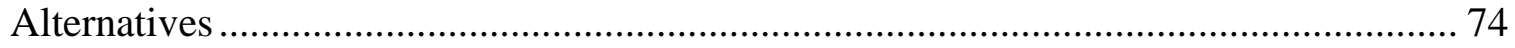

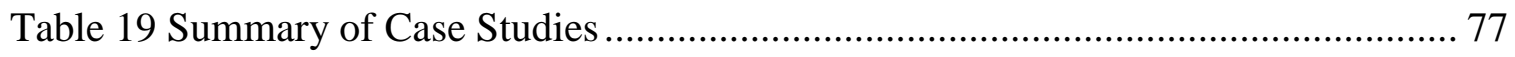

Table 20 Summary of R-squared $\left(\mathrm{R}^{2}\right)$ and Dissimilarity Measures (d): Case Study 1..... 84 
Table 21 Summary of R-squared $\left(\mathrm{R}^{2}\right)$ and Dissimilarity Measures (d): Case Study 2..... 84

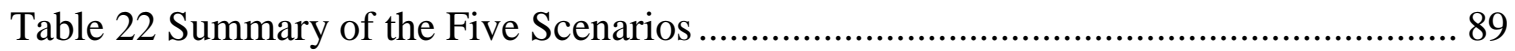

Table 23 Longest Distance between Optimal Solutions ......................................... 107

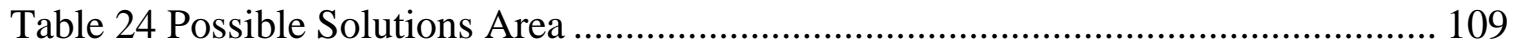




\section{LIST OF FIGURES}

FIGURE

PAGE

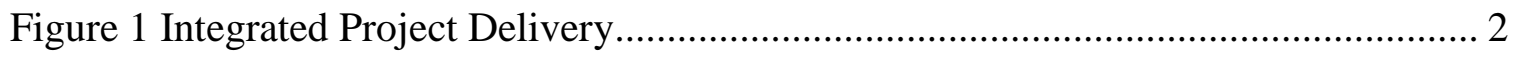

Figure 2 Life Cycle Assessment (LCA) .................................................................... 3

Figure 3 A Building and Components ..................................................................... 5

Figure 4 Information at the Different Levels from the Material Level, the Component

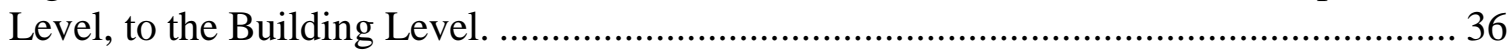

Figure 5 Time, Cost and Environmental Impact Analysis for Sustainable Design at Multiple Building Levels Flowchart.....

Figure 6 Graph Relationship between Average $\mathrm{CO}_{2}$ Emissions per Material Unit and Average Unit Cost for Structural Component (left) and Roofing (right) in Scenario 1 ... 58

Figure 7 Graph Relationship between Average $\mathrm{CO}_{2}$ Emissions per Material Unit and Average Unit Cost (left), and between Average $\mathrm{CO}_{2}$ Emissions per Material Unit and Installation time (right) for Roofing in Scenario 2

Figure 8 Graph Relationship between Average $\mathrm{CO}_{2}$ Emissions per Material Unit and Average Unit Cost (left), and between Average $\mathrm{CO}_{2}$ Emissions per Material Unit and Installation Time (right) for Concrete Footing 3000 psi in Scenario 2 .......................... 59

Figure 9 Graph Relationships between Average $\mathrm{CO}_{2}$ Emissions per Material Unit and Average Unit Cost for Insulation Shows Effect of Material Installation in Percentage ... 70

Figure 10 Three-dimension Models of Case Study 1 (left) and Case Study 2 (right) ...... 73

Figure 11 Optimal Solutions Shown in Graphs Relationships between Construction Time, Initial Construction Cost, and $\mathrm{CO}_{2}$ Emissions of Case Study 1 ......................... 81

Figure 12 Optimal Solutions Shown in Graphs Relationships between Construction Time, Initial Construction Cost, and $\mathrm{CO}_{2}$ Emissions of Case Study 2 ....................... 81

Figure 13 Combined Solutions and Their Frequencies Histogram: Case Study 1 .......... 83

Figure 14 Combined Solutions and Their Frequencies Histogram: Case Study 2 ......... 83

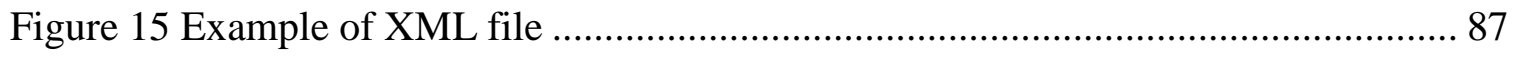

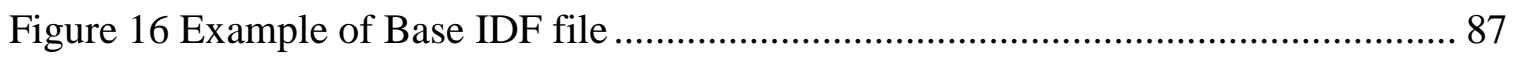

Figure 17 Building Zones; Living Zone, Mechanic Zone, and Electrical Zone .............. 89 
Figure 18 Parametric XML File of the Zero Energy Laboratory Building

Figure 19 Graph Relationships between Cost and $\mathrm{CO}_{2}$ Emissions for 0 Year-Usage

Phase

Figure 20 Graph Relationships between Cost and $\mathrm{CO}_{2}$ Emissions for 5 Year-Usage Phase

Figure 21 Graph Relationships between Cost and $\mathrm{CO}_{2}$ Emissions for 10 Year-Usage

Phase

Figure 22 Graph Relationships between Cost and $\mathrm{CO}_{2}$ Emissions for 15 Year-Usage

Phase

Figure 23 Graph Relationships between Cost and $\mathrm{CO}_{2}$ Emissions for 20 Year-Usage Phase

Figure 24 Graph Relationships between Cost and $\mathrm{CO}_{2}$ Emissions for 25 Year-Usage

Phase

Figure 25 Graph Relationships between Cost and $\mathrm{CO}_{2}$ Emissions for 30 Year-Usage

Phase 96

Figure 26 Graph Relationships between Cost and $\mathrm{CO}_{2}$ Emissions for 35 Year-Usage Phase

Figure 27 Graph Relationships between Cost and $\mathrm{CO}_{2}$ Emissions for 40 Year-Usage

Phase

Figure 28 Graph Relationships between Cost and $\mathrm{CO}_{2}$ Emissions for 45 Year-Usage

Phase

Figure 29 Graph Relationships between Cost and $\mathrm{CO}_{2}$ Emissions for 50 Year-Usage Phase

Figure 30 Graph Relationships between Cost and $\mathrm{CO}_{2}$ Emissions for 60 Year-Usage

Phase 98

Figure 31 Graph Relationships between Cost and $\mathrm{CO}_{2}$ Emissions for 70 Year-Usage Phase

Figure 32 Graph Relationships between Cost and $\mathrm{CO}_{2}$ Emissions for 80 Year-Usage Phase

Figure 33 Graph Relationships between Cost and $\mathrm{CO}_{2}$ Emissions for 90 Year-Usage Phase 100 
Figure 34 Graph Relationships between Cost and $\mathrm{CO}_{2}$ Emissions for 100 Year-

Figure 35 Graph Relationships between Cost and $\mathrm{CO}_{2}$ Emissions for 120 Year-

Figure 36 Graph Relationships between Cost and $\mathrm{CO}_{2}$ Emissions for 140 Year-

Figure 37 Graph Relationships between Cost and $\mathrm{CO}_{2}$ Emissions for 160 Year-

Figure 38 Graph Relationships between Cost and $\mathrm{CO}_{2}$ Emissions for 180 YearUsage Phase

Figure 39 Graph Relationships between Cost and $\mathrm{CO}_{2}$ Emissions for 200 YearUsage Phase

Figure 40 Graph Relationships between Cost and $\mathrm{CO}_{2}$ Emissions for 250 Year-

Figure 41 Graph Relationships between Cost and $\mathrm{CO}_{2}$ Emissions for 300 YearUsage Phase

Figure 42 Graph Relationship between Cost and $\mathrm{CO}_{2}$ Emissions for 0-15 YearUsage Phase

Figure 43 Graph Relationships between Cost and $\mathrm{CO}_{2}$ Emissions for 20-35 Year-

Figure 44 Graph Relationships between Cost and $\mathrm{CO}_{2}$ Emissions for 40-60 YearUsage Phase

Figure 45 Graph Relationships between Cost and $\mathrm{CO}_{2}$ Emissions for 70-100 YearUsage Phase 106

Figure 46 Graph Relationships between Cost and $\mathrm{CO}_{2}$ Emissions for 120-180 Year-

Usage Phase 106

Figure 47 Graph Relationships between Cost and $\mathrm{CO}_{2}$ Emissions for 200-300 YearUsage Phase 107

Figure 48 Graph Shows Area of Possible Solutions for 5 Year-Usage Phase 


\section{CHAPTER 1 INTRODUCTION}

\subsection{Research Background}

Construction projects are complex endeavors that require the application of different professional disciplines in order to meet various objectives that are often conflicting. The level of complexity and the multi-objective nature of construction projects lend themselves to the application of Integrated Project Delivery (IPD), in which relevant disciplines work together during project conception, design and construction (e.g., AIA, 2007; Hellmund et al., 2008). Traditionally, the main objectives of construction projects have been to build in the least amount of time with the lowest cost possible, and thus the inherent and well-established relationship between cost and time has been the focus of many studies. However, public concerns for the impact that human activities have on the environment has been growing steadily over the past decade; the construction industry is no exception and construction professionals are constantly facing the challenge of integrating environmental sustainability as one of the project objectives.

The environmental impact of buildings and their operations has been the subject of a significant amount of research. Buildings affect the environment in every stage of their lifespan, including manufacturing and transportation of materials, construction, usage, maintenance, disassembly and waste management; collectively, these stages are called the building lifecycle. Recent studies have also shown attempts to understand environmental impact of buildings and construction, as well as their relationships with cost and time. For example, Ofori (1992) suggested the adoption of environmental 
performance of a construction project as a significant objective along with time, cost, and quality. Some studies, such as Morel et al. (2001), looked into the selection of materials and construction methods to reduce environmental impact of construction. Others were interested in developing algorithms for multi-objective optimization, such as Marzouk et al. (2008), Ozcan-Deniz et al. (2011) and Ashuri and Tavakolan (2012). Recently, Zhu et al. (2012) discussed a multi-objective analytical tool, SimulEICon, for studying time, cost and environmental impact. Inyim et al. (2014) further developed SimulEICon as a simulation-based approach for selecting design solutions that considered time, cost, and environmental impact of the whole building life cycle to support sustainable construction in the architecture, engineering and construction (AEC) industry.

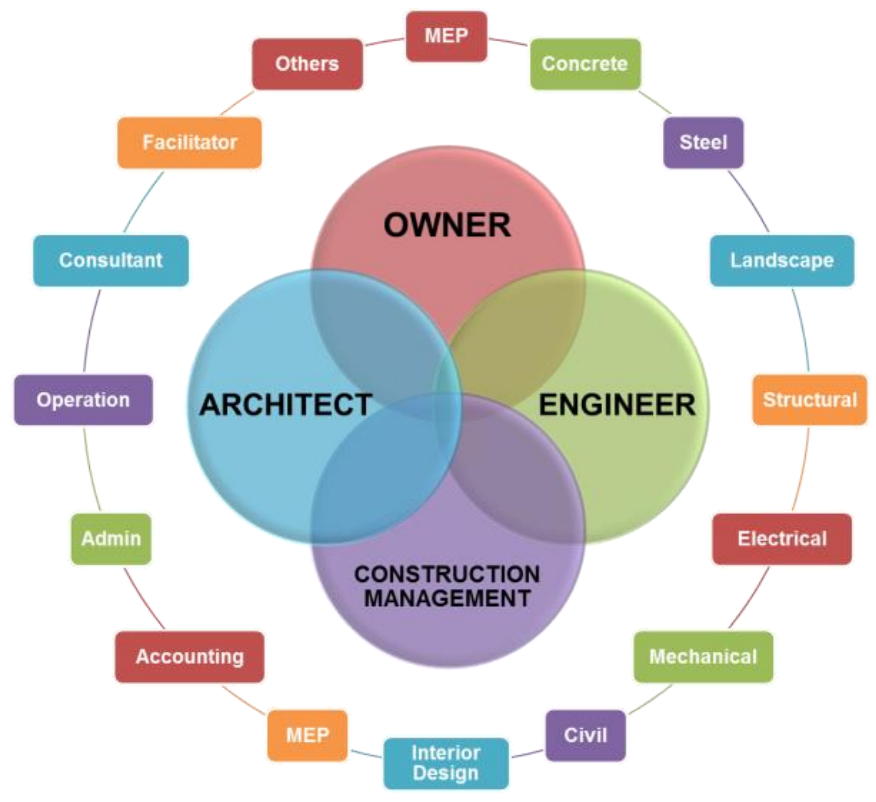

Figure 1 Integrated Project Delivery

To achieve sustainability, a tool or method capable of quantifying the environmental impact of a building's lifecycle is required (Rebitzer et al., 2004). Life 
cycle assessment (LCA) is a quantitative method to determine the environmental impacts of materials, products, processes or buildings (Flager et al., 2012). LCA can evaluate and interpret environmental impacts of the building throughout its life stages, raw material acquisition, material manufacturing, construction, occupancy/maintenance, and demolition/waste management (e.g., Kruger \& Seville, 2012; EPA, 2014). Greenhouse gas (GHG) emissions are one of the environmental impacts quantifiable by LCA, among others such as stratospheric ozone depletion, acidification potential, eutrophication potential, toxicological stress on humans and others.

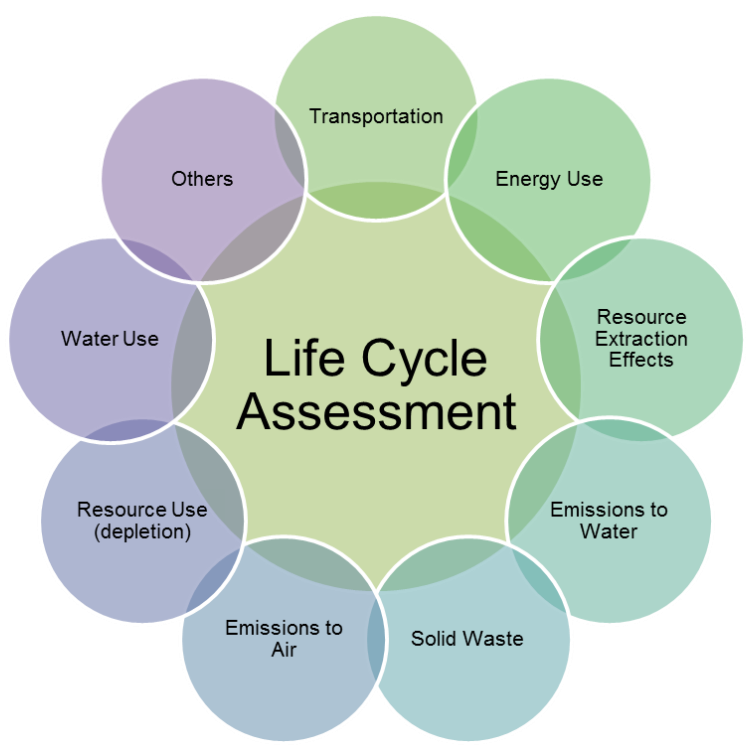

Figure 2 Life Cycle Assessment (LCA)

GHG emissions are considered to be the most significant cause of global warming (Ürge-Vorsatz et al., 2007). Carbon dioxide $\left(\mathrm{CO}_{2}\right)$ is the most important emission of GHG, and it accounts for approximately $80 \%$ of the total GHG emissions (Pachauri \& Reisinger, 2007). Loh et al. (2009) also emphasized the importance of considering $\mathrm{CO}_{2}$ 
emissions in the design phase. Attempting to reduce $\mathrm{CO}_{2}$ emissions in the building's lifecycle often leads to increasing its energy efficiency. This happens because fuel, which is used to power buildings and the machines used to build them, is a critical source of $\mathrm{CO}_{2}$ emissions (e.g., Thyholt \& Hestnes, 2008; Gustavsson \& Joelsson, 2010; Ramesh et al. 2010). Thus, energy consumption is an important factor as a source of GHG emissions, especially $\mathrm{CO}_{2}$. Research acknowledged that buildings are responsible for a significant amount of energy consumption in the world. For example, in the United States, reports revealed that buildings account for $38 \%$ of $\mathrm{CO}_{2}$ emissions (USGCB, 2008) and $40 \%$ of the energy consumption of the U.S. (DOE, 2012). LCA is essential in understanding and optimizing energy consumption in buildings and construction projects. However, it is often challenging to quantify the energy consumption of a building during the usage phase due to its dynamic nature. A feasible set of tools in dealing with the energy efficiency problem during design are energy simulation programs, which allow the evaluation of energy performance of different building designs and the selection of the most appropriate alternatives.

The selection of a building's materials, components and construction methods to achieve the required duration, cost and environmental impact is also a significant challenge for design and construction professionals. Selection of construction alternatives during design must be done at the material and component level, but with the possibility of assessing its impact at the building level. For example, in a small project having only ten construction activities and two design alternatives per activity, if all combinations of alternatives are considered, the project has a total of 1,024 possible solutions, each having 
a unique cost, duration and environmental impact, from which a single solution must be selected for construction. Given the fact that most construction projects can have well over a million possible solutions, the need for a tool capable of systematical analysis and optimization of design alternatives selection becomes evident.
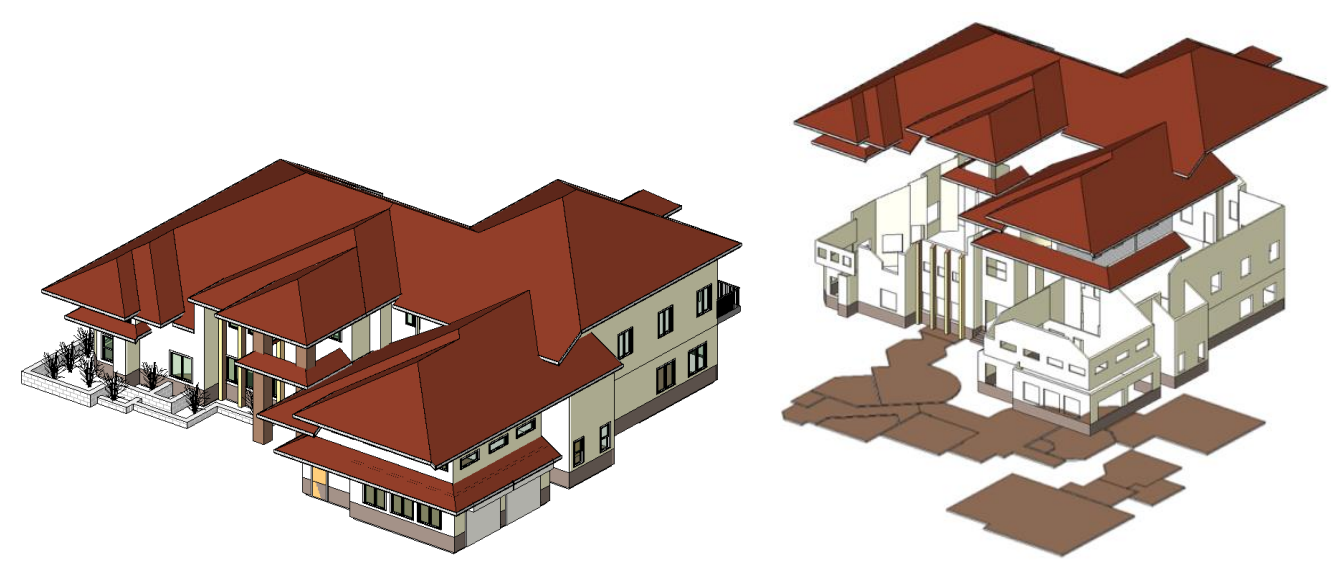

Figure 3 A Building and Components

Furthermore, during the early design stage, there are often multiple options for selecting materials and components that make up a building. This variety of options results in multiple possible solutions, which having a different building cost, construction time, and environmental impact. Decision-making support is often needed to help those professionals participating in the design phase to find optimal solutions that can best satisfy all project objectives. However, current optimization procedures do not consider data uncertainties in productivity, environmental impact, and unit costs of labor, building materials, and equipment; therefore, it is not known how data uncertainties may impact the determination of optimal solutions. Research carefully acknowledged the effect of uncertainties in multi-objective models (e.g., Ghanmi et al. 2007; Feng et al. 2000). Bruni 
et al. (2011) addressed the importance of uncertainty and the availability of resources as a constraint to the project's schedule. Currently, there are many computer-based tools that are developed in the AEC industry for aid in sustainable design. However, there is no tool that can help design and construction professionals to optimize material and component selections to successfully satisfy multi-objectives at the building level (Zhu et al. 2012). Moreover, those optimization methods are focused on the pre-use phase without considering environmental impact and cost in the usage phase.

\subsection{Problem Statement}

The importance of being able to effectively model relationships between multiple objectives in building construction has been emphasized in a wide range of research. Traditionally, decisions have been made to satisfy two main objectives in the construction projects, which are cost and time. Many research studies were conducted to solve and examine the relationship between them (e.g., Hegazy, 1999; Feng et al., 2000; Leu et al., 2001; Chan, 2001; Choudhury \& Rajan, 2003; Eshtehardin et al., 2009; Sonmez \& Bettemir, 2012). In general, the trade-off relationship between time and cost is well understood and there is ample research on the subject. Moreover, several studies also reveal the trade-off between multiple objectives, such as time, cost, and quality (e.g., Babu et al., 1996; Khang \& Myint, 1999; El-Rayes \& Kandil, 2005; Afshar et al., 2007; Mungle et al., 2013) However, despite sustainable building designs, relationships between time and environmental impact, as well as cost and environmental impact, have

not been fully investigated and further research is required to gain a complete understanding. The studies of time, cost and environmental impact are usually limited to 
the pre-use phase. While the usage phase or the occupancy phase supportably account for the largest amount of energy consumption in the building's life cycle, this also contributes to environmental impact (e.g., Cole \& Kernan, 1996; Thormark, 2006). Understanding the relationship between these objectives is a key in successfully planning and designing environmentally sustainable construction projects.

\subsection{Research Objectives}

The objectives of this research are:

1. To analyze and identify relationships of construction time, initial construction cost, and environmental impact, in terms of $\mathrm{CO}_{2}$ emissions, within different levels of a building: material, component, and building, at the pre-use phase; the manufacturing and construction phase.

2. To analyze and identify relationships between life cycle cost, and life cycle environmental impact, in terms of $\mathrm{CO}_{2}$ emissions, within the building level at the usage phase.

3. To develop a simulation-based multi-objective decision-support tool, Simulation of Environmental Impact of Construction (SimulEICon), which takes construction data uncertainty into account, and it is capable of incorporating life cycle assessment information to the decision-making process. 


\subsection{Research Questions and Hypothesis}

This research is focused on answering the following questions:

Question \#1 Is there an observable relationship between time, cost and $\mathrm{CO}_{2}$ emissions at different levels of the building? Do the relationships exhibit a trade-off behavior?

Hypothesis \#1 There are observable relationships between time and cost, and between $\mathrm{CO}_{2}$ emissions and time, within each of the three levels of the building; both exhibit trade-off behaviors. There is an observable relationship between $\mathrm{CO}_{2}$ emissions and cost; however, it does not exhibit a trade-off behavior. This finding can be advantageous to construction and design professionals during the decisions-making process and it encourages further research and analysis on the subject.

Question \#2 Is it possible that a dominant solution exists at the material, component or building design level?

Hypothesis \#2 The trade-off relationship, observed between time and cost, and between $\mathrm{CO}_{2}$ emissions and time, greatly reduces the likelihood of the existence of a dominant solution at any level. However, the existence of data uncertainty at the material level allows for a 
chance, albeit low, that a dominant solution appears at any of the three levels considered.

Question \#3 Does energy consumption at the occupancy phase of a building affect the finding of optimal or near optimal solutions in sustainable building designs?

Hypothesis \#3 Disregarding energy consumption leads to ignoring possible materials and components that may lead to savings at the occupancy phase of a building, and thus has a definite impact in the search process for optimal solutions and their outcome.

\subsection{Research Significance and Methodology}

The methodology presented enables to accurately analyze and identify those relationships. The methodology is applied in the developing of a simulation-based, multiobjective and decision support tool called SimulEICon. This analytical tool is capable of searching for near optimal building design solutions and studying the relationships of time, cost and $\mathrm{CO}_{2}$ emissions at the material, component and building level of the designs. SimulEICon addresses uncertainty in construction data and integrates energy consumption data for the entire life cycle of a building.

The following steps are critical: 
- The creation of a database that contains information on cost, time and $\mathrm{CO}_{2}$ emissions of materials and components; furthermore, sufficient data for performing life cycle assessment were also gathered. Quantity of each components based on a case study is also needed as the database.

- The uncertainty in the material unit cost, equipment unit cost, labor unit cost, $\mathrm{CO}_{2}$ emissions, and installation productivity is behaviorally modeled using probability distributions from literature reviews and historical data (Inyim \& Zhu, 2013).

- The life cycle assessment and the consideration of energy consumption during the building's usage phase are achieved by performing a building energy simulation.

- The analysis at the building level is examined in two parts; pre-use phase and usage phase. In the pre-use phase, it considers three main objectives, which are construction time, initial construction, and $\mathrm{CO}_{2}$ emissions. Only life cycle cost and $\mathrm{CO}_{2}$ emissions are considered in the usage phase since construction time is not necessary. However, different life span of the building is estimated to see the impact to the relationship between life cycle cost and $\mathrm{CO}_{2}$ emissions.

- The search for optimal design solutions at the building level entails the consideration of millions of possible solutions; optimization of the search process is achieved by using Genetic Algorithms.

- For validation of results generated by SimulEICon, the proposed methodology is applied to two case studies that are already designed and built. 
- The relationships between time, cost and $\mathrm{CO}_{2}$ emissions can be observed by using the pairwise graphs between parameters. These relationships are also tested using statistical models such as regression analysis.

\subsection{Dissertation Organization}

This dissertation is divided into seven chapters. The first chapter consists of research background, problem statement, research objectives, research questions and hypothesis, research significant and methodology, and organization of the dissertation. The literature review of sustainable building designs, trade-off problems in multiple objectives optimization, genetic algorithms, Monte Carlo simulation, building life cycle assessment tools and building energy simulation is in chapter 2. The framework and description of building levels are provided in the integrated simulation framework for sustainable design chapter. The following chapters are the analysis of relationships between time, cost and environmental impact in the different building levels at the preuse phase, and the analysis of life cycle cost and life cycle environmental impact at the usage phase. The final chapter includes discussions, conclusions, limitation, and future studies. 


\section{CHAPTER 2 LITERATURE REVIEW}

\subsection{Sustainable Building Designs}

Currently, the concept of sustainability is embraced by a wide variety of industries and business (Jung \& Joo, 2011). It has been over 20 years since environmental issues became critical in those industries. In 1980, World Conservation Strategy by the International Union of the Conservation of Nature (UCN) in Gland, Switzerland firstly used the word 'Sustainability' to intentionally indicate to development of environment purpose (Steele, 1997). In 1987, World Commission on Environment and Development, afterward known as the Brundtland Commission or the Brundtland Report which is named after Gro Harlem Brundtland, reported the critical issues of environmental and development according to the world population growth problems (Brundtland, 1987). This report was aimed to incorporate the concept of sustainability with the principle of economic growth. The sustainability concept was introduced as an integration of environmental, social and economic issues and it was recognized for its significance in addressing the present policies among industries as well as future policies and developments. Moreover, the publication from the commission titled "Our Common Future" recommenced that decision-making parties at all levels be required to participate in sustainable development.

In late spring 1992, Agenda 21 was published by Rio Earth Summit. Agenda 21 specially provided 12 recommendation of the management of human settlement as follows (Steele, 1997): 
1) The use of local materials and indigenous building sources

2) Incentives to promote the continuation of traditional techniques, with regional resources and self-help strategies

3) Recognition of the toll that natural disasters take on developing countries, due to unregulated construction and use of inadequate materials and the need for improvements both in use and manufacture of materials and in construction techniques, as well as training programs

4) Regulation of energy-efficient design principles

5) Standards that would discourage construction in ecologically inappropriate areas

6) The use of labor-intensive rather than energy-intensive construction techniques

7) The restructuring of credit institutions to allow the poor to buy building materials and services

8) International information exchange on all aspects of construction related to the environment, among architects and contractors, particularly about nonrenewable resources

9) Exploration of methods to encourage and facilitate the recycling and reuse of building materials, especially those requiring intensive energy consumption in their manufacture

10) Financial penalties to discourage the use of materials that damage the environment 
11) Decentralization of the construction industry, through the encouragement of smaller firms

12) The use of "Clean Technologies"

It is commonly acknowledged today that sustainable development has an important role and has been a significant factor in the architecture, engineering and construction (AEC) industry. Over the years, sustainability has been the focus of many studies. A search of 'sustainable construction' in the Google search engine yields over 80 million results. Many definitions of sustainable concept in the AEC industry were reported. Steele (1997) defined sustainable architecture as "a basic definition extends that of sustainability itself, an architecture that meets the needs of the present without compromising the ability of future generations to meet their own needs". Matar et al. (2010) stated that sustainable construction is an emergent science that combines sustainable concept and construction projects. Several sustainable standards and guidelines for building designs, such as the Building Research Establishment Environmental Assessment Method (BREEAM), Leadership in Energy and Environmental Design (LEED), and Green Building rating System (GBRS), have been established within the AEC industry in order to encourage construction and designs of environmentally sustainable buildings. However, there are numerous research that identify and expose several technical and non-technical obstacles that still hinder widespread adoption.

The practice of sustainable designs in the building sector often referred to as green buildings and it includes features, such as low energy consumption, or low pollution 
emissions (GhaffarianHoseini et al., 2013). It brings more players, new construction methods, and advanced designs and analysis into the projects. Furthermore, it requires inter-collaboration between all the involved parties to effectively communicate and share information, including making decisions to serve common goals. Most research and literature, dealing with the delivery of sustainable design projects, identify integrated design as a critical process for the optimization of building systems and fulfillment of project objectives (e.g., Pluaski et al., 2006; Raphael, 2011). When the traditional project system cannot handle the integration of designs, research support that and best performing project delivery practice in the sustainable construction is the integrated project delivery (IPD). It is the system, in which all design and construction professionals working in the building projects associate in the early stage of design construction. In addition, IPD can be developed to support the new trends in the sustainable development of the building designs (Hellmund et al., 2008).

The decision making process for sustainable design projects still relates to the selection of construction methods, materials, crews, and planning, such as resource leveling or scheduling. A particularly critical step in sustainable projects is the selection of the building's components and materials at the design stage, this selection involves the assessment of the impact that these components will have on the sustainable, economic and time related to the project's objectives. The difficulty of this selection process is compounded by the fact that these objectives are often conflicting. Often the wide range of sustainable design options challenges professionals in selecting appropriate building materials and components, which can best satisfy all project objectives. Furthermore, 
choosing different construction material assemblies or systems, having different construction time, initial cost, maintenance cost, environmental impacts, etc., can be done in many ways. Moreover, considering these components at the building level presents the additional difficulty that thousands or even millions of design combinations, depending on project size, type and location, are possible; the designer is confronted with the challenge of selecting the optimum design combination of the building components in order to better meet required project's objectives. Cantoni et al. (2000) reported how significant the design phase is because there are many available and reliable options related to optimal plant design. It entails design professionals to encounter design problems in order to find the appropriate components for generating optimal design solutions. Moreover, ecologically sustainable designs are broad. In the AEC industry, the behaviors of the designs change in some such way when it considers environmentally efficient design objectives. This can substantially challenge design and construction professionals in finding suitable multi-objective design solutions.

Bunz et al. (2006) conducted a survey research comparing sustainable design programs and guidelines in North America, Europe and Asia. They posed that building designs should consider the whole life cycle of the buildings and, more importantly, sustainable designs should be implemented in all phases of the building life cycle. However, they highlighted that the most sustainable building programs and guidelines mainly place their focus on the design phase and they supported that these selection considerations in the design phase are essential. 


\subsection{Trade-off Problems in Multiple Objectives Optimization}

The design and planning of construction projects often consider the successful satisfaction and completion of multiple objectives. Traditional objectives considered in construction are project cost and duration. The adoption of the sustainable construction paradigm has introduced another objective and also increased the difficulty of selecting design options that satisfy all objectives. This increment in difficulty calls for further development and optimization of the design, and perceptive decision making process.

There is a significant amount of literature discussing the interdependent relationship of time and cost (Kasprowicz, 1994). Many algorithms for studying time-

cost trade- offs have been developed, including heuristic methods (Moselhi, 1993), mathematical programming (Jiang \& Zhu, 2010) and more recently evolutionary algorithms including genetic algorithms (GAs) and ant colony optimization algorithms. Besides time- cost trade- off analysis, some studies had also incorporated other objectives into analysis. For example, Khang and Myint (1999) applied linear programming and network simulation to study the time, cost and quality trade-offs. ElRayes and Kandil (2005) presented a GAs-based method for time, cost, and quantity trade-offs. Similarly, Rahimi and Iranmanesh (2008) discussed the application of the multi-colony ant algorithms and particle swarm optimization to the same subject. Recently, several studies on time, cost and environmental impacts were reported. For 
example, Marzouk et al. (2008) applied genetic algorithms to the optimization of time, cost and pollution. Ozcan-Deniz et al. (2011) discussed an analytic framework for time, cost and carbon emission analysis of the building and construction processes by using genetic algorithms.

The advantages and disadvantages of optimization methods have been welldocumented in previous studies. Most importantly, evolutionary algorithms have become popular because heuristic methods or mathematical programming methods often fail when dealing with a large number of variables or non-linear objective functions (Elbeltagi et al., 2005). In addition, evolutionary algorithms (EAs) are search-based so they do not need to address the structure of problems, which makes EAs very flexible in applications and easier to apply for trade-off problems.

\subsection{Genetic Algorithms}

Optimization according to a single objective perhaps rarely exits in existing sustainable building designs. On the contrary, most problems imply multiple objectives. This created a need of effective search techniques in order to find acceptable optimal solutions based on a set of objectives. Evolutionary Algorithms (EAs) are often used to solve multiple objectives' optimization problems because they are able to deal with

complex issues, such as discontinuous objective functions, feasible disjoint patterns, and multimodality (Fonseca \& Fleming, 1995). Examples of EAs are evolutionary programming, and evolution strategies (Bäck \& Schwefel, 1993). Genetic Algorithms (GAs) are a type of evolutionary algorithms and an optimization method based on the 
theory of evolution, survival of the fittest and adaptation. They were firstly developed by Holland (1975) with the idea of natural selection. In GAs, possible solutions are treated as individuals and by application of evolution operators this individuals can produce offspring (Magnier, 2008). The Genetic Algorithm (GA) is a stochastic optimization method based on the principles of Charles Darwin's theory of evolution, the survival of the fittest; the GA is comprised of four main parameters which are: number of generations, size of population, crossover rate and mutation rate (Elbeltagi et al., 2005). Many researches proposed this method because it can handle large-scale problems often found in construction projects. The basic functioning of genetic algorithms is as follows:

1) Initial solutions are generated

2) The fitness of each solution is analyzed and a probability of reproduction is assigned

3) Evolution operators are applied to obtain the next generation of solutions

4) The process is repeated with the solutions obtained.

The evaluation of the fitness of each solution is of utmost importance as it is the criteria used to ascertain whether generated solutions conform to the optimization objectives. Reproduction is the process by which solutions pass from one generation to another; keeping with the principle of evolution, the fittest solutions are the ones more likely survive. Crossover is an operator that allows the generation of solutions by exchanging characteristics from two other solutions. The mutation operator introduces the possibility of random changes when passing characteristics from parents to their offspring; this allows the possibility of exploring solutions that might be otherwise 
overlooked (Camp et al., 1998). Genetic algorithms were utilized in many design optimizations, such as design optimization of trusses (e.g., Rajeev \& Krishnamoorthy, 1997; Wang \& Ohmori, 2010). Cieniawski et al. (1995) examined multi-objective issues in groundwater monitoring using genetic algorithms. They concluded that genetic algorithms had more advantages over traditional methods. They also used Monte Carlo simulation to randomly generate aquifer parameters and leakage events from presumed distributions. Wang et al. (2007) mentioned that GAs is a powerful technique for solving conflicting multiple objectives in pavement design. Jun and El-Rayes (2010) used GAs in multiple labor shifts problem in construction projects. Multi-objective genetic algorithms can overcome the hindrance of traditional resource leveling algorithms (Leu et al., 2000).

\subsection{Monte Carlo Simulation}

The Monte Carlo simulation is a method for obtaining solutions to problems where analytical techniques are not available (Farah, 1985). For the design, planning and construction stages of construction projects, there is an inherent uncertainty in the data of construction time, material unit cost, equipment unit cost and labor unit cost as well as in energy consumption and the overall environmental impact. This uncertainty in the data must be accounted in the multi-objective optimization process; otherwise, the validity of the obtained solutions is questionable. Monte Carlo simulations using behavioral modeling of data uncertainty through probability distributions can be applied to the process of determining the optimal solutions for a project.

Several studies acknowledged the effect of uncertainties in multi-objective 
models (e.g., Ghanmi et al., 2007; Feng et al., 2000). Bruni et al. (2011) addressed the importance of uncertainty and availability of resources as a constraint to the project schedule. Monte Carlo simulation is a well-known stochastic technique applied commonly to uncertainty analysis. Monte Carlo simulation has been integrated with GAs in order to account for data uncertainty and availability in the real world situation. Lazo et al. (2003) proposed a decision-making model using genetic algorithms and Monte Carlo simulation for oil field development. Monte Carlo simulation was applied to simulate oil prices based on market uncertainties. Babayan et al. (2005) also combined Monte Carlo simulation and genetic algorithms to solve the design of a water distribution system. The results showed that oversight of uncertainty in the stochastic design problems could lead to risk in the design. Many other researchers have also presented their work which applied both genetic algorithms and Monte Carlo simulation, such as finding effective maintenance policies optimization (Marseguerra \& Zio, 2000; Marseguerra et al., 2002), modeling knowledge management performance measurement (Kuah et al., 2012), and managing spare part inventories (Marseguerra et al., 2005). Cantoni et al. (2000) presented integration of GAs and Monte Carlo simulation to find optimal designs for several plant design alternatives. They proposed this approach to solve optimization problems under conflicting economic and safety issue.

\subsection{Building Life Cycle Assessment Tools}

Currently, building sector clearly understands and rapidly develops emerging of

the sustainability concept to the building designs. The term of effective building performance is raised as well as the adaptation of standardization of environmental 
assessment tools (Cole, 1998). A building performance is affected by many parameters of designs. Environmental considerations have substantially enhanced the number of performance paradigm, indicators, and potential material or product to develop environmental building assessment methods and there are many internationally life cycle assessment tools available raising the acknowledgement of sustainability. They vitally contribute to acknowledge and systematize the importance and linkage between the building and its environmental performance measurement, such as energy consumption (e.g., Cole, 1998; Ding, 2008). Many studies reviewed and provided characteristics of existing LCA tools. For instance, Ding (2008) listed twenty environmental building assessment methods and further summarized that there are two main characters of LCA tools, which are a rating tool and an assessment tool. The rating tool category aims to estimate a level of performances of the buildings based on different criteria, while the assessment tool comprehends environmental agenda in a quantitative measurement.

Examples of life cycle assessment tools are, such as Leadership in Energy and Environmental design (LEED), GreenStar originated from Australia, BEES developed by U.S. National Institute of Standards and Technology (NIST), USA, BREEAM by Building Research Establishment (BRE), UK, EcoEffect by Royal Institute of Technology (KTH), Sweden, ESCALE designed by CTSB and the University of Savoie, France, and Athena Building Impact Estimator by Athena Sustainable Materials Institute, Canada, presented in Table 1, which they greatly help to support sustainability in the building designs (Haapio \& Viitaniemi, 2008). 
Those tools are designed and developed for different purposes, such as for existing buildings, for new buildings, and building products. Haapio and Viitaniemi (2008) studied and categorized most life cycle assessment tools. Their study showed that the existing life cycle assessment tools were purposed on various types of buildings, they were relied on different guidelines. Some of them also might not completely cover the whole cycle life information. Table 2 summarized building types and life cycle phases covered by different life cycle assessment tools (e.g., Haapio \& Viianiemi, 2008; Ding, 2008).

Table 1 Example of Environmental Building Performance Assessment Methods

Environmental Assessment Methods Developer/ Origin

$\begin{array}{ll}\text { ABGR } & \text { Australian Building Department of Commerce, NSW } 2005 \\ \text { Greenhouse Rating } & \end{array}$

AccuRate

CRIRO 2006

Athena $\quad$ Athena Impact Estimator for

Athena Sustainable Material Institute, Buildings Canada

BASIX

Building Sustainability Index

Department of Infrastructure, Planning and Natural Resources 2004

BEAT 2002

Danish Building Research Institute 


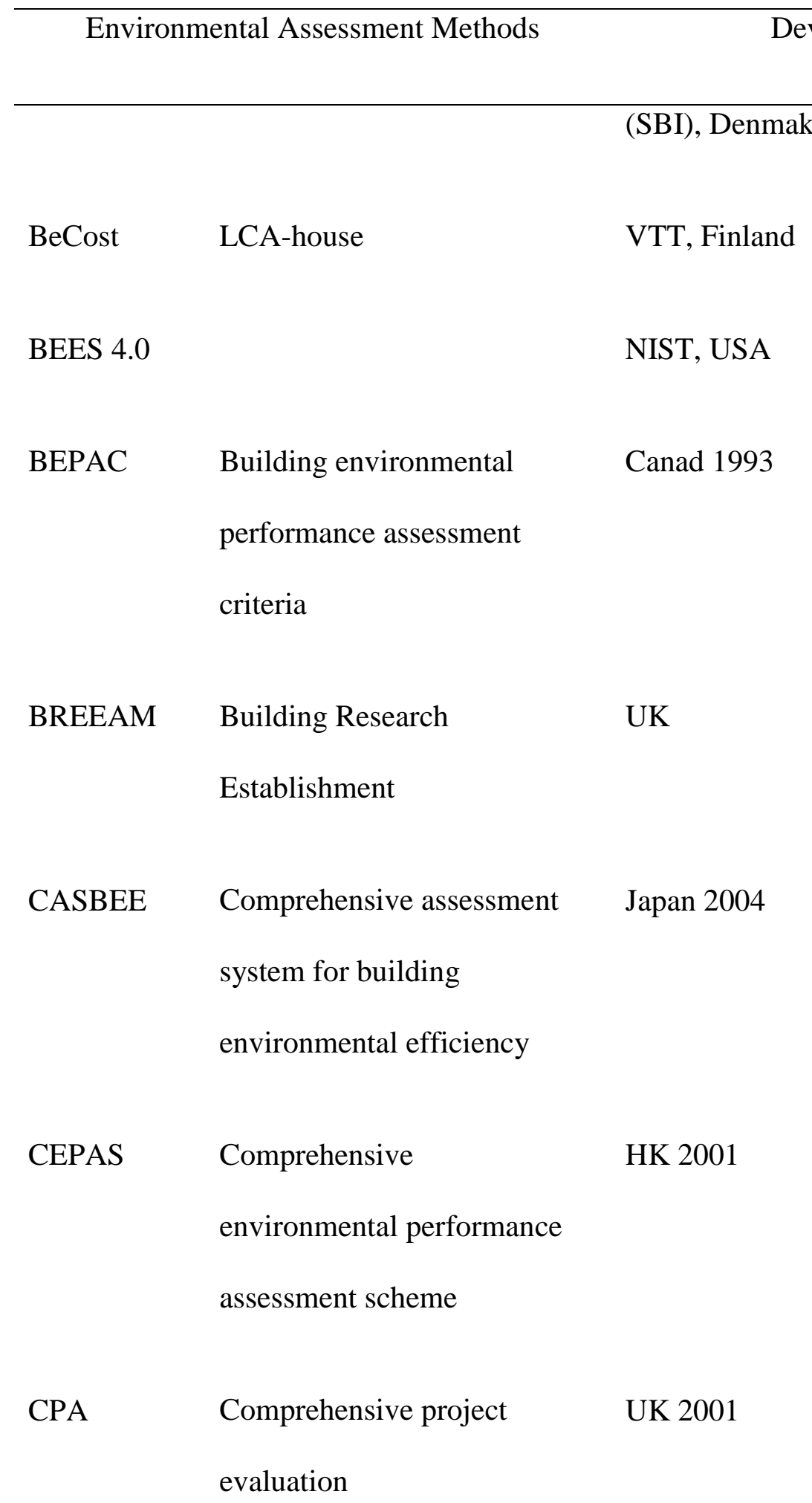




\begin{tabular}{|c|c|c|}
\hline \multicolumn{2}{|c|}{ Environmental Assessment Methods } & \multirow[t]{2}{*}{ Developer/ Origin } \\
\hline DQI & Design quality indicator & \\
\hline EcoEffect & & Royal Institute of Technology, Sweden \\
\hline EcoProfile & & Norwegian Building Research Institute, \\
\hline & & Norway \\
\hline EcoQuantum & & Netherlands \\
\hline EMGB & Evaluation manual for green & Taiwan 1998 \\
\hline & buildings & \\
\hline Envest 2 & & Building Research Establishment, UK \\
\hline EPGB & Environmental performance & Department of Public Works and \\
\hline & guide for building & Services, NSW \\
\hline ESCALE & & France \\
\hline GbTool & Green building challenge & International 1995 \\
\hline GHEM & $\begin{array}{l}\text { Green home evaluation } \\
\text { manual }\end{array}$ & China 2001 \\
\hline GreenStar & & Green building council \\
\hline
\end{tabular}




\begin{tabular}{|c|c|c|}
\hline Enviror & ental Assessment Methods & Developer/ Origin \\
\hline HKBEam & $\begin{array}{l}\text { Hong Kong building } \\
\text { environmental assessment } \\
\text { method }\end{array}$ & Hong Kong 1996 \\
\hline LEED® & $\begin{array}{l}\text { Leadership in energy and } \\
\text { environmental design }\end{array}$ & USA 200 \\
\hline LEGEP® & Legoe & University of Karlsruhe, Germany \\
\hline NABERS & $\begin{array}{l}\text { National Australian building } \\
\text { environmental rating system }\end{array}$ & $\begin{array}{l}\text { Department of Environmental and } \\
\text { Heritage } 2001\end{array}$ \\
\hline NatHERS & & CSIRO \\
\hline PAPOOSE & & TRIBU, France \\
\hline SBAT & $\begin{array}{l}\text { Sustainable building } \\
\text { assessment tool }\end{array}$ & South Africa \\
\hline SPeAR & $\begin{array}{l}\text { Sustainable project appraisal } \\
\text { routine }\end{array}$ & \\
\hline TEAM $^{\mathrm{TMa}}$ & & Ecobilan, France \\
\hline
\end{tabular}




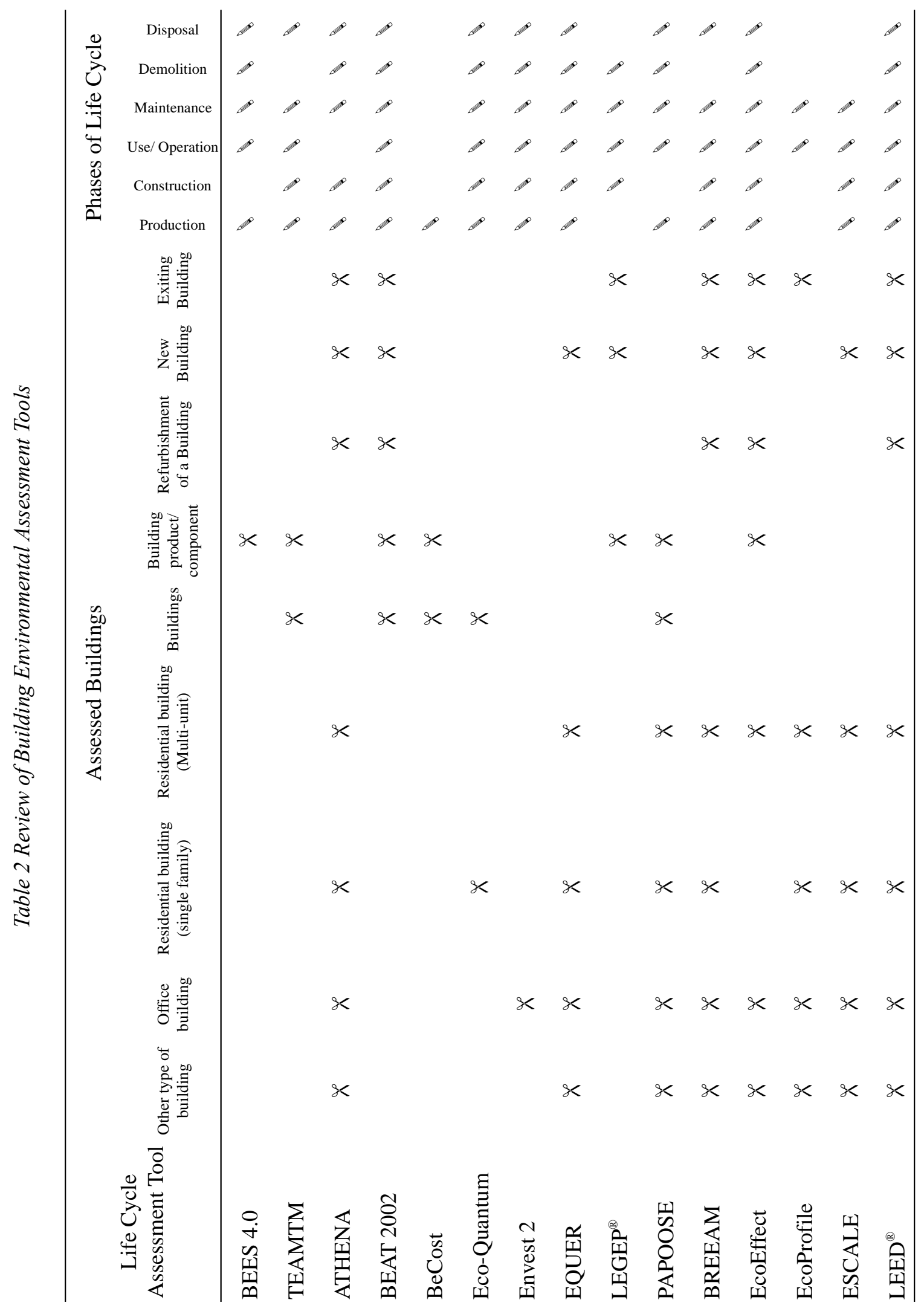




\subsection{Building Energy Simulation}

The building energy simulation was firstly introduced and developed in the mid 1960's for the purpose of energy consumption calculation in buildings (Van der Veken et al., 2004). The first simulation methods used at that time neglected the building and the system synergy. By the end of 1970s, building energy simulation programs were further developed; examples of simulation methods are EPW, TRANSYS, ESP-r, DOE-2, and BLAST (Spencer, 2010). In the United States, the congress authorized the Energy Independence and Security Act of 2007 to support and persuade the construction of the zero-net-energy buildings by 2030 (Kassab, 2008). This encourages the use of energy simulation in the construction projects. There has been an improvement in energy simulation tools; for instance, DOE-2 and BLAST features were taken to develop a new building simulation tool called EnergyPlus, which was completely rewritten new in Fortran 90 language. Crawley et al. (2001) stated the significant of this new program over DOE-2 and BLAST, such as realistic system controls, and radiant heating, and cooling system. DOE-2 and BLAST are a step sequential simulation, while EnergyPlus is an integrated system simulation. It is not only a combination of previous features, but also a development of computation techniques, program, and structures.

Jingran Ma et al. (2011) studied the model predictive control (MPC) using EnergyPlus and a co-simulation program, the building controls virtual test bed (BCVTB), in the system framework in order to indicate an effectiveness of the reducibility in the energy cost and demand cost in the model. EnergyPlus was used, compared and integrated with computer algorithms in various researches (e.g., Andolsun et al., 2011; 
Kämpf et al., 2010; Wang et al., 2009; Zhu, 2006). EnergyPlus is widely used because it can provide all general basic function in comparison with other energy simulation programs.

Another energy simulation program that is commonly applied in building energy simulation is eQUEST. The program was developed to be a user-friendly tool while it can incorporate features from DOE-2.2. The latest version of eQUEST is version 3.64 released in 2010. Yu et al. (2008) mentioned that eQUEST has expansion capabilities beyond DOE-2.2. He demonstrated these capabilities by applying eQUEST to residential building analysis for different climate zones in China. eQUEST can provide energy savings results as the effects of envelope factors. Sclafani (2010) also used eQUEST to predict future energy consumption based upon historical weather data. He focused on the effect of weather data and energy performance. Crawley et al. (2008) presented twenty building energy performance simulation programs, listed in table 3 , and they also compared their performances in various features.

Table 3 Examples of Building Energy Simulation Programs

Programs Developers

\begin{tabular}{ll}
\hline BLAST & $\begin{array}{l}\text { University of Illinois at Urbana- } \\
\text { Champaign }\end{array}$ \\
BSim $\quad$ Building Simulation & Danish Building Research Institute
\end{tabular}


DeST

DOE-2

ECOTECT Autodesk® Ecotect ${ }^{\circledR}$

Analysis

Ener-Win Energy Simulation Software for Buildings

Energy Express

Energy-10

EnergyPlus EnergyPlus Energy

Simulation Software

eQuest
The Quick Energy Simulation
Tool

ESP-r

Energy Systems Research

Hour Analysis Program
Tsinghua University

Lawrence Berkeley National Laboratory

\section{AUTODESK}

Texas A\&M University \& Degelman

Engineering Group, Inc.

\section{CSIRO}

National Renewable Energy Laboratory

U.S. Department of Energy

U.S. Department of Energy

University of Strathclyde

Carrier Software Systems, Carrier

Corporation 


\begin{tabular}{lll}
\hline & Programs & Developers \\
\hline HEED & Home Energy Efficient & University of California, Los Angeles \\
& Design & \\
& \\
\hline
\end{tabular}




\section{CHAPTER 3 AN INTEGRATED SIMULATION FRAMEWORK FOR SUSTAINABLE DESIGN ANALYSIS}

The proposed methodology enables to accurately analyze and identify relationships of time, cost and environmental impact, in terms of $\mathrm{CO}_{2}$ emissions. The methodology is applied in the developing of a tool named Simulation of Environmental Impact of Construction or SimulEICon. This tool is designed to help construction and design professionals in the construction projects to find the optimal or near optimal design solutions during the selection process of a building components based on multiple objectives. SimulEICon simulates and generates results using non-dominated sorting genetic algorithm-II (NSGA-II), which is one of well-known GAs. Sets of optimal or near optimal solutions are obtained by considering multiple objectives. SimulEICon can be used to observe those relationships at the different levels; material, component and building level. SimulEICon addresses the uncertainty in the construction data by applying Monte Carlo simulation to database and integrates energy consumption information, in terms of energy consumption cost and energy related $\mathrm{CO}_{2}$ emissions, for the entire life cycle of a building. The following steps are critical:

- The creation of a database that contains information on cost, time and $\mathrm{CO}_{2}$ emissions of materials and components; furthermore, sufficient data for performing life cycle assessment were also gathered. Quantity of each components based on a case study is also needed as the database. 
- The uncertainty in the material unit cost, equipment unit cost, labor unit cost, $\mathrm{CO}_{2}$ emissions, and installation productivity is behaviorally modeled using probability distributions from literature reviews and historical data.

- The life cycle assessment and the consideration of energy consumption during the building's usage phase are achieved by performing a building energy simulation.

- The analysis at the building level is examined in two parts; pre-use phase and usage phase. In the pre-use phase, it considers three main objectives, which are construction time, initial construction, and $\mathrm{CO}_{2}$ emissions. Only life cycle cost and $\mathrm{CO}_{2}$ emissions are considered in the usage phase since construction time is not necessary. However, different life span of the building is estimated to see the impact to the relationship between life cycle cost and $\mathrm{CO}_{2}$ emissions.

- The search for optimal design solutions at the building level entails the consideration of millions of possible solutions; optimization of the search process is achieved by using Genetic Algorithms.

- For validation of results generated by SimulEICon, the proposed methodology is applied to two case studies that are already designed and built.

- The relationships between time, cost and $\mathrm{CO}_{2}$ emissions can be observed by using the pairwise graphs between parameters. These relationships are also tested using statistical models such as regression analysis. 


\subsection{Material Level}

Data granularity of the SimulEICon database starts at the building material level, such as the quantity of each material used in an activity, unit cost, productivity, and environmental impact per unit, shown in figure 4, as an input to Monte Carlo simulation. Examples of data are the mean unit costs obtained from RS Means and the average $\mathrm{CO}_{2}$ emissions per material unit from the Athena Impact Estimator for Buildings software tool. Most importantly, all data are behaviorally modeled using probability distributions based on various parameters and used to simulate $\mathrm{CO}_{2}$ emissions per material unit, productivity and unit cost of materials. In order to use the Monte Carlo simulation technique, established distributions of parameters are needed, which can be simply generated from historical data. However, in reality, the historical data of unit cost, productivity and $\mathrm{CO}_{2}$ emissions of the same material, component or building and construction operations are very difficult to obtain due to the one-time nature of the buildings and their construction. Instead of using the historical data, the recommended probability distributions from the literature were used to derive the probability distributions of the database in order to describe its likelihood to occur. For example, triangular distributions, beta distributions and lognormal distributions have been commonly used to describe the construction cost function. Back et al. (2000) used the triangular distribution to fit the cost data for a case study project in Texas. They also tested the fitness of the distribution with three methods, the least-square method, the maximum likelihood method, and the moment matching method, to find the most accurate technique for estimating distribution parameters. On the other hand, Sonmez 
(2005) reviewed that the beta distribution was the best fit for construction cost. The example of using the lognormal distribution simulating the construction cost comparing with other distributions was also conducted by Touran and Wiser (1992). The beta distribution was suggested for suitably presenting construction time as well (e.g., AbouRizk et al., 1991; Fente at al., 1991; Schexnayder et al., 2005). The normal distribution was suggested for modeling data of $\mathrm{CO}_{2}$ emissions since the maximum and the minimum of $\mathrm{CO}_{2}$ emissions were not always obvious to define (e.g., Rypdal \& Winiwarter, 2001; Goedkoop et al., 2009; Peña-Mora et al., 2009). All parameters in the database including the quantity, unit cost, productivity, and $\mathrm{CO}_{2}$ emissions per material unit along with their probability distributions are required as an initial input to the application. The database from the material level is also analyzed and described in detail in the next chapter.

\subsection{Component Level}

The data at the material level are used to calculate construction time, initial construction cost, and carbon emissions for alternatives at the component, or assembly level. For each component, there are possibly several material options to form different assembly or component solutions. For example, exterior walls can be structure insulation panels (SIPs) or a steel studs wall, or a wood studs wall, with different types of drywalls

and insulations. The data from the material level are incorporated with quantities of components in order to get the output at this level, which are construction duration, cost and $\mathrm{CO}_{2}$ emissions of component's alternatives. Generally, quantity can be festinated by 
performing quantity taking-off from the project's drawings or retrieving a data from a BIM model if the model is available.

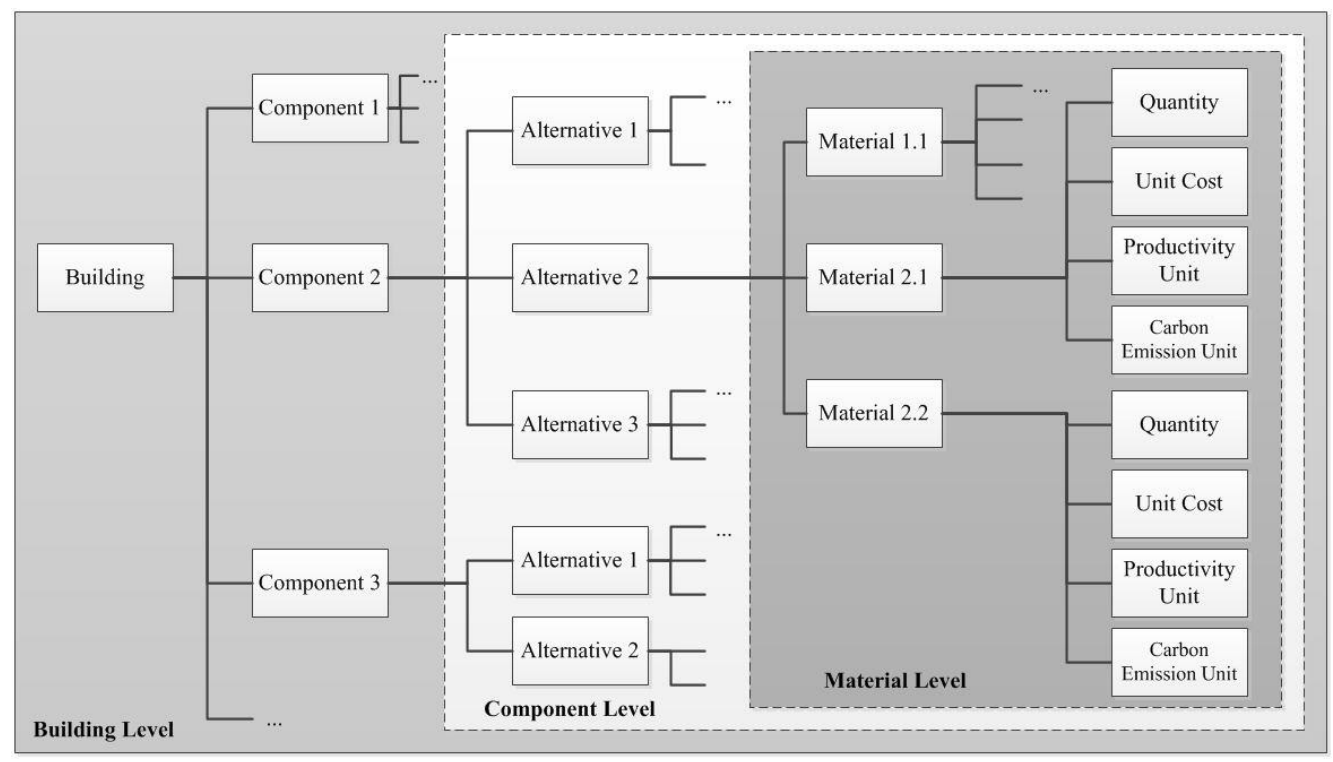

Figure 4 Information at the Different Levels from the Material Level, the Component Level, to the Building Level.

\subsection{Building Level}

The components' alternatives are the basic unit of analysis and the variables for GAs at this level. Different optimal or near optimal building designs based on available components' alternatives are searched in the optimization process. In this research, NonDominating Sort Genetic Algorithm-II (NSGA-II) is used as an optimization model. NSGA-II can greatly handle non-linear programming problem. It is the most commonly applied to the multiple objectives' optimization and it is also widely used in sustainable building design (Evins, 2013). NSGA-II provides optimal or near optimal solutions based on the number of population and generation. In this research, building life cycle was 
separated into two phases which are the pre-use phase and the usage phase. At the pre-use phase analysis, three objective functions are considered which are 1) minimizing initial construction cost $(\mathrm{C}), 2)$ minimizing construction time $(\mathrm{T})$, and 3) minimizing $\mathrm{CO}_{2}$ emissions in the project (EI). Optimization models for NSGA-II are shown below.

Decision Variables:

$$
\begin{aligned}
& x_{i}^{m} \triangleq \text { Alternatives of component } i \text { and } m=\text { alternative number } \\
& \qquad i=1,2,3, \ldots, k \text {, where } \mathrm{k}=\text { number of project components }
\end{aligned}
$$

Objective Functions:

$$
\begin{aligned}
& C=\min \left\{\sum_{i=1}^{k} c_{x_{i}^{m}} \times Q_{i}\right\} \\
& T=\min \left\{\max \left(s t_{i}+d_{i} \mid i=1,2, \ldots, k\right)\right\} \\
& E I=\min \left\{\sum_{i=1}^{k} e i_{x_{i}^{m}} \times Q_{i}\right\}
\end{aligned}
$$

s.t. $s t_{j}>s t_{i}+d_{i},>i \forall j \in S_{i}$, and $E S_{i}<s t_{i}<L S_{i}$

where $\mathrm{d}_{\mathrm{i}}=\frac{\mathrm{Q}_{\mathrm{i}}}{\mathrm{P}_{\mathrm{x}_{\mathrm{i}}^{\mathrm{m}}}} ; \mathrm{T}=$ Total construction time; $s t_{i}=$ Start date of component $i ; d_{i}=$ Duration of component $i$; $Q_{i}=$ Quantity of component $i ; P_{x_{i}^{m}}=$ Productivity of component $\mathrm{i}$ and alternative $m ; E S_{i}=$ Early start of component $i ; L S_{i}=$ Late start of component $i ; \quad \mathrm{C}=$ Total initial construction cost, $c_{x_{i}^{m}}=$ Initial construction cost of component $i$ and 
alternative $\mathrm{m} ; \mathrm{EI}=$ Total $\mathrm{CO}_{2}$ emissions of the project; $e i_{x_{i}^{m}}=\mathrm{CO}_{2}$ emissions of component $i$ and alternative $m$.

Moreover, Mont Carlo simulation is utilized at this phase. The number of sets of optimal solutions generated by the NSGA-II algorithm is directly related to the ' $\mathrm{n}$ ' number of Monte Carlo simulations inputted by the users. For the usage phase, the construction time is not considered as the main objective since it does not have an effect on the operation of the building. However, different year-life spans of the building are considered to see the impact of operating time to the relationship between life cycle cost and $\mathrm{CO}_{2}$ emissions. Also different year-life span will provide different maintenance cost, energy consumption cost, and energy consumption related $\mathrm{CO}_{2}$ emissions. The energy simulation is incorporated in the usage phase at the building level to find yearly energy consumption based on different building designs. The two objective functions are 1) minimizing life cycle cost (C), and 2) minimizing life cycle $\mathrm{CO}_{2}$ emissions (EI) in the project. Optimization models for NSGA-II are shown below.

Decision Variables:

$$
\begin{aligned}
& x_{i}^{m} \triangleq \text { Alternatives of component } i \text { and } m=\text { alternative number } \\
& \qquad i=1,2,3, \ldots, k \text {, where } \mathrm{k}=\text { number of project components }
\end{aligned}
$$

Objective Functions:

$$
C_{l}=\min \left\{\sum_{i=1}^{k}\left(\left(c_{x_{i}^{m}} \times Q_{i}\right)+\left(C_{x_{i}^{m}}^{e}+C_{x_{i}^{m}}^{m}\right) \times Y\right)\right\}
$$




$$
E I_{l}=\min \left\{\sum_{i=1}^{k}\left(\left(e i_{x_{i}^{m}} \times Q_{i}\right)+\left(e i_{x_{i}^{m}}^{e} \times Y\right)\right)\right\}
$$

where $\mathrm{d}_{\mathrm{i}}=\frac{\mathrm{Q}_{\mathrm{i}}}{\mathrm{P}_{\mathrm{x}_{\mathrm{i}}^{\mathrm{m}}}} ; \mathrm{T}=$ Total project duration; $s t_{i}=$ Start date of component $i ; d_{i}=$ Duration of component $i ; Q_{i}=$ Quantity of component $i ; \mathrm{C}_{1}=$ Total life cycle cost, $c_{x_{i}}=$ Initial construction cost of component $i$ and alternative $\mathrm{m} ; C_{x_{i}^{m}}^{e}=$ Energy consumption cost per year of component $i$ and alternative m; $C_{x_{i}^{m}}^{m}=$ Maintenance cost per year of component $i$ and alternative $\mathrm{m} ; \mathrm{EI}_{1}=$ Total life cycle $\mathrm{CO}_{2}$ emissions of the building; $e i_{x_{i}^{m}}=\mathrm{CO}_{2}$ emissions of component $i$ and alternative $m ; e i_{x_{i}^{m}}^{e}=$ Energy related $\mathrm{CO}_{2}$ emissions of component $i$ and alternative $m$; Y $=$ Life span of the building.

Figure 5 shows the time, cost and environmental impact analysis for sustainable design at multiple building levels in the flowchart. Three different levels of the building analysis are presented. The process, input and output of each analysis are displayed as well. 


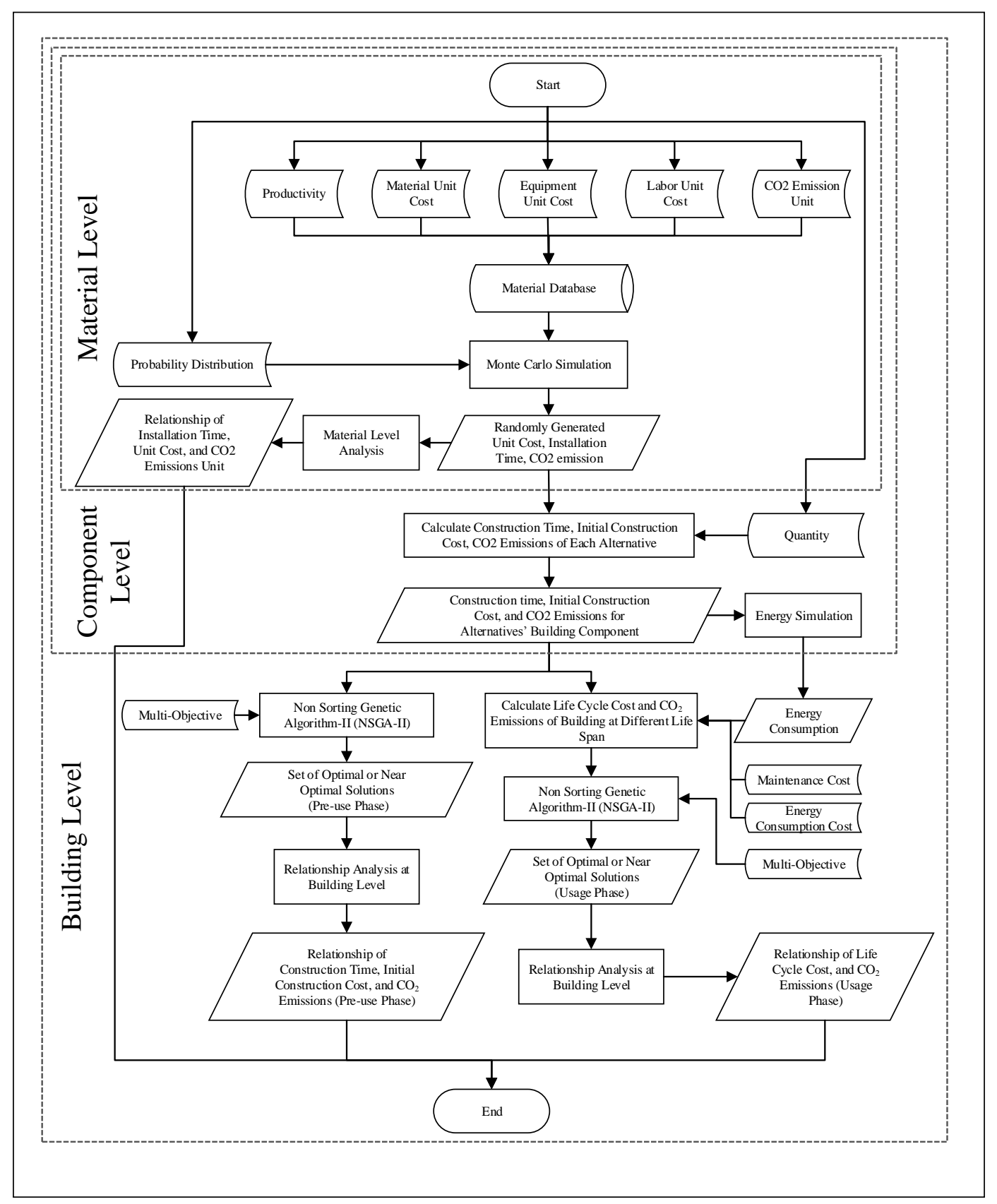

Figure 5 Time, Cost, and Environmental Impact Analysis for Sustainable Design at Multiple Building Levels Flowchart 


\section{CHAPTER 4 ANALYSIS OF TIME, COST AND ENVIRONMENTAL IMPACT RELATIONSHIPS AT BUILDING MATERIAL LEVEL}

The objectives of this chapter are mainly to determine data patterns of time, cost and environmental impact, in terms of $\mathrm{CO}_{2}$ emissions, and observe the level of confidence that a dominant alternative exists in any material category at the material level. In this study, time, cost and $\mathrm{CO}_{2}$ emissions of a material alternative are represented by productivity, unit cost and $\mathrm{CO}_{2}$ emissions per material unit respectively. To achieve the objectives, this study was designed to answer the following questions:

1) What is the level of confidence that a dominant alternative exists in a material category selected for this study? A dominant alternative is the one in a material category, whose unit cost and $\mathrm{CO}_{2}$ emissions per material unit are the smallest, and the installation productivity is the largest, among all other alternatives in the same category. As an optimization process always seeks a dominant alternative in each material category, if there is a dominant alternative in each material category, the optimal solutions at building level most likely converge to a limited number of options. Given the fact that the previous case study did not show such a convergence (Zhu et al, 2012), it was believed that it is highly likely that not all material categories have a dominant solution. The key issue is the level of confidence to this observation. If the

level of confidence is high, it can be inferred that trade-off relationships of time, cost and $\mathrm{CO}_{2}$ emissions also exist at the material level. 
2) If productivity and unit cost of all material in the same category are sorted by $\mathrm{CO}_{2}$ emissions per material unit, are there any clear data patterns? Answers to this question can help to demonstrate relationships of time, cost and $\mathrm{CO}_{2}$ emissions of all materials in a material category, which complements any observations or answers to the first question.

In addition, the study consists of two scenarios to observe the impact of machine and equipment use during the construction or installation phase of a project. In other words, one scenario only includes unit costs and $\mathrm{CO}_{2}$ emissions per material unit without considering the installation data of materials. The second scenario not only includes unit costs and $\mathrm{CO}_{2}$ emissions per material unit, but also considers corresponding data of operator unit cost, equipment unit cost, $\mathrm{CO}_{2}$ emissions per material unit from the installation phase or construction phase of materials, and installation time. The comparison of the two scenarios helps to understand how much installation methods contribute to changes in any relationship of time, cost and environmental impact that is observed in the first scenario.

\subsection{Data Collection and Preparation}

\subsubsection{Data Scope and Sources}

In this chapter, six categories of building envelope materials are studied, including structural components, exterior cladding, insulation, roofing, concrete footings, and concrete slabs-on-grade. All material alternatives in each category are compared at the same functional unit. For example, exterior cladding materials are compared using per 
square foot, insulation materials are compared using the same thermal resistance value or R-value, and concrete materials are studied in per cubic foot. Table 1 shows the alternatives in each category.

Each alternative has three important pieces of data: unit cost, productivity, and $\mathrm{CO}_{2}$ emissions per material unit. Unit cost data include material unit cost, labor unit cost, and equipment unit cost. Productivity and unit cost data were mostly collected from the RS Means Building Construction Cost Data. Market productivity and cost data were also collected for verification purposes. The $\mathrm{CO}_{2}$ emission data were derived from the Athena Impact Estimator for Buildings, which cover life cycle phases mainly up to the manufacturing phase of building materials. $\mathrm{CO}_{2}$ emissions due to construction phase were estimated based on hours of equipment use and the environmental impact of fuel consumption. The selection of data was also constrained by the availability of life cycle inventory data published in third-party sources and literature such as Athena handbook. In many cases, environmental impact data were not available for many construction materials or processes, even though cost and productivity data were mostly available. Therefore, only the materials listed in table 1 were selected for this study. Details of data processing are discussed in the following section.

Table 4 Material Alternatives and Categories

\begin{tabular}{llll}
\hline Category & Description & Alt. & Description
\end{tabular}




\begin{tabular}{|c|c|c|c|}
\hline Category & Description & Alt. & Description \\
\hline \multirow[t]{3}{*}{1} & Structural Component & 1 & Steel Stud \\
\hline & & 2 & Wood Stud \\
\hline & & 3 & Concrete Block Wall \\
\hline \multirow[t]{7}{*}{2} & Exterior Cladding & 1 & Cedar Bevel \\
\hline & & 2 & Concrete Brick \\
\hline & & 3 & Fiber Cement \\
\hline & & 4 & Metric Modular Brick \\
\hline & & 5 & Natural Stone \\
\hline & & 6 & Stucco \\
\hline & & 7 & Vinyl \\
\hline \multirow[t]{3}{*}{3} & Insulation & 1 & Expanded Polystyrene \\
\hline & & 2 & Extruded Polystyrene \\
\hline & & 3 & Blown Cellulose \\
\hline
\end{tabular}




\begin{tabular}{|c|c|c|c|}
\hline Category & Description & Alt. & Description \\
\hline & & 4 & Batt Rockwool \\
\hline & & 5 & Batt Fiberglass \\
\hline & & 6 & Foam Polyisocyanurate \\
\hline \multirow[t]{4}{*}{4} & Roofing & 1 & Clay Tiles \\
\hline & & 2 & Concrete Tiles \\
\hline & & 3 & Organic Felt Shingles 30 yr \\
\hline & & 4 & Roof Steel Panels \\
\hline \multirow[t]{6}{*}{5} & Concrete Footing & 1 & $3000 \mathrm{psi}$, average flyash \\
\hline & & 2 & 3000 psi, $25 \%$ flyash \\
\hline & & 3 & 3000 psi, 35\% Flyash \\
\hline & & 4 & 4000 psi, average Flyash \\
\hline & & 5 & 4000 psi, 25\% Flyash \\
\hline & & 6 & 4000 psi, 35\% Flyash \\
\hline
\end{tabular}




\begin{tabular}{llll}
\hline Category & Description & Alt. & Description
\end{tabular}

\begin{tabular}{|c|c|c|c|}
\hline 6 & Concrete Slab-on-grade & 1 & 4 inches, 3000 psi, average Flyash \\
\hline & & 2 & 4 inches, 3000 psi, 25\% Flyash \\
\hline & & 3 & 4 inches, 3000 psi, 35\% Flyash \\
\hline & & 4 & 4 inches, 4000 psi, average Flyash \\
\hline & & 5 & 4 inches, 4000 psi, 25\% Flyash \\
\hline & & 6 & 4 inches, 4000 psi, 35\% Flyash \\
\hline & & 7 & 8 inches, 3000 psi, average Flyash \\
\hline & & 8 & 8 inches, 3000 psi, 25\% Flyash \\
\hline & & 9 & 8 inches, 3000 psi, 35\% Flyash \\
\hline & & 10 & 8 inches, 4000 psi, average Flyash \\
\hline & & 11 & 8 inches, 4000 psi, $25 \%$ Flyash \\
\hline & & 12 & 8 inches, 4000 psi, 35\% Flyash \\
\hline
\end{tabular}




\subsubsection{Data Preparation}

1) Material Installation Time Since this chapter is focused on the building materials, the construction time was only referred to as a material installation time, which can be estimated by using the productivity of material installation, and the quantity of a particular material or, in this case, the functional unit of material. The RS Means Building Construction Cost Data provides productivity data of building materials, in terms of a daily output (unit/day). Additionally, installation time is only considered in the second scenario of this study.

2) Construction Cost Construction cost can be estimated by multiplying the unit cost and the quantity of materials. In scenario 1 , the unit cost only refers to the material unit cost, as shown in table 2; while, in scenario 2, the unit cost, including material, labor and equipment unit costs, are considered.

3) Environmental Impact The Athena Impact Estimator for Buildings (version 4.5) was used in this study to generate data of environmental impact, in terms of $\mathrm{CO}_{2}$ emissions, as $\mathrm{kg} \mathrm{CO}_{2}$ equivalent per material unit. The database of Athena can capably model a construction project with over 1,500 structural components and building envelopes (Athena Sustainable Material Institute, 2013). Results from the program include typical impact categories, fossil fuel consumption (MJ), global warming potential ( $\mathrm{kg} \mathrm{CO}_{2} \mathrm{eq}$ ), acidification potential ( $\mathrm{kg} \mathrm{SO}$ eq), $\mathrm{HH}$ Particulate (kg PM2.5 eq), eutrophication potential ( $\mathrm{kg} \mathrm{N}$ eq), ozone depletion potential ( $\mathrm{kg} \mathrm{CFC}-11 \mathrm{eq}$ ), and smog 
potential ( $\mathrm{kg} \mathrm{O}_{3} \mathrm{eq}$ ). Currently, as mentioned before, the only environmental impact considered in this research was $\mathrm{CO}_{2}$ emissions.

$\mathrm{CO}_{2}$ emissions, reflecting the manufacturing phase of materials, were used in Scenario 1; while scenario 2 also included $\mathrm{CO}_{2}$ emissions from the use of equipment during the installation phase. Crew types, provided by the RS Mean Building Cost Data, were used to gather equipment information in order to estimate $\mathrm{CO}_{2}$ emissions from equipment used during construction. Table 5 shows a summary of the two scenarios.

\section{Table 5 Summary of the Two Scenarios}

\begin{tabular}{cccc}
\hline Scenario & Time (hours) & Cost $(\$)$ & $\mathrm{CO}_{2}$ Emission $\left(\mathrm{kg} \mathrm{CO}_{2}\right.$ eq) \\
\hline 1 & - & Material unit cost & $\mathrm{CO}_{2}$ emissions per material unit \\
& Installation & Material unit cost + & $\mathrm{CO}_{2}$ emissions per material unit \\
& time & from the manufacturing phase \\
& equipment unit cost & from manufacturing $+\mathrm{CO}_{2}$ \\
& & emissions per material unit from \\
& & installation
\end{tabular}

Additionally, input data for each material need to be aligned because data disparities had been identified between the two major data sources, the RS Means Building Construction Cost Data and Athena Impact Estimator for Building, which 
occasionally provide data in different units. For instance, insulation materials need to have the same equipotential function for meaningful comparisons. Thus, instead of using area in square foot or thickness in inch, thermal resistance value (R-value) was applied as a functional unit for the insulation category. However, all six chosen alternatives had varied R-values. The foam polyisocyanrate had lowest conductivity (Btu/h-ft-F) or the highest R-value (h-ft-F/Btu), which was selected as the base value in this category. All other alternatives were adjusted to match this R-value. Since Athena allows users to input the desired thickness of materials to derive environmental impact data based on a specific R-value $\left(\mathrm{h}-{ }^{\circ} \mathrm{F}-\mathrm{ft}^{2} / \mathrm{Btu}\right)$, the thickness (inches) of other insulation materials was first calculated to match the R-5.15 of foam polyisocyanrate by using thermal conductivity data $\left(\mathrm{Btu} / \mathrm{h}-\mathrm{ft}-{ }^{\circ} \mathrm{F}\right)$, and it was also used as input data to derive $\mathrm{CO}_{2}$ emissions from Athena. On the other hand, RS Means provides cost data based on specific thicknesses and R-values, such as fiberglass $3 \frac{1}{2}$ inches thick with R-11, or fiberglass 6 inches thick with R-19. Cost data and thickness values from RS Means were plotted to find relationship functions between them by using the traditional curve fitting technique. Without any other information, unit cost data for insulation materials were estimated by interpolation based on the curve fitting function and the previously calculated thicknesses data of insulation materials in Athena.

Another example is fiber cement siding in the exterior cladding category. There are more than ten options of fiber cement siding with different textures at the MasterFormat level 4 in RS Means; while Athena only provides information at the MasterFormat level 2. To match the $\mathrm{CO}_{2}$ emission scope of Athena (MasterFormat level 
2), costs at the MasterFormat level 4 from RS Means were first grouped to match the level 3 and level 2 classifications for $\mathrm{CO}_{2}$ emissions; then costs in each level of classification were averaged to match the $\mathrm{CO}_{2}$ emission data. The roofing category used the same approach for matching data as well as exterior cladding, while structural component, concrete footing, and concrete slab-on-grade category can similarly match data from RS Means and Athena at the same level of information.

\subsection{Additional Data Generation}

In general, data sources, such as the Athena database and RS Means, provide average data in a local or nation context. In order to determine the level of confidence regarding an observed pattern, uncertainties in unit costs, $\mathrm{CO}_{2}$ emissions, and construction productivities need to be addressed. Due to limitations of data availability, the Monte Carlo simulation was used for additional data generation and uncertainty propagation. In this research, the beta distribution was used for describing the functions of unit costs and productivities, and the normal distribution was applied to model data distribution of $\mathrm{CO}_{2}$ emissions per material unit.

The mean values $(\bar{x})$ of probability functions in both beta distributions and normal distributions were defined by using data from Athena and RS Means Moreover, in this research, historical data from 25 school projects, which are located in the Miami-Dade county area, were collected to identify the maximum and minimum possible range of unit costs and installation time. The total cost of the projects ranged from $\$ 63,000$ to $\$ 12,000,000$. If the historical data from school projects existed, maximum and minimum 
values were set based on the historical data, otherwise a range of $20 \%$ from the mean value was utilized (e.g., Nasir et al., 2003; Rypdal \& Winiwarter, 2001; Rypdal \& Flugsrud, 2001; Winiwarter \& Rypdal, 2001). For example, from historical data, there was maximum duration to install one square foot of fiberglass insulation, as well as minimum and maximum unit cost of fiberglass insulation. Thus, the missing data of minimum installation time was determined at $20 \%$ less than the average installation time derived from RS Means' data. Mean, maximum, and minimum values were used to calculate the standard deviation $(\rho)$ of the normal distribution and the variance $\left(s^{2}\right)$ of the beta distribution. Moreover, alpha $(\alpha)$ and beta $(\beta)$ were also calculated as input parameters for the beta distribution as shown in Table 3 (e.g., Owen, 2008; MathWorks, 2014). Furthermore, installation time (hours) was estimated by using productivity from RS Means and a quantity of material.

In the Monte Carlo simulation, inverse cumulative distribution functions were utilized in order to find representative unit costs, time, and $\mathrm{CO}_{2}$ emissions per material unit. The Monte Carlo simulation started by randomly generating a number ranging from 0 to 1 for variables, i.e., material unit cost, labor unit cost, productivity, and $\mathrm{CO}_{2}$ emissions per material unit. Thus, by using the inverse cumulative distribution functions, the generated numbers are interpolated to represent unit costs, productivity, and also $\mathrm{CO}_{2}$ emissions per material unit in each simulation run. 
Table 6 Summary Functions Representing Variables' Distribution

\begin{tabular}{|c|c|c|c|}
\hline Variables & $\begin{array}{c}\text { Inverse Cumulative Distribution } \\
\text { Function }\end{array}$ & Input Parameter & Source \\
\hline \multirow[t]{2}{*}{ Cost } & $\begin{array}{l}\text { Beta Distribution; } x= \\
F^{-1}(p \mid \alpha, \beta)=\{x: F(x \mid \alpha, \beta)= \\
p\} \text { where } p=F(x \mid \alpha, \beta)= \\
\frac{1}{B(\alpha, \beta)} \int_{0}^{x} t y^{\alpha-1}(1-t)^{\beta-1} d y \\
\text { and } B(\alpha, \beta) \text { is called beta } \\
\text { function converges for } \alpha>0 \\
\text { and } \beta>0,0<p<1\end{array}$ & $\begin{array}{l}\bar{x} \text { (mean) } \\
\max \\
\min \end{array}$ & $\begin{array}{l}\text { RS Means } \\
\text { historical data and } \\
\text { literature review } \\
\text { historical data and } \\
\text { literature review }\end{array}$ \\
\hline & & $\begin{array}{l}s^{2} \text { (varience) } \\
\alpha \\
\beta\end{array}$ & $\begin{array}{l}\text { mean, max, and min } \\
\text { value } \\
\bar{x}\left(\frac{\bar{x}(1-\bar{x})}{s^{2}}-1\right) \\
(1-\bar{x})\left(\frac{\bar{x}(1-\bar{x})}{s^{2}}\right. \\
-1)\end{array}$ \\
\hline \multirow[t]{2}{*}{ Time } & $\begin{array}{l}\text { Beta Distribution; } x= \\
F^{-1}(p \mid \alpha, \beta)=\{x: F(x \mid \alpha, \beta)= \\
p\} \text { where } p=F(x \mid \alpha, \beta)= \\
\frac{1}{B(\alpha, \beta)} \int_{0}^{x} t y^{\alpha-1}(1-t)^{\beta-1} d y \\
\text { and } B(\alpha, \beta) \text { is called beta } \\
\text { function converges for } \alpha>0 \\
\text { and } \beta>0,0<p<1\end{array}$ & $\begin{array}{l}\bar{x}(\text { mean }) \\
\max \\
\min \end{array}$ & $\begin{array}{l}\text { RS Means } \\
\text { historical data and } \\
\text { literature review } \\
\text { historical data and } \\
\text { literature review }\end{array}$ \\
\hline & & $s^{2}$ (varience) & $\begin{array}{l}\text { mean, max, and } \min \\
\text { value }\end{array}$ \\
\hline
\end{tabular}




\begin{tabular}{|c|c|c|c|}
\hline Variables & $\begin{array}{c}\text { Inverse Cumulative Distribution } \\
\text { Function }\end{array}$ & Input Parameter & Source \\
\hline $\begin{array}{l}\mathrm{CO}_{2} \\
\text { emissions } \\
\text { per } \\
\text { material } \\
\text { unit }\end{array}$ & $\begin{array}{l}\text { Normal Distribution; } x= \\
F^{-1}(p \mid \mu, \sigma)=\{x: F(x \mid \mu, \sigma)= \\
p\} \\
\quad \text { where } p=F(x \mid \mu, \sigma)= \\
\frac{1}{\sigma \sqrt{2 \pi}} \int_{-\infty}^{x} e^{\frac{-(t-\mu)^{2}}{2 \sigma^{2}}} d y,-\infty<\mu< \\
\quad \infty, \sigma>0, \text { and } 0<p<1\end{array}$ & $\begin{array}{l}\mu \\
\text { (corresponding } \\
\text { mean) } \\
\max \\
\text { min } \\
\sigma \text { (standard } \\
\text { deviation) }\end{array}$ & $\begin{array}{l}\bar{x}\left(\frac{\bar{x}(1-\bar{x})}{s^{2}}-1\right) \\
(1-\bar{x})\left(\frac{\bar{x}(1-\bar{x})}{s^{2}}-1\right) \\
\text { Athena Impact } \\
\text { Estimator } \\
\text { literature review } \\
\text { literature review } \\
\text { corresponding mean, } \\
\text { max, and min value }\end{array}$ \\
\hline
\end{tabular}

\subsection{Level of Confidence}

The level of confidence of material alternatives were evaluated based on the frequency of a material alternative being selected as a dominant option using the Monte Carlo simulation. In scenario 1, the formula that was used to determine the frequency of dominant occurrence of materials in each material category is, 


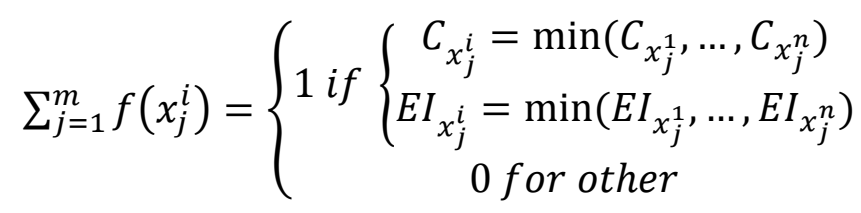

subject to $i=1, \ldots, n$ and $j=1, \ldots, m$

where $x_{j}^{i}=$ variable alternative $\mathrm{i}$ with $\mathrm{j}^{\text {th }}$ Monte Carlo simulation, $C_{x_{j}^{i}}=$ unit cost of $x_{j}^{i}$ (\$), $E I_{x_{j}^{i}}=\mathrm{CO}_{2}$ emissions per material unit of $x_{j}^{i}\left(\mathrm{~kg} \mathrm{CO}_{2} \mathrm{eq}\right), \mathrm{n}=$ number of alternative in category, and $\mathrm{m}=$ number of Monte Carlo simulation.

In scenario 2, the material installation time was included in the analysis. Thus, objective function will consider the third parameter as shown below.

$$
\sum_{j=1}^{m} f\left(x_{j}^{i}\right)=\left\{\begin{array}{c}
T_{x_{j}^{i}}=\min \left(T_{x_{j}^{1}}, \ldots, T_{x_{j}^{n}}\right) \\
C_{x_{j}^{i}}=\min \left(C_{x_{j}^{1}}, \ldots, C_{x_{j}^{n}}\right) \\
E I_{x_{j}^{i}}=\min \left(E I_{x_{j}^{1}}, \ldots, E I_{x_{j}^{n}}\right) \\
0 \text { for other }
\end{array}\right.
$$

subject to $i=1, \ldots, n$ and $j=1, \ldots, m$

where $x_{j}^{i}=$ variable alternative $\mathrm{i}$ with $\mathrm{j}^{\text {th }}$ Monte Carlo simulation, $T_{x_{j}^{i}}=$ installation time of $x_{j}^{i}$ (hours), $C_{x_{j}^{i}}=$ unit cost of $x_{j}^{i}(\$), E I_{x_{j}^{i}}=\mathrm{CO}_{2}$ emissions per material unit of $x_{j}^{i}(\mathrm{~kg}$ $\mathrm{CO}_{2}$ eq), $\mathrm{n}=$ number of alternative in category, and $\mathrm{m}=$ number of Monte Carlo simulation. 


\subsection{Pattern Analysis}

In order to study patterns among cost, installation time and $\mathrm{CO}_{2}$ emissions, the average value of those data generated from the Monte Carlo simulation were first plotted in pairwise graphs between time and $\mathrm{CO}_{2}$ emissions per material unit, as well as unit cost and $\mathrm{CO}_{2}$ emissions per material unit. Observable patterns were then further analyzed by using the concept of trade-off patterns.

Firstly, the analysis studied the patterns using average values, as shown in the examples of structural component, roofing and concrete footing 3,000 psi in figures 6,7 and 8. The average values were derived based on the Monte Carlo simulation as discussed previously. Examples show that, when all materials in each category are considered, trade-off relationship does not obviously exist. However, trade-off relationships do seem to exist in subsets of materials in each category. For example, in figure 6 , the wood stud alternative dominates the other two options based on average values. Nevertheless, if the wood stud alternative is not considered, it seems that a tradeoff relationship exists between the concrete block alternative and the steel stud alternative. Other material categories have a similar pattern.

Moreover, in one material category, multiple data patterns may exist. For example, in the roofing category, options such as organic felt shingles, concrete tiles and clay tiles may form non-trade-off relationships or direct variation relationships between them, but roof steel panels may have trade-off relationships with other options as shown 
in figure 7. Figure 8 presents an example of general relationship behaviors for the concrete material.

For each of the above data patterns, a statistical analysis was performed to determine its probability using the data from the Monte Carlo simulation, including

1. A trade-off relationship when all materials are considered,

2. A trade-off relationship when a subset of materials is considered, and

3. Existence of multiple relationships when all materials are considered.

In scenario 1, a trade-off relationship exists when one alternative has one higher variable and one lower variable than another. In scenario 2, if an alternative does not have all three variables higher or lower than another, there is a trade-off relationship between two alternatives. The equations used to determine trade-off relationships in scenarios 1 and 2 are shown below.

Scenario 1:

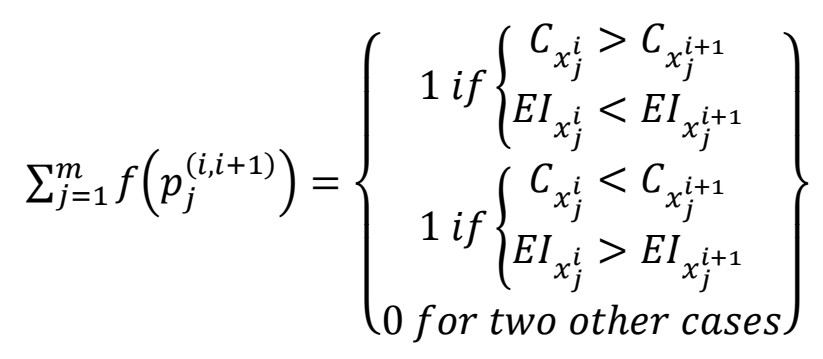


subject to $i=1, \ldots, \mathrm{n}-1$ and $j=1, \ldots, \mathrm{m}$

where $p_{j}^{(i, i+1)}=$ pairwise alternatives $(i, i+1)$ for $\mathrm{j}^{\text {th }}$ Monte Carlo simulation, $x_{j}^{i}=$ variable alternative $\mathrm{i}$ with $\mathrm{j}^{\text {th }}$ Monte Carlo simulation, $x_{j}^{i+1}=$ variable alternative $\mathrm{i}+1$ with $\mathrm{j}^{\text {th }}$ Monte Carlo simulation, $C_{x_{j}^{i}}=$ unit cost of $x_{j}^{i}(\$), C_{x_{j}^{i+1}}=$ unit cost of $x_{j}^{i+1}(\$), E I_{x_{j}^{i}}=$ $\mathrm{CO}_{2}$ emissions per material unit of $x_{j}^{i}\left(\mathrm{~kg} \mathrm{CO}_{2} \mathrm{eq}\right), E I_{x_{j}^{i+1}}=\mathrm{CO}_{2}$ emissions per material unit of $x_{j}^{i+1}\left(\mathrm{~kg} \mathrm{CO}_{2} \mathrm{eq}\right), \mathrm{n}=$ number of alternative in category, and $\mathrm{m}=$ number of Monte Carlo simulation.

Scenario 2:

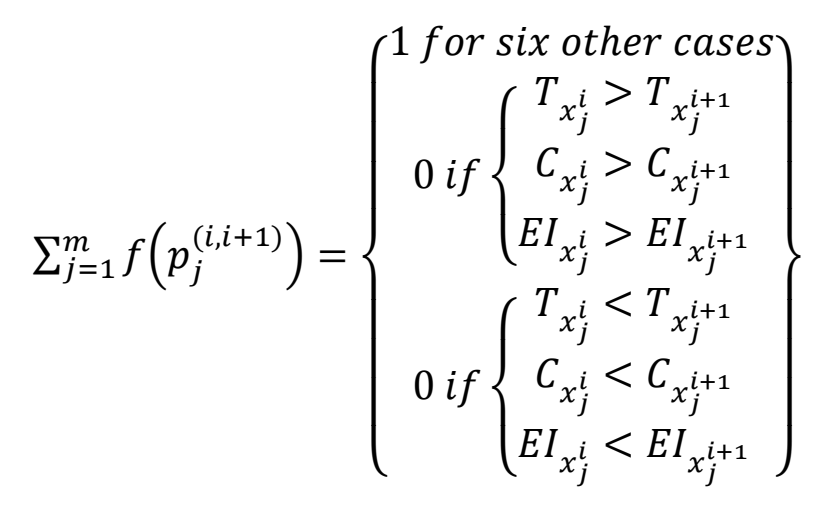

subject to $i=1, \ldots, \mathrm{n}-1$ and $j=1, \ldots, \mathrm{m}$

where $p_{j}^{(i, i+1)}=$ pairwise alternatives $(i, i+1)$ for $\mathrm{j}^{\text {th }}$ Monte Carlo simulation, $x_{j}^{i}=$ variable alternative $\mathrm{i}$ with $\mathrm{j}^{\text {th }}$ Monte Carlo simulation, $x_{j}^{i+1}=$ variable alternative $\mathrm{i}+1$ with $\mathrm{j}^{\text {th }}$ Monte Carlo simulation, $T_{x_{j}^{i}}=$ installation time of $x_{j}^{i}$ (hours), $T_{x_{j}^{i+1}}=$ installation time of $x_{j}^{i+1}$ (hours), $C_{x_{j}^{i}}=$ unit cost of $x_{j}^{i}(\$), C_{x_{j}^{i+1}}=$ unit cost of $x_{j}^{i+1}(\$), E I_{x_{j}^{i}}=\mathrm{CO}_{2}$ 
emissions per material unit of $x_{j}^{i}\left(\mathrm{~kg} \mathrm{CO}_{2} \mathrm{eq}\right), E I_{x_{j}^{i+1}}=\mathrm{CO}_{2}$ emissions per material unit of $x_{j}^{i+1}\left(\mathrm{~kg} \mathrm{CO}_{2} \mathrm{eq}\right), \mathrm{n}=$ number of alternative in category, and $\mathrm{m}=$ number of Monte Carlo simulation.

In both scenarios, percentages of direct variation relationships also calculated. A direct variation relationship exists when one alternative has all variables' values higher than another alternative. Thus, trade-off patterns and direct variation patterns are exclusive to each other in all pairwise alternatives.

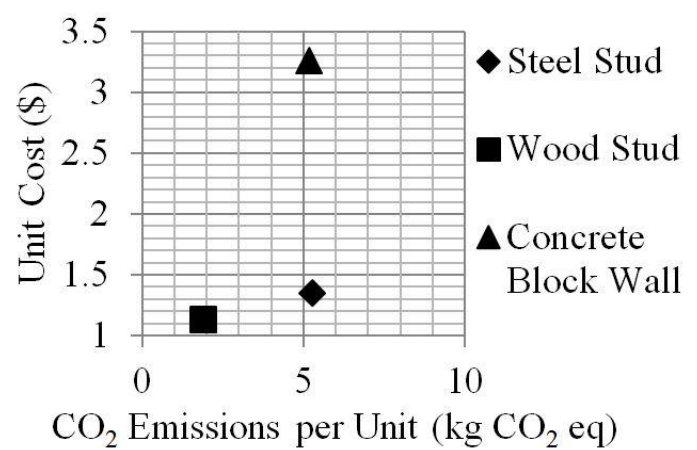

$\mathrm{CO}_{2}$ Emissions per Unit ( $\mathrm{kg} \mathrm{CO}$ eq)

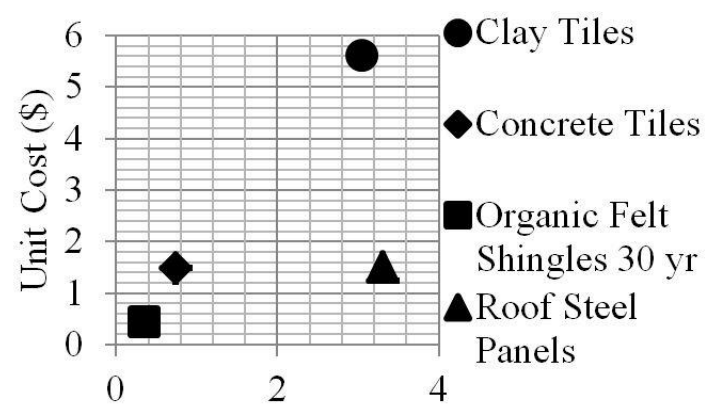

$\mathrm{CO}_{2}$ Emissions per Unit ( $\left.\mathrm{kg} \mathrm{CO} 2 \mathrm{eq}\right)$

Figure 6 Graph Relationship between Average $\mathrm{CO}_{2}$ Emissions per Material Unit and Average Unit Cost for Structural Component (left) and Roofing (right) in Scenario 1

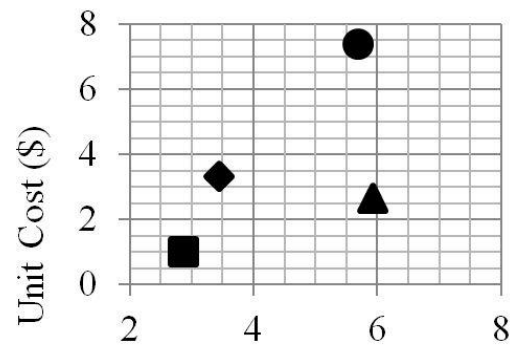

$\mathrm{CO}_{2}$ Emissions per Unit ( $\mathrm{kg} \mathrm{CO}$ eq)

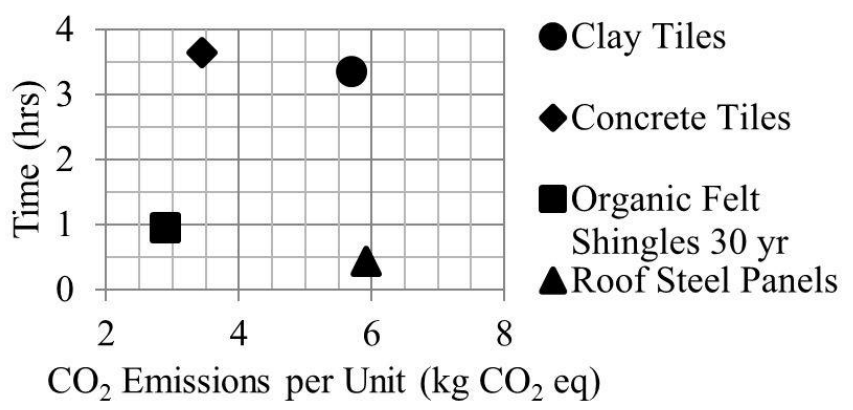

Figure 7 Graph Relationship between Average $\mathrm{CO}_{2}$ Emissions per Material Unit and Average Unit Cost (left), and between Average $\mathrm{CO}_{2}$ Emissions per Material Unit and Installation time (right) for Roofing in Scenario 2 

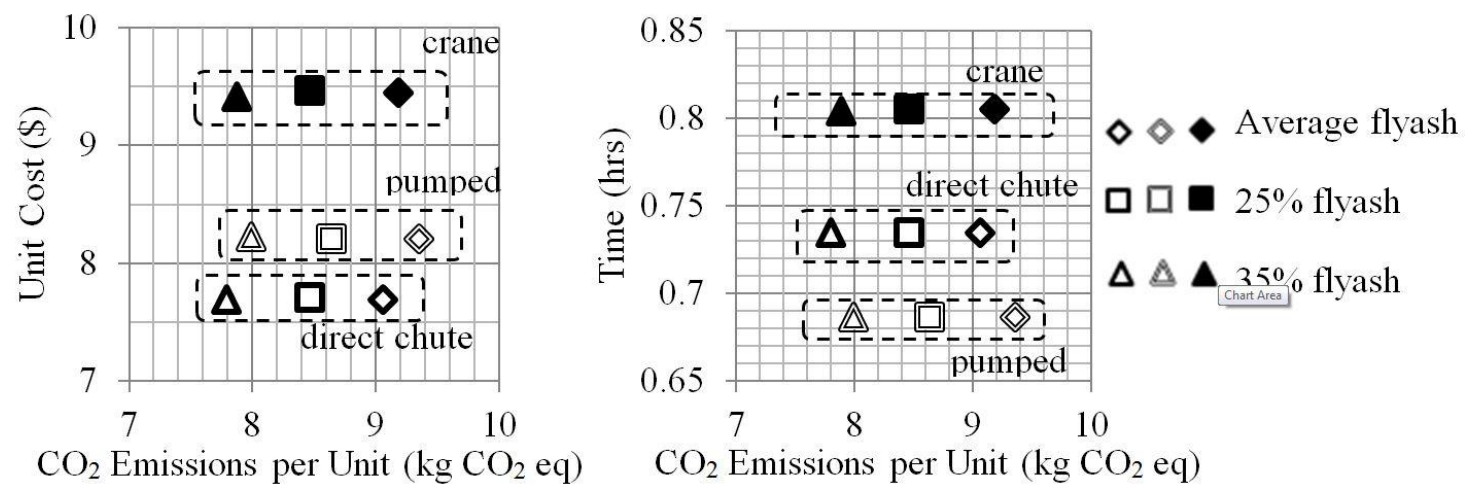

Figure 8 Graph Relationship between Average $\mathrm{CO}_{2}$ Emissions per Material Unit and Average Unit Cost (left), and between Average $\mathrm{CO}_{2}$ Emissions per Material Unit and Installation Time (right) for Concrete Footing 3000 psi in Scenario 2

\subsection{Significance Test}

To determine how significant an observed pattern is, this research hypothesized that the probability of a certain pattern between pairwise alternatives in each category is significantly greater than an assumed mean at 5\% confidence level. Since outcomes of pairwise analysis followed binomial probability distributions, i.e., there are only two possible values, 'trade-off' or 'non-trade-off'. Z-tests were applied in the study to determine the statistical significance of analysis.

To determine the assumed mean in each scenario, fair chance outcomes were firstly formulated using above corresponding equations of scenarios due to the lack of historical data. In scenario 1, since two of the four cases represent the existence of a trade-off relationship, the fair chance of outcomes is $50 \%$. In order words, the probability (p) that trade-offs significantly exist is equal to 500 times out of 1,000 Monte Carlo simulation runs. This ratio is selected as the assumed value for Scenario 1. Thus, in 
scenario 1 , the $\mathrm{z}$-test investigated null hypothesis, $\mathrm{H}_{\mathrm{o}}: \mathrm{p}=500$, against alternative hypothesis, $\mathrm{H}_{\mathrm{a}}: \mathrm{P}>500$ at the $5 \%$ significance level. The rejection of null hypothesis represents there is a significant level of trade-offs.

In scenario 2, there are eight cases in total from the pattern analysis. In two out of the eight cases, 1) all three variables are lower or 2) all three variables are higher, tradeoff relationships do not exist between pairwise alternatives, and there are six other cases where trade-off relationships exist. Thus, the probability for the significant existence of trade-off relationships is 750 out of 1,000 simulation runs. Consequently, the null hypothesis is $\mathrm{H}_{\mathrm{o}}: \mathrm{p}=750$ and alternative hypothesis is $\mathrm{H}_{\mathrm{a}}: \mathrm{p}>750$ at the $5 \%$ significance level. Again, rejection of the null hypothesis represents there is a significant level of trade-offs. If a z-test returns that ' $h$ ' equals to 1 and ' $p$ ' converges to 0 , the null hypothesis is falsified at the $5 \%$ significance level and a result is significantly better than the assumed value. If a $z$-test shows the value of ' $h$ ' as 0 , the results fail to reject null hypothesis.

\subsection{Analysis and Results}

Table 7 shows a summary of the dominant alternatives of materials in the six categories with their respective percentages of being selected as a dominant alternative. It is interesting to observe that, in the structural component category, the wood stud alternative was selected as a dominant alternative at $92.3 \%$ and $70.1 \%$, respectively, in the two scenarios. In addition, when installation time was considered in scenario 2 , the percentage dropped almost $22 \%$. This is because wood studs produced comparatively low 
$\mathrm{CO}_{2}$ emissions in the manufacturing phase or less than approximately $50 \%$ compared to steel studs and concrete blocks. However, when the installation phase was considered, concrete blocks delivered almost $80 \%$ less $\mathrm{CO}_{2}$ emissions than wood studs in this phase. Thus, the concrete blocks alternative might have a chance to be more competitive than wood studs, if its $\mathrm{CO}_{2}$ emissions per material unit are relatively low in a simulation run.

In the exterior cladding category, stucco only had a small chance, $0.5 \%$, of being selected as a dominant material among six alternatives, but when installation cost and time were taken into account, there was no dominant alternative that occurred in Scenario 2. This is because cedar bevel and metric modular brick had a similar amount of $\mathrm{CO}_{2}$ emissions per material unit in scenario 2 .

In the insulation category, the blown cellulose alternative had the highest probability of being chosen as a predominant alternative in both scenarios. The probabilities of this category were the second highest among all material categories under study. Also, between scenarios 1 and 2, the probabilities in the two scenarios were obviously similar. The reason is that the blown cellulose alternative had the highest productivity; or the shortest installation time. Both the unit cost and $\mathrm{CO}_{2}$ emissions per material unit of the blown cellulose alternative were lower than others as well. In the roofing category, only scenario 1 showed that the organic shingle with 30 years of warranty was the dominant alternative at a percentage of $99.8 \%$. However, it is interesting to see that there was no dominant material alternative in scenario 2 . These points out that material installation in the construction phase may have an important impact on the selection of dominant alternatives. 
For all concrete categories including the concrete footing and the concrete slabon-grade categories, the level of confidence of all categories was fairly low with a highest of 32.9\% (4000 psi 8" slab-on-grade in scenario 1). In scenario 2, the level of confidence being a dominant alternative was even lower with a highest of $0.6 \%$ (3000 psi 8" slab-ongrade). Alternatives of concrete with different percentages of flyash, average flyash, $25 \%$ flyash, and 35\% flyash, and different design strength, 3000 psi and 4000 psi, were also compared. The results showed that concrete with a $35 \%$ flyash mix had a higher chance to be a dominant solution in all scenarios. The main reason is that concrete with different flyash mixes has the same unit cost and construction productivity from the RS Means database. Therefore, the distinction between them is only the $\mathrm{CO}_{2}$ emissions per material unit. Concrete with $35 \%$ flyash had the lowest carbon emissions per material unit compared to the other two, thus, concrete with $35 \%$ flyash tended to show the highest possibility to be chosen as a dominant alternative. However, the difference of $\mathrm{CO}_{2}$ emissions per material unit between different fly ash mixes was less than $20 \%$. The percentage of concrete with $35 \%$ flyash being a dominant alternative was not considered large.

In addition, in scenario 2, three methods of placing concrete were analyzed. From the RS Means Building Construction Cost Data, the pumped method had the best daily output approximately $40 \%$ more than the crane and bucket method, and its cost was almost $60 \%$ less than the crane and bucket method. Thus, concrete with the pumped method had a higher probability to be treated as a dominant option in all concrete alternatives with different flyash mixes. However, the direct chute method had slightly 
higher cost and lower productivity than the pumped method. Thus, both methods could be competitive, which leaded to that concrete with the pumped method had a small advantage of being chosen as a dominant option.

Table 7 Summary of Dominant Alternatives and Probability in Percentage

\begin{tabular}{|c|c|c|c|c|}
\hline Categories & Sub & Unit & Scenario & Dominant Alternative (\%) \\
\hline & Categories & Function & & \\
\hline \multicolumn{2}{|l|}{ Structural } & S.F. & 1 & Wood Stud $(92.3 \%)$ \\
\hline \multicolumn{5}{|l|}{ Component } \\
\hline & & & 2 & Wood Stud $(70.1 \%)$ \\
\hline Exterior & & S.F. & 1 & Stucco $(0.5 \%)$ \\
\hline \multicolumn{5}{|l|}{ Claddings } \\
\hline & & & 2 & - \\
\hline \multirow[t]{2}{*}{ Insulation } & & R-value & 1 & Blown Cellulose (67.5\%) \\
\hline & & & 2 & Blown Cellulose (66.5\%) \\
\hline \multirow[t]{2}{*}{ Roofing } & & S.F. & 1 & Organic Shingle $30 \mathrm{yr}(99.8 \%)$ \\
\hline & & & 2 & - \\
\hline Concrete Footing & Footing & C.F. & 1 & $35 \%$ flyash $(33.9 \%)$ \\
\hline
\end{tabular}




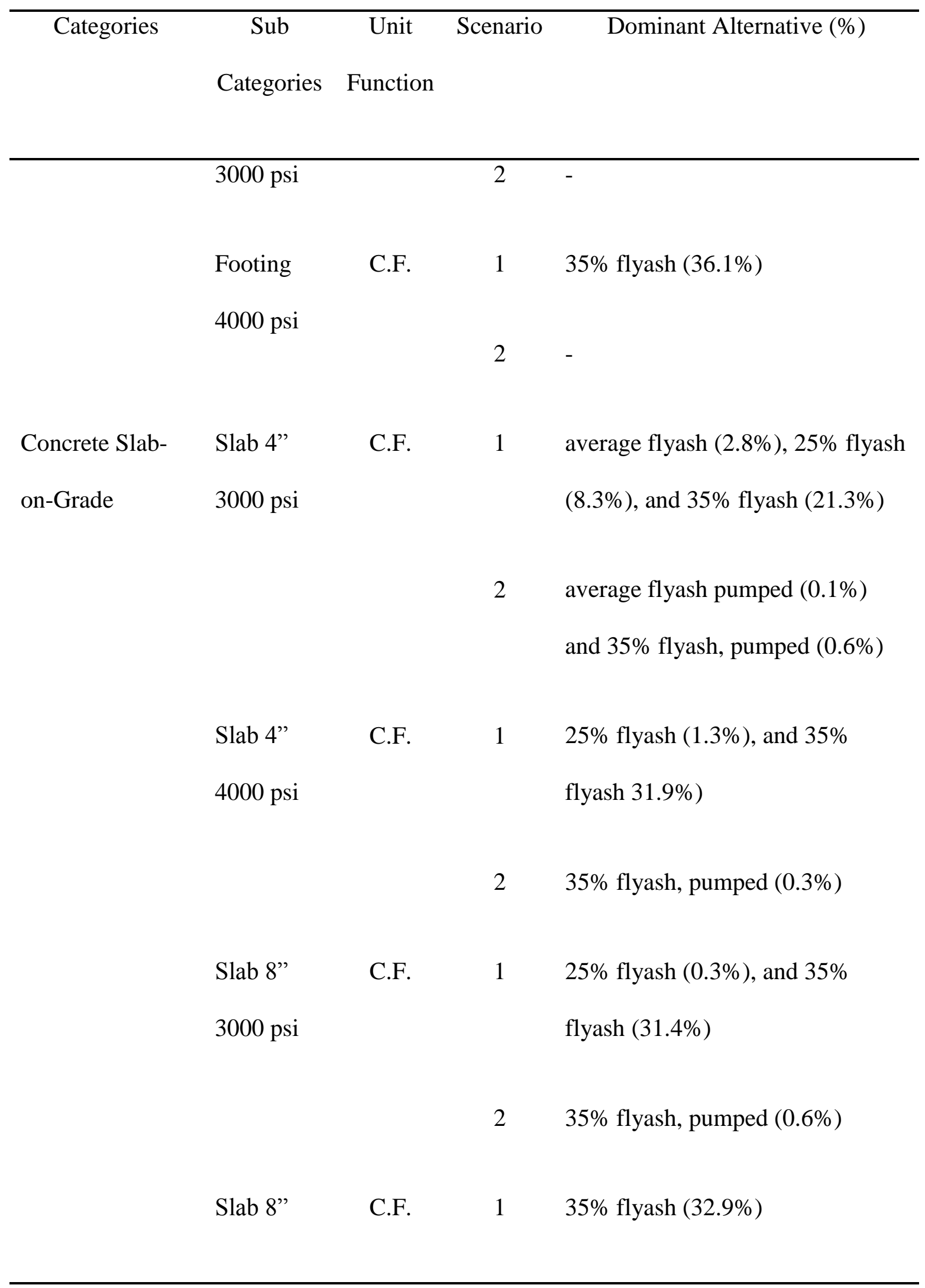



Categories
Sub
Unit Scenario
Dominant Alternative (\%)
Categories Function

4000 psi

$235 \%$ flyash, pumped $(0.3 \%)$

Tables 8-17 contain probabilities of trade-off relationships between pairwise alternatives of all categories in the upper triangle and probabilities of direct variations in the lower triangle. The probabilities were derived pattern analysis equations. The results showed that there was no perfect trade-off relationship when all materials in each category were considered. Trade-off relationships of pairwise alternatives in concretebased category were high or greater than $75 \%$ in all cases. By comparing unit cost across placing concrete methods, the crane method gave greatly higher unit cost in terms of labor cost and equipment cost, since it might need more workers, operators and instruments than others. While the direct chute method had importantly low equipment cost or it had almost $93 \%$ less equipment unit cost than crane and pumped techniques. Percentages of flyash still showed the same pattern in different placing concrete methods.

From the tables, a trade-off relationship was also observed when a subset of materials was considered. Moreover, there were noticeable multiple relationships between alternatives. Tables 8-17 also present z-test results. The numbers with '*' indicate that z-test rejected the null hypothesis at the 5\% significance level and the results were significantly greater than pure chances. 
Figure 9 presents values of average $\mathrm{CO}_{2}$ emissions per material unit and average unit cost in both scenarios, as well as changes of the percentage of $\mathrm{CO}_{2}$ emissions (value below arrow) and unit cost (value above arrow) due to the effect for material installation. This highlights the importance of material installation that needed to be considered in the early decision making process of material selections in the project. For example, the foam polyisocyanurate insulation option had lower unit cost than the batt fiberglass insulation option in Scenario 1. However, the foam polyisocyanurate insulation unit cost option had increased almost 200\%, when material installation cost (labor unit cost and equipment unit cost) was considered, while the unit cost of the batt fiberglass insulation option had increased only $41.9 \%$. Thus, in scenario 2 , the foam polyisocyanurate insulation option showed higher unit cost than the batt fiberglass insulation option.

Table 8 Alternative Pairwise Analysis in Structural Component Category

\begin{tabular}{cc|rrr|rrr}
\hline & \multicolumn{8}{c}{ Percentage of Trade-off } \\
\hline & Alt. & 1 & \multicolumn{3}{c}{ Scenario 1 } & \multicolumn{3}{c}{ Scenario 2 } \\
\hline Percentage & 1 & - & 7.7 & $86.8^{*}$ & - & 29.9 & $100^{*}$ \\
of Direct & 2 & 92.3 & - & 0 & 70.1 & - & 0 \\
Variation & 3 & 13.2 & 100 & - & 0 & 100 & - \\
\hline
\end{tabular}


Table 9 Alternative Pairwise Analysis in Exterior Cladding Category

\begin{tabular}{|c|c|c|c|c|c|c|c|c|c|c|c|c|c|c|c|}
\hline & \multicolumn{15}{|c|}{ Percentage of Trade-off } \\
\hline & \multirow[b]{2}{*}{ Alt. } & \multicolumn{7}{|c|}{ Scenario 1} & \multicolumn{7}{|c|}{ Scenario 2} \\
\hline & & 1 & 2 & 3 & 4 & 5 & 6 & 7 & 1 & 2 & 3 & 4 & 5 & 6 & 7 \\
\hline \multirow{7}{*}{ 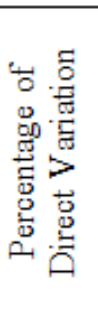 } & 1 & - & $78.7^{*}$ & $100^{\circ}$ & $50.1^{*}$ & 0 & $97.1^{*}$ & $94.4^{*}$ & - & 0 & $100^{\circ}$ & 55.9 & 0 & $99.2^{*}$ & $100^{\circ}$ \\
\hline & 2 & 21.3 & - & 0 & $88.1^{*}$ & 0 & 0 & 0 & 100 & - & 0 & 0 & $90.9^{*}$ & 0 & 0 \\
\hline & 3 & 0 & 100 & - & $100^{*}$ & 0 & 0.2 & $93.8^{*}$ & 0 & 100 & - & $100^{*}$ & 0 & $94.9^{*}$ & $99.8^{*}$ \\
\hline & 4 & 49.9 & 11.9 & 0 & - & 0 & $97.8^{*}$ & $95.7^{*}$ & 44.1 & 100 & 0 & - & 0 & $98.9^{*}$ & $98^{*}$ \\
\hline & 5 & 100 & 100 & 100 & 100 & - & 0 & 0 & 100 & 9.1 & 100 & 100 & - & 0 & 0 \\
\hline & 6 & 2.9 & 100 & 99.8 & 2.2 & 100 & - & $61.1^{*}$ & 0.8 & 100 & 5.1 & 1.1 & 100 & - & 74.6 \\
\hline & 7 & 5.6 & 100 & 6.2 & 4.3 & 100 & 38.9 & - & 0 & 100 & 0.2 & 2 & 100 & 25.4 & - \\
\hline
\end{tabular}

Table 10 Alternative Pairwise Analysis in Insulation Category

\begin{tabular}{|c|c|c|c|c|c|c|c|c|c|c|c|c|c|}
\hline & & \multicolumn{12}{|c|}{ Percentage of Trade-off } \\
\hline & \multirow[b]{2}{*}{ Alt. } & \multicolumn{6}{|c|}{ Scenario 1} & \multicolumn{6}{|c|}{ Scenario 2} \\
\hline & & 1 & 2 & 3 & 4 & 5 & 6 & 1 & 2 & 3 & 4 & 5 & 6 \\
\hline \multirow{6}{*}{ 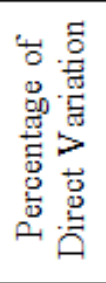 } & 1 & - & 2 & 10.5 & 30.2 & $66.7^{*}$ & 49.0 & & 26.8 & 13.7 & $96.0^{8}$ & $79.3^{8}$ & 57.8 \\
\hline & 2 & 98.0 & - & 0 & 43.1 & 14.2 & 1.3 & 73.2 & - & 0 & 42.9 & 4.4 & $99.7^{*}$ \\
\hline & 3 & 89.5 & 100 & - & 0 & 22.1 & 9.1 & 86.3 & 100 & - & 0.1 & 22.8 & 10.6 \\
\hline & 4 & 69.8 & 56.9 & 100 & - & $98.4^{*}$ & 48.1 & 4.0 & 57.1 & 99.9 & - & $97.2^{*}$ & $95.4^{*}$ \\
\hline & 5 & 33.3 & 85.8 & 77.9 & 1.6 & - & $67.8^{*}$ & 20.7 & 95.6 & 77.2 & 2.8 & - & 66.8 \\
\hline & 6 & 51.0 & 98.7 & 90.9 & 51.9 & 32.2 & - & 42.2 & 0.3 & 89.4 & 4.6 & 33.2 & 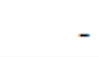 \\
\hline
\end{tabular}

Table 11 Alternative Pairwise Analysis in Roofing Category

\begin{tabular}{|c|c|c|c|c|c|c|c|c|c|}
\hline & & \multicolumn{8}{|c|}{ Percentage of Trade-off } \\
\hline & \multirow[b]{2}{*}{ Alt. } & \multicolumn{4}{|c|}{ Scenario 1} & \multicolumn{4}{|c|}{ Scenario 2} \\
\hline & & 1 & 2 & 3 & 4 & 1 & 2 & 3 & 4 \\
\hline \multirow{4}{*}{$\begin{array}{l}\text { Percentage } \\
\text { of Direct } \\
\text { Variation }\end{array}$} & 1 & - & 0 & 0 & $96.9^{8}$ & - & $88.0^{8}$ & 0 & $95.0^{*}$ \\
\hline & 2 & 100 & - & 0.2 & 44.0 & 12.0 & - & 0 & $100^{*}$ \\
\hline & 3 & 100 & 99.8 & - & 0 & 100 & 100 & - & $100^{*}$ \\
\hline & 4 & 3.1 & 56.0 & 100 & - & 5.0 & 0 & 0 & - \\
\hline
\end{tabular}


Table 12 Alternative Pairwise Analysis in Concrete Footing 3000 psi Category

\begin{tabular}{|c|c|c|c|c|c|c|c|c|c|c|c|c|c|}
\hline & \multicolumn{13}{|c|}{ Percentage of Trade-off } \\
\hline & \multirow[b]{3}{*}{ Alt. } & \multirow{2}{*}{\multicolumn{3}{|c|}{ Scenario 1}} & \multicolumn{9}{|c|}{ Scenario 2} \\
\hline & & & & & \multicolumn{3}{|c|}{ Direct Chute } & \multicolumn{3}{|c|}{ Pumped } & \multicolumn{3}{|c|}{ Crane and Bucket } \\
\hline & & 1 & 2 & 3 & 1 & 2 & 3 & 1 & 2 & 3 & 1 & 2 & 3 \\
\hline \multirow{3}{*}{$\begin{array}{c}\text { Percentage } \\
\text { of Direct } \\
\text { Variation }\end{array}$} & 1 & - & 49.1 & $50.7^{*}$ & - & $76.2^{*}$ & 73.9 & - & 74.3 & $76.3^{*}$ & - & 74.8 & 72.7 \\
\hline & 2 & 50.9 & - & 49.9 & 23.8 & - & 74.8 & 25.7 & - & $76.7^{*}$ & 25.2 & - & 74.5 \\
\hline & 3 & 49.3 & 50.1 & - & 26.1 & 25.2 & - & 23.7 & 23.3 & - & 27.3 & 25.5 & - \\
\hline
\end{tabular}

Table 13 Alternative Pairwise Analysis in Concrete Footing 4000 psi Category

\begin{tabular}{|c|c|c|c|c|c|c|c|c|c|c|c|c|c|}
\hline & \multicolumn{13}{|c|}{ Percentage of Trade-off } \\
\hline & \multirow[b]{3}{*}{ Alt. } & \multirow{2}{*}{\multicolumn{3}{|c|}{ Scenario 1}} & \multicolumn{9}{|c|}{ Scenario 2} \\
\hline & & & & & \multicolumn{3}{|c|}{ Direct Chute } & \multicolumn{3}{|c|}{ Pumped } & \multicolumn{3}{|c|}{ Crane and Bucket } \\
\hline & & 4 & 5 & 6 & 4 & 5 & 6 & 4 & 5 & 6 & 4 & 5 & 6 \\
\hline \multirow{3}{*}{$\begin{array}{c}\text { Percentage } \\
\text { of Direct } \\
\text { Variation }\end{array}$} & 4 & - & 48.8 & 47.7 & - & $77.5^{*}$ & $75.5^{*}$ & - & 74.6 & 73.4 & - & 73.6 & $75.1^{*}$ \\
\hline & 5 & 51.2 & - & 48.8 & 22.5 & - & 72.6 & 25.4 & - & 73.6 & 26.4 & - & 73.6 \\
\hline & 6 & 52.3 & 51.2 & - & 24.5 & 27.4 & - & 26.6 & 26.4 & - & 24.9 & 26.4 & - \\
\hline
\end{tabular}

Table 14 Alternative Pairwise Analysis in Concrete Slab 4 inches 3000 psi Category

\begin{tabular}{|c|c|c|c|c|c|c|c|c|c|c|c|c|c|}
\hline & \multicolumn{13}{|c|}{ Percentage of Trade-off } \\
\hline & \multirow[b]{3}{*}{ Alt. } & \multirow{2}{*}{\multicolumn{3}{|c|}{ Scenario 1}} & \multicolumn{9}{|c|}{ Scenario 2} \\
\hline & & & & & \multicolumn{3}{|c|}{ Direct Chute } & \multicolumn{3}{|c|}{ Pumped } & \multicolumn{3}{|c|}{ Crane and Bucket } \\
\hline & & 1 & 2 & 3 & 1 & 2 & 3 & 1 & 2 & 3 & 1 & 2 & 3 \\
\hline \multirow{3}{*}{$\begin{array}{l}\text { Percentage } \\
\text { of Direct } \\
\text { Variation }\end{array}$} & 1 & - & 49.6 & 47.7 & - & $85^{*}$ & $93.5^{*}$ & - & $76.1^{*}$ & $76.7^{*}$ & - & 74.4 & 74.2 \\
\hline & 2 & 50.4 & - & $52.9^{*}$ & 15 & - & 74.5 & 23.9 & - & $76.2^{*}$ & 25.6 & - & 74.9 \\
\hline & 3 & 52.3 & 47.1 & - & 6.5 & 25.5 & - & 23.3 & 23.8 & - & 25.8 & 25.1 & - \\
\hline
\end{tabular}


Table 15 Alternative Pairwise Analysis in Concrete Slab 4 inches 4000 psi Category

\begin{tabular}{|c|c|c|c|c|c|c|c|c|c|c|c|c|c|}
\hline & \multicolumn{13}{|c|}{ Percentage of Trade-off } \\
\hline & \multirow[b]{3}{*}{ Alt. } & \multirow{2}{*}{\multicolumn{3}{|c|}{ Scenario 1}} & \multicolumn{9}{|c|}{ Scenario 2} \\
\hline & & & & & \multicolumn{3}{|c|}{ Direct Chute } & \multicolumn{3}{|c|}{ Pumped } & \multicolumn{3}{|c|}{ Crane and Bucket } \\
\hline & & 4 & 5 & 6 & 4 & 5 & 6 & 4 & 5 & 6 & 4 & 5 & 6 \\
\hline \multirow{3}{*}{$\begin{array}{l}\text { Percentage } \\
\text { of Direct } \\
\text { Variation }\end{array}$} & 4 & - & 48.7 & $50.1^{*}$ & - & $78.4^{*}$ & $77.6^{8}$ & - & $76.3^{8}$ & $75.6^{*}$ & - & $75.9^{*}$ & 74.0 \\
\hline & 5 & 51.3 & - & $50.7^{*}$ & 21.6 & - & $75.2^{*}$ & 23.7 & - & $76.9^{*}$ & 24.1 & - & 73.5 \\
\hline & 6 & 49.9 & 49.3 & - & 22.4 & 24.8 & - & 24.4 & 23.1 & - & 26.0 & 26.5 & - \\
\hline
\end{tabular}

Table 16 Alternative Pairwise Analysis in Concrete Slab 8 inches 3000 psi Category

\begin{tabular}{|c|c|c|c|c|c|c|c|c|c|c|c|c|c|}
\hline & \multicolumn{13}{|c|}{ Percentage of Trade-off } \\
\hline & \multirow[b]{3}{*}{ Alt. } & \multirow{2}{*}{\multicolumn{3}{|c|}{ Scenario 1}} & \multicolumn{9}{|c|}{ Scenario 2} \\
\hline & & & & & \multicolumn{3}{|c|}{ Direct Chute } & \multicolumn{3}{|c|}{ Pumped } & \multicolumn{3}{|c|}{ Crane and Bucket } \\
\hline & & 7 & 8 & 9 & 7 & 8 & 9 & 7 & 8 & 9 & 7 & 8 & 9 \\
\hline \multirow{3}{*}{$\begin{array}{l}\text { Percentage } \\
\text { of Direct } \\
\text { Variation }\end{array}$} & 7 & - & $51.0^{3}$ & $50.9^{8}$ & - & 74.3 & 73.3 & - & $75.3^{8}$ & 73.9 & - & $75.8^{8}$ & $77.2^{8}$ \\
\hline & 8 & 49.0 & - & 48.5 & 25.7 & - & 74.3 & 24.7 & - & $76.8^{*}$ & 24.2 & - & $76.1^{*}$ \\
\hline & 9 & 49.1 & 51.5 & - & 26.7 & 25.7 & - & 26.1 & 23.2 & - & 22.8 & 23.9 & - \\
\hline
\end{tabular}

Table 17 Alternative Pairwise Analysis in Concrete Slab 8 inches 4000 psi Category

\begin{tabular}{|c|c|c|c|c|c|c|c|c|c|c|c|c|c|}
\hline & \multicolumn{13}{|c|}{ Percentage of Trade-off } \\
\hline & \multirow[b]{3}{*}{ Alt. } & \multirow{2}{*}{\multicolumn{3}{|c|}{ Scenario 1}} & \multicolumn{9}{|c|}{ Scenario 2} \\
\hline & & & & & \multicolumn{3}{|c|}{ Direct Chute } & \multicolumn{3}{|c|}{ Pumped } & \multicolumn{3}{|c|}{ Crane and Bucket } \\
\hline & & 10 & 11 & 12 & 10 & 11 & 12 & 10 & 11 & 12 & 10 & 11 & 12 \\
\hline \multirow{3}{*}{$\begin{array}{c}\text { Percentage } \\
\text { of Direct } \\
\text { Variation }\end{array}$} & 10 & - & 48.5 & 49.6 & - & $76^{*}$ & 73.4 & - & 74.8 & 74.8 & - & 74.1 & $76.7^{*}$ \\
\hline & 11 & 51.5 & - & $50.5^{*}$ & 24 & - & 75 & 25.2 & - & $77.4^{*}$ & 25.9 & - & $76.1^{*}$ \\
\hline & 12 & 50.4 & 49.5 & - & 26.6 & 25 & - & 25.2 & 22.6 & - & 23.3 & 23.9 & - \\
\hline
\end{tabular}




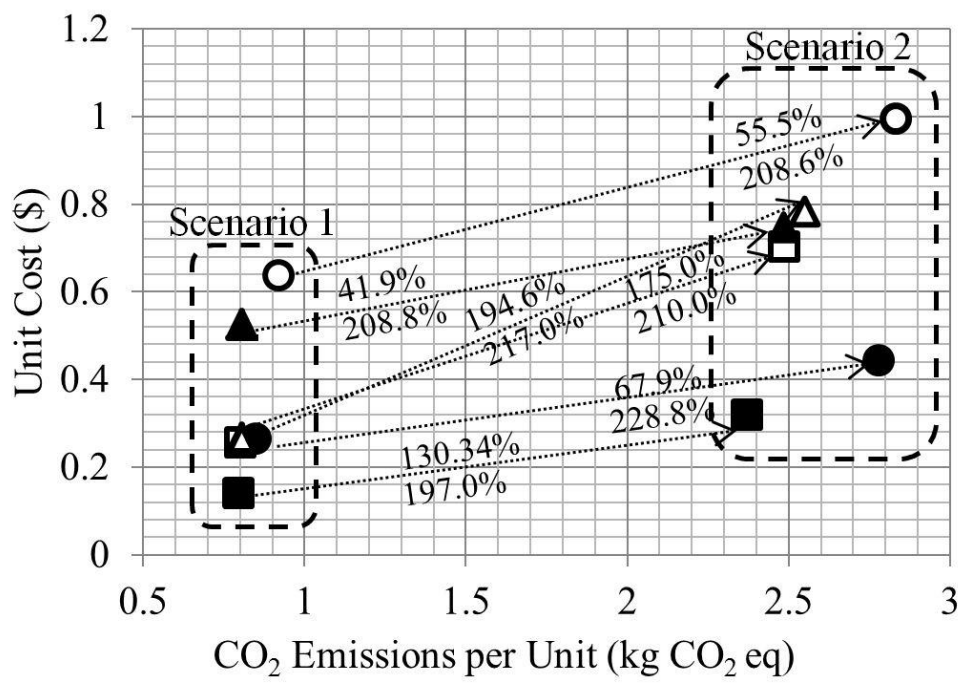

口Expanded Polystyrene

o Extruded Polystyrene

Blown Cellulose

- Batt Rockwool

$\Delta$ Batt Fiberglass

$\Delta$ Foam Polyisocyanurate

$\%$ Increasing in Unit Cost

$\%$ Increasing in $\mathrm{CO}_{2}$ Emissions per Unit

Figure 9 Graph Relationships between Average $\mathrm{CO}_{2}$ Emissions per Material Unit and Average Unit Cost for Insulation Shows Effect of Material Installation in Percentage 


\section{CHAPTER 5 ANALYSIS OF CONSTRUCTION TIME, INITIAL CONSTRUCTION COST, AND ENVIRONMENTAL IMPACT RELATIONSHIP AT COMPONENT AND BUILDING LEVEL AT PRE-USE PHASE}

This chapter presents the application of SimulEICon, during the pre-use phase, that can help to define relationships between construction time, initial construction cost, and $\mathrm{CO}_{2}$ emissions. Two case studies are used to compare the results. The databases consist of material unit cost, labor unit cost, crew types, equipment unit cost, productivity, and $\mathrm{CO}_{2}$ emissions per material unit. Total initial construction cost and total $\mathrm{CO}_{2}$ emissions are aggregately calculated to the project level. The Critical Path Method (CPM) approach is used to estimate total construction time. The NSGA-II is applied as the optimization technique in this stage. The construction time is significantly considered at this level, as well as cost and $\mathrm{CO}_{2}$ emissions, because it substantially has a major impact on the decision-making process during the construction phase. Delay in construction time can also cost the project in various ways, including money.

Two case studies' components for building design are selected based on studied material from the previous chapter. For instance, the four inches slab on grade have several alternatives based on different percentages of flyash mixes, e.g., average flyash, $25 \%$ flyash, and $35 \%$ flyash, and different methods of placing concrete, e.g., the direct chute or the pump method. As well as roofing, there are a few options that are used in this chapter, such as clay tiles, concrete tiles, organic felt shingles. 


\subsection{Data Collection and Case Study Descriptions}

Information of case studies was collected to define possible alternatives. Database was stored based on the construction activity or component level of the building, such as site cleaning activity, excavation, stem wall construction, etc. Each activity or component has its alternatives. One alternative can be combined from two or more materials. For example, one of the exterior wall alternatives consists of fiberglass insulation, steel stud, and drywall. Each of them separately has unit cost, productivity, and $\mathrm{CO}_{2}$ emissions per material unit.

The first case study is a zero net energy building named the Zero Energy Research Laboratory. The building was built at the University of North Texas, providing advantageous utilities for researchers and students (Gregorski, 2012). It has the 1,200 square feet of spacing and it offers a wide range of advanced technologies, such as solar

panels, and a building energy monitoring and controlling system. In this research, the laboratory building, presented in figure 10, has 17 established components or activities, including start activity and finish activity. The example of building activities and their alternatives are shown in table 18.

The second case study is a project called the Future House USA, shown in figure 10. It is a two-story residential building, which was built and located in Beijing, China. The building has approximately 1,200 square feet as well. Based on the design of the project, many possible components can be chosen to achieve the efficient design during the early design stage. The total number of options for building components is 185 
alternatives. Within all possible options of the building components, there are over 31 billion possible combinations that professional designers should consider.
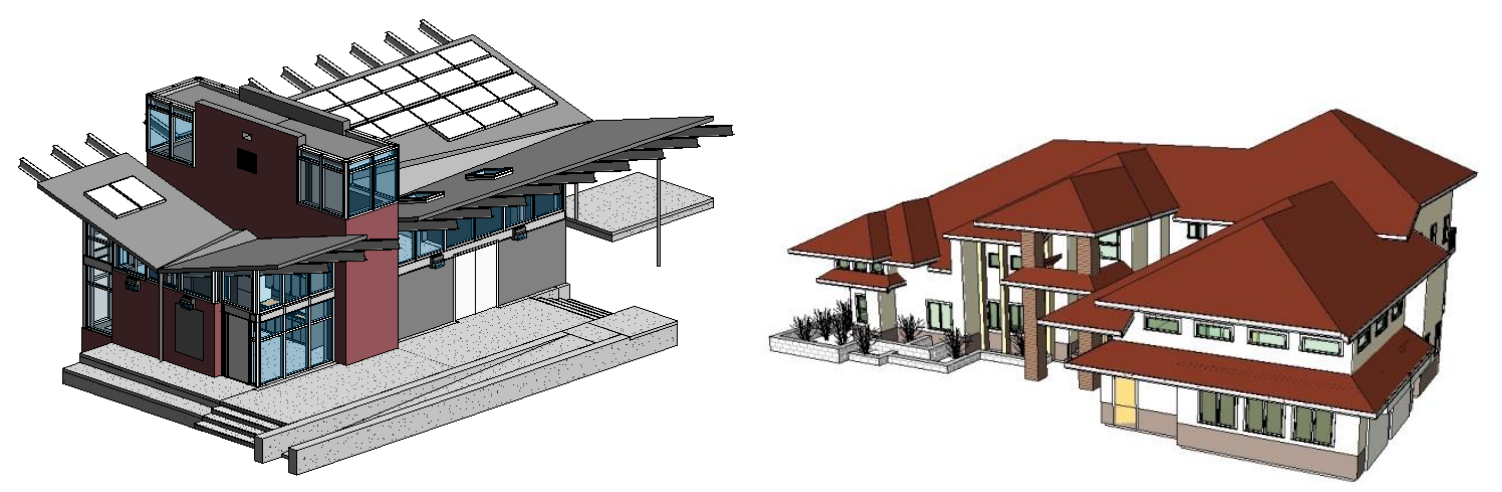

Figure 10 Three-dimension Models of Case Study 1 (left) and Case Study 2 (right)

Both buildings were designed as zero-net-energy (ZNE) houses that aim to maximize building energy efficiency and generate balance energy between their energy consumption and renewable resources. Summary of case studies is provided in table 18. Alternatives of building components and materials in both cases are chosen based on the comparable function of assemblies, construction methods, and available combinations among materials. For example, all exterior wall construction options in this research represented the same thermal resistance value (R-Value). 
Table 18 Examples of the Zero Energy Research Laboratory Activities and Theirs Alternatives

\begin{tabular}{|c|c|c|c|}
\hline $\begin{array}{l}\text { Activity } \\
\text { Number }\end{array}$ & Activity Name & $\begin{array}{l}\text { Alternative } \\
\text { Number }\end{array}$ & Alternative Description \\
\hline \multirow[t]{6}{*}{4} & $\begin{array}{l}\text { Footing } \\
\text { Construction }\end{array}$ & 1 & $\begin{array}{l}3000 \text { psi, average flyash, pumped, } \\
\text { reinforcing in place, footings }\end{array}$ \\
\hline & & 2 & $\begin{array}{l}3000 \mathrm{psi}, 25 \% \text { flyash, pumped, } \\
\text { reinforcing in Place, footings }\end{array}$ \\
\hline & & 3 & $\begin{array}{l}3000 \text { psi, 30\% flyash, pumped, } \\
\text { reinforcing in Place, footings }\end{array}$ \\
\hline & & 4 & $\begin{array}{l}3000 \text { psi, average flyash, direct chute, } \\
\text { reinforcing in Place, footings }\end{array}$ \\
\hline & & 5 & $\begin{array}{l}3000 \mathrm{psi}, 25 \% \text { flyash, direct chute, } \\
\text { reinforcing in Place, footings }\end{array}$ \\
\hline & & 6 & $\begin{array}{l}3000 \text { psi, } 30 \% \text { flyash, direct chute, } \\
\text { reinforcing in Place, footings }\end{array}$ \\
\hline 6 & Subgrade & 1 & Blown Cellulose Board \\
\hline
\end{tabular}




\begin{tabular}{|c|c|c|c|}
\hline Activity & Activity Name & Alternative & Alternative Description \\
\hline Number & & Number & \\
\hline & Insulation & 2 & Batt Rockwool \\
\hline & & 3 & Batt Fiberglass \\
\hline 8 & Slab-on-Grade & 1 & 4", 3000 psi, average flyash, pumped, \\
\hline & Construction & & reinforcing in Place, walls \\
\hline & & 2 & 4", 3000 psi , $25 \%$ flyash, pumped, \\
\hline & & & reinforcing in Place, walls \\
\hline & & 3 & 4", 3000 psi, 35\% flyash, pumped, \\
\hline & & & reinforcing in Place, walls \\
\hline & & 4 & 4", $3000 \mathrm{psi}$, average flyash, direct chute, \\
\hline & & & reinforcing in Place, walls \\
\hline & & 5 & 4", $3000 \mathrm{psi}, 25 \%$ flyash, direct chute, \\
\hline & & & reinforcing in Place, walls \\
\hline & & 6 & 4", $3000 \mathrm{psi}, 35 \%$ flyash, direct chute, \\
\hline & & & reinforcing in Place, walls \\
\hline
\end{tabular}




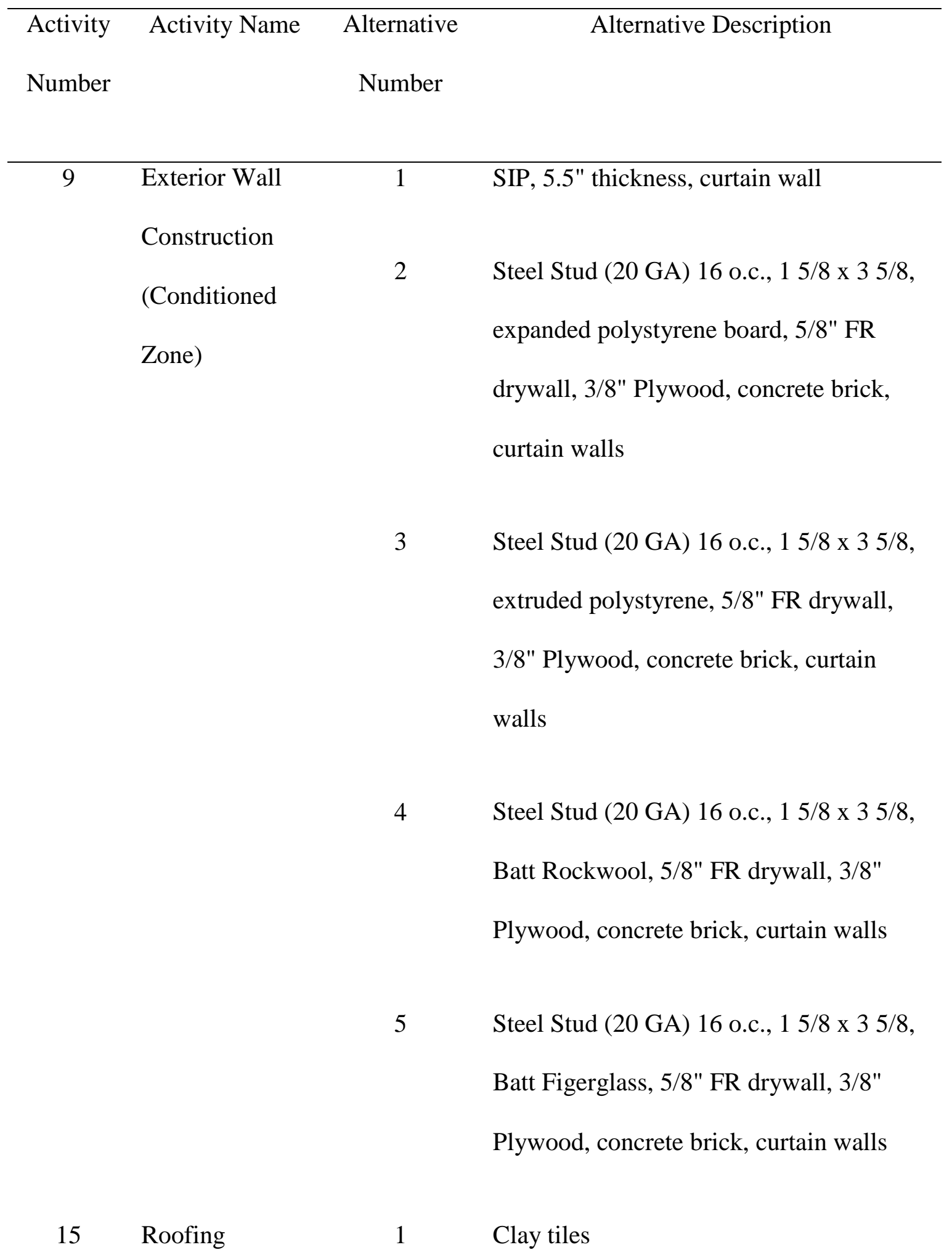




\begin{tabular}{|c|c|c|c|}
\hline Activity & Activity Name & Alternative & Alternative Description \\
\hline Number & & Number & \\
\hline & & 2 & Concrete tiles \\
\hline \multirow{4}{*}{16} & \multirow{4}{*}{ Flooring } & 3 & Organic felt shingles $30 \mathrm{yr}$ \\
\hline & & 4 & Steel Roof Panel 30 GA (Residential) \\
\hline & & 1 & Bamboo flooring \\
\hline & & 2 & Wood flooring \\
\hline
\end{tabular}

Table 19 Summary of Case Studies

Case Study 1

Case Study 2

Description Zero Net Energy Building $\quad$ Future House Project

Building Spacing (S.F.)

1,200

1,250

Location

Texas, United States

Beijing, China

Total Number of Activities

17

16 
Total Number of Alternatives $\quad 54$

Total Possible Design Solutions $\quad 5,832,000$
171

$27,214,258,176$

\subsection{Analysis and Results}

In both case studies, results were obtained from 200 Monte Carlo simulation runs. In each Monte Carlo simulation, there were 20 populations and 200 generations utilized in the NSGA-II. Most of the results obtained with the NSGA-II exhibited a balanced behavior, where construction time, initial construction cost, and $\mathrm{CO}_{2}$ emissions tended to be medium or low magnitude; the results which show a higher value for any of these parameters also show reduced values in the other two, this trade-off behavior is to be expected when using the genetic algorithms. Figures 11 and 12 show 200 sets of 20 optimal solutions generated from the NSGA-II in three dimensions, as well as graph relationships between construction time and initial construction cost, graph relationships between construction time and $\mathrm{CO}_{2}$ emissions, and graph relationship between initial construction cost and $\mathrm{CO}_{2}$ emissions during the pre-use phase for both case studies. There is no point that is located in the lowest values; most of optimal solutions are located in the middle, where they show a balanced behavior and a trade-off between all three parameters. The graph showing relationship between construction time and initial construction cost indicated general trade-off behavior, i.e., shorter construction time 
results in higher project cost. However, when considering all three parameters, one could not observe a clear pattern from the results. The solutions giving high value in one parameter are also seen in middle or low values range of others.

From graphs of simulations' results, different markers represent different Monte Carlo simulation runs and thus they are different sets of results. As can be seen, solutions tend to exhibit similar behavior across simulation runs. The different occurs due to the random input variables generated by the Monte Carlo simulation to account for data uncertainty. By running different simulations the effect that data uncertainty could have on the project becomes apparent, for different simulations, the set solutions changed to reflect the new set of random variables generated by the Monte Carlo simulation. For instance, variations of construction material can have a significant impact on the outcome of the overall project design as significantly presented in the previous chapter. Moreover, lowest construction time or high productivity alternatives might not always be desirable since they showed ostentatiously great value in others.

From the total 4,000 optimal solutions, the results from SimulEICon showed that only 2,390 combined solutions in the case study 1 and 1,376 combined solutions in the case study 2 were occurred and accounted for optimal solutions based on multiple objectives. Figures 13 and 14 show histograms of unique optimal solutions with their frequencies. Those solutions had the highest frequency, which were however only 20 times out of the total 4,000 solutions. If each Monte Carlo simulation can be related to a different construction context defined key project features such as a productivity rate, 
unit cost and material selections, this observation shows that in theory there does not exist an absolute optimal solution, which may appear in the majority of simulations

Furthermore, the results were analyzed in order to statistically observe the relationship between multiple objectives. Regression techniques were used to fit the data derived from each simulation. Data patterns from 200 Monte Carlo simulation runs were then compared to determine the consistency of observations. Three expectation data patterns were used in this case study, linear, second-order polynomial and third-order polynomial functions. Comparing the fits of different functions in this searched is presented by $\mathrm{R}$-squared measures $\left(\mathrm{R}^{2}\right)$ or coefficient of determination. $\mathrm{R}$-squared is a statistical model widely used to determine the fitness of studied models (e.g., Nagelkerke, 1991; Cameron \& Windmeijer, 1997). It is well known in regression analysis as well as goodness of fit or Pearson chi-square. Chi-square illustrates the observed data follow a particular function while R-square is useful in comparing models of different fitness functions. Values of R-squared are in the range of 0 to 1 . The closer of an R-squared value to 1 , the better fit of the data pattern. Moreover, the confidence of results is examined by dissimilarity measurements between the data pattern of each simulation using Procrustes analysis. This analysis is used to compare two set of data in term of shape (Ross 2004). The results from the analysis are shown as dissimilarity measures (d). 1,000 simulations are paired and estimated d values are calculated. The value of 'd' closer to 0 signifies the greater similarity between the data patterns of two simulations. 

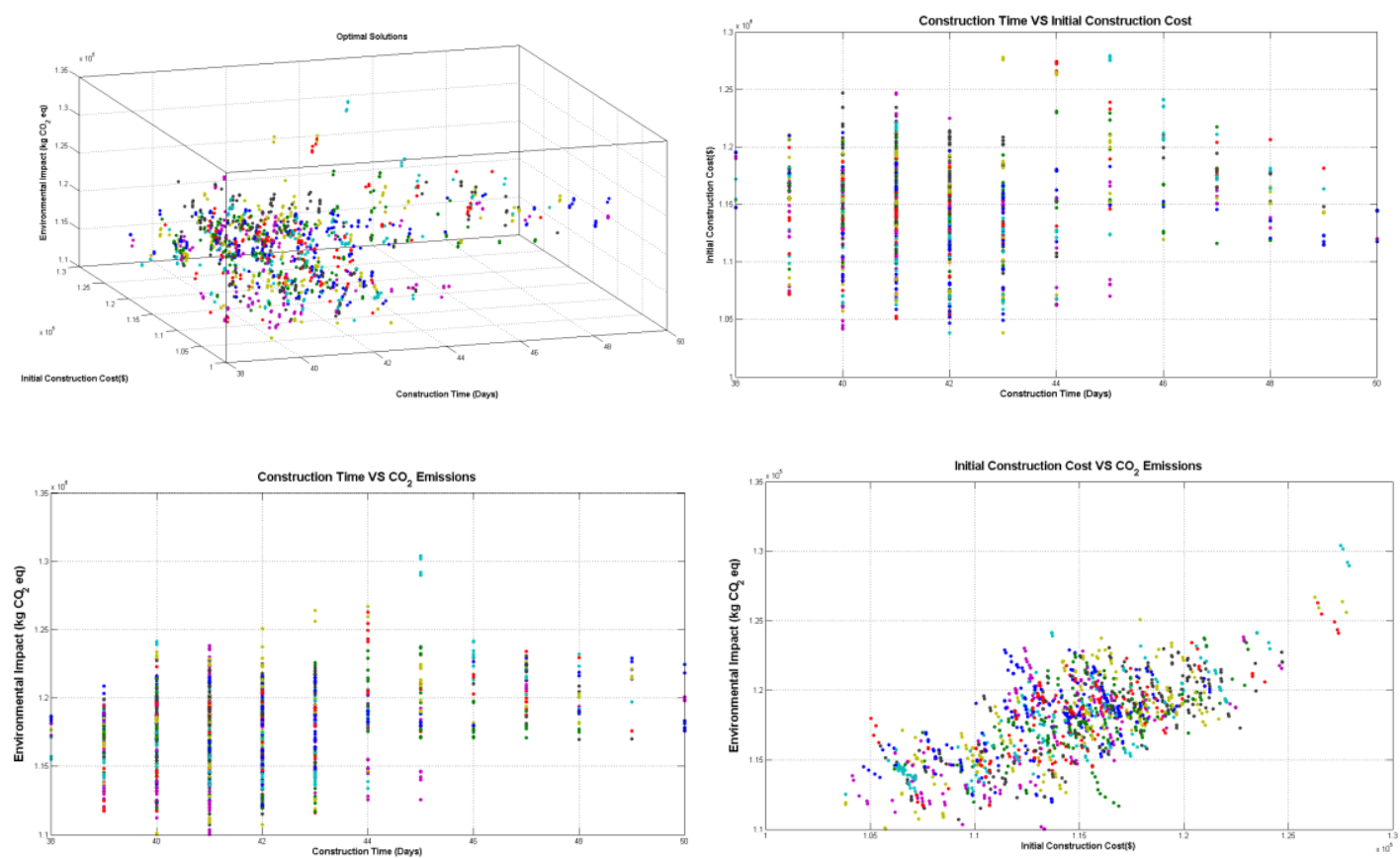

Figure 11 Optimal Solutions Shown in Graphs Relationships between Construction Time, Initial Construction Cost, and $\mathrm{CO}_{2}$ Emissions of Case Study 1
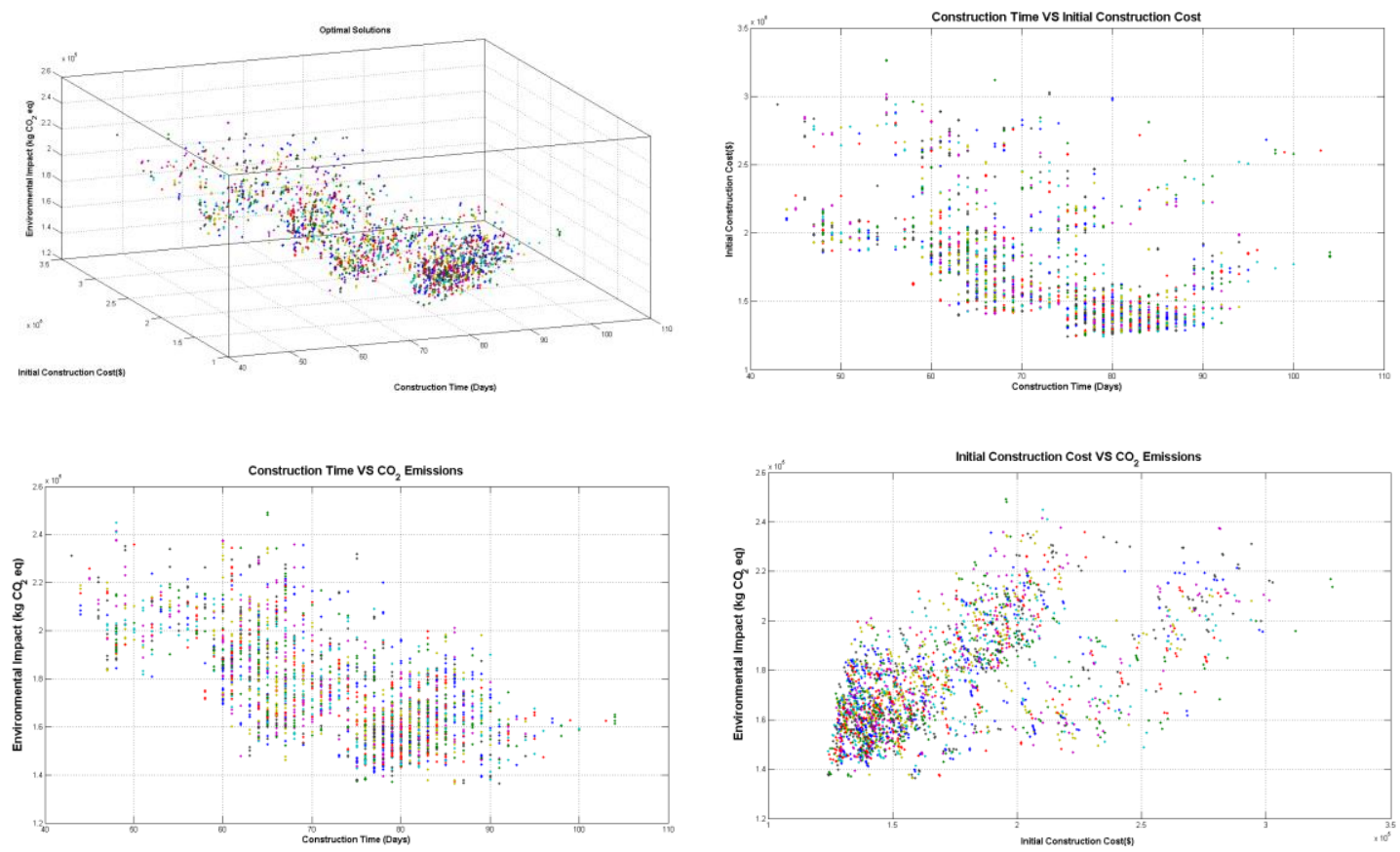

Figure 12 Optimal Solutions Shown in Graphs Relationships between Construction Time, Initial Construction Cost, and $\mathrm{CO}_{2}$ Emissions of Case Study 2 
From Table 20 and 21, one can observe that:

- Regarding construction time and initial construction cost - if $\mathrm{R}^{2}$ is set to 0.9 or better, the third-order polynomial distribution function seemed to be the most frequent best fit to data in the case study 2. While both second-order polynomial and third-order polynomial showed approximately similar percentages in the case study 1 . However, the frequencies were still relatively low, about $45-48 \%$. This means there are other data patterns observed as well. On the other hand, similarity of data patterns between simulations was highest using the linear function.

- Regarding construction time and $\mathrm{CO}_{2}$ emissions, there were not many data patterns that fitted to one particular regression function. Similarity of data patterns between simulations was relatively high.

- Regarding initial construction cost and $\mathrm{CO}_{2}$ emissions, the third-order polynomial function provided the highest percentage of the best fit in both cases. However, it did not serve the best similarity between simulations. The linear function seemed to give the better similarity but the percentages are still comparatively low.

The above observations seem to suggest that data sets from 200 simulation runs do not converge to a particular pattern. On the other hand, visual observations to data indicated that trade-offs between construction time and initial construction cost, as well 
as construction time and $\mathrm{CO}_{2}$ emissions existed in majority of the cases with few exceptions. On the other hand, data of initial construction cost and $\mathrm{CO}_{2}$ emissions showed a different pattern, which this seems to suggest non-trade-off behaviors with exceptions.

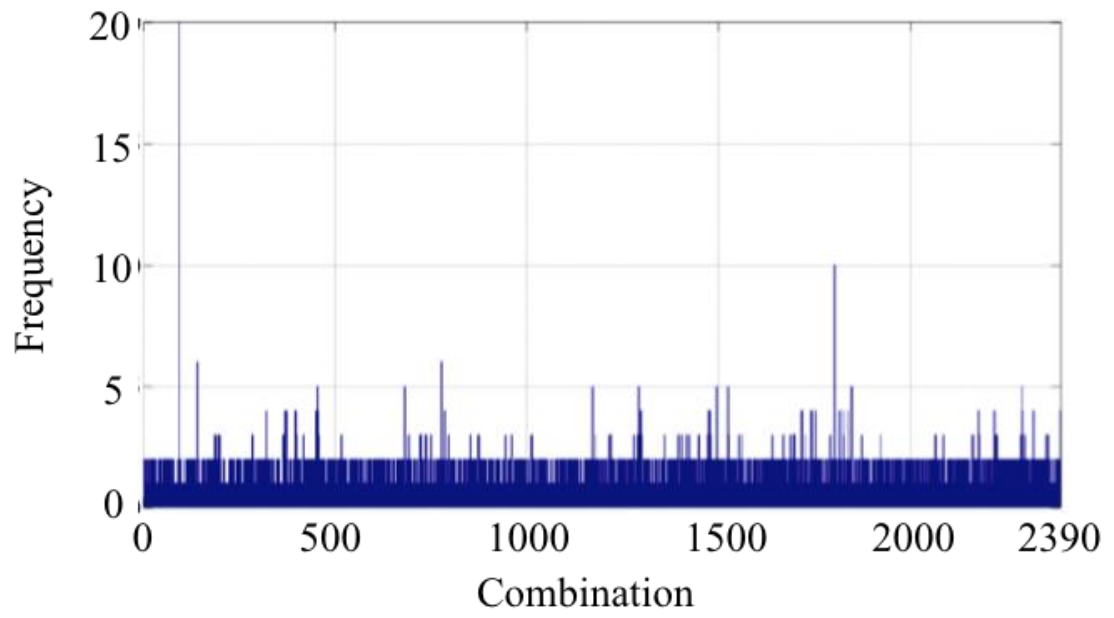

Figure 13 Combined Solutions and Their Frequencies Histogram: Case Study 1

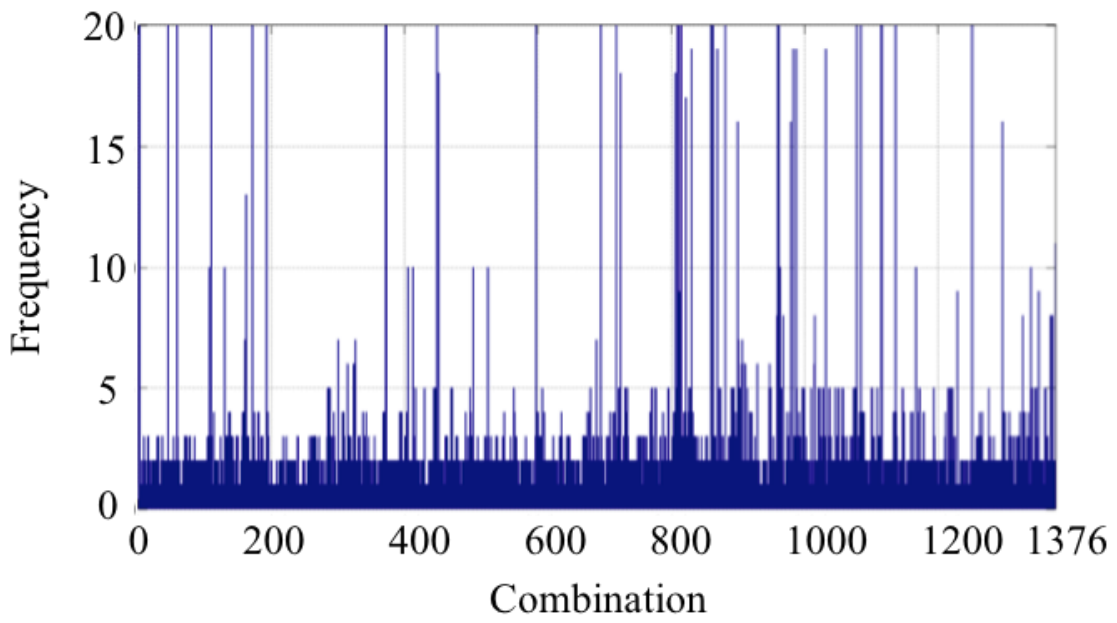

Figure 14 Combined Solutions and Their Frequencies Histogram: Case Study 2 
Table 20 Summary of $R$-squared $\left(R^{2}\right)$ and Dissimilarity Measures $(d)$ : Case Study 1

\begin{tabular}{ccccccc}
\hline $\begin{array}{c}\text { Percentage of graphs } \\
\text { relationship between }\end{array}$ & $\begin{array}{c}\text { Construction time } \\
\text { and Initial } \\
\text { Construction cost }\end{array}$ & $\begin{array}{c}\text { Construction Time } \\
\text { and } \mathrm{CO}_{2} \text { Emissions }\end{array}$ & $\begin{array}{c}\text { Initial Construction } \\
\text { cost and } \mathrm{CO}_{2} \\
\text { Emissions }\end{array}$ \\
\cline { 2 - 7 } & $\mathrm{R}^{2}>0.9$ & $\mathrm{~d}<0.1$ & $\mathrm{R}^{2}>0.9$ & $\mathrm{~d}<0.1$ & $\mathrm{R}^{2}>0.9$ & $\mathrm{~d}<0.1$ \\
\hline $\begin{array}{c}\text { Linear } \\
\text { Second-order }\end{array}$ & $33.00 \%$ & $19.78 \%$ & $12.00 \%$ & $22.38 \%$ & $20.00 \%$ & $16.87 \%$ \\
Polynomial & $47.50 \%$ & $19.49 \%$ & $19.5 \%$ & $21.84 \%$ & $30.00 \%$ & $15.50 \%$ \\
Third-order & $45.00 \%$ & $20.24 \%$ & $18.50 \%$ & $14.47 \%$ & $55.50 \%$ & $14.05 \%$ \\
Polynomial & & & & & & \\
\hline
\end{tabular}

Table 21 Summary of $R$-squared $\left(R^{2}\right)$ and Dissimilarity Measures (d): Case Study 2

\begin{tabular}{ccccccc}
\hline $\begin{array}{c}\text { Percentage of graphs } \\
\text { relationship between }\end{array}$ & $\begin{array}{c}\text { Construction time } \\
\text { and Initial } \\
\text { Construction cost }\end{array}$ & $\begin{array}{c}\text { Construction Time } \\
\text { and } \mathrm{CO}_{2} \text { Emissions }\end{array}$ & $\begin{array}{c}\text { Initial Construction } \\
\text { cost and } \mathrm{CO}_{2} \\
\text { Emissions }\end{array}$ \\
\cline { 2 - 7 } & $\mathrm{R}^{2}>0.9$ & $\mathrm{~d}<0.1$ & $\mathrm{R}^{2}>0.9$ & $\mathrm{~d}<0.1$ & $\mathrm{R}^{2}>0.9$ & $\mathrm{~d}<0.1$ \\
\hline Linear & $20.5 \%$ & $18.20 \%$ & $10.5 \%$ & $18.20 \%$ & $20.00 \%$ & $21.21 \%$ \\
Second-order & $35.00 \%$ & $11.73 \%$ & $24.00 \%$ & $14.33 \%$ & $32.00 \%$ & $12.41 \%$ \\
Polynomial & & & & & & \\
Third-order & $48.50 \%$ & $9.56 \%$ & $38.50 \%$ & $12.21 \%$ & $45.00 \%$ & $8.83 \%$ \\
Polynomial & & & & & & \\
\hline
\end{tabular}




\section{CHAPTER 6 ANALYSIS OF LIFE CYCLE COST AND ENVIRONMENTAL IMPACT RELATIONSHIPS AT BUILDING LEVEL AT USAGE PHASE}

Application of SimulEICon for the usage phase is presented in this chapter to find the relationship between life cycle cost and life cycle $\mathrm{CO}_{2}$ emission. Different life spans of the building are also analyzed in order to find the effect of considering occupancy time of the building into the relationship. In this chapter, the case study, the Zero Net Energy Laboratory, is continually used to present and observe any change in the relationships of cost and $\mathrm{CO}_{2}$ emissions between the pre-use phase and the usage phase. Energy simulation program, EnergyPlus, is a significant tool to find energy consumption of the building design in this chapter.

\subsection{Integration of Energy Simulation}

SimulEICon analysis is expanded to integrate energy simulation. Hence, the simulation can incorporate how much energy will be consumed with the selected optimal design alternatives. Over half of the total energy consumed by building stems, from its usage phase, specifically by heat ventilation and air conditioning HVAC systems. Building energy simulations are capable of estimating energy performance based on design parameters. The energy simulation software, EnergyPlus, is used in order to calculate energy consumption during the usage phase. EnergyPlus is written in the different programming language than SimulEICon and it requires the specific input file called *idf file. Thus, the co-simulation is required to overcome this issue. Additional data of the building is requested as an input to the energy simulation, such as user 
behavior, HVAC and lighting system. IDF Generator is a program that developed with SimulEICon to help create multiple IDFs based on many alternatives and also automatically run the energy simulation by directly using EnergyPlus. It extracts the required data and writes them out to one text file. This can help with the idea of limited storage because, if many IDFs are created and simulated, the storage space can be an issue. Consequently, SimulEICon can easily retrieve final energy consumption outputs from the IDF Generator and they can be converted to energy consumption cost and energy related $\mathrm{CO}_{2}$ emissions as input to the optimization process.

Why is IDF generator needed? EnergyPlus has a function, named ParametricPreprocessor, to aid users in combining the objects with different options. However, ParametricPreprocessor cannot combine all parametric objects properly. For example, if two parametric objects, A and B, have two options, A1, A2, B1, and B2, the ParametricPreprocessor will create only two IDFs that would have A1B1 and A2B2 combinations. It does not describe all possible combinations. If object $\mathrm{A}$ has the third option, this option will not be considered. From the example, IDF Generator can create all four possible combinations, A1B1, A1B2, A2B1 and A2B2. IDF Generator requires a base IDF file and variable XML file. Figure 15 shows an example of two variables, which are the exterior wall and interior wall, with three alternatives each in XML file and the base IDF presented in figure 16 specifics variables in it. The '\$' is used to define variable in the base IDF file. 


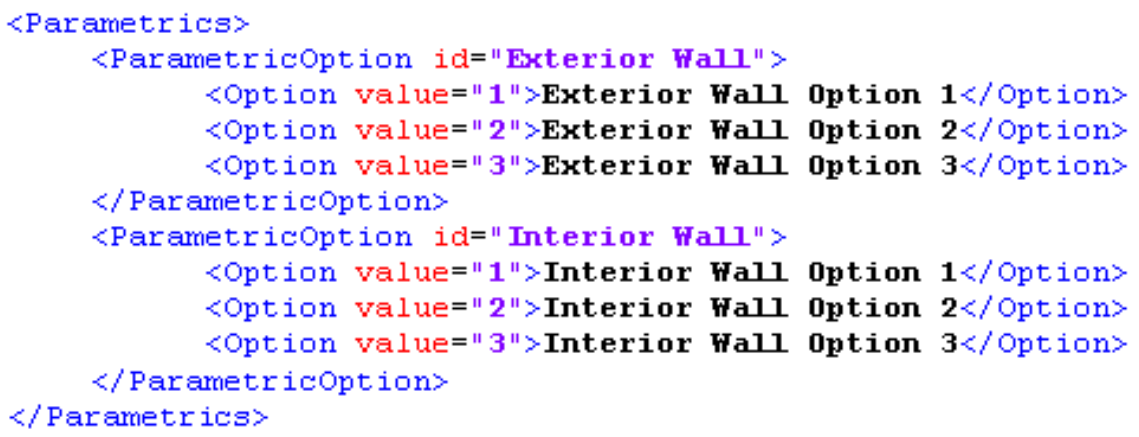

Figure 15 Example of XML file

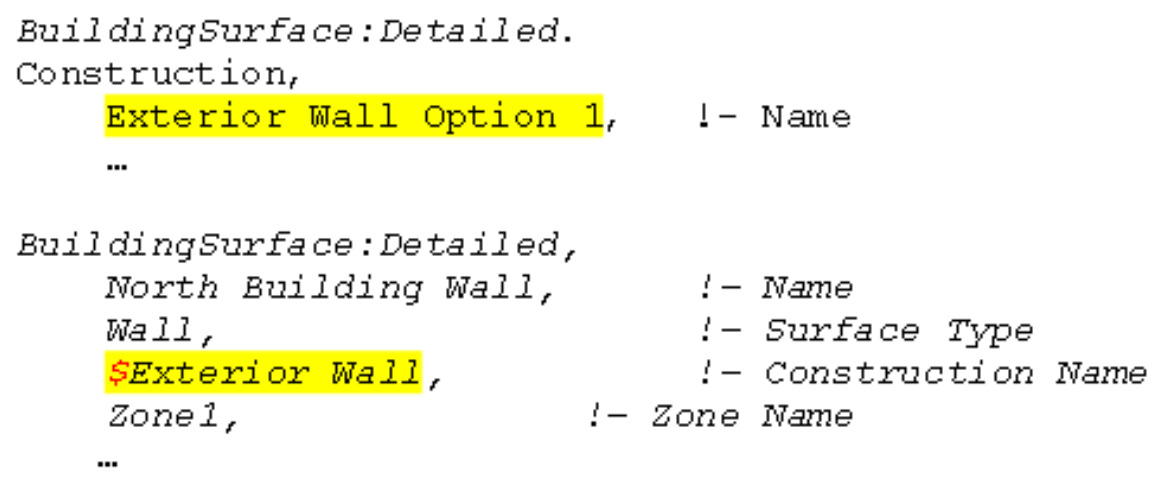

Figure 16 Example of Base IDF file

\subsection{Data Collection and Case Study Description}

SimulEICon incorporates the energy consumption data and interprets it to cost and $\mathrm{CO}_{2}$ emissions for each design. Those data are also considered in the NGSA-II. The zero energy laboratory at University of North Texas is continually used as the case study in this section. The building consists of three zones; living zone, mechanic zone, and electrical zone, presented in figure 17. Each zone is used to define different building envelopes or exterior wall in this case; thus, all exterior walls in the same zone use the 
same design alternative. Roofing is another variable in the EnergyPlus. Figure 18 shows an IDF file alternative. For this project, parametric XML file has 5 variables. The variables and their alternatives shown in figure 18 are created based on activity from the previous chapter.

Thus, from all five variables, IDF Generator created 500 combinations of IDFs. Output of yearly energy consumptions is provided in kilowatt-hour (kWh). Those outputs are used to calculate energy consumption cost and energy related $\mathrm{CO}_{2}$ emissions from energy consumption. In this research, the $\mathrm{CO}_{2}$ emissions factor is equal to $6.89551 \times 10^{4}$ metric tons $\mathrm{CO}_{2}$ per $\mathrm{kWh}(\mathrm{EPA}, 2014)$. This factor only considered $\mathrm{CO}_{2}$ emissions of GHG emissions; other GHG emissions are not included. The emission factor of electricity reductions was calculated based on the non-baseload $\mathrm{CO}_{2}$ output emission rate in 2010. The building is located in Texas; therefore, the energy consumption costs approximately 10.98 cents per kWh based on published electricity statistics (EIA, 2015). Additionally, maintenance cost from RS Means Building Construction and RS Means Facilities Maintenance \& Repair Cost Data, and $\mathrm{CO}_{2}$ emissions during the maintenance phase from the Athena impact estimator are considered in the analysis.

In this chapter, five scenarios are considered. All scenarios cover the ranges of possible solutions that can be generated in this building. The first scenario simulates the case of using lowest possible unit cost and $\mathrm{CO}_{2}$ emissions per material unit from all building components' alternatives. Thus, from the probability distribution, lowest values of all unit cost and $\mathrm{CO}_{2}$ emissions per material unit are selected. Scenario 2 applies the values possible highest unit cost and lowest $\mathrm{CO}_{2}$ emissions per material unit. Scenario 3 
represents mean value of both unit cost and $\mathrm{CO}_{2}$ emissions per material unit of all building components' alternatives. Highest $\mathrm{CO}_{2}$ emissions per material unit and lowest unit cost are input to scenario 4. The last scenario considers extreme situations, when all highest unit cost and $\mathrm{CO}_{2}$ emission unit are applied to NSGA-II. Table 22 shows a summary of the five scenarios.

Moreover, building different life spans are utilized in order to observe relationships between life cycle costs and $\mathrm{CO}_{2}$ emissions over time. The relationship at the beginning of occupancy, 0-year life span, is used as the base line. The other observation life spans are $5,10,15,20,25,30,35,45,40,45,50,60,70,80,90,100$, $120,140,160,180,200,250$, and 300 years.
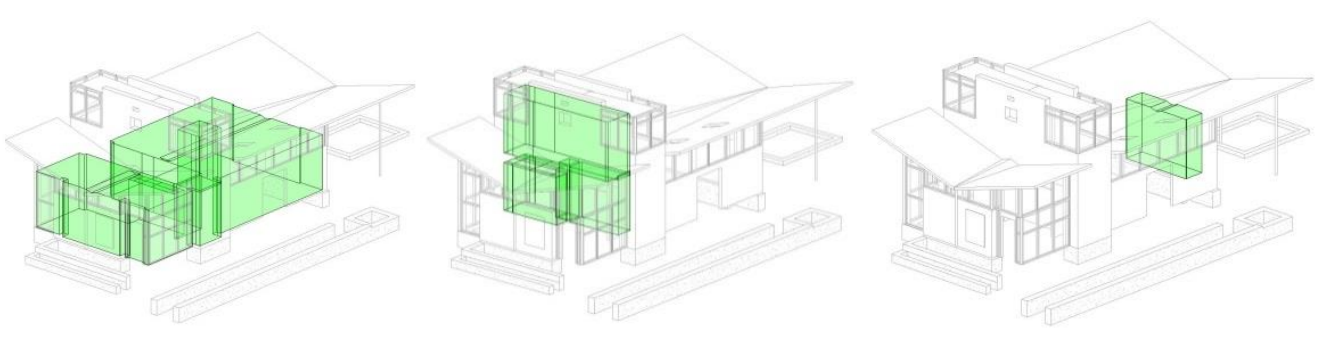

Figure 17 Building Zones; Living Zone, Mechanic Zone, and Electrical Zone

Table 22 Summary of the Five Scenarios

\begin{tabular}{ccc}
\hline Scenario & Unit Cost & $\begin{array}{c}\mathrm{CO}_{2} \text { emissions per } \\
\text { Material Unit }\end{array}$ \\
& & \\
\hline 1 & Lowest Value & Lowest Value \\
& & \\
\hline
\end{tabular}




\begin{tabular}{ccc}
\hline Scenario & Unit Cost & $\begin{array}{c}\mathrm{CO}_{2} \text { emissions per } \\
\text { Material Unit }\end{array}$ \\
\hline 2 & Highest Value & Lowest Value \\
3 & Mean Value & Mean Value \\
4 & Lowest Value & Highest Value \\
5 & Highest Value & Highest Value \\
\hline
\end{tabular}

\subsection{Analysis and Results}

From the energy simulation, 500 IDFs provided different energy consumption data. For all five scenarios, 200 generations and 20 populations were utilized in the NSGA-II in all life spans. The results of 200 sets of 20 optimal solutions for each year are presented in figures 19-41. The lowest cluster represented the optimal solutions from scenario 1 . On the other hand, results of scenario 5 provided the highest life cycle costs and $\mathrm{CO}_{2}$ emissions cluster. Optimal solutions from scenario 3 exhibited in the middle between scenario 1 and scenario 5. When scenarios 2 and 4 were considered, they provided the range of possible solutions that could happen in all cases. An area between optimal solutions from scenario 1, 2, 4, and 5 can be acknowledged where uncertainty could take place in the data.

From figures 19-41, optimal solutions in each scenario exhibited trade-off behavior between them. However, the difference between them was too small. If all 
scenarios were recognized and all data at the unit cost and productivity were randomly generated, optimal solutions would actively demonstrate a proportional relationship as in the pre-use phase. After 100 years, gaps between optimal solutions between scenario 1, 3, and 5 are smaller and differences between optimal solutions in each scenario are larger. The changing of pattern with time was displayed in figures 19-41.

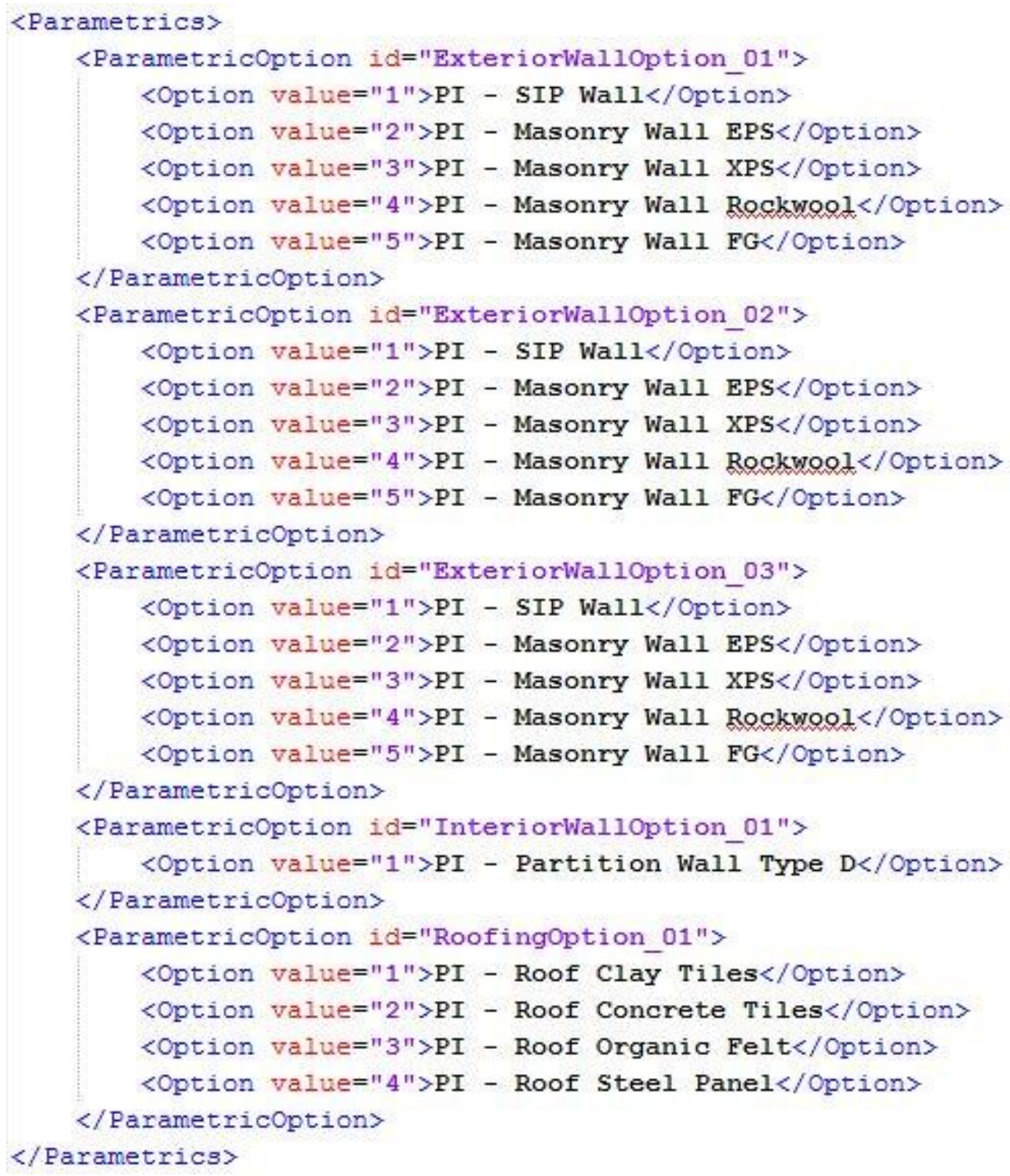

Figure 18 Parametric XML File of the Zero Energy Laboratory Building 
In the figures, from the start to a 15 year-life span, the relationship between cost and $\mathrm{CO}_{2}$ emissions was the same as shown in the pre-use phase. Lowest value in unit cost and $\mathrm{CO}_{2}$ emissions gave the lowest set of optimal solutions. More life span can be competitive with a high value of parameters. For example, optimal solutions from a 5 year-life span in scenario 3 were approximately located as optimal solutions from a 15 year-life span in scenario 1 . This means uncertainty in the data is larger than the increasing of cost and $\mathrm{CO}_{2}$ emissions in years. Scenario 1 and scenario 5 are the extreme cases, which represent lowest possible values of optimal solutions and highest possible values of optimal solutions. Table 23 presents the longest distance between optimal solutions in scenario 1 and scenario 5 . The longest distances between optimal solutions in scenario 1 and optimal solutions in scenario 5 are also calculated in all observed year-life spans. If the distance in the last column is larger than others, it means that the gap of uncertainty controls the relationship and the relationship between cost and $\mathrm{CO}_{2}$ emissions has a proportional attitude. If the distance between optimal solutions within the scenario is greater, the trade-off relationship should be considered.

In all year-life spans, the relationships between cost and $\mathrm{CO}_{2}$ emissions showed direct variation, in which one increases as another increases. There was no trade-off relationship between them. From tables 23, 5 and 40 year-life spans show no distance between optimal solutions in scenario 1. Only one optimal solution is found in both. Additionally, the optimal solutions use the same component combination. All 5 scenarios can provide the range of possible solutions that can happen in all cases. Figure 48 shows an example of possible solutions area. These areas are estimated in all year-life spans 
presented in table 24 . The areas are similar in value, which encourage the consistent pattern of relationship over time.

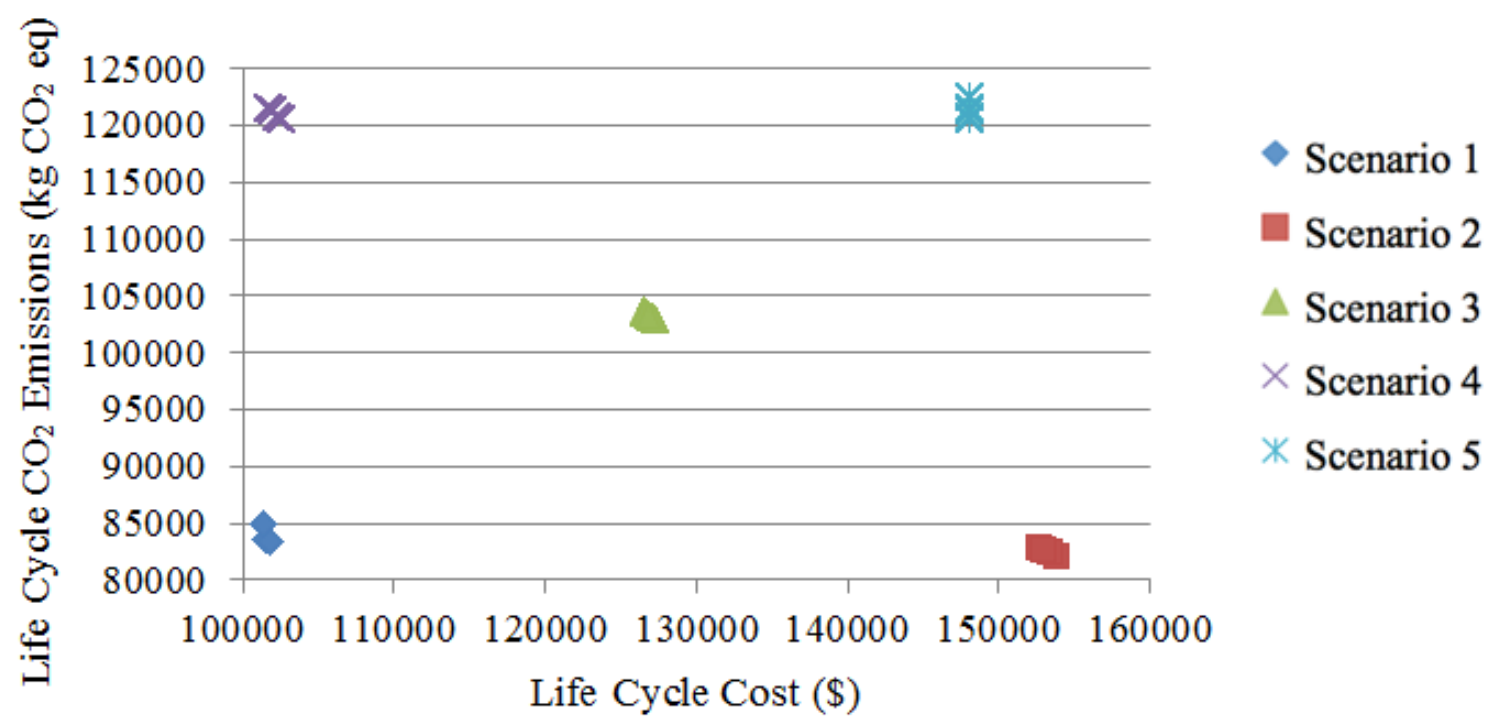

Figure 19 Graph Relationships between Cost and $\mathrm{CO}_{2}$ Emissions for 0 Year-Usage Phase

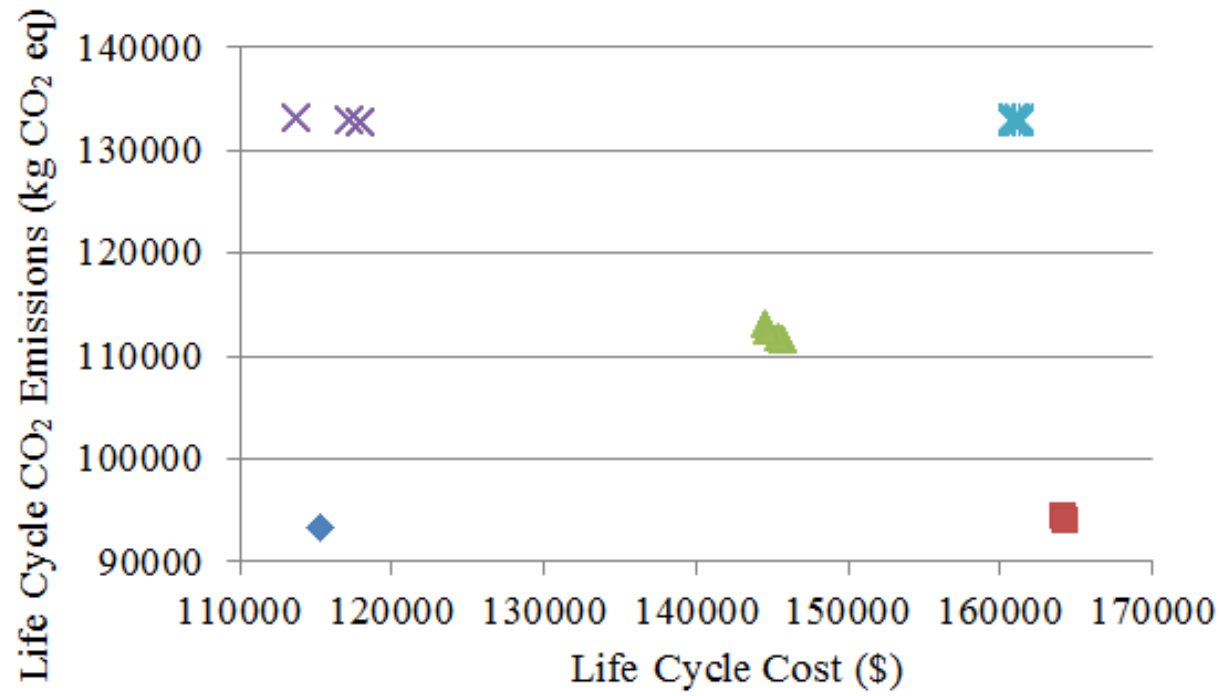

Scenario 1

Scenario 2

Scenario 3

$\times$ Scenario 4

$*$ Scenario 5

Figure 20 Graph Relationships between Cost and $\mathrm{CO}_{2}$ Emissions for 5 Year-Usage Phase 


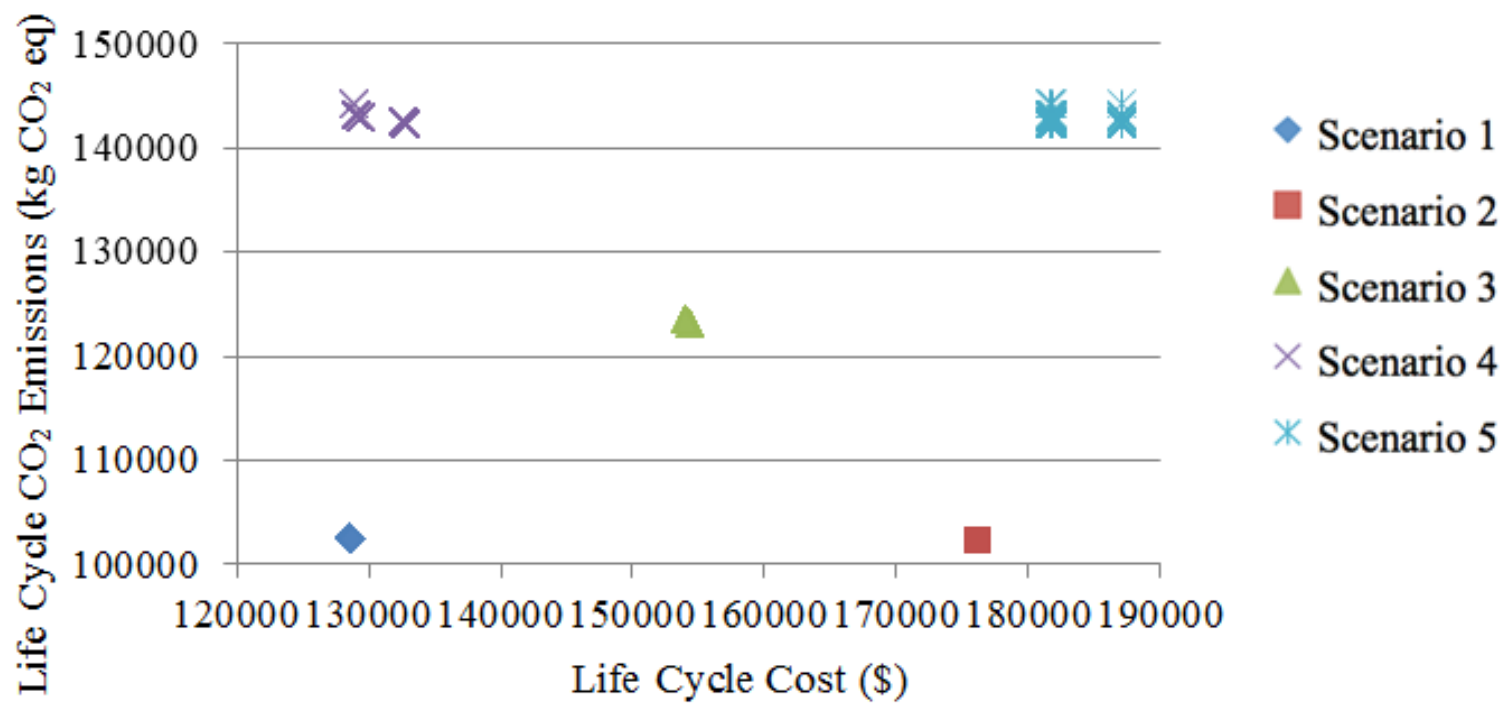

Figure 21 Graph Relationships between Cost and $\mathrm{CO}_{2}$ Emissions for 10 Year-Usage Phase

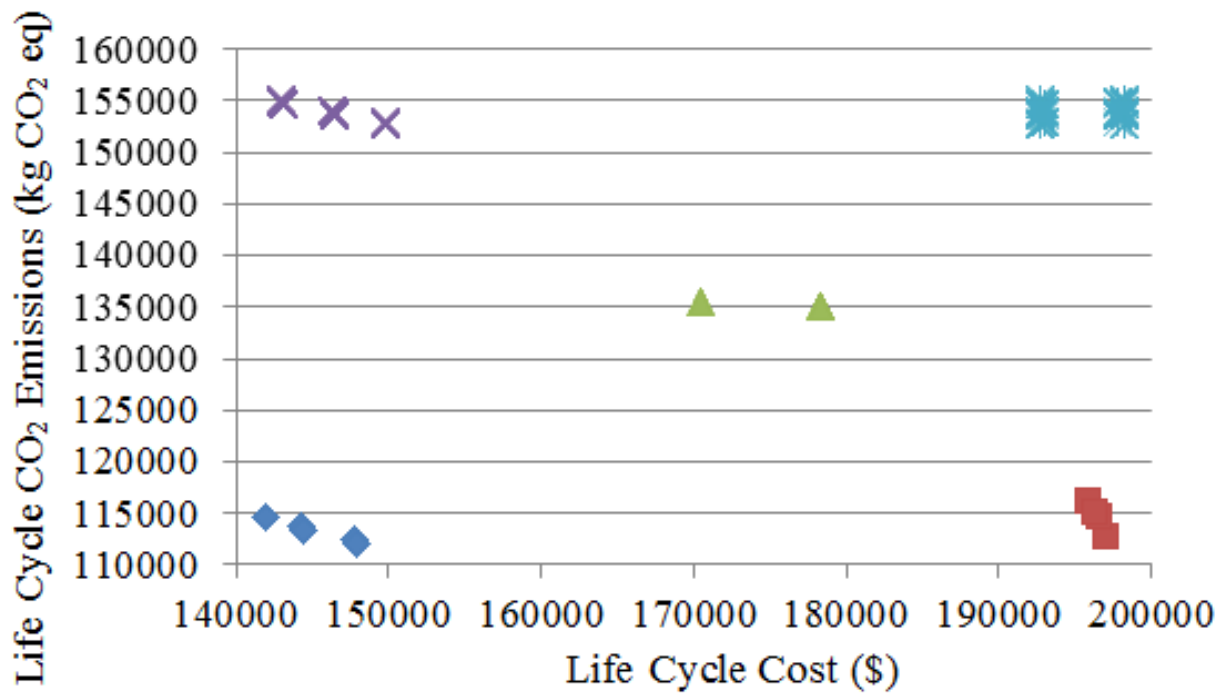

Scenario 1

Scenario 2

Scenario 3

$\times$ Scenario 4

* Scenario 5

Figure 22 Graph Relationships between Cost and $\mathrm{CO}_{2}$ Emissions for 15 Year-Usage Phase 


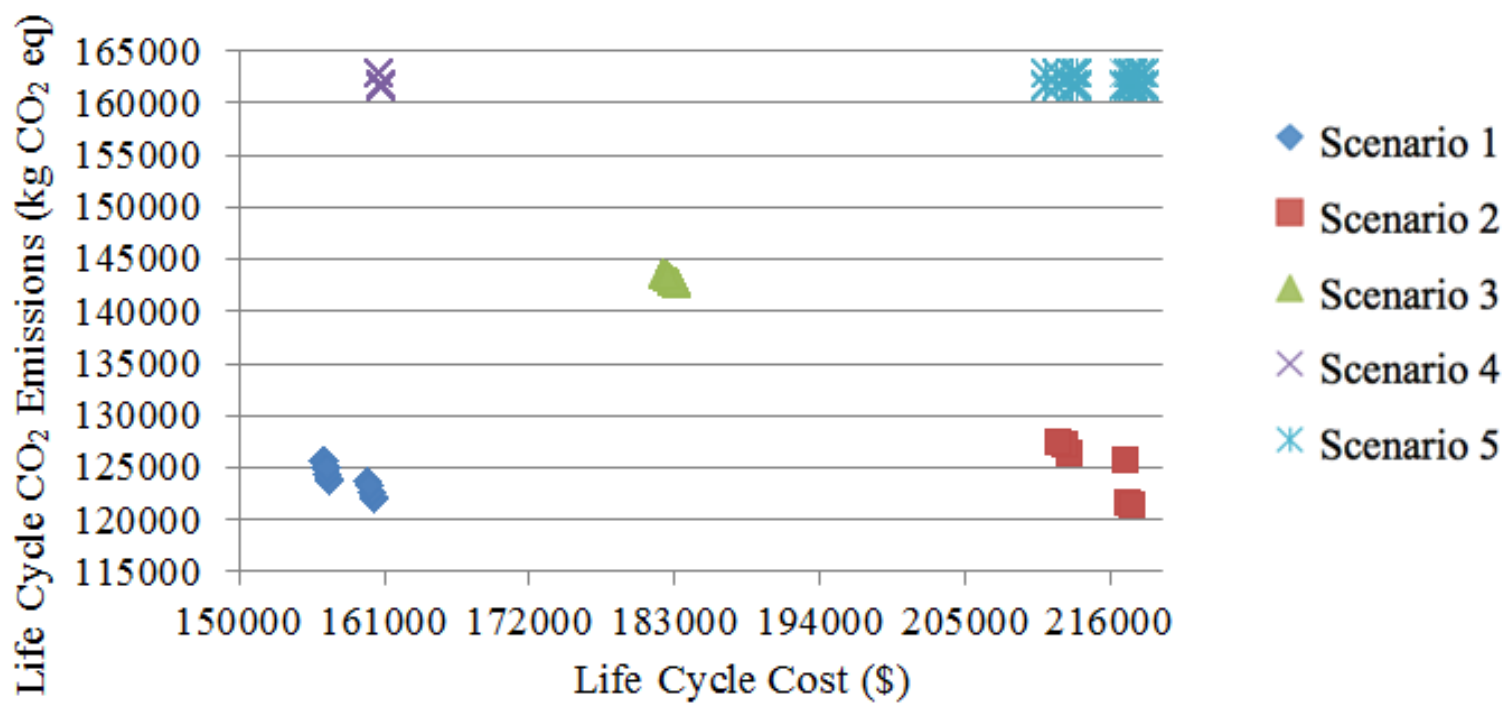

Figure 23 Graph Relationships between Cost and $\mathrm{CO}_{2}$ Emissions for 20 Year-Usage Phase

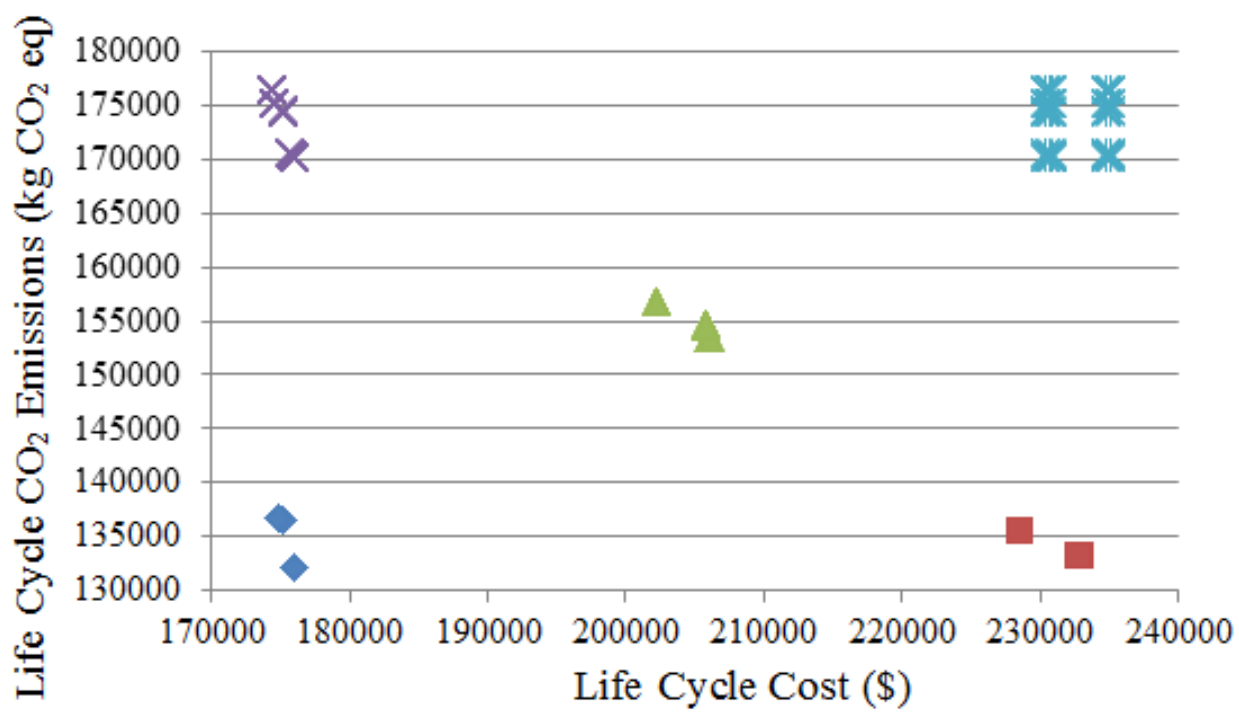

Scenario 1

Scenario 2

Scenario 3

Scenario 4

Scenario 5

Figure 24 Graph Relationships between Cost and $\mathrm{CO}_{2}$ Emissions for 25 Year-Usage Phase 


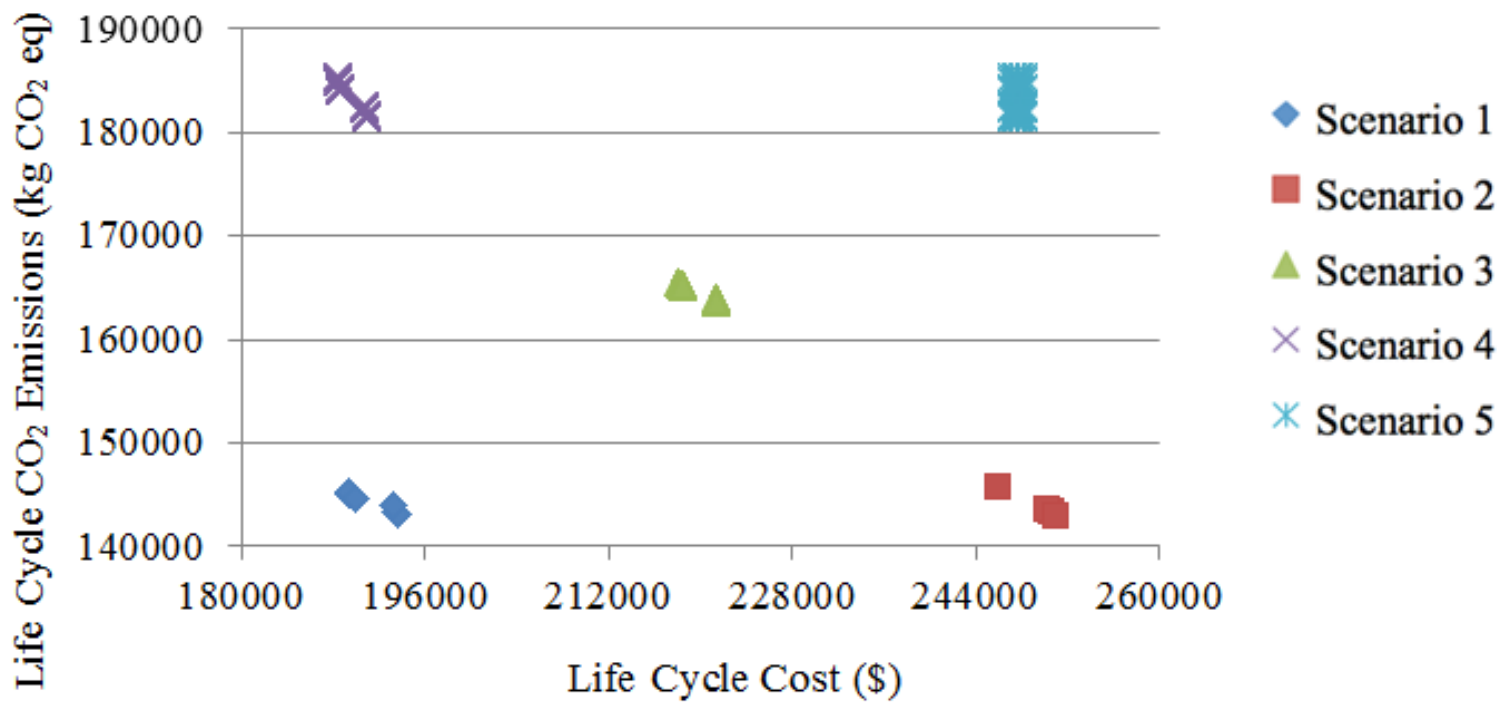

Figure 25 Graph Relationships between Cost and $\mathrm{CO}_{2}$ Emissions for 30 Year-Usage Phase

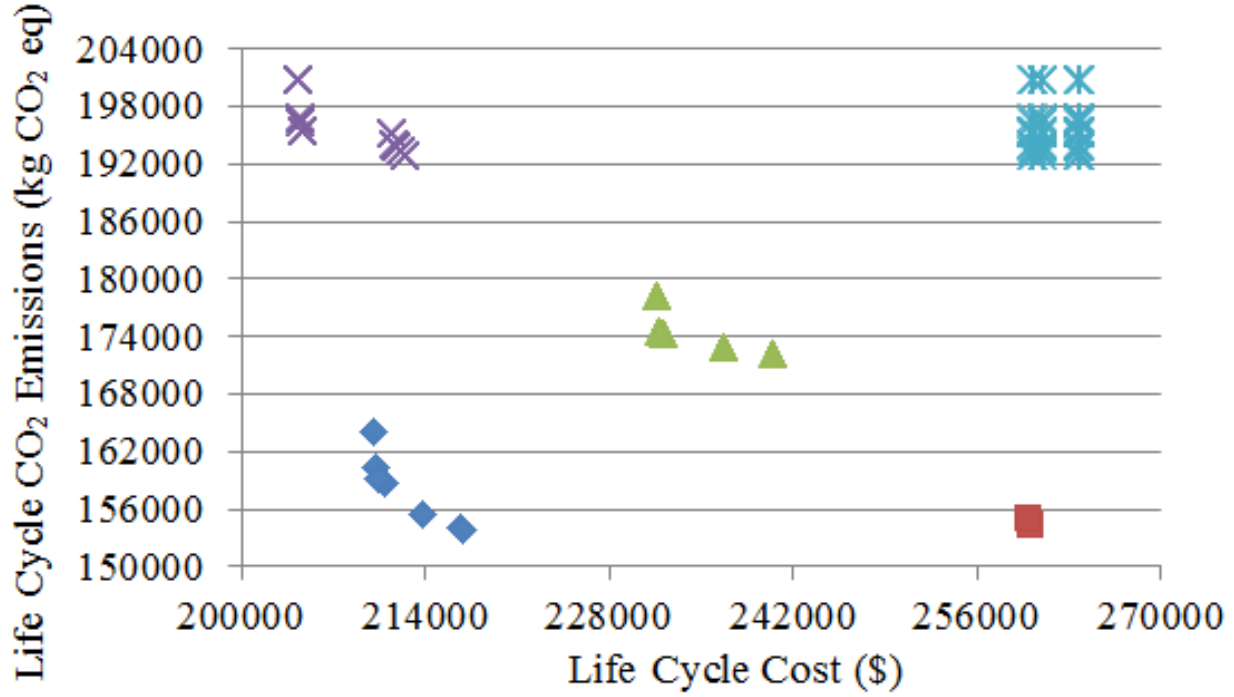

$\checkmark$ Scenario 1

Scenario 2

Scenario 3

Scenario 4

* Scenario 5

Figure 26 Graph Relationships between Cost and $\mathrm{CO}_{2}$ Emissions for 35 Year-Usage Phase 


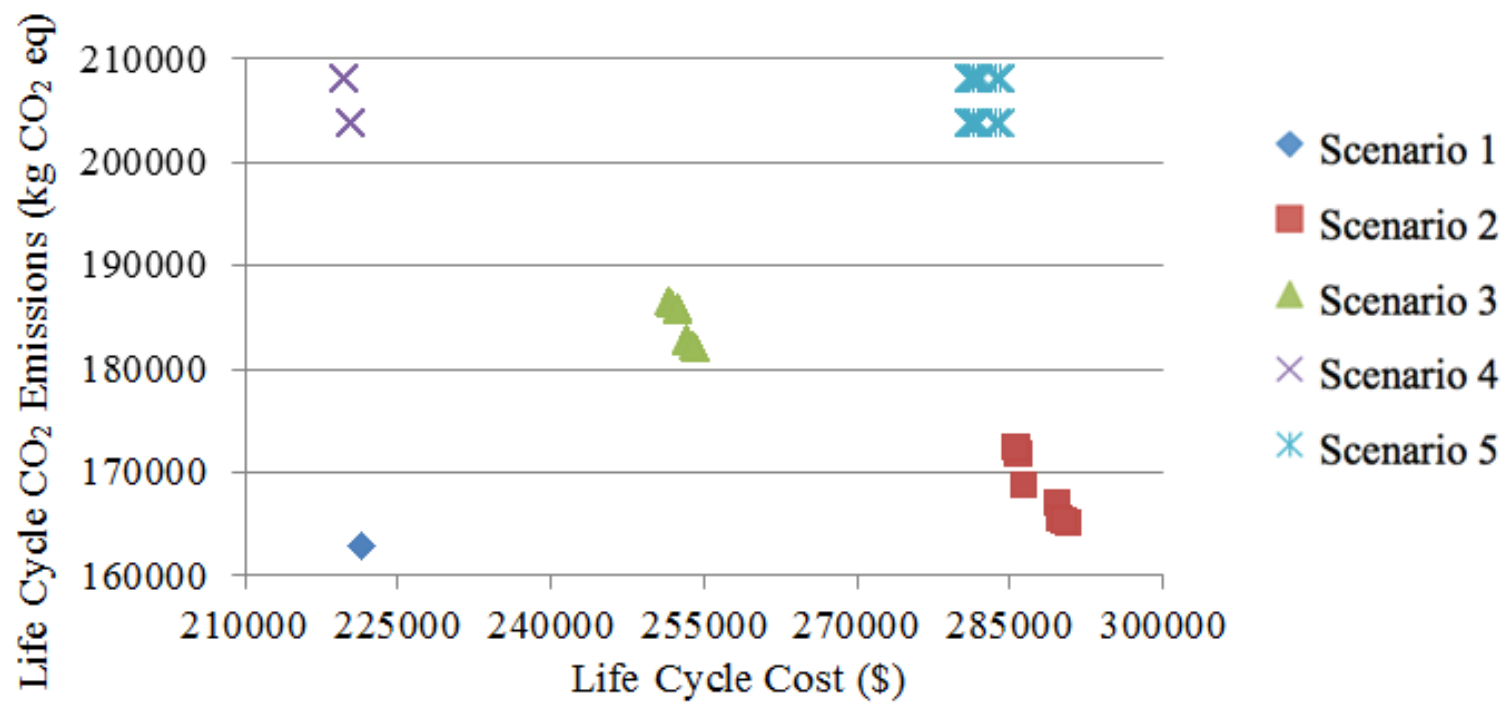

Figure 27 Graph Relationships between Cost and $\mathrm{CO}_{2}$ Emissions for 40 Year-Usage Phase

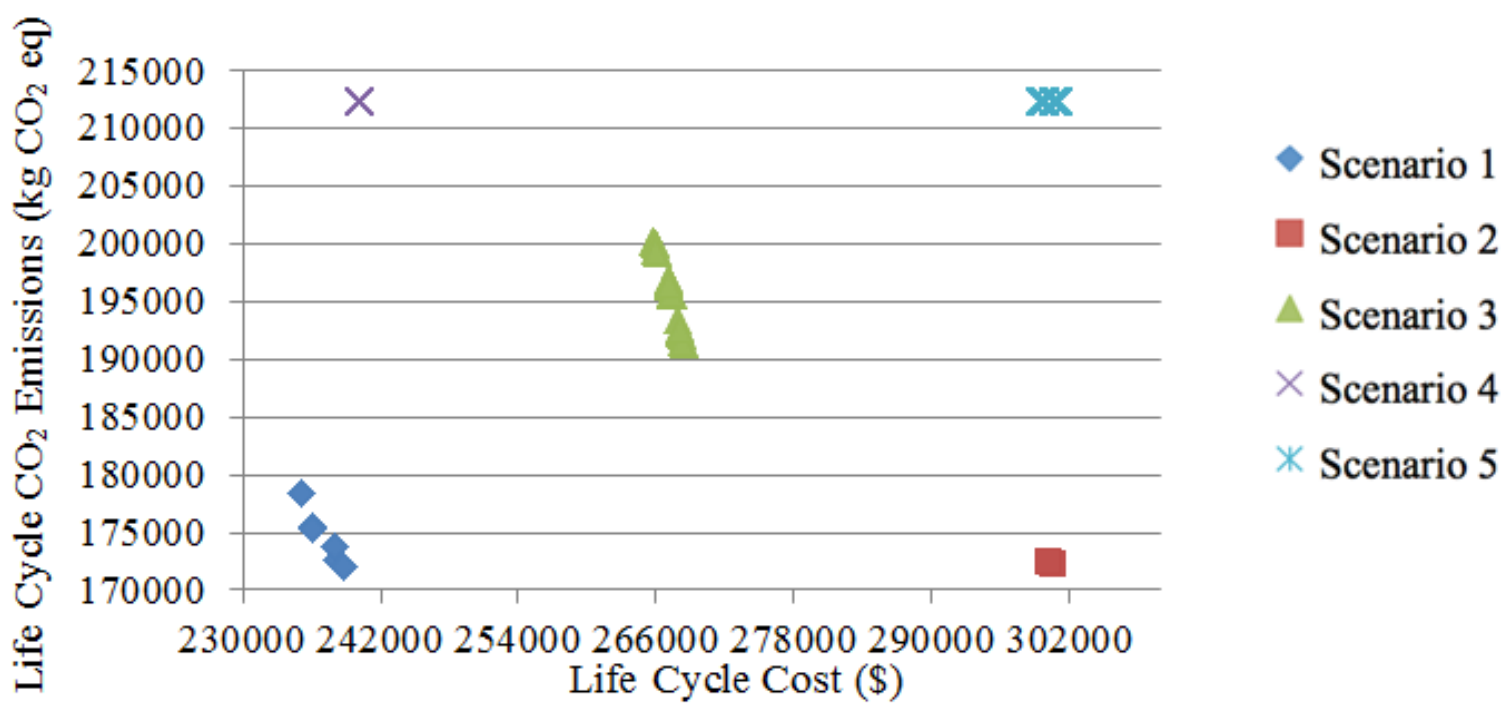

Figure 28 Graph Relationships between Cost and $\mathrm{CO}_{2}$ Emissions for 45 Year-Usage Phase 


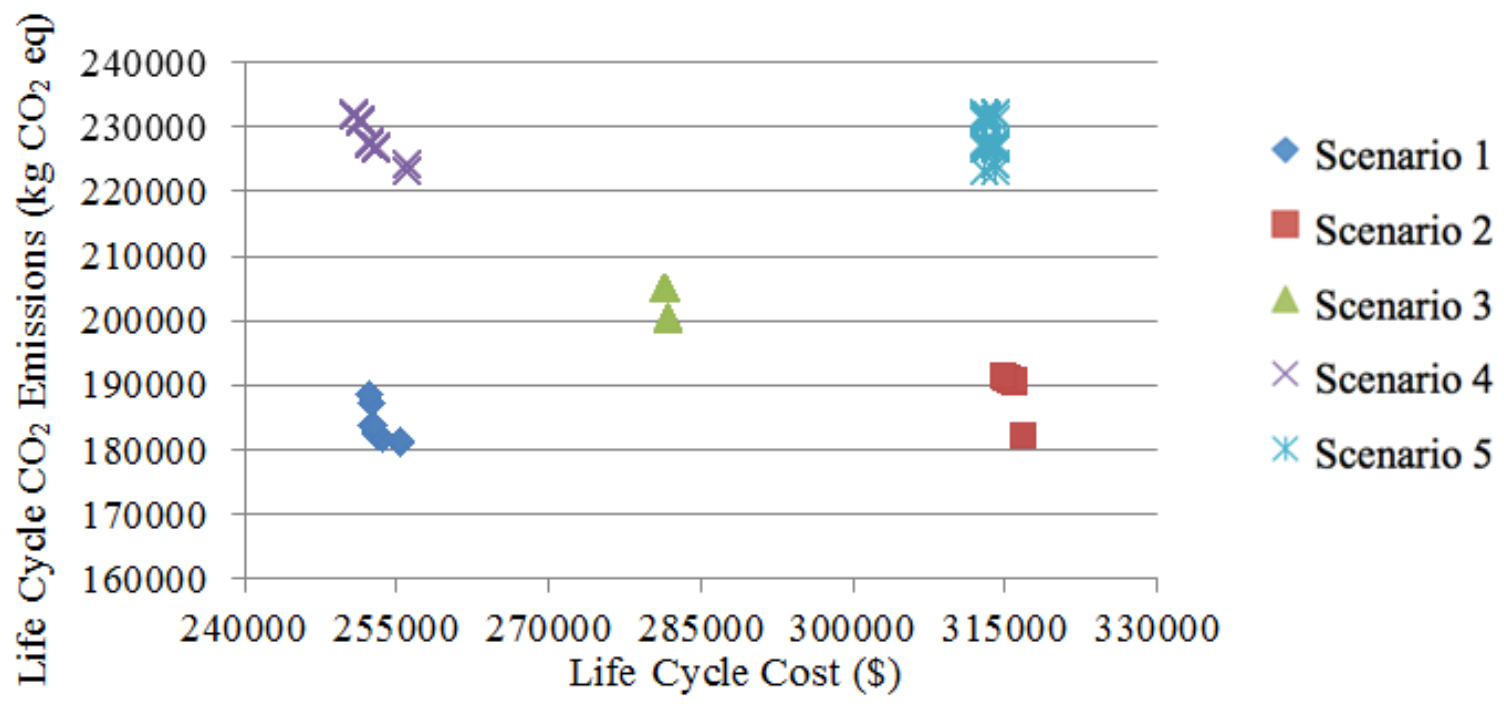

Figure 29 Graph Relationships between Cost and $\mathrm{CO}_{2}$ Emissions for 50 Year-Usage Phase

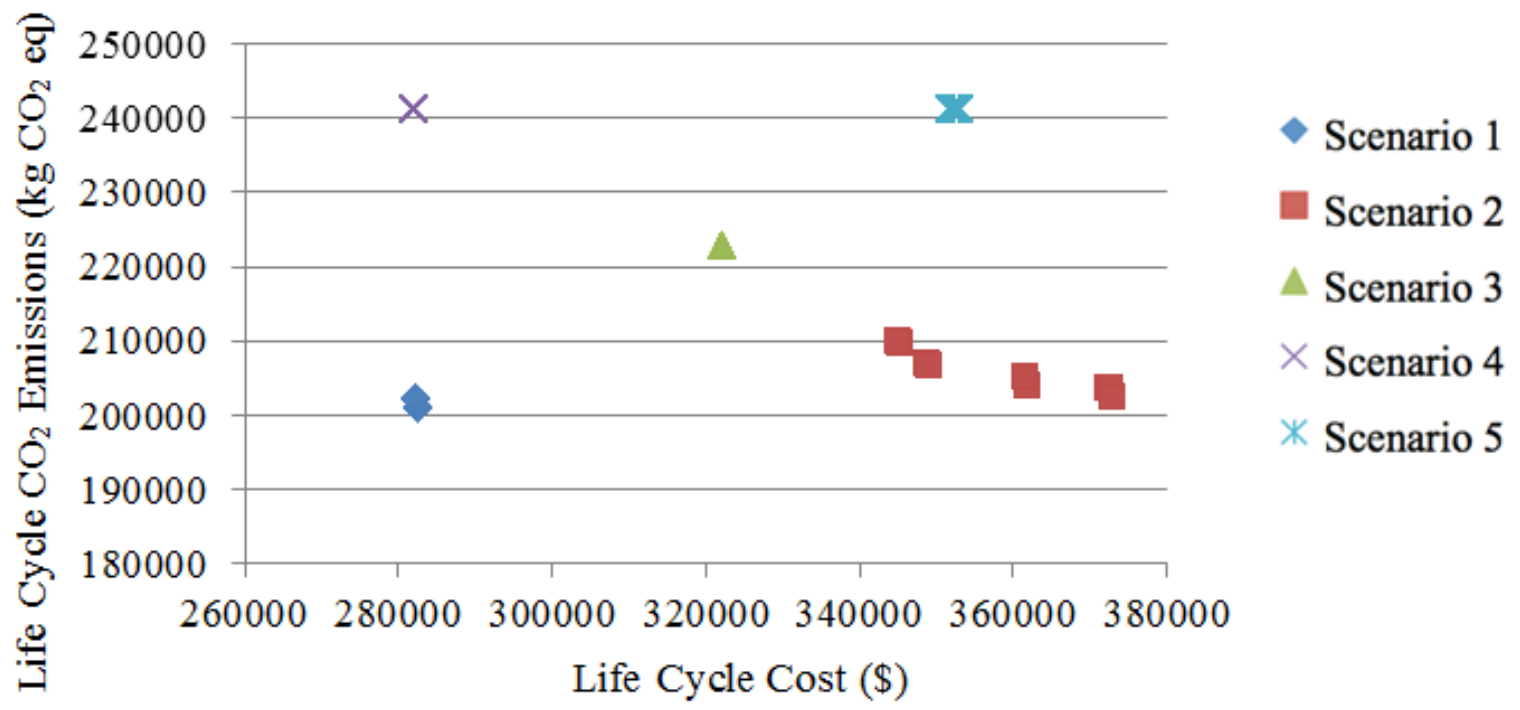

Figure 30 Graph Relationships between Cost and $\mathrm{CO}_{2}$ Emissions for 60 Year-Usage Phase 


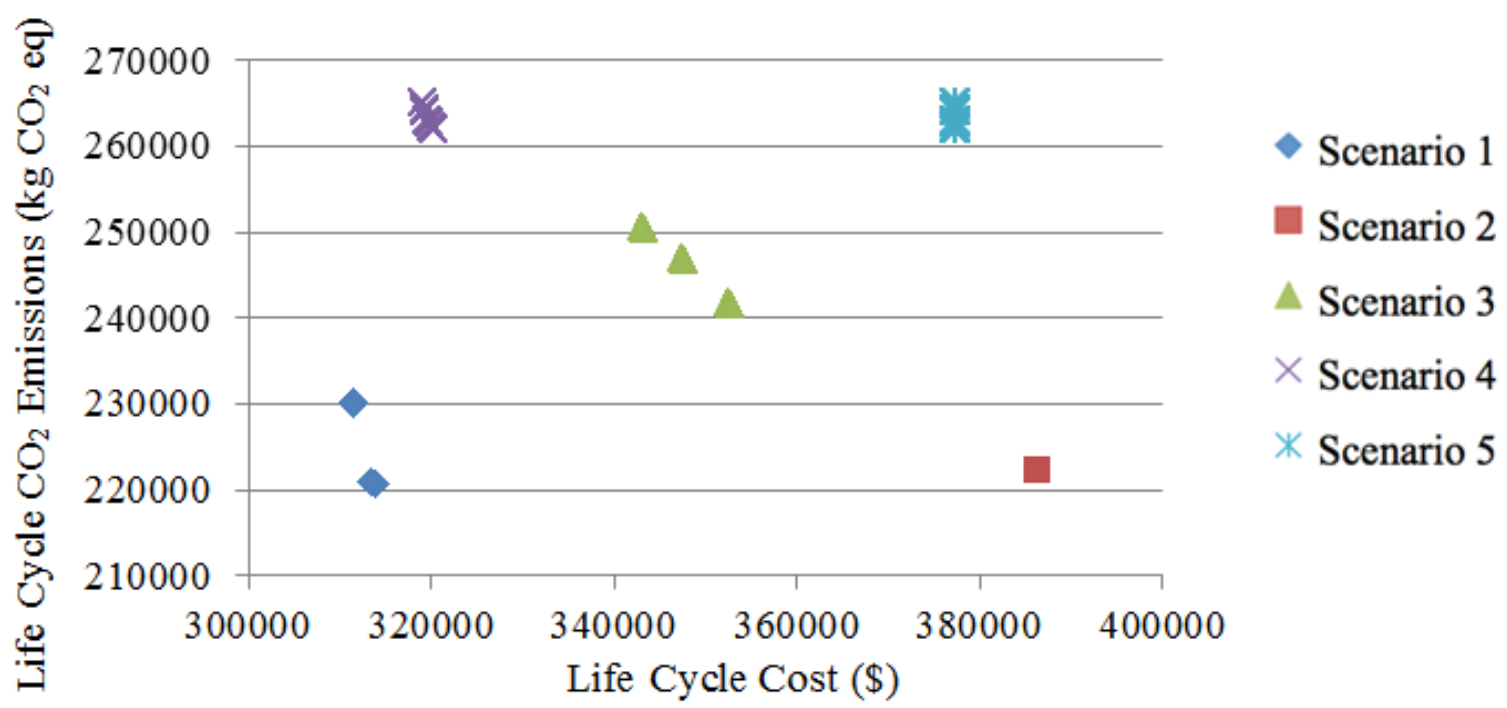

Figure 31 Graph Relationships between Cost and $\mathrm{CO}_{2}$ Emissions for 70 Year-Usage Phase

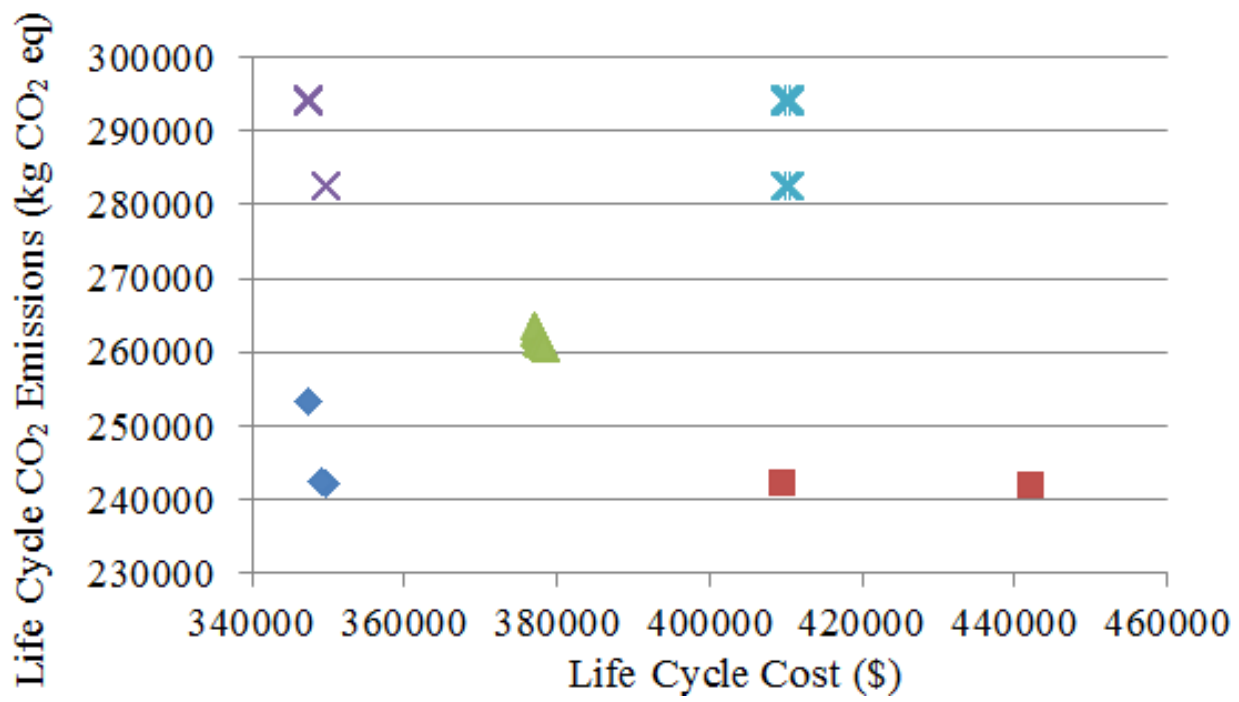

Scenario 1

Scenario 2

Scenario 3

$\times$ Scenario 4

* Scenario 5

Figure 32 Graph Relationships between Cost and $\mathrm{CO}_{2}$ Emissions for 80 Year-Usage Phase 


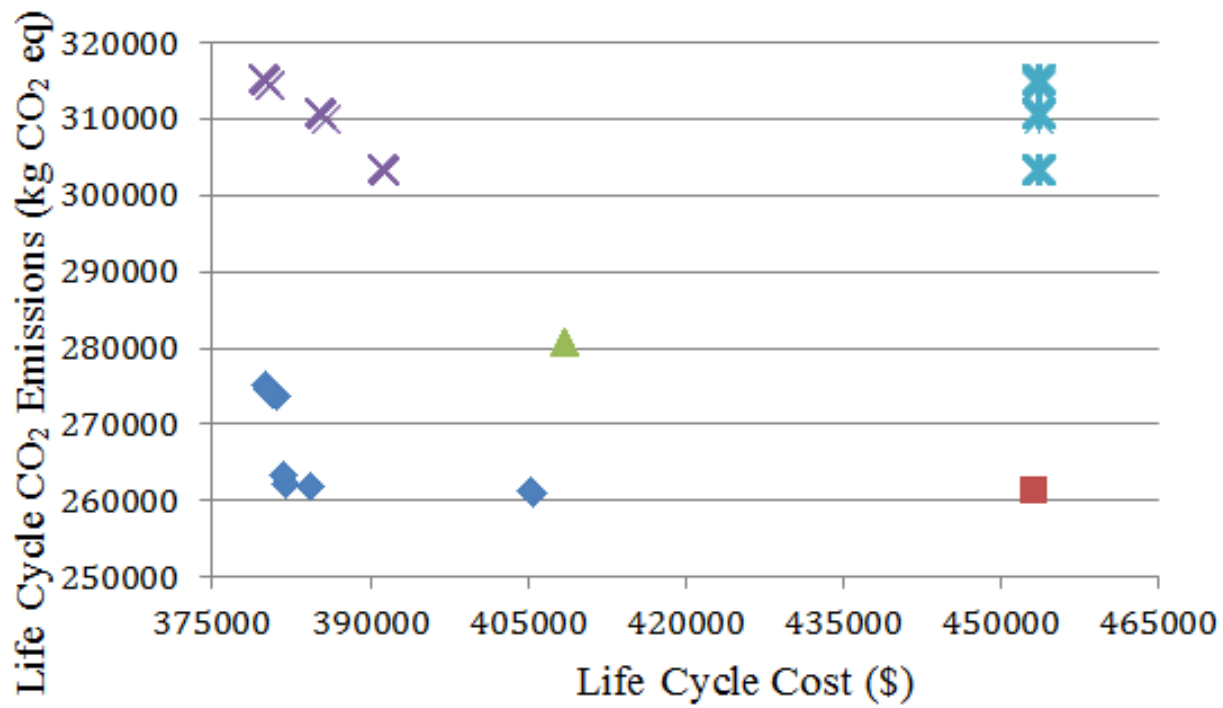

Scenario 1

Scenario 2

Scenario 3

Scenario 4

Scenario 5

Figure 33 Graph Relationships between Cost and $\mathrm{CO}_{2}$ Emissions for 90 Year-Usage Phase

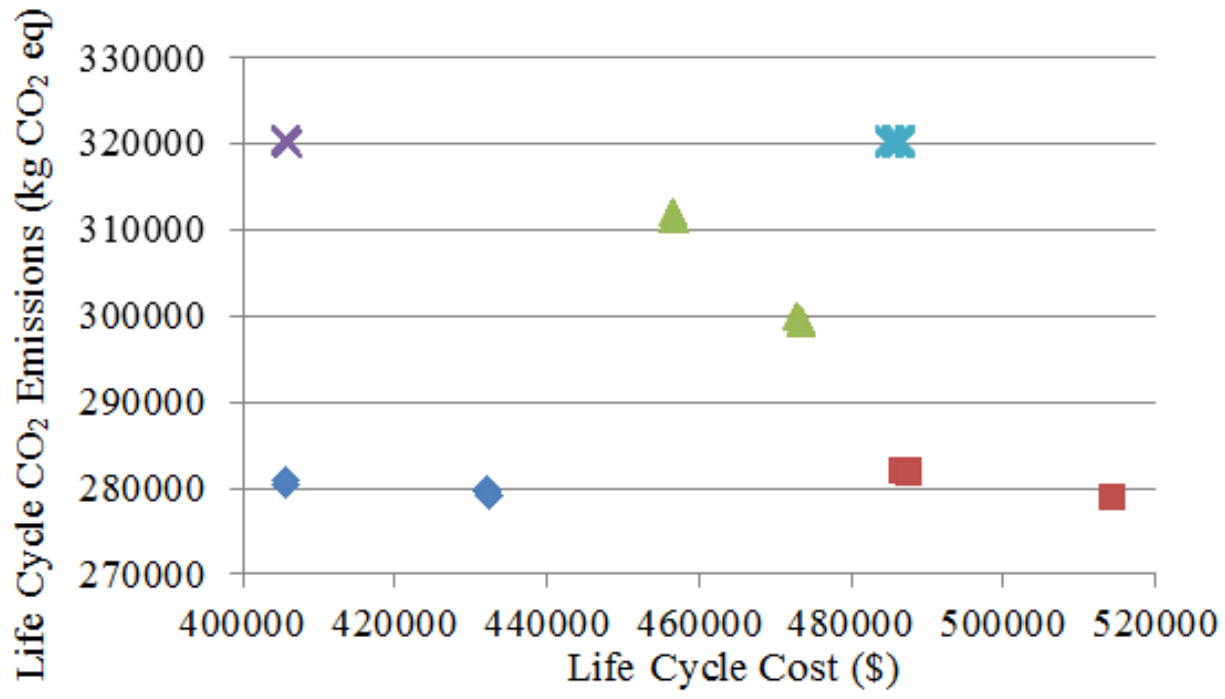

Scenario 1

Scenario 2

Scenario 3

Scenario 4

Scenario 5

Figure 34 Graph Relationships between Cost and $\mathrm{CO}_{2}$ Emissions for 100 Year-Usage Phase 


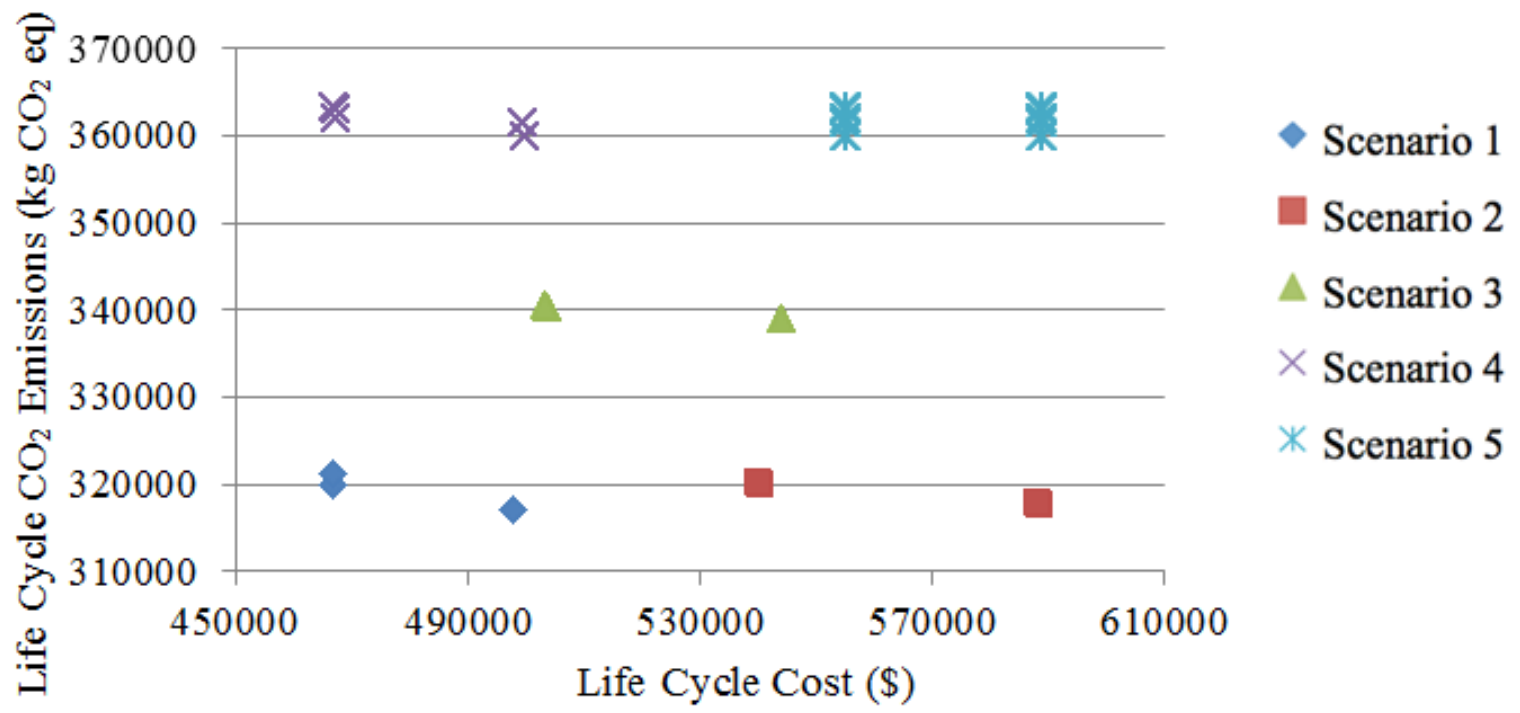

Figure 35 Graph Relationships between Cost and $\mathrm{CO}_{2}$ Emissions for 120 Year-Usage Phase

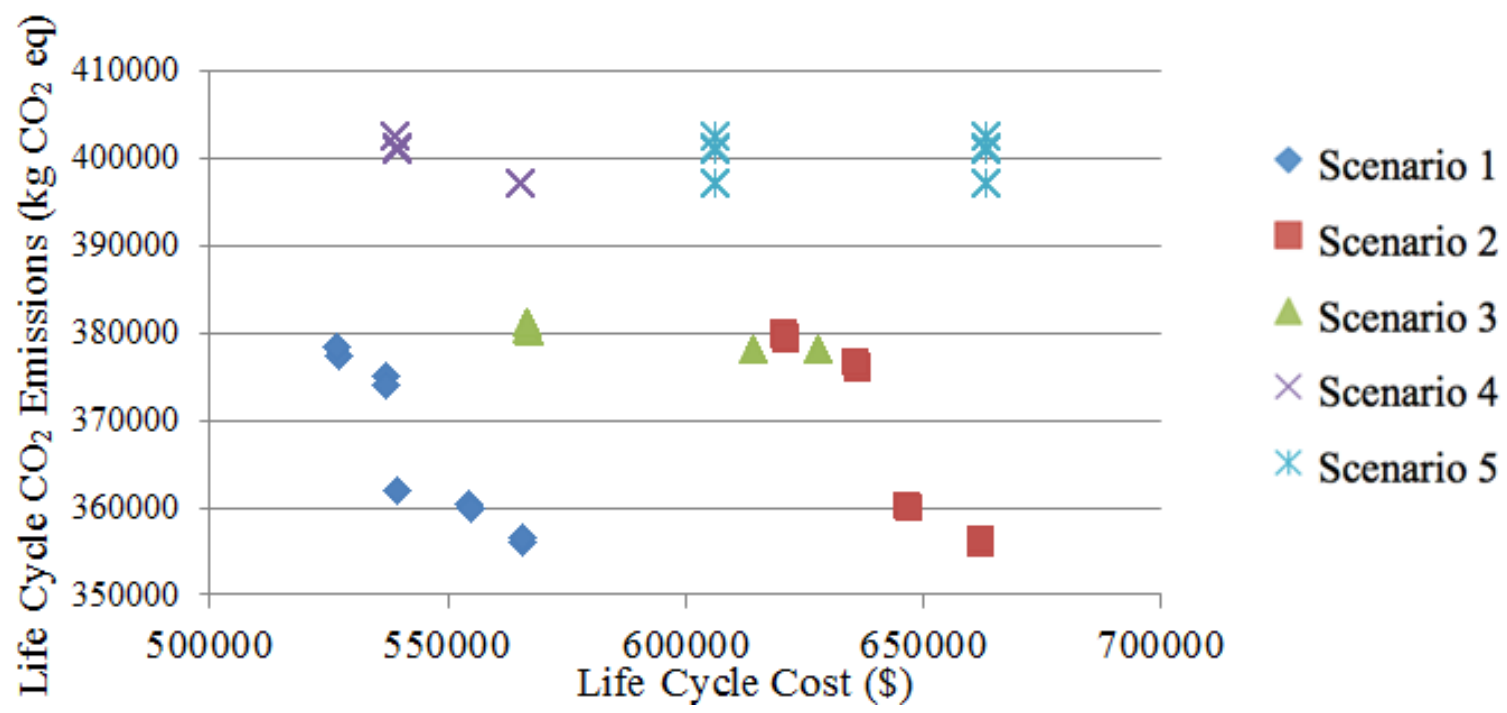

Figure 36 Graph Relationships between Cost and $\mathrm{CO}_{2}$ Emissions for 140 Year-Usage Phase 


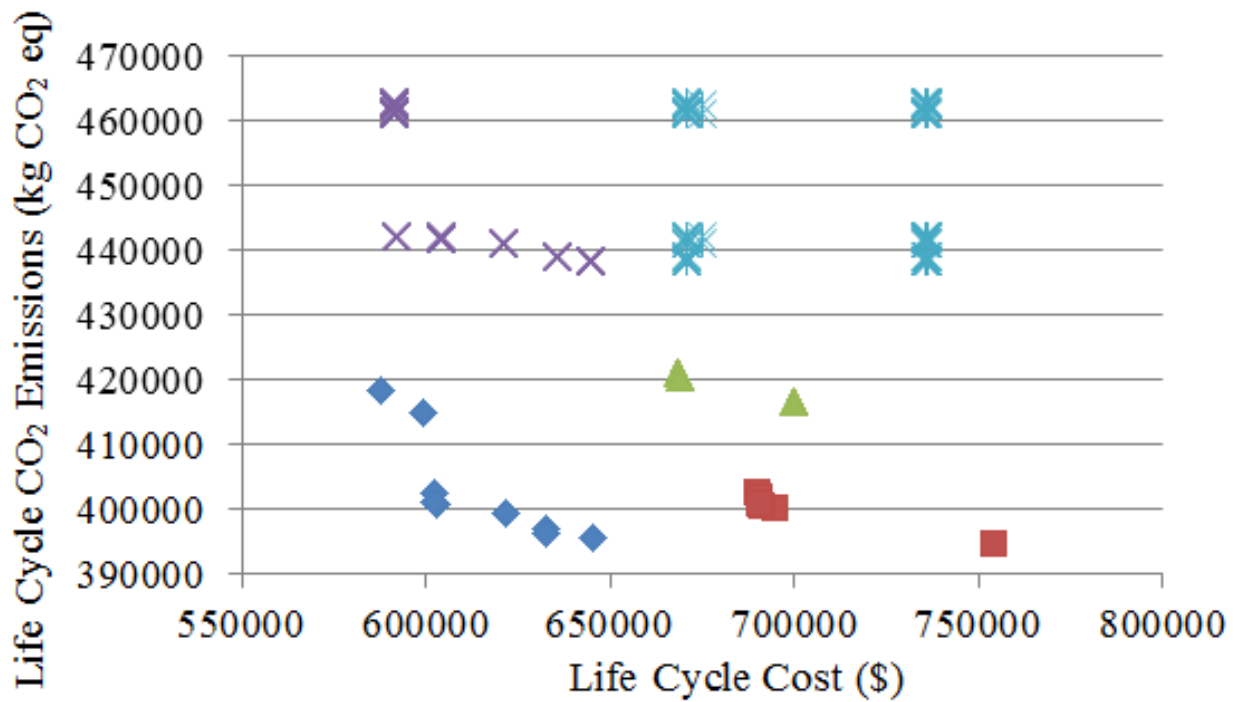

Scenario 1

Scenario 2

Scenario 3

Scenario 4

* Scenario 5

Figure 37 Graph Relationships between Cost and $\mathrm{CO}_{2}$ Emissions for 160 Year-Usage Phase

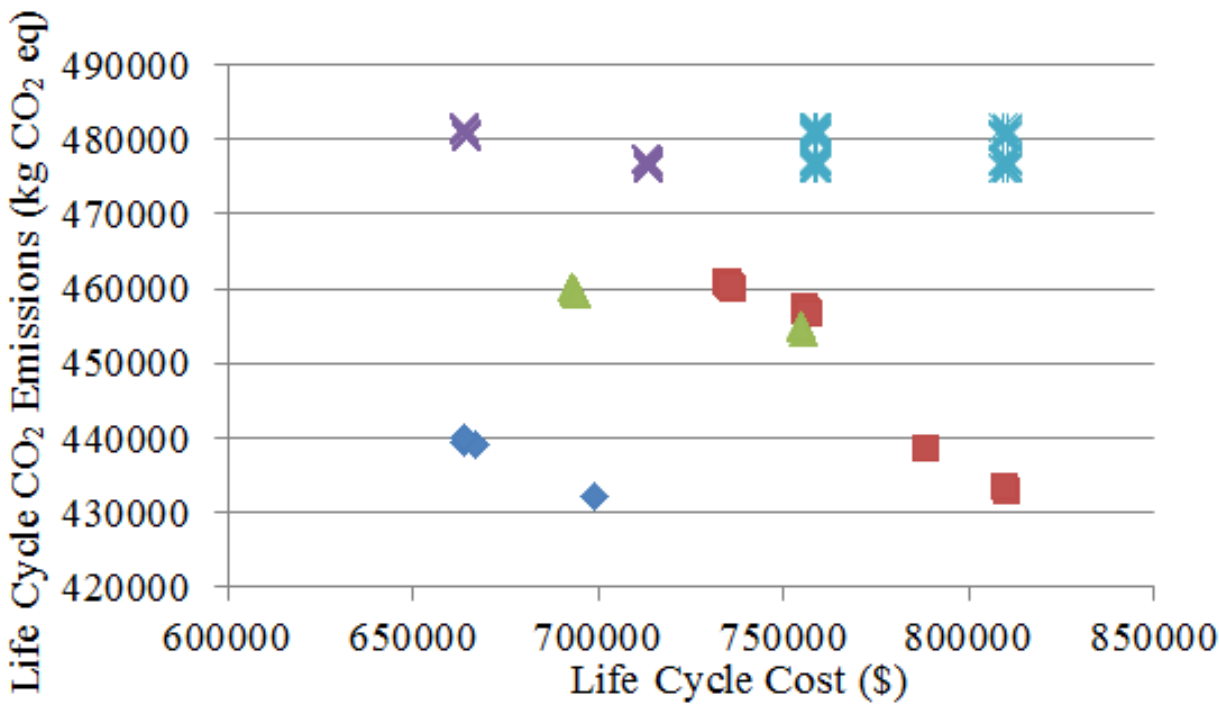

Scenario 1

Scenario 2

Scenario 3

Scenario 4

Scenario 5

Figure 38 Graph Relationships between Cost and $\mathrm{CO}_{2}$ Emissions for 180 Year-Usage Phase 


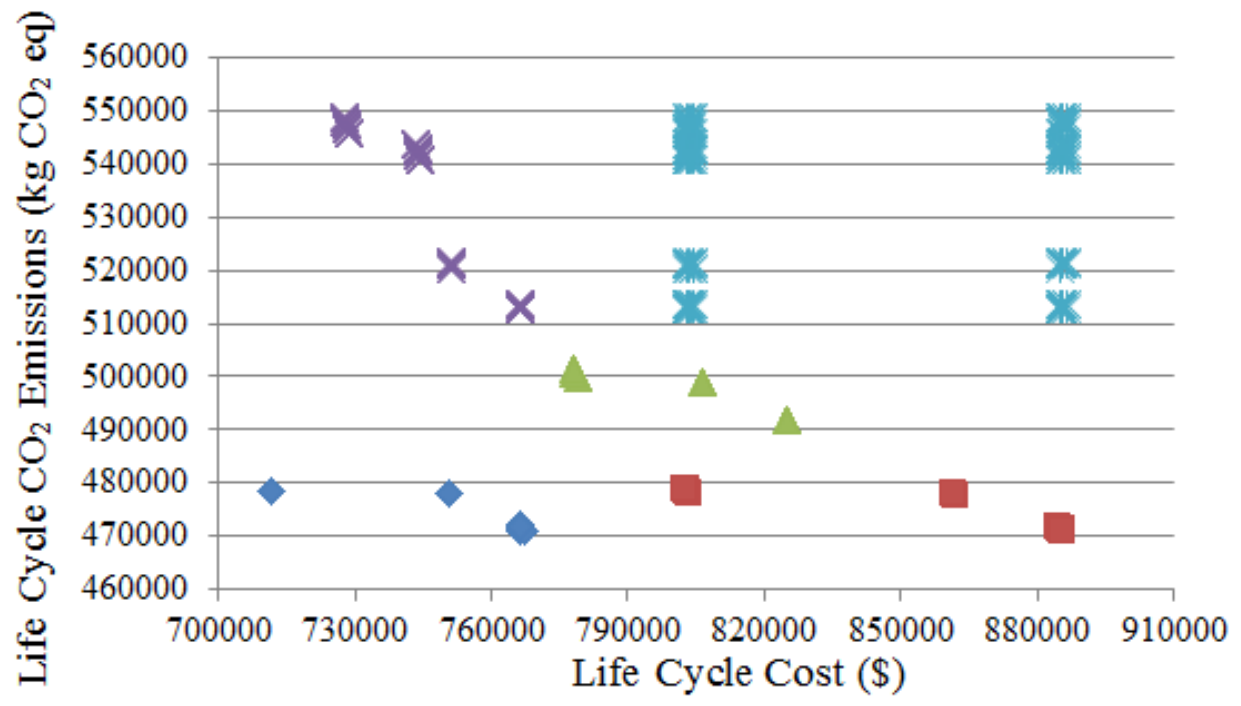

Scenario 1

Scenario 2

$\triangle$ Scenario 3

$\times$ Scenario 4

* Scenario 5

Figure 39 Graph Relationships between Cost and $\mathrm{CO}_{2}$ Emissions for 200 Year-Usage Phase

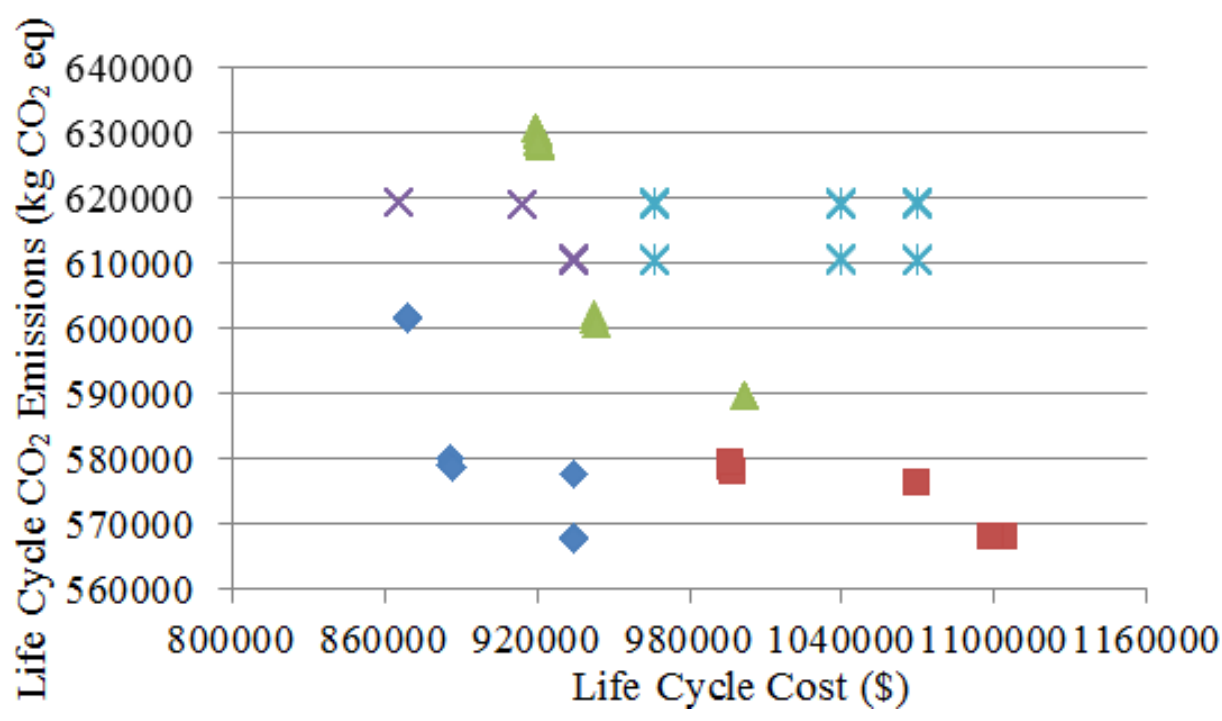

Scenario 1

Scenario 2

Scenario 3

Scenario 4

Scenario 5

Figure 40 Graph Relationships between Cost and $\mathrm{CO}_{2}$ Emissions for 250 Year-Usage Phase 


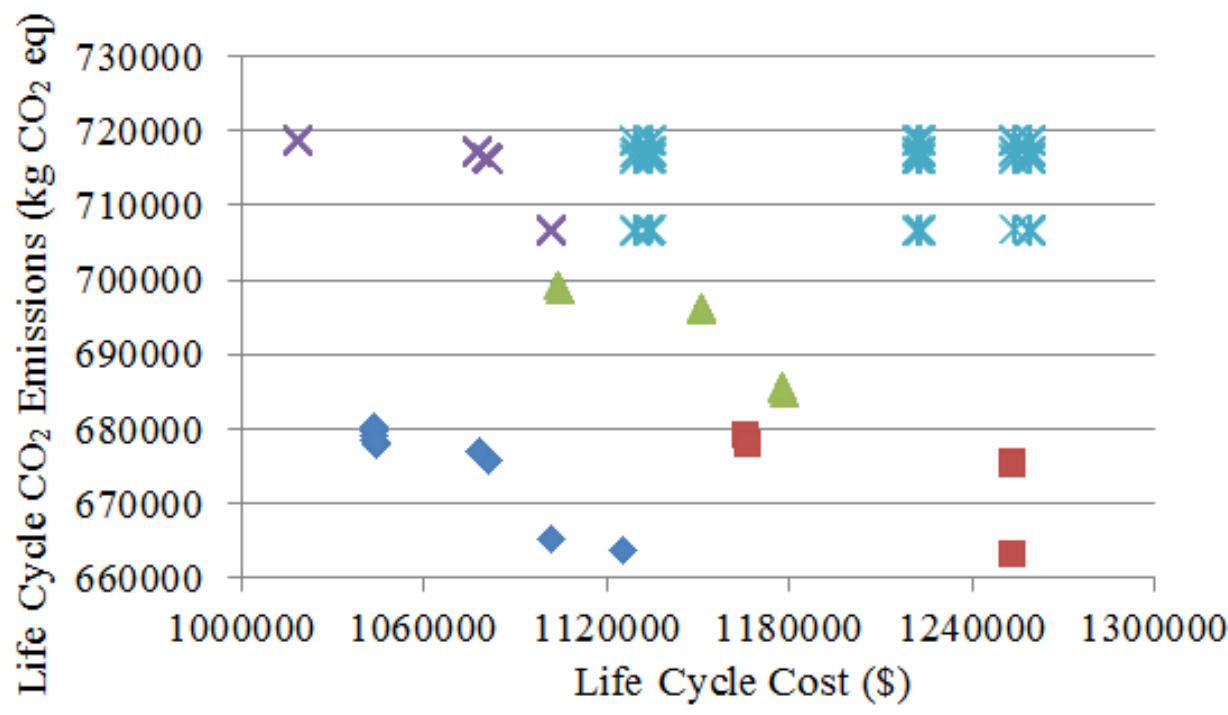

Scenario 1

Scenario 2

Scenario 3

Scenario 4

Scenario 5

Figure 41 Graph Relationships between Cost and $\mathrm{CO}_{2}$ Emissions for 300 Year-Usage Phase

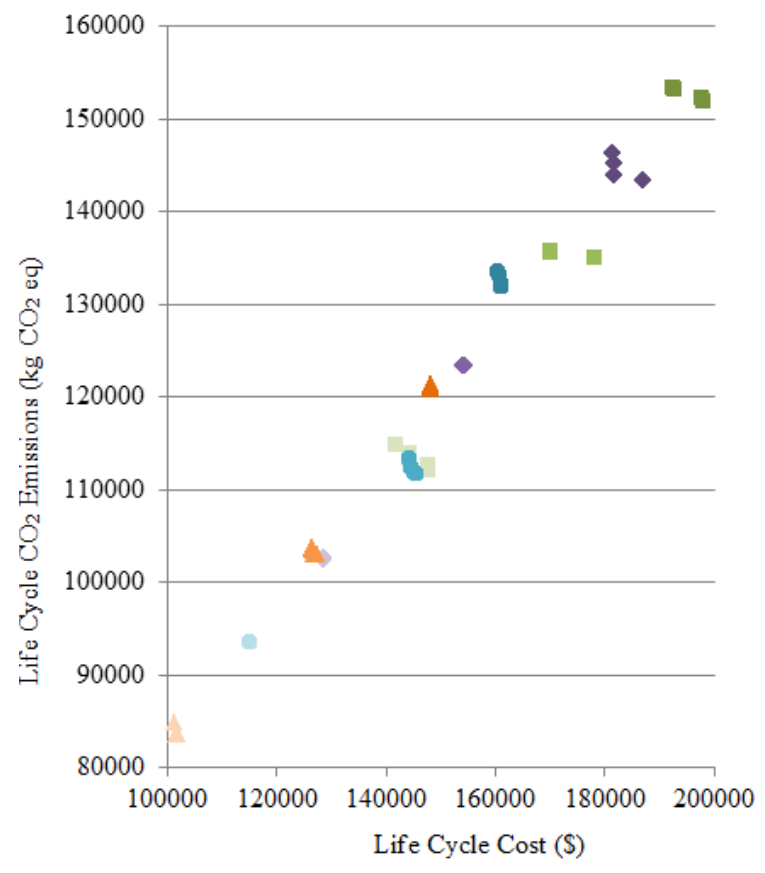

\begin{tabular}{c} 
0-Year \\
Scenario 1 \\
$\Delta$ Scenario 3 \\
$\Delta$ Scenario 5 \\
\hline 5-Year \\
Scenario 1 \\
Scenario 3 \\
Scenario 5 \\
\hline 10-Year \\
Scenario 1 \\
Scenario 3 \\
Scenario 5 \\
\hline 15-Year \\
\hline Scenario 1 \\
\hline Scenario 3 \\
\hline Scenario 5 \\
\hline
\end{tabular}

Figure 42 Graph Relationships between Cost and $\mathrm{CO}_{2}$ Emissions for 0-15 Year-Usage Phase 

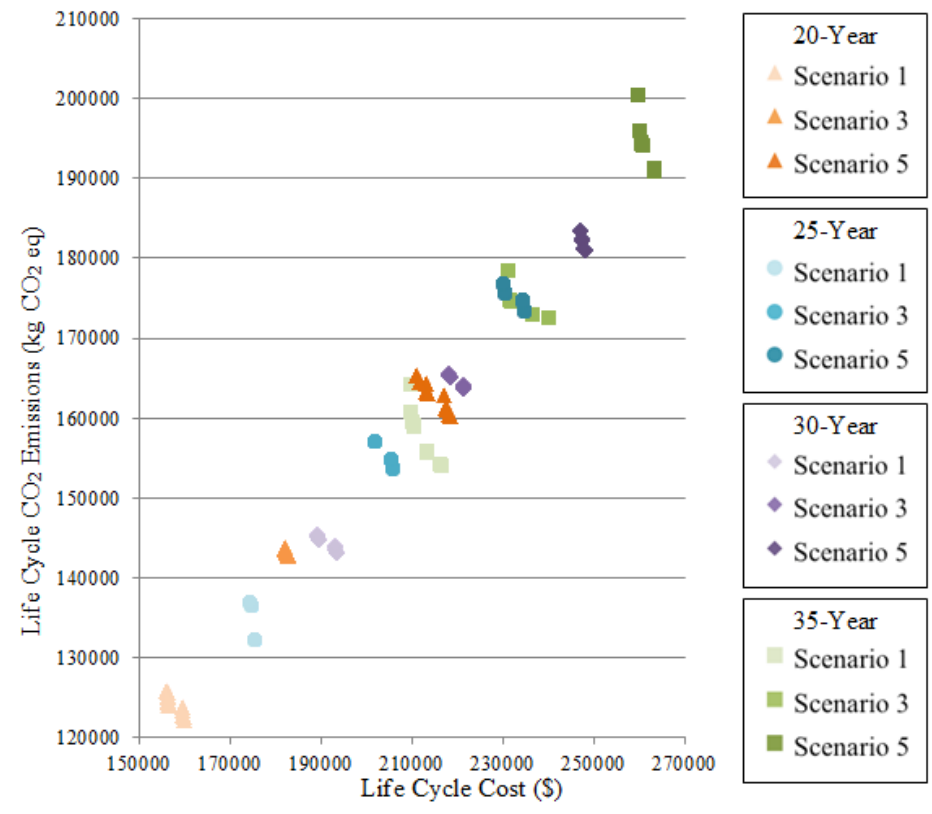

Figure 43 Graph Relationships between Cost and $\mathrm{CO}_{2}$ Emissions for 20-35 Year-Usage Phase

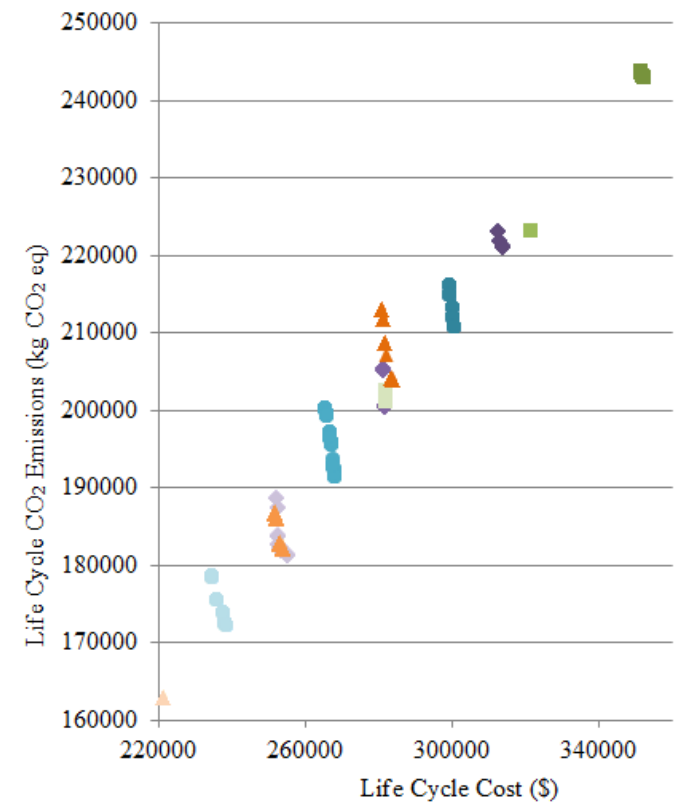

\begin{tabular}{|c|}
\hline 40 -Year \\
\hline Scenario 1 \\
\hline Scenario 3 \\
\hline Scenario 5 \\
\hline 55-Year \\
\hline Scenario 1 \\
Scenario 3 \\
Scenario 5 \\
\hline 50-Year \\
Scenario 1 \\
\hline Scenario 3 \\
Scenario 5 \\
\hline 60-Year \\
\hline Scenario 1 \\
Scenario 3 \\
Scenario 5 \\
\hline
\end{tabular}

Figure 44 Graph Relationships between Cost and $\mathrm{CO}_{2}$ Emissions for 40-60 Year-Usage Phase 

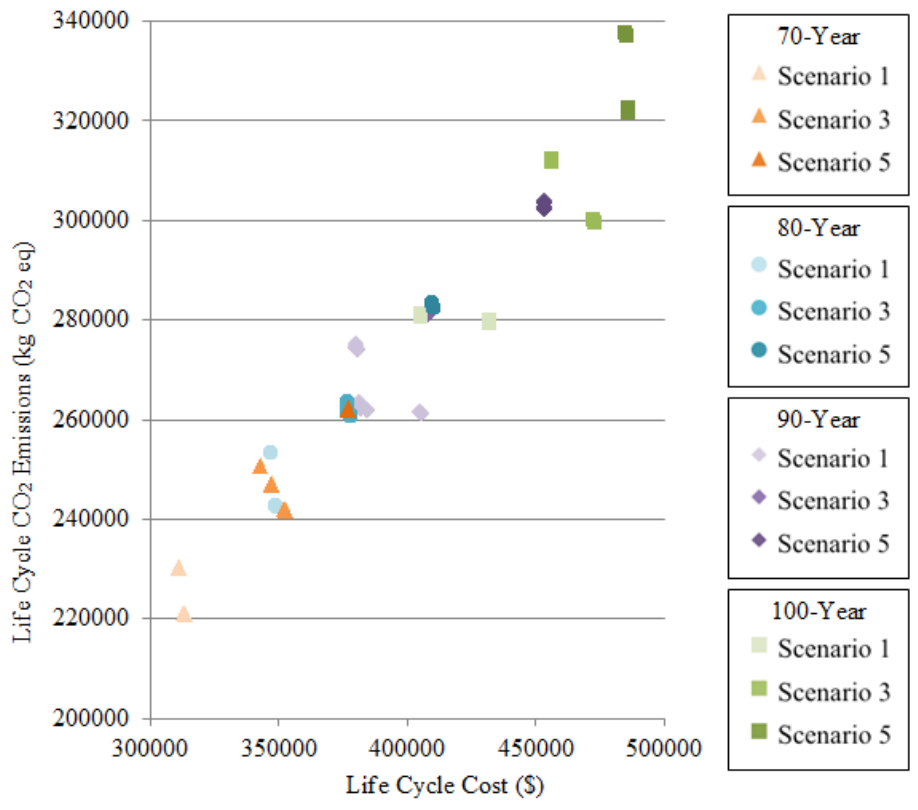

Figure 45 Graph Relationships between Cost and $\mathrm{CO}_{2}$ Emissions for 70-100 Year-Usage Phase

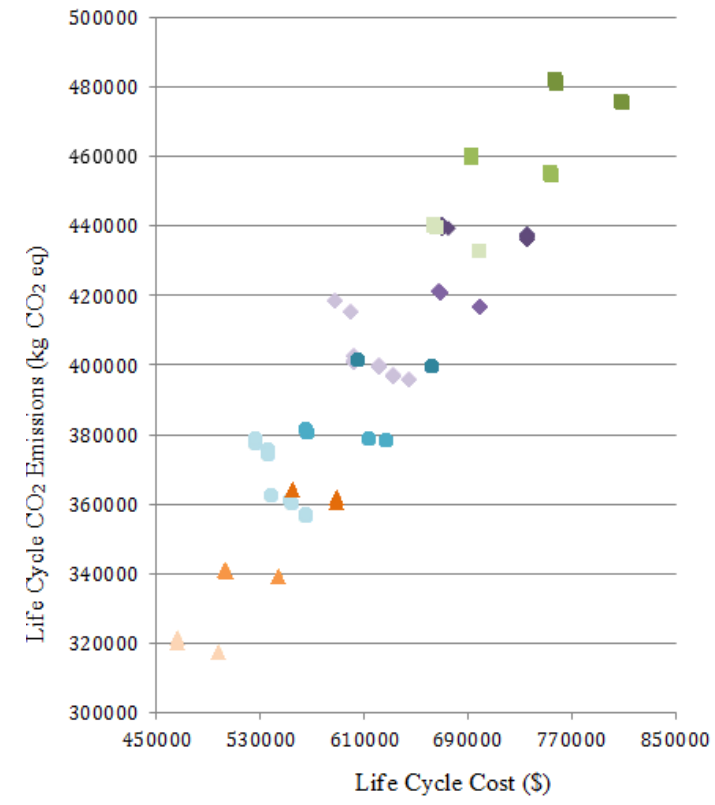

\begin{tabular}{|c|}
\hline \begin{tabular}{c}
120 -Year \\
Scenario 1 \\
$\Delta$ Scenario 3 \\
$\Delta$ Scenario 5 \\
\hline 140 -Year \\
\hline Scenario 1 \\
Scenario 3 \\
Scenario 5 \\
\hline 160 -Year \\
\hline Scenario 1 \\
Scenario 3 \\
Scenario 5 \\
\hline 180 -Year \\
\hline Scenario 1 \\
Scenario 3 \\
Scenario 5 \\
\hline
\end{tabular}
\end{tabular}

Figure 46 Graph Relationships between Cost and $\mathrm{CO}_{2}$ Emissions for 120-180 YearUsage Phase 


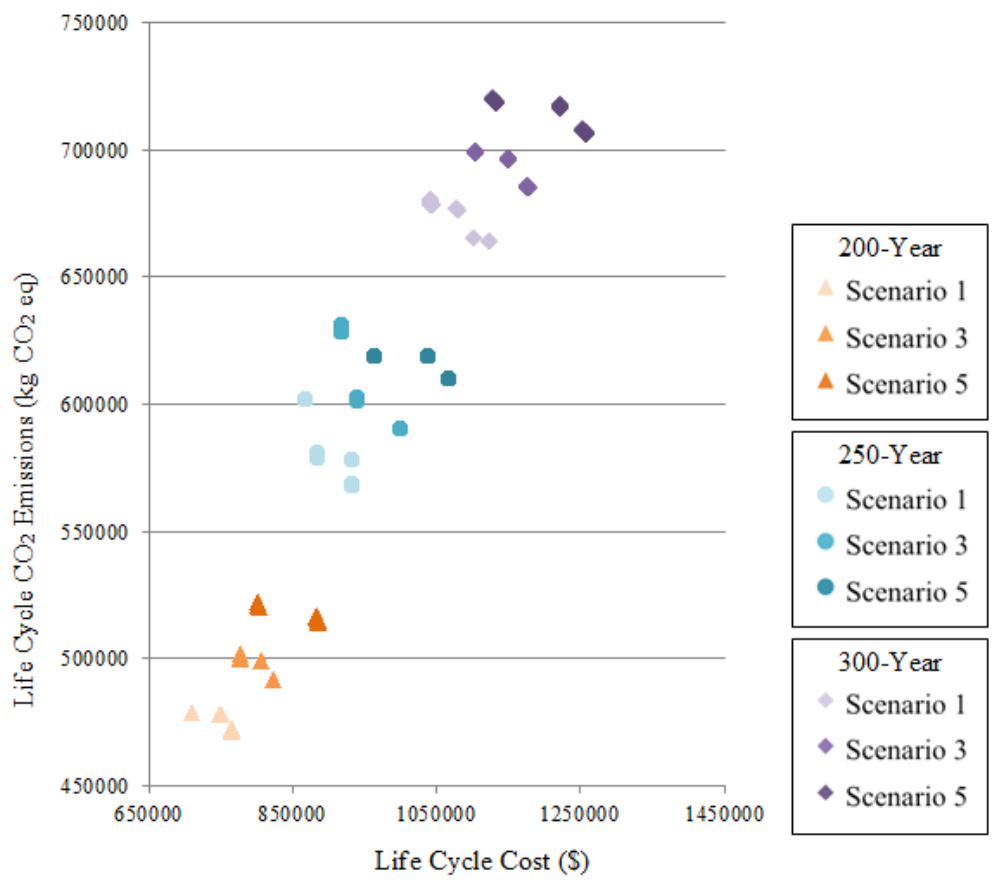

Figure 47 Graph Relationships between Cost and $\mathrm{CO}_{2}$ Emissions for 200-300 YearUsage Phase

Table 23 Longest Distance between Optimal Solutions

\begin{tabular}{cccc}
\hline Year-life & $\begin{array}{c}\text { Longest Distance } \\
\text { in Scenario 1 }\end{array}$ & $\begin{array}{c}\text { Longest Distance } \\
\text { in Scenario 2 }\end{array}$ & $\begin{array}{c}\text { Longest Distance between } \\
\text { Scenario 1 and Scenario 5 }\end{array}$ \\
\hline 0 & 1524.80 & 363.87 & 59706.00 \\
5 & 0.00 & 1539.70 & 60521.00 \\
10 & 212.82 & 6213.40 & 71270.00 \\
15 & 6606.40 & 5685.30 & 67449.00 \\
\hline
\end{tabular}




\begin{tabular}{|c|c|c|c|}
\hline Year-life & Longest Distance & Longest Distance & Longest Distance between \\
\hline Span & in Scenario 1 & in Scenario 2 & Scenario 1 and Scenario 5 \\
\hline 20 & 5309.10 & 8974.70 & 71756.00 \\
\hline 25 & 4676.40 & 5817.00 & 72524.00 \\
\hline 30 & 4813.80 & 2567.40 & 69326.00 \\
\hline 35 & 12196.00 & 10100.00 & 64434.00 \\
\hline 40 & 0.00 & 9602.60 & 77891.00 \\
\hline 45 & 7355.30 & 5694.80 & 75270.00 \\
\hline 50 & 8021.50 & 2364.40 & 72366.00 \\
\hline 60 & 1443.50 & 1544.40 & 81781.00 \\
\hline 70 & 9950.30 & 363.87 & 75886.00 \\
\hline 80 & 11354.00 & 868.31 & 73139.00 \\
\hline 90 & 29070.00 & 1622.50 & 82584.00 \\
\hline 100 & 26816.00 & 16096.00 & 98078.00 \\
\hline
\end{tabular}




\begin{tabular}{|c|c|c|c|}
\hline Year-life & Longest Distance & Longest Distance & Longest Distance between \\
\hline Span & in Scenario 1 & in Scenario 2 & Scenario 1 and Scenario 5 \\
\hline 120 & 31474.00 & 34208.00 & 128700.00 \\
\hline 140 & 44917.00 & 56815.00 & 137960.00 \\
\hline 160 & 61984.00 & 65628.00 & 149640.00 \\
\hline 180 & 36145.00 & 52258.00 & 150410.00 \\
\hline 200 & 55970.00 & 83808.00 & 178350.00 \\
\hline 250 & 73802.00 & 103700.00 & 200470.00 \\
\hline 300 & 83514.00 & 130920.00 & 217390.00 \\
\hline
\end{tabular}

Table 24 Possible Solutions Area

\begin{tabular}{cccc}
\hline Year-life Span & Area & Year-life Span & Area \\
& & & \\
\hline 0 & $4,624,322,259$ & 70 & $2,487,263,500$ \\
5 & $1,884,892,437$ & 80 & $2,567,941,584$ \\
& & & \\
\hline
\end{tabular}




\begin{tabular}{|c|c|c|c|}
\hline Year-life Span & Area & Year-life Span & Area \\
\hline 10 & $2,136,728,498$ & 90 & $3,022,607,567$ \\
\hline 15 & $2,005,638,557$ & 100 & $3,831,183,598$ \\
\hline 20 & $1,997,452,267$ & 120 & $3,467,015,776$ \\
\hline 25 & $2,225,180,820$ & 140 & $1,827,117,616$ \\
\hline 30 & $2,241,579,858$ & 160 & $3,582,412,096$ \\
\hline 35 & $2,157,759,259$ & 180 & $2,456,031,705$ \\
\hline 40 & $2,717,006,625$ & 200 & $4,820,645,408$ \\
\hline 45 & $2,417,392,774$ & 250 & $3,051,588,804$ \\
\hline 50 & $2,333,636,211$ & 300 & $4,624,322,259$ \\
\hline 60 & $2,396,333,904$ & & \\
\hline
\end{tabular}




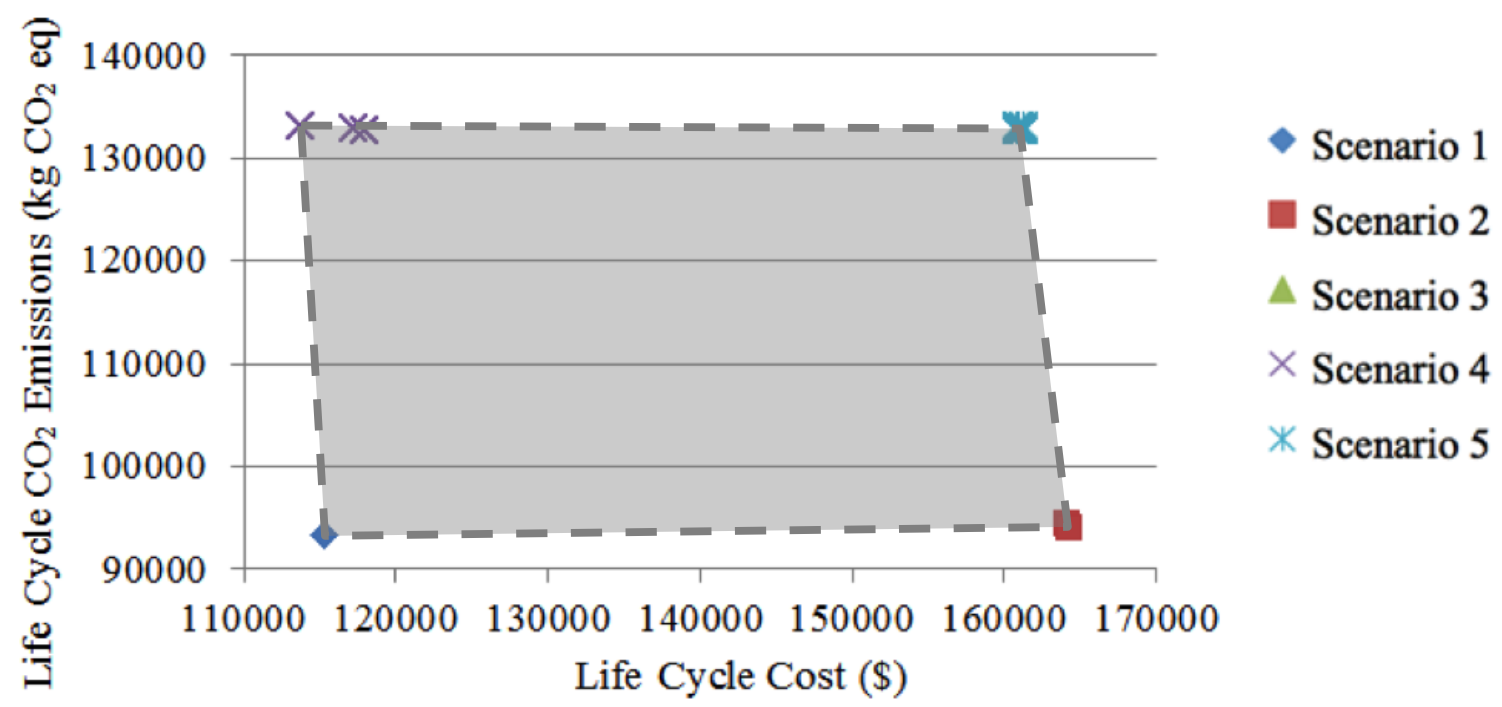

Figure 48 Graph Shows Area of Possible Solutions for 5 Year-Usage Phase 


\section{CHAPTER 7 CONCLUSIONS}

\subsection{Discussions and Conclusions}

Sustainable building design is a rapidly emerging trend in the architecture, engineering, and construction (AEC) industry. The design process has resulted in greater integration of various AEC disciplines during the early design stages of construction projects. The delivery of sustainable building projects is a critical aspect of the AEC industry. These projects often face multiple and even conflicting objectives, such as time, cost, and environmental impact. A building design may have many options for using different materials, crews, and equipment, including construction methods that can be combined to meet project objectives. The number of possible design alternatives can be very large. Design professionals, construction professionals, and decision makers often face the challenge of selecting optimal building components and solutions in order to appropriately meet multi-objective and standard requirements. To effectively support the

decision-making process during the early design phase, robust simulation-based technology is desirable.

Integrated applications in construction project management have been widely used in the AEC industry for many decades. Currently, there are many simulation-based tools that were developed in the industry for aid in sustainable design. Simulation of Environmental Impacts of Construction or SimulEICon is a multi-objective analytical tool for studying the relationships between time, cost, and environmental impact, which is capable of considering building life cycle information to optimization process and it 
also takes data uncertainty and availability of data into account. Its functionality includes the ability to help design and construction professionals in the selection of building materials, components, and building design in order to find optimal design solutions based on the current three objectives: minimizing time, minimizing cost, and minimizing environmental impact, in terms of $\mathrm{CO}_{2}$ emissions. The SimulEICon application is developed to analyze the relationships between multiple objectives in different levels of a building: material, component, and building. The relationships between construction time, initial construction cost, and $\mathrm{CO}_{2}$ emissions are considered in the pre-use phase analysis, while only life cycle cost and $\mathrm{CO}_{2}$ emissions are accounted for in the usage phase within various building year-life spans. To address data uncertainty and availability, Monte Carlo simulation is applied in this research. Moreover, the selection process applies Genetic Algorithms, NSGA-II, to obtain a set of optimal solutions.

At the material level, six envelope material categories, which are structural component, exterior cladding, insulation, roofing, concrete footing, and concrete slab-ongrade, were chosen for SimulEICon analysis. Two scenarios were investigated to understand the importance of material installation. Scenario 1 considered the relationship between cost and $\mathrm{CO}_{2}$ emissions at the manufacturing phase. In scenario 2, installation time was considered in the analysis, along with cost and $\mathrm{CO}_{2}$ emissions. Dominant alternatives were observed in all categories in scenario 1. However, the level of confidence for having a dominant alternative varied among categories from $99.8 \%$ to $0.3 \%$. Only three categories had a level of confidence greater than $50 \%$. Thus, the level of confidence that all categories had a dominant solution at the same time was very small. 
The level of confidence consequently dropped in almost all categories of scenario 2 . Additionally, in some categories, such as roofing, exterior cladding, and concrete footing, the level of confidence for having a dominant solution was near $0 \%$. This is because there was commonly known trade-off behavior between time and cost. When installation was considered along with unit cost and $\mathrm{CO}_{2}$ emissions per material unit, the level of confidence changed significantly. Categories did not provide a meaningful percentage of predominant alternatives. Material alternatives in those categories could have a fair chance to be chosen in the material selection process at the building design stage. In structural component and insulation categories, dominant alternatives still existed and they might have a potential impact on other levels. Thus, if those categories also quantitatively represented a major portion of materials in the building, the dominant alternatives of a structural component category and an insulation category should be carefully considered in a decision-making process.

The pattern analysis showed that the majority of data sets did not support the existence of trade-off patterns when all materials of a category are considered. Multiple relationships in subsets of a category made proper material decisions more complex. The study showed that the relationship between time, cost and $\mathrm{CO}_{2}$ emissions at the material level is rather random. For example, installation time is mainly dependent upon the method of installation, which may not be directly and properly related to cost and $\mathrm{CO}_{2}$ emissions; similarly, greener products may not be less expensive or faster to install. Such disconnections apparently exist in todays' construction materials, which contributes to the "randomness" observed in this study. Therefore, the trade-off pattern at the material 
level is not as obvious as many studies at building level claim. While market forces may sort out the randomness in material installation time, cost and environment impact in the long run, a more effective way to help decision makers properly select materials is important.

At the component and building level, during the pre-use phase, two case studies were used to demonstrate the relationships between construction time, initial construction cost, and $\mathrm{CO}_{2}$ emissions. The results of case studies showed that if only considering three objectives without other design, engineering and construction constraints, there was not one design solution that was clearly dominating. It is thus unlikely that a chosen design option is absolutely dominant to others, or dominated by others, if the chosen design option is one of the optimal design solutions. This proposition is reflected in the real world where the decision of building design selection is often influenced by many factors other than construction time, cost, and environmental impact. It seems that trade-off relationships do exist between construction time and initial construction cost, and between construction time and $\mathrm{CO}_{2}$ emissions in many cases. While the trade-off relationship between cost and time has been well understood, it is interesting to see the trade-off relationship between construction time and $\mathrm{CO}_{2}$ emissions. The results showed that, in many cases, there was no trade-off relationship between cost and $\mathrm{CO}_{2}$ emissions. This is mainly because the cost was an initial cost or direct cost, such as materials, equipment, and labor. As stated, adding more resources can results in higher $\mathrm{CO}_{2}$ emission. Thus, higher costs may be associated with higher $\mathrm{CO}_{2}$ emissions. 
In the last analysis, maintenance and energy consumption from the usage phase were considered in the optimal solutions. The case study 1 with energy simulation information was used in this stage. Five scenarios were simulated to represent all possible solution ranges. Maintenance and energy consumption cost were accounted for completing life cycle cost of the building, while $\mathrm{CO}_{2}$ emissions from energy consumption is used as energy-related $\mathrm{CO}_{2}$ emissions data in the optimization process. Different building life spans were utilized to see if the relationship transformed with time. During the pre-use phase, as stated above, the trade-off relationship between initial construction cost and $\mathrm{CO}_{2}$ emissions did not exist. Proportional relationship continually occurred after the construction phase to the usage phase. However, the relationship between life cycle cost and $\mathrm{CO}_{2}$ emissions developed its interrelation and starts to compromisingly exhibit trade-off behavior. However, the results from the case study showed that there was no trade-off between life cycle cost and $\mathrm{CO}_{2}$ emissions in all observed life span.

Validation of SimulEICon or similar approaches is difficult for several reasons (Sargent, 2005). Most validation approaches require experts or professionals to assess the validity of the simulation results and there is no exact test to determine the validity of the model because the results are not implemented. This problem is compounded by the fact that SimulEICon yields a wide array of different possible solutions that change with each different simulation due to the effects of uncertainty and the optimization process. Thus, in this research, instead of striving for a full-scale validation, two validity concepts were performed. Construct validity was accomplished by examining the reliability of SimulEICon's results (Lucko \& Rojas, 2009). The tool was utilized with other research's 
data to ensure the performance and accuracy of its output. The case studies using in the research are the real buildings that had already been constructed. Content validity was possible to calibrate the simulations' results with the real data. For example, the actual annual energy consumption of the case study 1 was used in comparison with results from energy simulation and to create a factor in order to match data.

To reach a conclusion, the proposed application, SimulEICon, is presented as an analytical tool for multi-objective optimization problems. This tool is meant to not only help identify the relationship between the project's objectives but also to aid design and construction professionals during the design phase of the buildings. It was pointed out that the construction project tends to have multiple objectives and those objectives should not be independently assessed during the decisions-making process. Understanding the relationships between those objectives is a key in successfully planning and designing environmentally sustainable construction projects.

\subsection{Limitation and Future Studies}

Within limited resources and data, this research did not identify factors at the material level that contributed to data patterns at the building level. Further studies should have a focus on this topic. In addition, since material quantities can have a significant impact on building-level data patterns, analysis should be performed to better understand the impact of material quantities on connecting material level time, cost and environment impacts to the building level. The study was based on limited data samples. Future studies should also focus on increasing the data samples. Moreover, conclusions are 
derived based on two similar buildings case study, which limited the scope of work. Energy simulation for larger buildings takes time to calculate and construct. Most data is not available or ready to input to the simulation.

Finally, future studies should include more cases and a larger scope in each case study to derive better results. Furthermore, in reality, historical data is considerably hard to obtain and also not always available. A literature review can provide probability distributions to present the behavior of the data. Additional data is necessary for future studies to provide more accurate and appropriate design solutions. 


\section{REFERENCES}

AbouRizk, S., Halpin, D., \& Wilson, J. (1991). Visual Interactive Fitting of Beta Distributions. Journal of Construction Engineering and Management, 117(4), 589-605.

Afshar, A., Kaveh, A., \& Shoghli, O. R. (2007). Multi-objective optimization of timecost-quality using multi-colony ant algorithm. Asian Journal of Civil Engineering (Building and Housing), 8(2), 113-124.

AIA (2007). Integrated Project Delivery: A guide (Version 1). The American Institute of Architects (AIA) and AIA California Council. Retrieved September 1, 2012, from http:// http://info.aia.org/SiteObjects/files/ IPD_Guide_2007.pdf.

Andolsun, S., Culp, C.H., Haberl, J., \& Witte, M. J. (2011). EnergyPlus vs. DOE-2.1e: The effect of ground-coupling on energy use of a code house with basement in a hothumid climate. Energy and Buildings, 43(7), 1663-1675.

Ashuri, B., \& Tavakolan, M. (2012). A Fuzzy Enabled Hybrid Genetic AlgorithmParticle Swarm Optimization Approach to Solve Time-Cost-Resource Optimization (TCRO) Problems in Construction Project Planning. Journal of Construction Engineering and Management, 138(9), 1065-1074.

Athena Sustainable Materials Institute (2013). Athena Impact Estimator for Buildings V 4.5 User's Manual, Software and Database Overview. Athena Impact Estimator for Buildings, Retrieved April 14, 2014, from http://calculatelca.com/wpcontent/uploads /2013/11/IE4B_User_Guide_Nov2013.pdf .

Babayan, A., Kapelan, Z., Savic, D., \& Walters, G. (2005). Least-cost design of water distribution networks under demand uncertainty. Journal of Water Resources Planning and Management, 131(5), 375-382.

Babu, A. J. G., \& Suresh, N. (1996). Project management with time, cost, and quality considerations. European Journal of Operational Research, 88(2), 320-327.

Bäck, T., \& Schwefel, H. P. (1993). An overview of evolutionary algorithms for parameter optimization. Evolutionary computation, 1(1), 1-23.

Back, W., Boles, W., \& Fry, G. (2000). Defining Triangular Probability Distributions from Historical Cost Data. Journal of Construction Engineering and Management, 126(1), 29-37.

Bruni, M. E., Beraldi, P., Guerriero, F., \& Pinto, E. (2011). A heuristic approach for resource constrained project scheduling with uncertain activity durations. Computers \& Operations Research, 38(9), 1305-1318. 
Bunz, K., Henze, G., and Tiller, D. (2006). Survey of Sustainable Building Design Practices in North America, Europe, and Asia. Journal of architectural engineering, 12(1), 33-62.

Cameron, A. C., \& Windmeijer, F. A. (1997). An R-squared measure of goodness of fit for some common nonlinear regression models. Journal of Econometrics, 77(2), 329-342.

Camp, C., Pezeshk, S., \& Cao, G. (1998). Optimized Design of Two-Dimensional Structures Using a Genetic Algorithm. Journal of Structural Engineering, 124(5), 551559.

Cantoni, M., Marseguerra, M., \& Zio, E. (2000). Genetic algorithms and Monte Carlo simulation for optimal plant design. Reliability Engineering \& System Safety, 68(1), 2938.

Chan, A. P. (2001). Time-cost relationship of public sector projects in Malaysia. International Journal of Project Management, 19(4), 223-229.

Choudhury, I., \& Rajan, S. S. (2003). Time-cost relationship for residential construction in Texas. CIB REPORT, 284, 73.

Cieniawski, S. E., Eheart, J. W., \& Ranjithan, S. (1995). Using genetic algorithms to solve a multiobjective groundwater monitoring problem. Water Resources Research, 31(2), 399-409.

Cole, R. J. (1998). Emerging trends in building environmental assessment methods. Building Research \& Information, 26(1), 3-16.

Cole, R. J., \& Kernan, P. C. (1996). Life-cycle energy use in office buildings. Building and environment, 31(4), 307-317.

Crawley, D. B., Hand, J. W., Kummert, M., \& Griffith, B. T. (2008). Contrasting the capabilities of building energy performance simulation programs. Building and environment, 43(4), 661-673.

Crawley, D. B., Lawrie, L. K., Winkelmann, F. C., Buhl, W. F., Huang, Y. J., Pedersen, C. O., Strand, R. K., Liesen, R. J., Fisher, D. E., Witte, M. J., \& Glazer, J. (2001). EnergyPlus: creating a new-generation building energy simulation program. Energy and Buildings, 33(4), 319-331.

Ding, G. K. (2008). Sustainable construction - the role of environmental assessment tools. Journal of environmental management, 86(3), 451-464.

DOE. (2012). Buildings Energy Data Book, U.S. Department of Energy, Retrieved March 4, 2013, from http://buildingsdatabook.eren.doe.gov/ChapterIntro1.aspx . 
EIA (2015) Electricity, U.S. Energy Information Administration, Retrieved Jan 7, 2015, from http://www.eia.gov/electricity/.

Elbeltagi, E., Hegazy, T., \& Grierson, D. (2005). Comparison among five evolutionarybased optimization algorithms. Advanced Engineering Informatics, 19(1), 43-53.

El-Rayes, K., \& Kandil, A. (2005). Time-cost-quality trade-off analysis for highway construction. Journal of construction Engineering and Management, 131(4), 477-486.

EPA (2009). Potential for reducing greenhouse gas emissions in the construction sector. Environmental Protection Agency, Washington, D.C.

EPA (2014) Clean Energy, U.S. Environmental Protection Agency, Retrieved Jan 7, 2015, from http://www.epa.gov/cleanenergy/energy-resources/refs.html.

Eshtehardian, E., Afshar, A., \& Abbasnia, R. (2009). Fuzzy-based MOGA approach to stochastic time-cost trade-off problem. Automation in Construction, 18(5), 692-701.

Evins, R. (2013). A review of computational optimisation methods applied to sustainable building design. Renewable and Sustainable Energy Reviews, 22, 230-245.

Farah, A. (1985). Monte Carlo Simulation in Civil Engineering Applications. Proceedings from American Society for Engineering Education Annual Conference, 2, 449-453.

Feng, C. W., Liu, L., \& Burns, S. A. (2000). Stochastic construction time-cost trade-off analysis. Journal of Computing in Civil Engineering, 14(2), 117-126.

Fente, J., Knutson, K., \& Schexnayder, C. (1999). Defining a beta distribution function for construction simulation. Proceedings from the 31st conference on Winter simulation: Simulation - a bridge to the future, 2, 1010-1015.

Flager, F., Basbagill, J., Lepech, M., \& Fischer, M. (2012). Multi-objective building envelope optimization for life-cycle cost and global warming potential. Proceedings from the European Conference on Product and Process Modeling 2012In EWork and EBusiness in Architecture, Engineering and Construction, Reykjavik, Iceland, 25-27 July 2012, 193, CRC Press.

Fonseca, C. M., \& Fleming, P. J. (1995). An overview of evolutionary algorithms in multiobjective optimization. Evolutionary computation, 3(1), 1-16.

Ghanmi, S., Guedri, M., Bouazizi, M. L., \& Bouhaddi, N. (2007). Use of metamodels in the multi-objective optimization of mechanical structures with uncertainties. International Journal for Computational Methods in Engineering Science and Mechanics, 8(5), 283-302. 
Goedkoop, M., Schryver, A. D., Oele, M., Durksz, S., \& de Roest, D. (2009). Introduction to LCA with SimaPro 7. Pré Consultants.

Gregorski, T. (2012). Zero Energy Research Lab opens at North Texas. Building Design \& Construction.

Gustavsson, L., \& Joelsson, A. (2010). Life cycle primary energy analysis of residential buildings. Energy and Buildings, 42(2), 210-220.

Haapio, A., \& Viitaniemi, P. (2008). A critical review of building environmental assessment tools. Environmental impact assessment review, 28(7), 469-482.

Hegazy, T. (1999). Optimization of construction time-cost trade-off analysis using genetic algorithms. Canadian Journal of Civil Engineering, 26(6), 685-697.

Hellmund, A. J., Van Den Wymelenberg, K. G., \& Baker, K. (2008). Facing the Challenges of Integrated Design and Project Delivery. Energy Engineering, 105(6), 3647.

Holland, J. H. (1975). Adaptation in natural and artificial systems: an introductory analysis with applications to biology, control, and artificial intelligence. U Michigan Press.

Inyim, P., Rivera, J., \& Zhu, Y. (2014). Integration of Building Information Modeling and Economic and Environmental Impact Analysis to Support Sustainable Building Design. Journal of Management in Engineering, 31(1), A4014002.

Inyim, P., \& Zhu, Y. (2013). A Simulation-based Approach For Selecting Sustainable building Designs. Proceedings from CIB W78 2013: $30^{\text {th }}$ International Conference, Beijing, China.

Inyim, P., \& Zhu, Y. (2013). A Framework for Integrated Analysis of Building Designs Using Life Cycle Assessment and Energy Simulation. Proceedings from The International Conference on Construction \& Real Estate Management. Karlsruhe, Germany, 316-327.

Inyim, P., \& Zhu, Y. (2014) Application of Monte Carlo Simulation and Optimization to Multiple Objectives Analysis of Sustainable Building Designs. Proceedings from Computing in Civil and Building Engineering, 2009-2016.

Inyim, P., \& Zhu, Y. (2014), Integration of Monte Carlo Simulation and Genetic Algorithms for Sustainable Designs Analysis. Proceedings from Construction Research Congress 2014, ASCE, VA, 699-708.

Jiang, A. \& Zhu, Y. (2010). A multi-stage approach for time-cost trade-off analysis using mathematical programming. International Journal of Construction Management, 10(3), 13-27. 
Jingran Ma, Qin, S. J., Bo Li, \& Salsbury, T. (2011). Economic model predictive control for building energy systems. Innovative Smart Grid Technologies (ISGT), 1-6.

Jun, D. H., \& El-Rayes, K. (2010). Optimizing the utilization of multiple labor shifts in construction projects. Automation in Construction, 19(2), 109-119.

Kämpf, J. H., Wetter, M., \& Robinson, D. (2010). A comparison of global optimization algorithms with standard benchmark functions and real-world applications using EnergyPlus. Journal of Building Performance Simulation, 3(2), 103-120.

Kasprowicz, T. (1994). Multi-objective optimization of construction schedules. Computing in Civil Engineering, 185-190, ASCE.

Kassab, M. S. M. (2008). Enhancing the energy-efficient design of office buildings using a based-simulation design support system. University of Calgary, Canada.

Khang, D. B., \& Myint, Y. M. (1999). Time, cost and quality trade-off in project management: a case study. International Journal of Project Management, 17(4), 249256.

Kuah, C. T., Wong, K. Y., \& Wong, W. P. (2012). Monte Carlo data envelopment analysis with genetic algorithm from knowledge management performance measurement. Expert Systems with Applications, 39(10), 9348-9358.

Lazo, J. G. L., Pacheco, M. A. C., Vellasco, M. M. B. R., \& Dias, M. A. (2003). Real option decision rules for oil field development under market uncertainty using genetic algorithms and Monte Carlo simulation. Proceedings from the 7th Annual International Conference on Real Options-Theory Meets Practice, Washington, D.C.

Leu, S., Chen, A., \& Yang, C. (2001). A GA-based fuzzy optimal model for construction time-cost trade-off. International Journal of Project Management, 19(1), 47-58.

Leu, S. S., Yang, C. H., \& Huang, J. C. (2000). Resource leveling in construction by genetic algorithm-based optimization and its decision support system application. Automation in construction, 10(1), 27-41.

Loh, E., Dawood, N., \& Dean, J. (2009). Development of RIBA sub-process to assist reduction of building life cycle impact: Integration of RIBA workstage with EU EIA Legislation and ISO14040, Proceedings from Building Simulation, 27th-30th July. University of Strathclyde, Glasgow, UK.

Lucko, G., \& Rojas, E. M. (2009). Research validation: Challenges and opportunities in the construction domain. Journal of construction engineering and management, 136(1), 127-135.

Magnier, L. (2008). Multiobjective optimization of building design using artificial neural network and multiobjective evolutionary algorithms. Concordia University, Canada. 
Marseguerra, M., \& Zio, E. (2000). Optimizing maintenance and repair policies via a combination of genetic algorithms and Monte Carlo simulation. Reliability Engineering \& System Safety, 68(1), 69-83.

Marseguerra, M., Zio, E., \& Podofillini, L. (2005). Multiobjective spare part allocation by means of genetic algorithms and Monte Carlo simulation. Reliability Engineering \& System Safety, 87(3), 325-335.

Marseguerra, M., Zio, E., \& Podofillini, L. (2002). Condition-based maintenance optimization by means of genetic algorithms and Monte Carlo simulation. Reliability Engineering \& System Safety, 77(2), 151-165.

Marzouk, M., Madany, M. Abou-Zied, \& El-Said, M. (2008). Handling construction pollutions using multi-objective optimization. Construction Management and Economics, 26(10), $1113-1125$.

MathWorks (2014). Beta Distribution, MathWorks ${ }^{\circledR}$, Retrieved Oct 10, 2014, from http://www.mathworks.com/help/stats/ beta-distribution.html.

Morel, J. C., Mesbah, A., Oggero, M., \& Walker, P. (2001). Building houses with local materials: means to drastically reduce the environmental impact of construction. Building and Environment, 36(10), 1119-1126.

Moselhi, O. (1993). Schedule compression using the direct stiffness method. Canadian Journal of Civil Engineering, 20(1), 65-72.

Mungle, S., Benyoucef, L., Son, Y., \& Tiwari, M. K. (2013). A fuzzy clustering-based genetic algorithm approach for time-cost-quality trade-off problems: A case study of highway construction project. Engineering Applications of Artificial Intelligence, 26(8), 1953-1966.

Nagelkerke, N. J. (1991). A note on a general definition of the coefficient of determination. Biometrika, 78(3), 691-692.

Nasir, D. D., McBabe, B., \& Hartono, L. (2003). Evaluating Risk in ConstructionSchedule Model (ERIC-S): Construction Schedule Risk Model. Journal of Construction Engineering and Management, 129(5), 518-527.

Ofori, G. (1992). The environment: the fourth construction project objective?. Construction Management and Economics, 10(5), 369-395.

Owen, C. E. B. (2008). Parameter estimation for the Beta distribution. Brigham Young University, Provo, UT.

Ozcan-Deniz, G., Zhu, Y., \& Ceron, V. (2011). Time, cost, and environmental impact analysis on construction operation optimization using genetic algorithms. Journal of Management in Engineering, 28(3), 265-272. 
Pachauri, R. K., \& Reisinger, A. (2007). Climate change 2007: synthesis report. Contribution of working groups I. II and III to the fourth assessment report of the intergovernmental panel on climate change, IPCC, Geneva, Switzerland, 104.

Peña-Mora, F., Ahn, C., Golparvar-Fard, M., Hajibabai, L., Shiftehfar, S., An, S., \& Aziz, Z. (2009). A Framework for Managing Emissions from Construction Processes. Proceedings from Int. Conf. \& Workshop on Sustainable Green Bldg. Design \& Construction, National Science Foundation.

Pluaski, M. H., Horman, M. J., \& Riley, D. R. (2006). Constructability Practices to Manage Sustainable Building Knowledge. Journal of Architectural Engineering, 12(2), 83-92.

Rahimi, M. \& Iranmanesh, H. (2008). Multi objective particle swarm optimization for a discrete time, cost and quality trade-off problem. Journal of World Applied Science, 4(2), 270-276.

Rajeev, S., \& Krishnamoorthy, C. S. (1997). Genetic algorithms-based methodologies for design optimization of trusses. Journal of Structural Engineering, 123(3), 350-358.

Ramesh, T., Prakash, R., \& Shukla, K. K. (2010). Life cycle energy analysis of buildings: An overview. Energy and Buildings, 42(10), 1592-1600.

Raphael, B. (2011). Multi-criteria decision making for collaborative design optimization of buildings. Built Environment Project and Asset Management, 1(2), 122-136.

Rebitzer, G., Ekvall, T., Frischknecht, R., Hunkeler, D., Norris, G., Rydberg, T., \& Pennington, D. W. (2004). Life cycle assessment: Part 1: Framework, goal and scope definition, inventory analysis, and applications. Environment International, 30(5), 701720 .

Ross, A. (2004). Procrustes analysis. Course Report, Department of Computer Science and Engineering, University of South Carolina, SC.

Rypdal, K. \& Winiwarter, W. (2001) Uncertainties in Greenhouse Gas Emission Inventories - Evaluation, Comparability and Implications. Proceedings from Environmental science \& Policy, 107-116.

Rypdal, K., \& Flugsrud, K. (2001). Sensitivity analysis as a tool for systematic reductions in greenhouse gas inventory uncertainties. Environmental Science \& Policy, 4(2), 117135.

Sargent, R. G. (2005). Verification and validation of simulation models. Proceedings from the $37^{\text {th }}$ conference on Winter Simulation, Winter Simulation Conference, 130-143. 
Schexnayder, C., Knutson, K., \& Fente, J. (2005). Describing a Beta Probability Distribution Function for Construction Simulation. Journal of Construction Engineering and Management, 131(2), 221-229.

Sclafani, A. (2010). Assessing the Impact of Climate Change on Long-term Energy savings with eQUEST. Energy Engineering, 107(4), 8-27.

Sonmez, R. (2005). Review of Conceptual Cost Modeling Techniques. AACE International Transactions, ES71-ES74.

Sonmez, R., \& Bettemir, Ö. H. (2012). A hybrid genetic algorithm for the discrete timecost trade-off problem. Expert Systems With Applications, 39(13), 11428-11434.

Spencer, J. S. (2010). Analysis of EnergyPlus for use in residential building energy optimization. University of Colorado at Boulder, United States, Colorado.

Thormark, C. (2006). The effect of material choice on the total energy need and recycling potential of a building. Building and Environment, 41(8), 1019-1026.

Thyholt, M., \& Hestnes, A. G. (2008). Heat supply to low-energy buildings in district heating areas: analyses of $\mathrm{CO}_{2}$ emissions and electricity supply security. Energy and Buildings, 40(2), 131-139.

Touran, A., \& Wiser, E. P. (1992). Monte Carlo technique with correlated random variables. Journal of Construction Engineering and Management, 118(2), 258-272.

Ürge-Vorsatz, D., Danny Harvey, L. D., Mirasgedis, S., \& Levine, M. D. (2007). Mitigating $\mathrm{CO}_{2}$ emissions from energy use in the world's buildings. Building Research \& Information, 35(4), 379-398.

USGBC (2008). Green building facts. U.S. Green Building Council. Retrieved September 1, 2012, from http://www.usgbc.org/articles/ green-building-fact.

Van der Veken, J., Saelens, D., Verbeeck, G., \& Hens, H. (2004). Comparison of steadystate and dynamic building energy simulation programs. Proceedings from the Conference Performance of Exterior Envelopes of Whole Buildings IX, ASHRAE, Atlanta, GA.

Wang, H., \& Ohmori, H. (2010). Truss optimization using genetic algorithm, considering construction process. International Journal of Space Structures, 25(4), 205-215.

Wang, K. C., Nguyen, V., \& Zaniewski, J. P. (2007). Genetic algorithms-based network optimization system with multiple objectives. Transportation Research Record: Journal of the Transportation Research Board, 2016(1), 85-96.

Wang, L., Gwilliam, J., \& Jones, P. (2009). Case study of zero energy house design in UK. Energy and Buildings, 41(11), 1215-1222. 
Wang, L., Shen, W., Xie, H., Neelamkavil, J., \& Pardasani, A. (2002). Collaborative conceptual design - state of the art and future trends. Computer-Aided Design, 34(13), 981-996.

Winiwarter, W., \& Rypdal, K. (2001). Assessing the uncertainty associated with national greenhouse gas emission inventories: a case study for Austria. Atmospheric environment, $35(32), 5425-5440$.

Yu, J., Yang, C., \& Tian, L. (2008). Low-energy envelope design of residential building in hot summer and cold winter zone in China. Energy and Buildings, 40(8), 1536-1546.

Zhu, Y. (2006). Applying computer-based simulation to energy auditing: A case study. Energy and Buildings, 38(5), 421-428.

Zhu, Y., Inyim, P., \& Rivera, J. (2012). SimulEICon: A Multi-objective Decision-support Tool for Sustainable Construction. Proceedings from International Conference on Construction \& Real Estate Management, China Architecture \& Building Press, Kansas City, MO, 134-138. 
APPENDICES 
Appendix A: Flow Chart of SimulEICon 


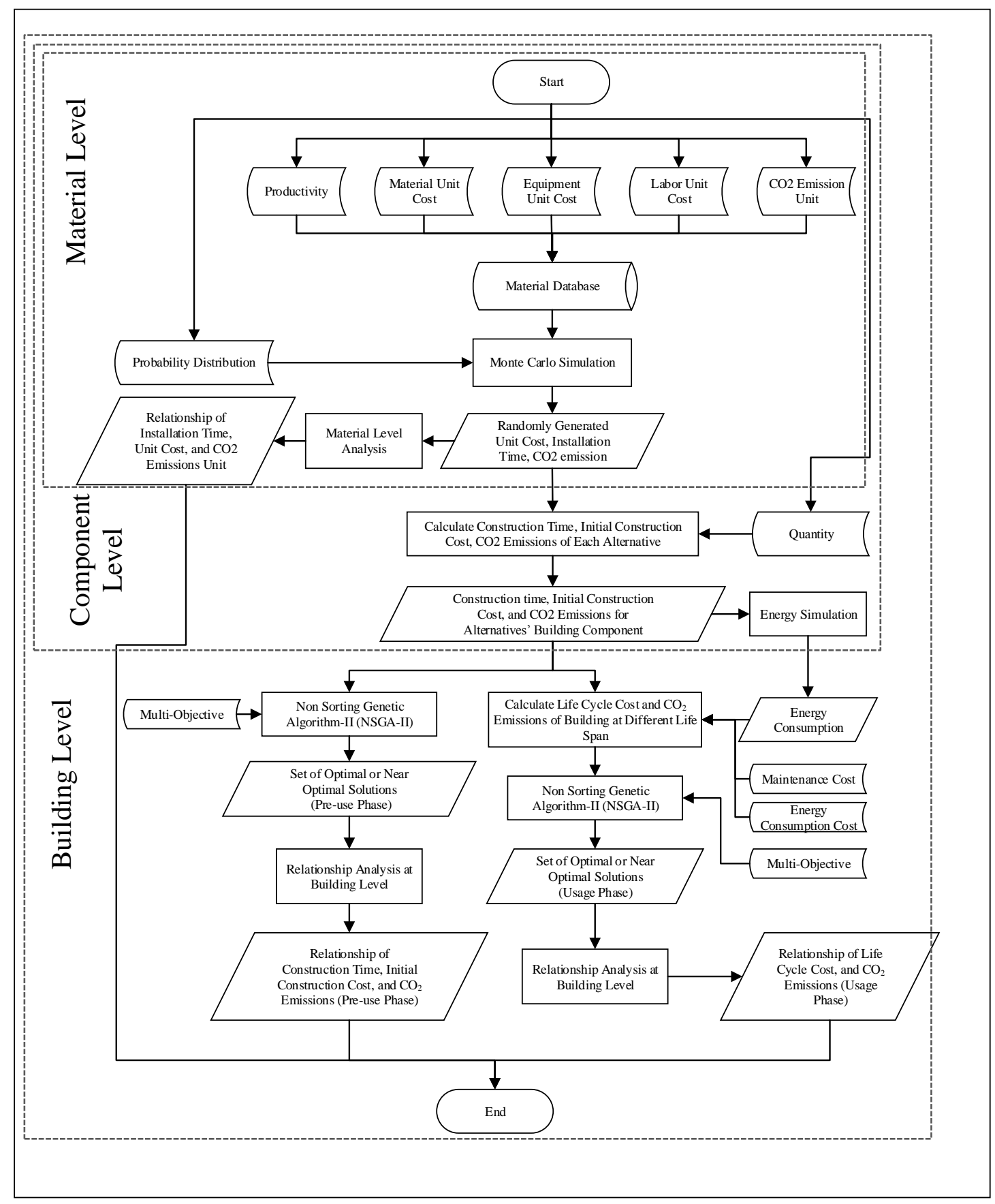

Simulation of Environmental Impact of Construction Framework 
Appendix B: Data Collection Form 


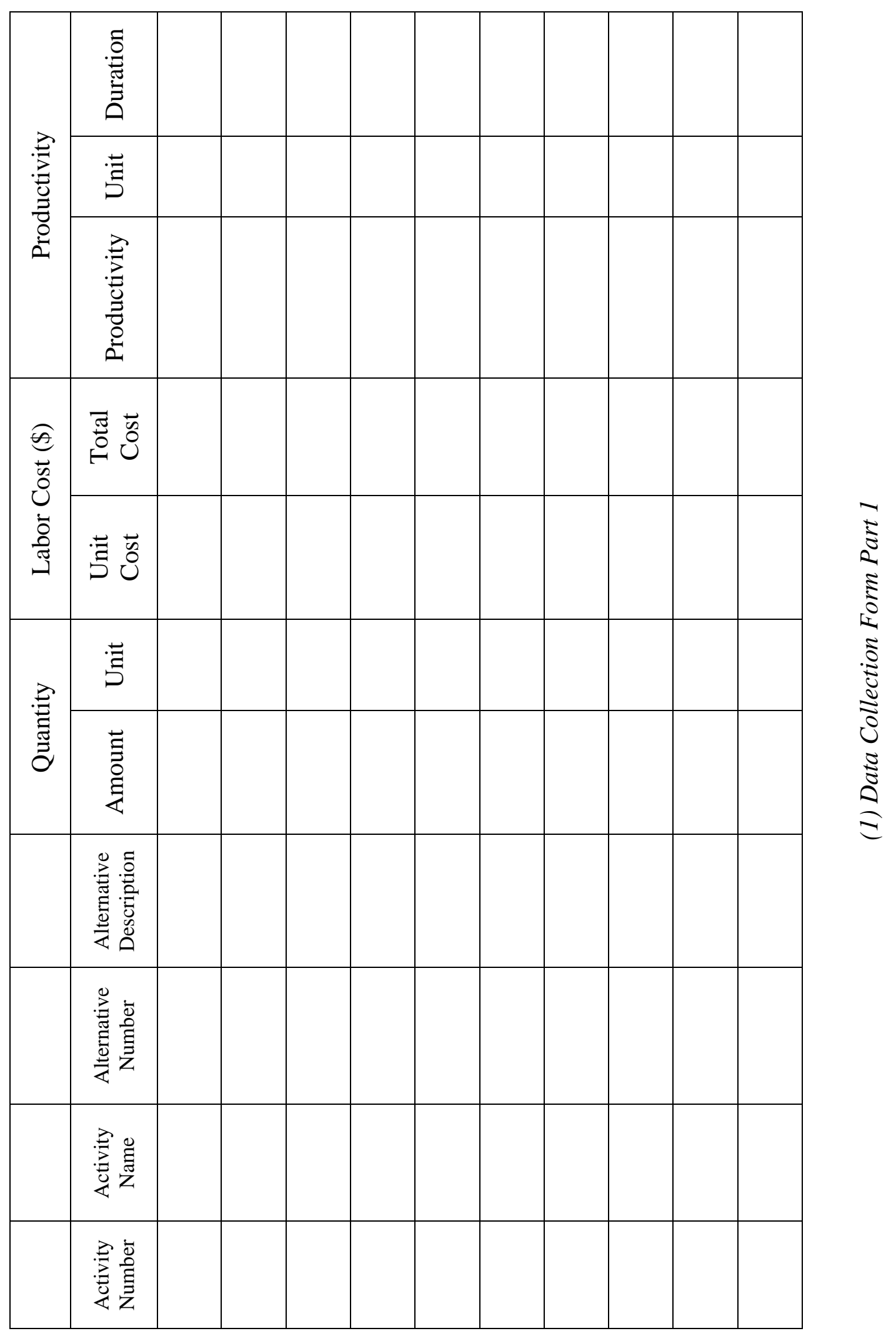




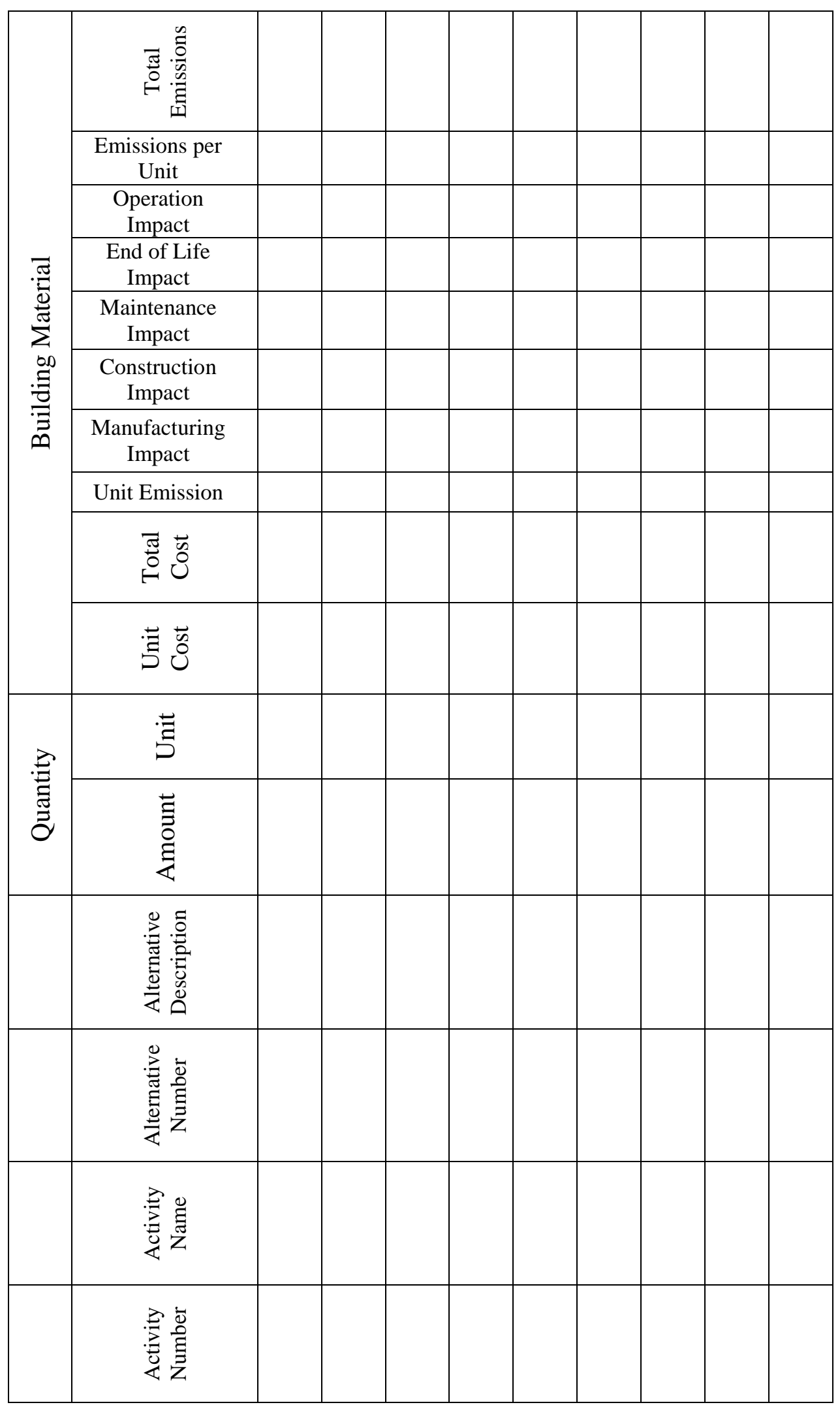

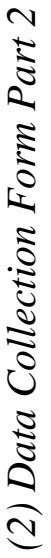




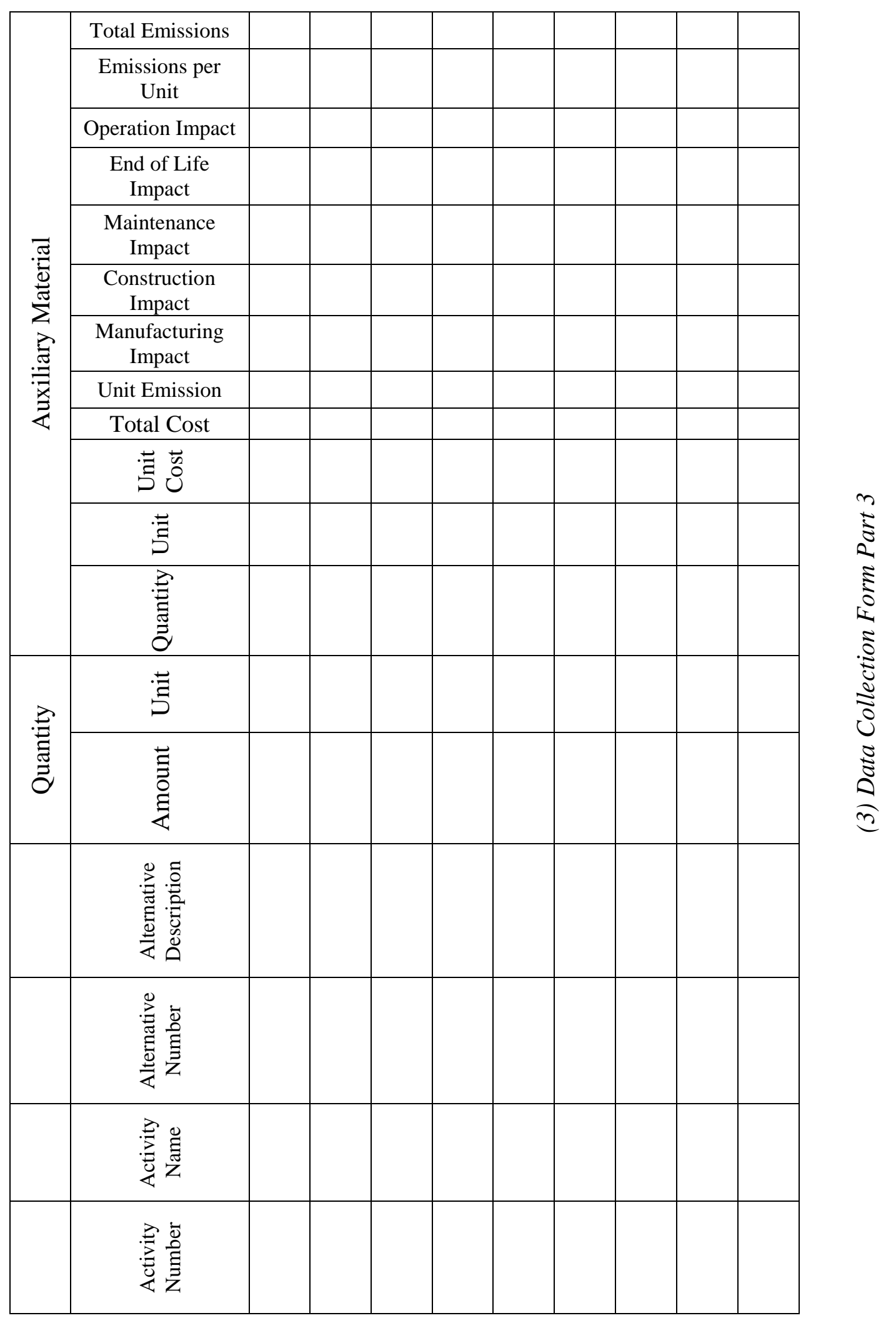




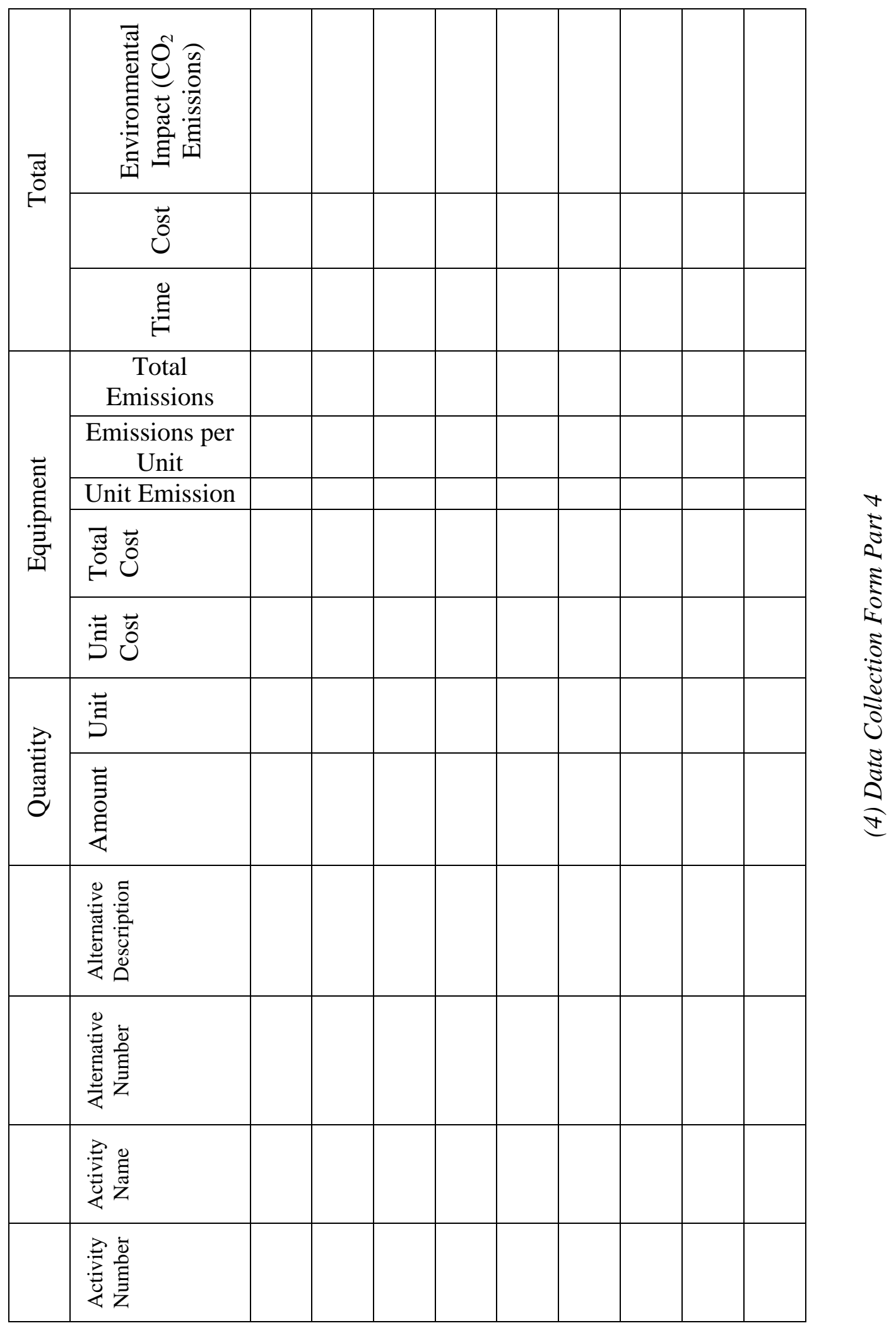


Appendix C: Case Studies Activates and Alternatives 
Case Study 1: The Zero Net Energy Laboratory

\begin{tabular}{|c|c|c|c|}
\hline $\begin{array}{l}\text { Activity } \\
\text { Number }\end{array}$ & Activity Name & $\begin{array}{l}\text { Alternative } \\
\text { Number }\end{array}$ & Alternative Description \\
\hline 1 & Start & 1 & Start \\
\hline \multirow[t]{3}{*}{2} & Site Clearing & & $\begin{array}{l}\text { Cut \& chip trees to } 12 " \text { diam, } \\
\text { Grading for small area }\end{array}$ \\
\hline & & 2 & $\begin{array}{l}\text { Cut } \& \text { chip trees to } 12 " \text { diam, grub } \\
\text { stumps and remove } \\
\text { Grading for small area }\end{array}$ \\
\hline & & 3 & No tree, Grading for small area \\
\hline \multirow[t]{3}{*}{3} & Excavation & 1 & Excavation using $3 / 8 \mathrm{CY}$ excavator \\
\hline & & 2 & Excavation using $1 / 2 \mathrm{CY}$ excavator \\
\hline & & 3 & Manual excavation \\
\hline \multirow[t]{8}{*}{4} & $\begin{array}{l}\text { Footing } \\
\text { Construction }\end{array}$ & 1 & $\begin{array}{l}3000 \text { psi, average flyash, pumped } \\
\text { Reinforcing in Place, footings }\end{array}$ \\
\hline & & 2 & $3000 \mathrm{psi}, 25 \%$ flyash, pumped \\
\hline & & & Reinforcing in Place, footings \\
\hline & & 3 & 3000 psi, 30\% flyash, pumped \\
\hline & & & Reinforcing in Place, footings \\
\hline & & 4 & $\begin{array}{l}3000 \text { psi, average flyash, direct chute } \\
\text { Reinforcing in Place, footings }\end{array}$ \\
\hline & & 5 & $\begin{array}{l}3000 \mathrm{psi}, 25 \% \text { flyash, direct chute } \\
\text { Reinforcing in Place, footings }\end{array}$ \\
\hline & & 6 & $\begin{array}{l}3000 \text { psi, } 30 \% \text { flyash, direct chute } \\
\text { Reinforcing in Place, footings }\end{array}$ \\
\hline \multirow[t]{7}{*}{5} & Stem Wall & 1 & $\begin{array}{l}3000 \mathrm{psi} \text {, average flyash, pumped } \\
\text { Reinforcing in Place walls }\end{array}$ \\
\hline & & 2 & $3000 \mathrm{psi}, 25 \%$ flyash, pumped \\
\hline & & & Reinforcing in Place, walls \\
\hline & & 3 & $\begin{array}{l}3000 \mathrm{psi}, 30 \% \text { flyash, pumped } \\
\text { Reinforcing in Place, walls }\end{array}$ \\
\hline & & 4 & $\begin{array}{l}3000 \text { psi, average flyash, direct chute } \\
\text { Reinforcing in Place, walls }\end{array}$ \\
\hline & & 5 & $\begin{array}{l}3000 \text { psi , } 25 \% \text { flyash, direct chute } \\
\text { Reinforcing in Place, walls }\end{array}$ \\
\hline & & 6 & $\begin{array}{l}3000 \mathrm{psi}, 30 \% \text { flyash, direct chute } \\
\text { Reinforcing in Place, walls }\end{array}$ \\
\hline \multirow[t]{2}{*}{6} & Subgrade & 1 & Blown Cellulose Board \\
\hline & Insulation & 2 & Batt Rockwool \\
\hline
\end{tabular}




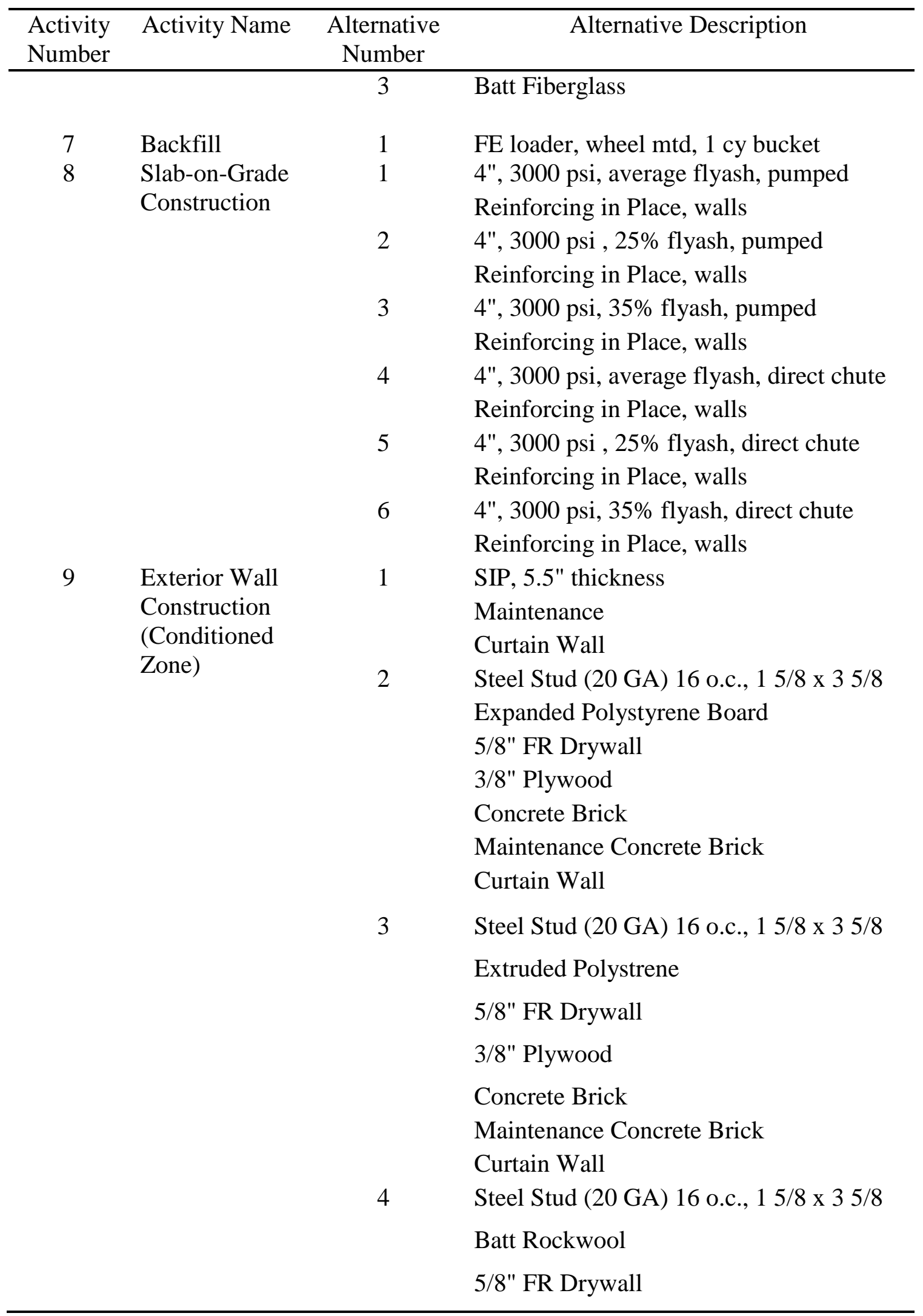




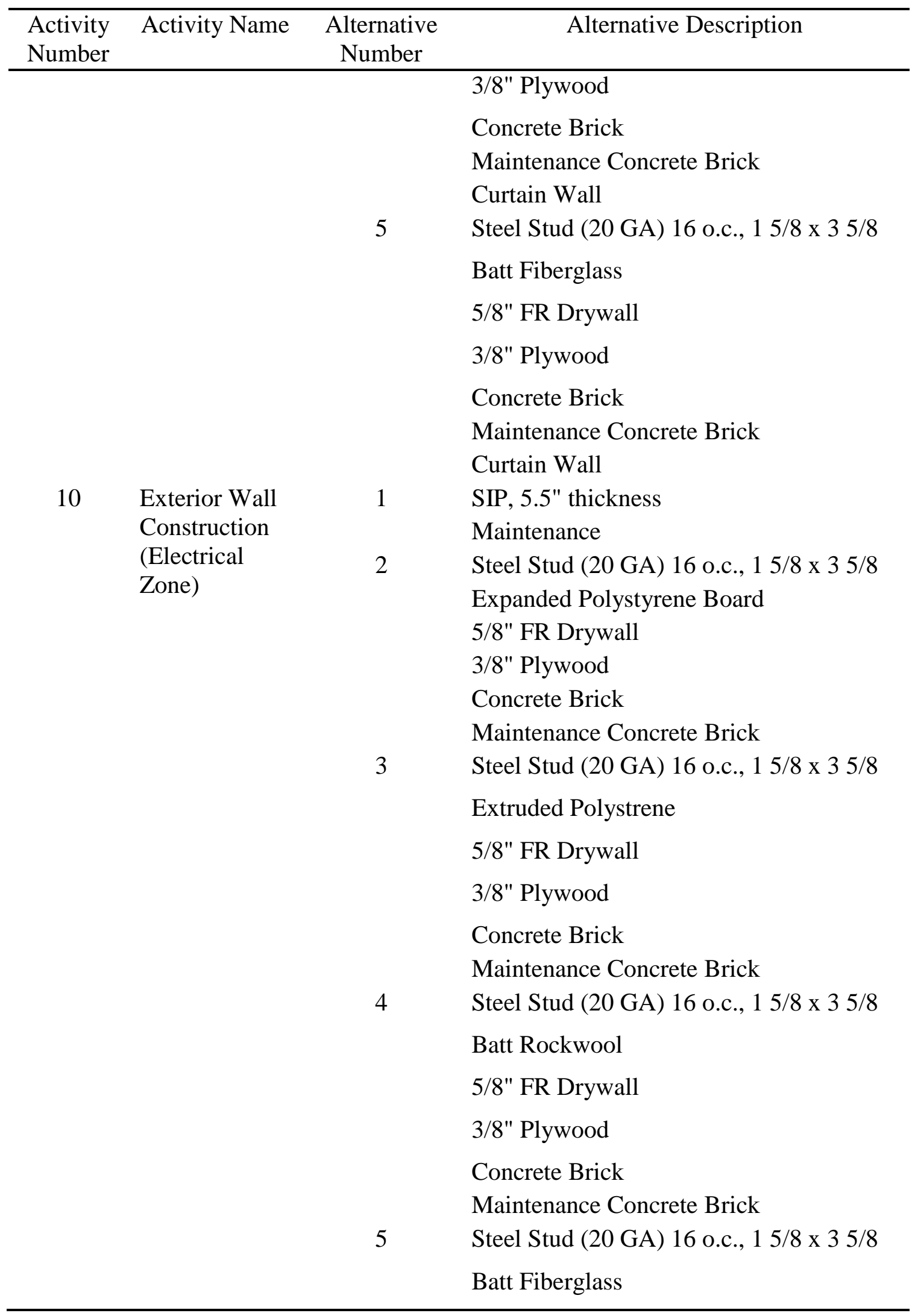




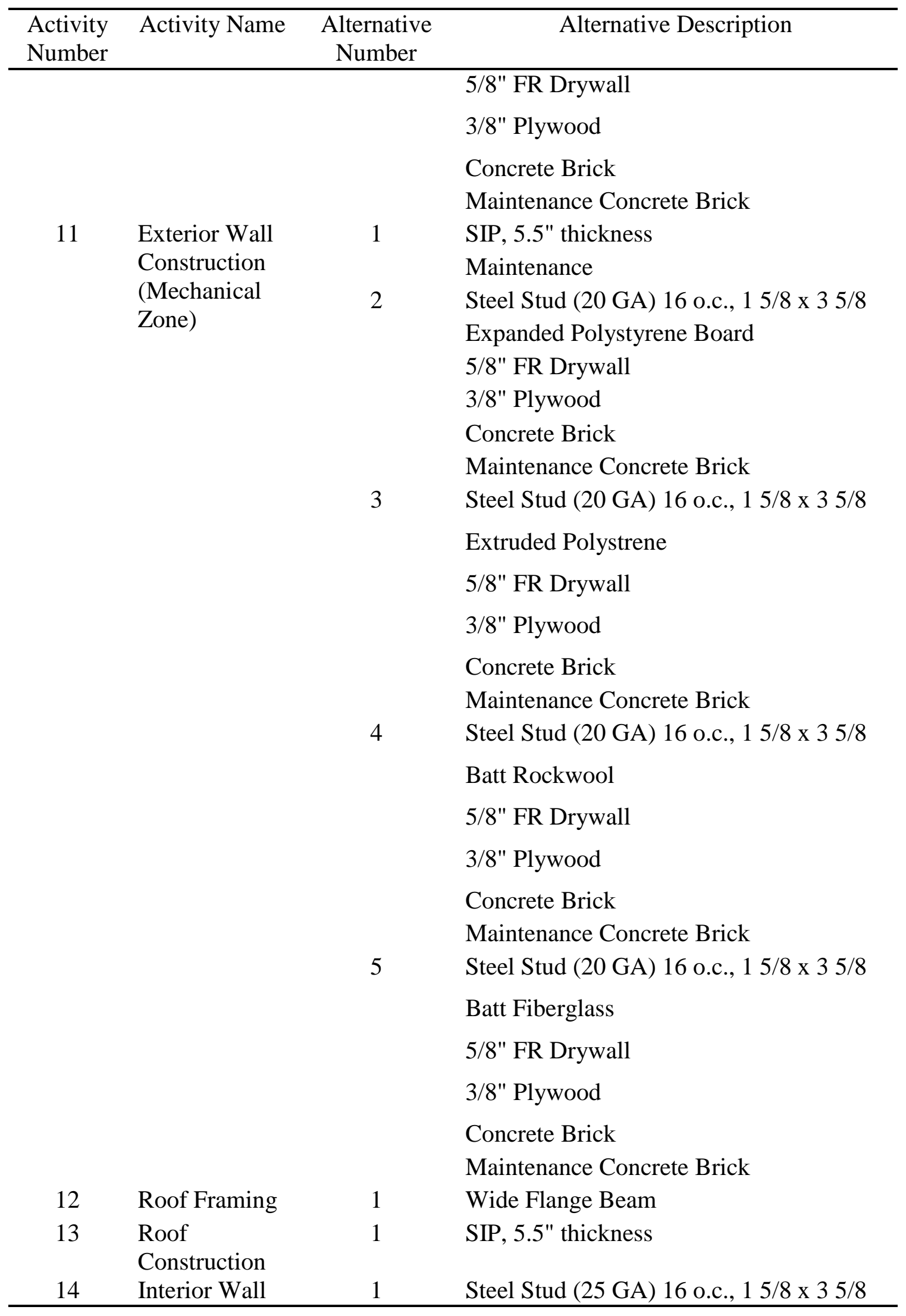




\begin{tabular}{|c|c|c|c|}
\hline $\begin{array}{l}\text { Activity } \\
\text { Number }\end{array}$ & Activity Name & $\begin{array}{l}\text { Alternative } \\
\text { Number }\end{array}$ & Alternative Description \\
\hline \multirow{15}{*}{15} & \multirow{2}{*}{\multicolumn{2}{|c|}{ Construction }} & Fiberglass Insulation \\
\hline & & & 5/8" FR Drywall \\
\hline & \multirow[t]{13}{*}{ Roofing } & \multirow[t]{3}{*}{1} & Clay tiles \\
\hline & & & Maintenance Inspection Yearly \\
\hline & & & Minor Repair \\
\hline & & \multirow[t]{3}{*}{2} & Concrete tiles \\
\hline & & & Maintenance Inspection Yearly \\
\hline & & & Minor Repair \\
\hline & & \multirow[t]{4}{*}{3} & Organic felt shingles $30 \mathrm{yr}$ \\
\hline & & & Maintenance Inspection Yearly \\
\hline & & & Minor Repair \\
\hline & & & Install New Over Old \\
\hline & & \multirow[t]{3}{*}{4} & Steel Roof Panel 30 GA (Residential) \\
\hline & & & Maintenance Inspection Yearly \\
\hline & & & Minor Repair \\
\hline \multirow[t]{2}{*}{16} & \multirow[t]{2}{*}{ Flooring } & 1 & Bamboo flooring \\
\hline & & 2 & Wood flooring \\
\hline 17 & Finish & 1 & Finish \\
\hline
\end{tabular}

Case Study 2: The Future House Project USA

\begin{tabular}{|c|c|c|c|}
\hline $\begin{array}{l}\text { Activity } \\
\text { Number }\end{array}$ & Activity Name & $\begin{array}{c}\text { Alternative } \\
\text { Number }\end{array}$ & Alternative Description \\
\hline 1 & Start & 1 & Start \\
\hline \multirow[t]{4}{*}{2} & Site Clearing & 1 & $\begin{array}{l}\text { Cut \& chip trees to } 12 " \text { diam, } \\
\text { Grading for small area }\end{array}$ \\
\hline & & 2 & $\begin{array}{l}\text { Cut \& chip trees to } 12 " \text { diam, grub } \\
\text { stumps and remove }\end{array}$ \\
\hline & & 2 & Grading for small area \\
\hline & & 3 & No tree, Grading for small area \\
\hline \multirow[t]{2}{*}{3} & Excavation & $\begin{array}{l}1 \\
2\end{array}$ & $\begin{array}{l}\text { Excavation using } 3 / 8 \mathrm{CY} \text { excavator } \\
\text { Excavation using } 1 / 2 \mathrm{CY} \text { excavator }\end{array}$ \\
\hline & & 3 & Manual excavation \\
\hline \multirow[t]{2}{*}{4} & $\begin{array}{l}\text { Footing } \\
\text { Construction }\end{array}$ & 1 & $\begin{array}{l}3000 \text { psi, average flyash, pumped } \\
\text { Reinforcing in Place, footings }\end{array}$ \\
\hline & & 2 & $\begin{array}{l}3000 \mathrm{psi}, 25 \% \text { flyash, pumped } \\
\text { Reinforcing in Place, footings }\end{array}$ \\
\hline
\end{tabular}




\begin{tabular}{|c|c|c|c|}
\hline $\begin{array}{l}\text { Activity } \\
\text { Number }\end{array}$ & Activity Name & $\begin{array}{c}\text { Alternative } \\
\text { Number }\end{array}$ & Alternative Description \\
\hline & & 3 & 3000 psi, $30 \%$ flyash, pumped \\
\hline & & & Reinforcing in Place, footings \\
\hline & & 4 & 3000 psi, average flyash, direct chute \\
\hline & & & Reinforcing in Place, footings \\
\hline & & 5 & 3000 psi , $25 \%$ flyash, direct chute \\
\hline & & & Reinforcing in Place, footings \\
\hline & & 6 & 3000 psi, $30 \%$ flyash, direct chute \\
\hline & & & Reinforcing in Place, footings \\
\hline \multirow[t]{12}{*}{5} & Stem Wall & 1 & 3000 psi, average flyash, pumped \\
\hline & Construction & & Reinforcing in Place, walls \\
\hline & & 2 & 3000 psi , 25\% flyash, pumped \\
\hline & & & Reinforcing in Place, walls \\
\hline & & 3 & 3000 psi, $30 \%$ flyash, pumped \\
\hline & & & Reinforcing in Place, walls \\
\hline & & 4 & 3000 psi, average flyash, direct chute \\
\hline & & & Reinforcing in Place, walls \\
\hline & & 5 & 3000 psi , $25 \%$ flyash, direct chute \\
\hline & & & Reinforcing in Place, walls \\
\hline & & 6 & 3000 psi, $30 \%$ flyash, direct chute \\
\hline & & & Reinforcing in Place, walls \\
\hline \multirow[t]{4}{*}{6} & Subgrade & 1 & Expanded Polystyrene Board \\
\hline & Insulation & 2 & Extruded Polystyrene Board \\
\hline & & 3 & Foam Polyisocyanurate Board \\
\hline & & 4 & Blown Cellulose Board \\
\hline 7 & Backfill & 1 & FE loader, wheel mtd, 1 cy bucket \\
\hline \multirow[t]{11}{*}{8} & Slab-on-Grade & & 4", 3000 psi, average flyash, pumped \\
\hline & & & Reinforcing in Place, walls \\
\hline & & 2 & 4", 3000 psi , $25 \%$ flyash, pumped \\
\hline & & & Reinforcing in Place, walls \\
\hline & & 3 & 4", 3000 psi, 35\% flyash, pumped \\
\hline & & & Reinforcing in Place, walls \\
\hline & & 4 & 4", 3000 psi, average flyash, direct chute \\
\hline & & & Reinforcing in Place, walls \\
\hline & & 5 & 4", 3000 psi , $25 \%$ flyash, direct chute \\
\hline & & & Reinforcing in Place, walls \\
\hline & & 6 & 4", 3000 psi, $35 \%$ flyash, direct chute \\
\hline
\end{tabular}




\begin{tabular}{|c|c|c|c|}
\hline $\begin{array}{l}\text { Activity } \\
\text { Number }\end{array}$ & Activity Name & $\begin{array}{l}\text { Alternative } \\
\text { Number }\end{array}$ & Alternative Description \\
\hline \multirow{13}{*}{9} & \multirow{13}{*}{$\begin{array}{l}\text { Exterior Wall } \\
\text { Construction }\end{array}$} & 7 & $\begin{array}{l}\text { Reinforcing in Place, walls } \\
8 ", 3000 \text { psi, average flyash }\end{array}$ \\
\hline & & 8 & $\begin{array}{l}8 ", 3000 \text { psi , } 25 \% \text { flyash } \\
\text { Reinforcing in Place, walls }\end{array}$ \\
\hline & & 9 & $8 ", 3000 \mathrm{psi}, 35 \%$ flyash \\
\hline & & 10 & $\begin{array}{l}\text { Reinforcing in Place, walls } \\
\text { 8", } 3000 \text { psi, average flyash } \\
\text { Reinforcing in Place, walls }\end{array}$ \\
\hline & & 11 & $\begin{array}{l}8 ", 3000 \mathrm{psi}, 25 \% \text { flyash } \\
\text { Reinforcino in Place walls }\end{array}$ \\
\hline & & 12 & $\begin{array}{l}8 ", 3000 \text { psi, } 35 \% \text { flyash } \\
\text { Reinforcing in Place, walls }\end{array}$ \\
\hline & & 1 & SIP, 5.5" thickness \\
\hline & & 2 & $\begin{array}{l}\text { Wood Stud Kiln Dired } 16 \text { o.c., } 2 \times 4 \\
\text { Expanded Polystyrene Board } \\
\text { 1/2" Regular Drywall } \\
\text { 3/8" Plywood }\end{array}$ \\
\hline & & 3 & $\begin{array}{l}\text { Wood Stud Kiln Dired } 16 \text { o.c., } 2 \times 4 \\
\text { Expanded Polystyrene Board } \\
\text { 5/8" Regular Drywall } \\
\text { 3/8" Plywood }\end{array}$ \\
\hline & & 4 & $\begin{array}{l}\text { Wood Stud Kiln Dired } 16 \text { o.c., } 2 \times 4 \\
\text { Expanded Polystyrene Board } \\
\text { 1/2" FR Drywall } \\
\text { 3/8" Plywood }\end{array}$ \\
\hline & & 5 & $\begin{array}{l}\text { Wood Stud Kiln Dired } 16 \text { o.c., } 2 \times 4 \\
\text { Expanded Polystyrene Board } \\
\text { 5/8" FR Drywall } \\
\text { 3/8" Plywood }\end{array}$ \\
\hline & & 6 & $\begin{array}{l}\text { Wood Stud Kiln Dired } 16 \text { o.c., } 2 \times 4 \\
\text { Expanded Polystyrene Board } \\
\text { 1/2" WR Drywall } \\
\text { 3/8" Plywood }\end{array}$ \\
\hline & & 7 & $\begin{array}{l}\text { Wood Stud Kiln Dired } 16 \text { o.c., } 2 \times 4 \\
\text { Expanded Polystyrene Board } \\
\text { 5/8" WR Drywall }\end{array}$ \\
\hline
\end{tabular}




\begin{tabular}{|c|c|c|c|}
\hline $\begin{array}{l}\text { Activity } \\
\text { Number }\end{array}$ & Activity Name & $\begin{array}{c}\text { Alternative } \\
\text { Number }\end{array}$ & Alternative Description \\
\hline & & \multirow{5}{*}{8} & 3/8" Plywood \\
\hline & & & Wood Stud Kiln Dired 16 o.c., $2 \times 4$ \\
\hline & & & Extruded Polystyrene Board \\
\hline & & & 1/2" Regular Drywall \\
\hline & & & 3/8" Plywood \\
\hline & & \multirow[t]{4}{*}{9} & Wood Stud Kiln Dired 16 o.c., $2 \times 4$ \\
\hline & & & Extruded Polystyrene Board \\
\hline & & & 5/8" Regular Drywall \\
\hline & & & 3/8" Plywood \\
\hline & & \multirow[t]{4}{*}{10} & Wood Stud Kiln Dired 16 o.c., $2 \times 4$ \\
\hline & & & Extruded Polystyrene Board \\
\hline & & & 1/2" FR Drywall \\
\hline & & & 3/8" Plywood \\
\hline & & \multirow[t]{4}{*}{11} & Wood Stud Kiln Dired 16 o.c., $2 \times 4$ \\
\hline & & & Extruded Polystyrene Board \\
\hline & & & 5/8" FR Drywall \\
\hline & & & 3/8" Plywood \\
\hline & & \multirow[t]{4}{*}{12} & Wood Stud Kiln Dired 16 o.c., $2 \times 4$ \\
\hline & & & Extruded Polystyrene Board \\
\hline & & & 1/2" WR Drywall \\
\hline & & & 3/8" Plywood \\
\hline & & \multirow[t]{4}{*}{13} & Wood Stud Kiln Dired 16 o.c., $2 \times 4$ \\
\hline & & & Extruded Polystyrene Board \\
\hline & & & 5/8" WR Drywall \\
\hline & & & 3/8" Plywood \\
\hline & & \multirow[t]{4}{*}{14} & Wood Stud Kiln Dired 16 o.c., $2 \times 4$ \\
\hline & & & Batt Rockwool \\
\hline & & & 1/2" Regular Drywall \\
\hline & & & 3/8" Plywood \\
\hline & & \multirow[t]{4}{*}{15} & Wood Stud Kiln Dired 16 o.c., $2 \times 4$ \\
\hline & & & Batt Rockwool \\
\hline & & & 5/8" Regular Drywall \\
\hline & & & 3/8" Plywood \\
\hline & & \multirow[t]{4}{*}{16} & Wood Stud Kiln Dired 16 o.c., $2 \times 4$ \\
\hline & & & Batt Rockwool \\
\hline & & & 1/2" FR Drywall \\
\hline & & & 3/8" Plywood \\
\hline
\end{tabular}




\begin{tabular}{|c|c|c|c|}
\hline $\begin{array}{l}\text { Activity } \\
\text { Number }\end{array}$ & Activity Name & $\begin{array}{c}\text { Alternative } \\
\text { Number }\end{array}$ & Alternative Description \\
\hline & & 17 & Wood Stud Kiln Dired 16 o.c., 2 x4 \\
\hline & & & Batt Rockwool \\
\hline & & & 5/8" FR Drywall \\
\hline & & & 3/8" Plywood \\
\hline & & 18 & Wood Stud Kiln Dired 16 o.c., $2 \times 4$ \\
\hline & & & Batt Rockwool \\
\hline & & & 1/2" WR Drywall \\
\hline & & & 3/8" Plywood \\
\hline & & 19 & Wood Stud Kiln Dired 16 o.c., $2 \times 4$ \\
\hline & & & Batt Roackwool \\
\hline & & & 5/8" WR Drywall \\
\hline & & & 3/8" Plywood \\
\hline & & 20 & Wood Stud Kiln Dired 16 o.c., $2 \times 4$ \\
\hline & & & Batt Fiberglass \\
\hline & & & 1/2" Regular Drywall \\
\hline & & & 3/8" Plywood \\
\hline & & 21 & Wood Stud Kiln Dired 16 o.c., 2 x 4 \\
\hline & & & Batt Fiberglass \\
\hline & & & 5/8" Regular Drywall \\
\hline & & & 3/8" Plywood \\
\hline & & 22 & Wood Stud Kiln Dired 16 o.c., 2 x 4 \\
\hline & & & Batt Fiberglass \\
\hline & & & 1/2" FR Drywall \\
\hline & & & 3/8" Plywood \\
\hline & & 23 & Wood Stud Kiln Dired 16 o.c., $2 \times 4$ \\
\hline & & & Batt Fiberglass \\
\hline & & 23 & 5/8" FR Drywall \\
\hline & & & 3/8" Plywood \\
\hline & & 24 & Wood Stud Kiln Dired 16 o.c., 2 x 4 \\
\hline & & & Batt Fiberglass \\
\hline & & & 1/2" WR Drywall \\
\hline & & & 3/8" Plywood \\
\hline & & 25 & Wood Stud Kiln Dired 16 o.c., 2x4 \\
\hline & & & Batt Fiberglass \\
\hline & & & 5/8" WR Drywall \\
\hline & & & 3/8" Plywood \\
\hline & & 26 & Steel Stud (20 GA) 16 o.c., 1 5/8 x 3 5/8 \\
\hline
\end{tabular}




\begin{tabular}{|c|c|c|c|}
\hline $\begin{array}{l}\text { Activity } \\
\text { Number }\end{array}$ & Activity Name & $\begin{array}{c}\text { Alternative } \\
\text { Number }\end{array}$ & Alternative Description \\
\hline & & & Expanded Polystyrene Board \\
\hline & & & 1/2" Regular Drywall \\
\hline & & & 3/8" Plywood \\
\hline & & 27 & Steel Stud (20 GA) 16 o.c., 1 5/8 x 3 5/8 \\
\hline & & & Expanded Polystyrene Board \\
\hline & & & 5/8" Regular Drywall \\
\hline & & & 3/8" Plywood \\
\hline & & 28 & Steel Stud (20 GA) 16 o.c., $15 / 8$ × $35 / 8$ \\
\hline & & & Expanded Polystyrene Board \\
\hline & & & 1/2" FR Drywall \\
\hline & & & 3/8" Plywood \\
\hline & & 29 & Steel Stud (20 GA) 16 o.c., 1 5/8 x 3 5/8 \\
\hline & & & Expanded Polystyrene Board \\
\hline & & & 5/8" FR Drywall \\
\hline & & & 3/8" Plywood \\
\hline & & 30 & Steel Stud (20 GA) 16 o.c., 1 5/8 x 3 5/8 \\
\hline & & & Expanded Polystyrene Board \\
\hline & & & 1/2" WR Drywall \\
\hline & & & 3/8" Plywood \\
\hline & & 31 & Steel Stud (20 GA) 16 o.c., 1 5/8 × 3 5/8 \\
\hline & & & Expanded Polystyrene Board \\
\hline & & & 5/8" WR Drywall \\
\hline & & & 3/8" Plywood \\
\hline & & 32 & Steel Stud (20 GA) 16 o.c., $15 / 8$ x 3 5/8 \\
\hline & & & Extruded Polystrene \\
\hline & & & 1/2" Regular Drywall \\
\hline & & & 3/8" Plywood \\
\hline & & 33 & Steel Stud (20 GA) 16 o.c., 1 5/8 x 3 5/8 \\
\hline & & & Extruded Polystrene \\
\hline & & & 5/8" Regular Drywall \\
\hline & & & 3/8" Plywood \\
\hline & & 34 & Steel Stud (20 GA) 16 o.c., 1 5/8 x 3 5/8 \\
\hline & & & Extruded Polystrene \\
\hline & & & 1/2" FR Drywall \\
\hline
\end{tabular}




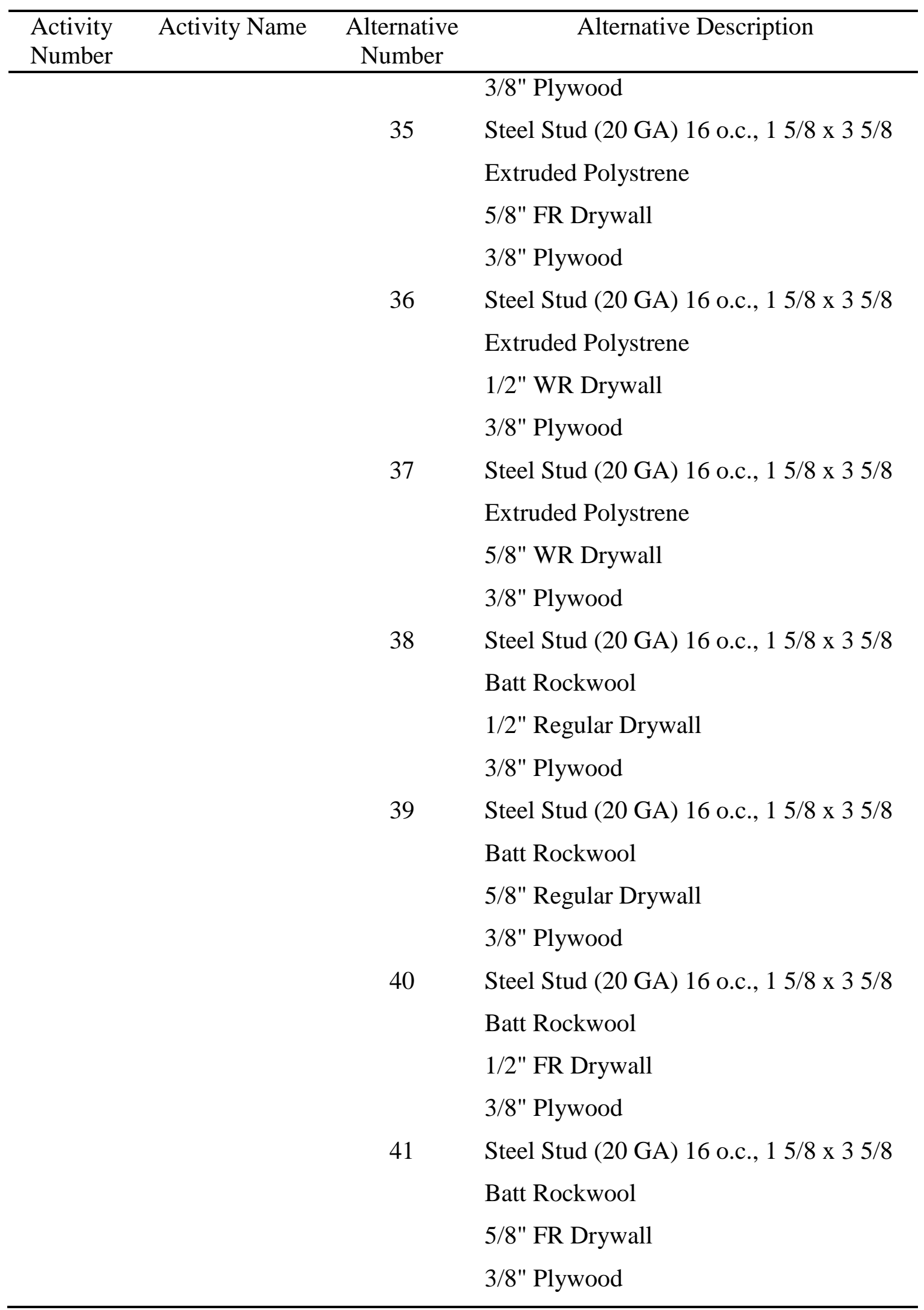




\begin{tabular}{|c|c|c|c|}
\hline $\begin{array}{l}\text { Activity } \\
\text { Number }\end{array}$ & Activity Name & $\begin{array}{l}\text { Alternative } \\
\text { Number }\end{array}$ & Alternative Description \\
\hline & & \multirow[t]{4}{*}{42} & Steel Stud (20 GA) 16 o.c., $15 / 8$ × 3 5/8 \\
\hline & & & Batt Rockwool \\
\hline & & & 1/2" WR Drywall \\
\hline & & & 3/8" Plywood \\
\hline & & \multirow[t]{4}{*}{43} & Steel Stud (20 GA) 16 o.c., $15 / 8$ × $35 / 8$ \\
\hline & & & Batt Rockwool \\
\hline & & & 5/8" WR Drywall \\
\hline & & & 3/8" Plywood \\
\hline & & \multirow[t]{4}{*}{44} & Steel Stud (20 GA) 16 o.c., $15 / 8$ × $35 / 8$ \\
\hline & & & Batt Fiberglass \\
\hline & & & 1/2" Regular Drywall \\
\hline & & & 3/8" Plywood \\
\hline & & \multirow[t]{4}{*}{45} & Steel Stud (20 GA) 16 o.c., $15 / 8$ × $35 / 8$ \\
\hline & & & Batt Fiberglass \\
\hline & & & 5/8" Regular Drywall \\
\hline & & & 3/8" Plywood \\
\hline & & \multirow[t]{4}{*}{46} & Steel Stud (20 GA) 16 o.c., $15 / 8$ x $35 / 8$ \\
\hline & & & Batt Fiberglass \\
\hline & & & 1/2" FR Drywall \\
\hline & & & 3/8" Plywood \\
\hline & & \multirow[t]{4}{*}{47} & Steel Stud (20 GA) 16 o.c., $15 / 8$ x $35 / 8$ \\
\hline & & & Batt Fiberglass \\
\hline & & & 5/8" FR Drywall \\
\hline & & & 3/8" Plywood \\
\hline & & \multirow[t]{4}{*}{48} & Steel Stud (20 GA) 16 o.c., $15 / 8$ x $35 / 8$ \\
\hline & & & Batt Fiberglass \\
\hline & & & 1/2" WR Drywall \\
\hline & & & 3/8" Plywood \\
\hline & & 49 & Steel Stud (20 GA) 16 o.c., $15 / 8$ × 3 5/8 \\
\hline
\end{tabular}




\begin{tabular}{|c|c|c|c|}
\hline $\begin{array}{l}\text { Activity } \\
\text { Number }\end{array}$ & Activity Name & $\begin{array}{c}\text { Alternative } \\
\text { Number }\end{array}$ & Alternative Description \\
\hline & & & Batt Fiberglass \\
\hline & & & 5/8" WR Drywall \\
\hline & & & 3/8" Plywood \\
\hline 10 & Roof Truss & 1 & $\begin{array}{l}\text { Light Frame Wood Truss Roof, span } 24 \text { ' } \\
\text { to } 29 \text { ', Light Frame Wood Truss Roof, } \\
\text { span 30' to 33' }\end{array}$ \\
\hline \multirow[t]{21}{*}{11} & Roof & 1 & SIP, 5.5" thickness \\
\hline & Construction & 2 & Glass fiber batt (Deck) \\
\hline & & & 3/8" Plywood (Deck) \\
\hline & & & Glass fiber batt (Truss) \\
\hline & & & 3/8" Plywood (Truss) \\
\hline & & 3 & Expanded Polystyrene Board (Deck) \\
\hline & & & 3/8" Plywood (Deck) \\
\hline & & & Expanded Polystyrene Board (Truss) \\
\hline & & & 3/8" Plywood (Truss) \\
\hline & & 4 & Extruded Polystyrene Board (Deck) \\
\hline & & & 3/8" Plywood (Deck) \\
\hline & & & Extruded Polystyrene Board (Truss) \\
\hline & & & 3/8" Plywood (Truss) \\
\hline & & 5 & Foam Polyisocyamurate Board (Deck) \\
\hline & & & 3/8" Plywood (Deck) \\
\hline & & & Foam Polyisocyamurate Board (Truss) \\
\hline & & & 3/8" Plywood (Truss) \\
\hline & & 6 & Blown Cellulose Board (Deck) \\
\hline & & & 3/8" Plywood (Deck) \\
\hline & & & Blown Cellulose Board (Truss) \\
\hline & & & 3/8" Plywood (Truss) \\
\hline \multirow[t]{8}{*}{12} & Interior Wall & 1 & Wood Stud Kiln Dired 16 o.c., $2 \times 4$ \\
\hline & Construction & & $\begin{array}{l}\text { Expanded Polystyrene Board (1" } \\
\text { thickness) }\end{array}$ \\
\hline & & & 1/2" Regular Drywall \\
\hline & & 2 & Wood Stud Kiln Dired 16 o.c., $2 \times 4$ \\
\hline & & & $\begin{array}{l}\text { Expanded Polystyrene Board (1" } \\
\text { thickness) }\end{array}$ \\
\hline & & & 5/8" Regular Drywall \\
\hline & & 3 & Wood Stud Kiln Dired 16 o.c., $2 \times 4$ \\
\hline & & & Expanded Polystyrene Board (1" \\
\hline
\end{tabular}




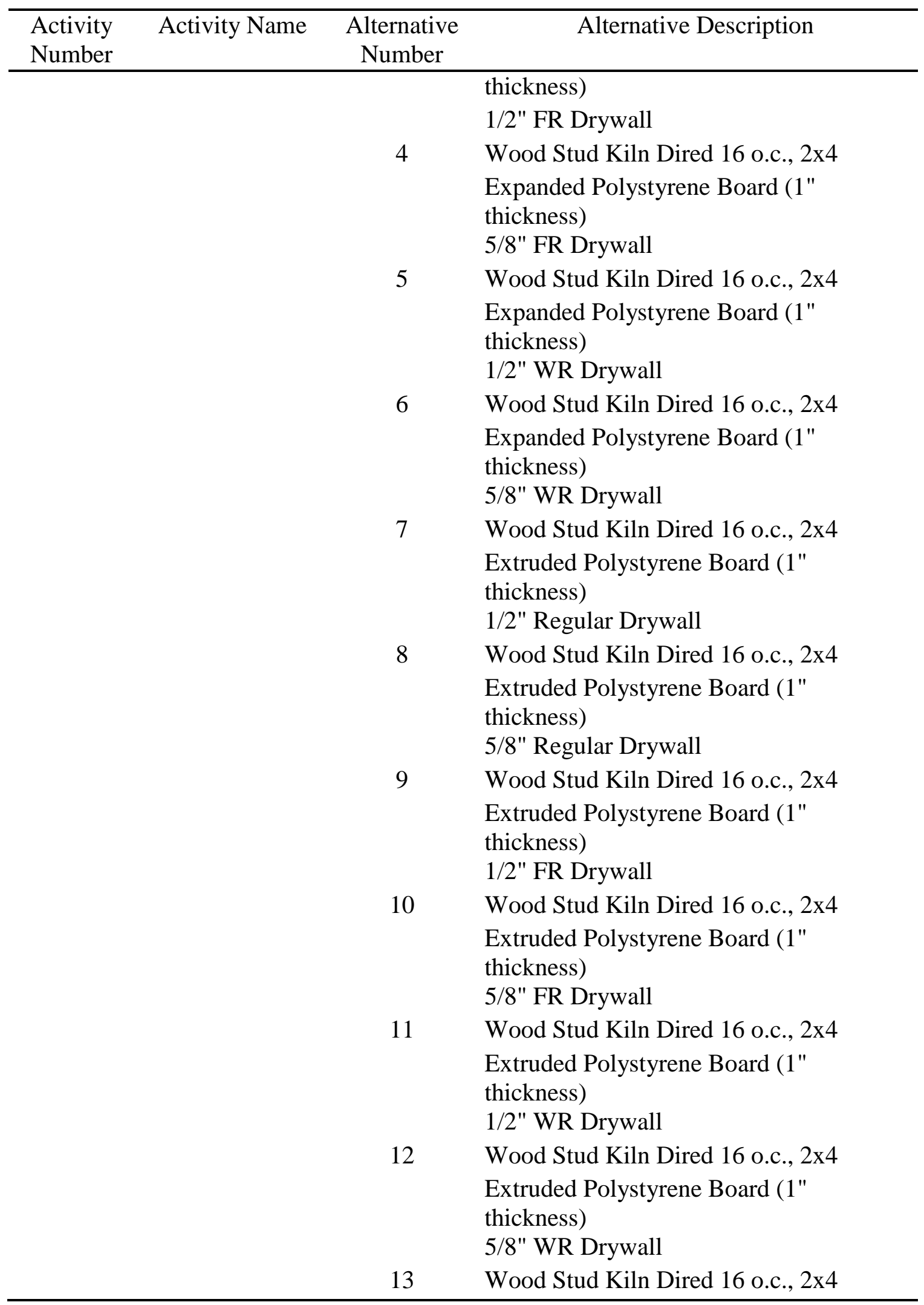




\begin{tabular}{|c|c|c|c|}
\hline \multirow[t]{38}{*}{$\begin{array}{l}\text { Activity } \\
\text { Number }\end{array}$} & Activity Name & $\begin{array}{c}\text { Alternative } \\
\text { Number }\end{array}$ & Alternative Description \\
\hline & & & Batt Rockwool (1" thickness) \\
\hline & & & 1/2" Regular Drywall \\
\hline & & 14 & Wood Stud Kiln Dired 16 o.c., $2 \times 4$ \\
\hline & & & Batt Rockwool (1" thickness) \\
\hline & & & 5/8" Regular Drywall \\
\hline & & 15 & Wood Stud Kiln Dired 16 o.c., $2 \times 4$ \\
\hline & & & Batt Rockwool (1" thickness) \\
\hline & & & 1/2" FR Drywall \\
\hline & & 16 & Wood Stud Kiln Dired 16 o.c., $2 \times 4$ \\
\hline & & & Batt Rockwool (1" thickness) \\
\hline & & & 5/8" FR Drywall \\
\hline & & 17 & Wood Stud Kiln Dired 16 o.c., $2 \times 4$ \\
\hline & & & Batt Rockwool (1" thickness) \\
\hline & & & 1/2" WR Drywall \\
\hline & & 18 & Wood Stud Kiln Dired 16 o.c., $2 \times 4$ \\
\hline & & & Batt Rockwool (1" thickness) \\
\hline & & & 5/8" WR Drywall \\
\hline & & 19 & Wood Stud Kiln Dired 16 o.c., $2 \times 4$ \\
\hline & & & Batt fiberglass (1" thickness) \\
\hline & & & 1/2" Regular Drywall \\
\hline & & 20 & Wood Stud Kiln Dired 16 o.c., $2 \times 4$ \\
\hline & & & Batt fiberglass (1" thickness) \\
\hline & & & 5/8" Regular Drywall \\
\hline & & 21 & Wood Stud Kiln Dired 16 o.c., $2 \times 4$ \\
\hline & & & Batt fiberglass (1" thickness) \\
\hline & & & 1/2" FR Drywall \\
\hline & & 22 & Wood Stud Kiln Dired 16 o.c., 2x4 \\
\hline & & & Batt fiberglass (1" thickness) \\
\hline & & & 5/8" FR Drywall \\
\hline & & 23 & Wood Stud Kiln Dired 16 o.c., $2 \times 4$ \\
\hline & & & Batt fiberglass (1" thickness) \\
\hline & & & 1/2" WR Drywall \\
\hline & & 24 & Wood Stud Kiln Dired 16 o.c., $2 \times 4$ \\
\hline & & & Batt fiberglass (1" thickness) \\
\hline & & & 5/8" WR Drywall \\
\hline & & 25 & Steel Stud (25 GA) 16 o.c., $15 / 8$ x 3 5/8 \\
\hline & & & Expanded Polystyrene Board (1" \\
\hline
\end{tabular}




\begin{tabular}{|c|c|c|c|}
\hline $\begin{array}{l}\text { Activity } \\
\text { Number }\end{array}$ & Activity Name & $\begin{array}{c}\text { Alternative } \\
\text { Number }\end{array}$ & Alternative Description \\
\hline & & \multirow{5}{*}{26} & thickness) \\
\hline & & & 1/2" Regular Drywall \\
\hline & & & Steel Stud (25 GA) 16 o.c., $15 / 8 \times 35 / 8$ \\
\hline & & & $\begin{array}{l}\text { Expanded Polystyrene Board (1" } \\
\text { thickness) }\end{array}$ \\
\hline & & & 5/8" Regular Drywall \\
\hline & & \multirow[t]{2}{*}{27} & Steel Stud (25 GA) 16 o.c., $15 / 8$ × $35 / 8$ \\
\hline & & & $\begin{array}{l}\text { Expanded Polystyrene Board (1" } \\
\text { thickness) } \\
1 / 2 \text { " FR Drywall }\end{array}$ \\
\hline & & \multirow[t]{3}{*}{28} & Steel Stud (25 GA) 16 o.c., $15 / 8 \times 35 / 8$ \\
\hline & & & $\begin{array}{l}\text { Expanded Polystyrene Board (1" } \\
\text { thickness) }\end{array}$ \\
\hline & & & 5/8" FR Drywall \\
\hline & & \multirow[t]{3}{*}{29} & Steel Stud (25 GA) 16 o.c., $15 / 8 \times 35 / 8$ \\
\hline & & & $\begin{array}{l}\text { Expanded Polystyrene Board (1" } \\
\text { thickness) }\end{array}$ \\
\hline & & & 1/2" WR Drywall \\
\hline & & \multirow[t]{3}{*}{30} & Steel Stud (25 GA) 16 o.c., $15 / 8 \times 35 / 8$ \\
\hline & & & $\begin{array}{l}\text { Expanded Polystyrene Board (1" } \\
\text { thickness) }\end{array}$ \\
\hline & & & 5/8" WR Drywall \\
\hline & & \multirow[t]{2}{*}{31} & Steel Stud (25 GA) 16 o.c., $15 / 8 \times 35 / 8$ \\
\hline & & & $\begin{array}{l}\text { Extruded Polystyrene Board (1" } \\
\text { thickness) } \\
1 / 2 \text { " Regular Drywall }\end{array}$ \\
\hline & & \multirow[t]{3}{*}{32} & Steel Stud (25 GA) 16 o.c., $15 / 8 \times 35 / 8$ \\
\hline & & & $\begin{array}{l}\text { Extruded Polystyrene Board (1" } \\
\text { thickness) }\end{array}$ \\
\hline & & & 5/8" Regular Drywall \\
\hline & & \multirow[t]{3}{*}{33} & Steel Stud (25 GA) 16 o.c., $15 / 8$ x $35 / 8$ \\
\hline & & & $\begin{array}{l}\text { Extruded Polystyrene Board (1" } \\
\text { thickness) }\end{array}$ \\
\hline & & & 1/2" FR Drywall \\
\hline & & \multirow[t]{3}{*}{34} & Steel Stud (25 GA) 16 o.c., $15 / 8 \times 35 / 8$ \\
\hline & & & $\begin{array}{l}\text { Extruded Polystyrene Board (1" } \\
\text { thickness) }\end{array}$ \\
\hline & & & 5/8" FR Drywall \\
\hline & & 35 & Steel Stud (25 GA) 16 o.c., $15 / 8$ × $35 / 8$ \\
\hline
\end{tabular}




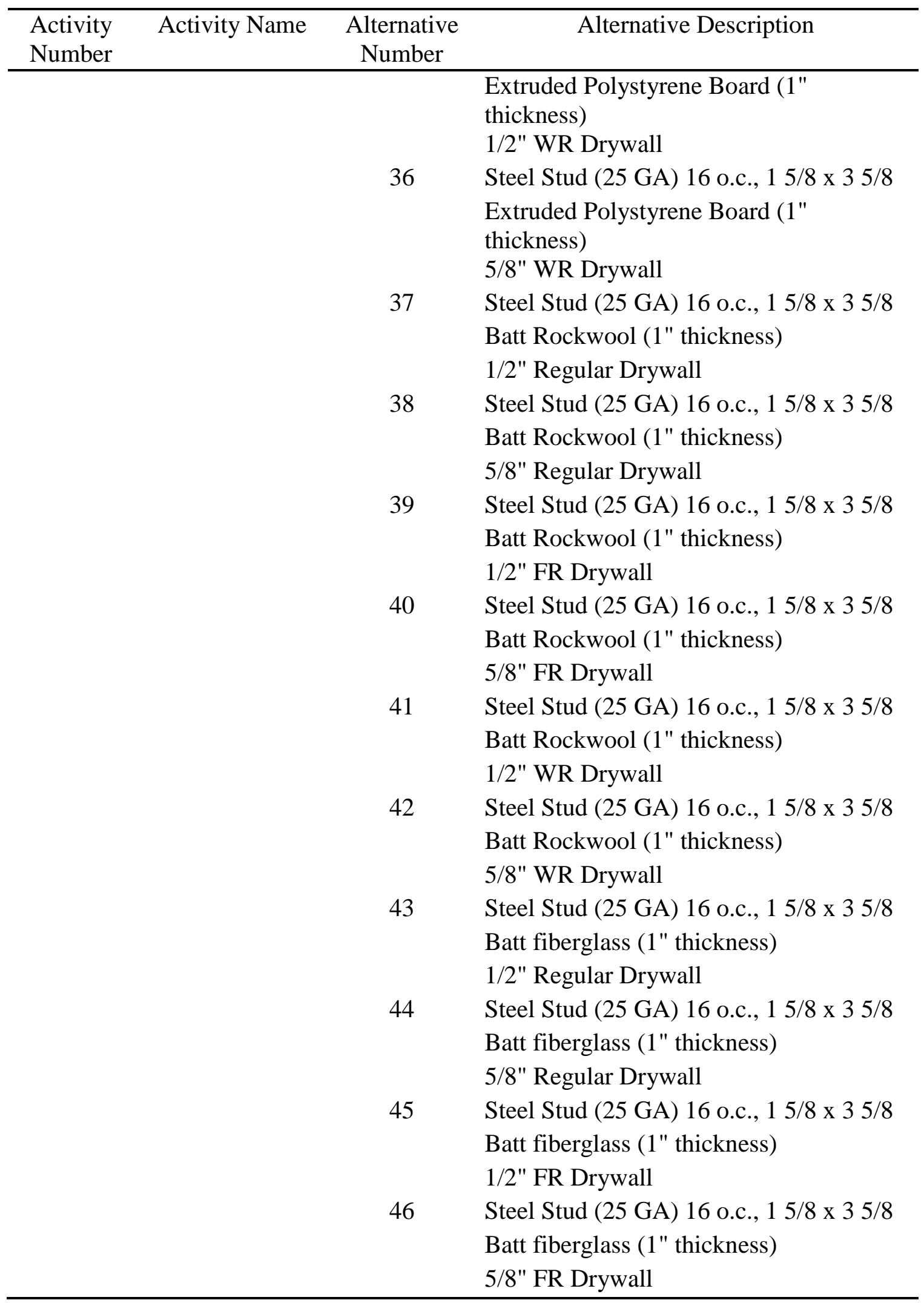




\begin{tabular}{|c|c|c|c|}
\hline $\begin{array}{l}\text { Activity } \\
\text { Number }\end{array}$ & Activity Name & $\begin{array}{c}\text { Alternative } \\
\text { Number }\end{array}$ & Alternative Description \\
\hline & & 47 & Steel Stud (25 GA) 16 o.c., $15 / 8$ × $35 / 8$ \\
\hline & & & Batt fiberglass (1" thickness) \\
\hline & & & 1/2" WR Drywall \\
\hline & & 48 & Steel Stud (25 GA) 16 o.c., $15 / 8$ × $35 / 8$ \\
\hline & & & Batt fiberglass (1" thickness) \\
\hline & & & 5/8" WR Drywall \\
\hline & & 49 & $\begin{array}{l}\text { Steel Stud ( } 25 \text { GA) } 16 \text { o.c., } 15 / 8 \text { x } 3 \text { 5/8 } \\
\text { 5/8" FR Drywall }\end{array}$ \\
\hline & & 50 & $\begin{array}{l}\text { Wood Stud Kiln Dired } 16 \text { o.c., } 2 \times 4 \\
\text { 1/2" Regular Drywall }\end{array}$ \\
\hline & & 51 & $\begin{array}{l}\text { Wood Stud Kiln Dired } 16 \text { o.c., } 2 \times 4 \\
5 / 8 " \text { Regular Drywall }\end{array}$ \\
\hline & & 52 & $\begin{array}{l}\text { Wood Stud Kiln Dired } 16 \text { o.c., } 2 \times 4 \\
\text { 1/2" FR Drywall }\end{array}$ \\
\hline & & 53 & $\begin{array}{l}\text { Wood Stud Kiln Dired } 16 \text { o.c., } 2 \times 4 \\
\text { 5/8" FR Drywall }\end{array}$ \\
\hline & & 54 & $\begin{array}{l}\text { Wood Stud Kiln Dired } 16 \text { o.c., } 2 \times 4 \\
\text { 1/2" WR Drywall }\end{array}$ \\
\hline & & 55 & $\begin{array}{l}\text { Wood Stud Kiln Dired } 16 \text { o.c., } 2 \times 4 \\
5 / 8 \text { " WR Drywall }\end{array}$ \\
\hline & & 56 & $\begin{array}{l}\text { Steel Stud (25 GA) } 16 \text { o.c., } 15 / 8 \text { x } 35 / 8 \\
1 / 2 \text { " Regular Drywall }\end{array}$ \\
\hline & & 57 & $\begin{array}{l}\text { Steel Stud (25 GA) } 16 \text { o.c., } 15 / 8 \text { x } 35 / 8 \\
5 / 8 \text { " Regular Drywall }\end{array}$ \\
\hline & & 58 & $\begin{array}{l}\text { Steel Stud (25 GA) } 16 \text { o.c., } 15 / 8 \text { x } 35 / 8 \\
1 / 2 \text { " FR Drywall }\end{array}$ \\
\hline & & 59 & $\begin{array}{l}\text { Steel Stud ( } 25 \text { GA) } 16 \text { o.c., } 15 / 8 \text { x } 35 / 8 \\
5 / 8 \text { " FR Drywall }\end{array}$ \\
\hline & & 60 & $\begin{array}{l}\text { Steel Stud (25 GA) } 16 \text { o.c., } 15 / 8 \text { x } 35 / 8 \\
1 / 2 \text { " WR Drywall }\end{array}$ \\
\hline & & 61 & $\begin{array}{l}\text { Steel Stud (25 GA) } 16 \text { o.c., } 15 / 8 \text { x } 35 / 8 \\
5 / 8 \text { " WR Drywall }\end{array}$ \\
\hline & & 62 & $\begin{array}{l}\text { Steel Stud (25 GA) } 16 \text { o.c., } 15 / 8 \text { x } 35 / 8 \\
5 / 8 " \text { FR Drywall }\end{array}$ \\
\hline \multirow[t]{3}{*}{13} & Roofing & 1 & Clay tiles \\
\hline & & 2 & Concrete tiles \\
\hline & & 3 & Organic felt shingles $20 \mathrm{yr}$ \\
\hline
\end{tabular}




\begin{tabular}{clcl}
\hline $\begin{array}{c}\text { Activity } \\
\text { Number }\end{array}$ & Activity Name & $\begin{array}{c}\text { Alternative } \\
\text { Number }\end{array}$ & \multicolumn{1}{c}{ Alternative Description } \\
\hline & & 4 & Organic felt shingles 25yr \\
& & 5 & Organic felt shingles 30yr \\
\multirow{3}{*}{14} & Flooring & 1 & Steel Roof Panel 30 GA (Residential) \\
& & 2 & Bamboo flooring \\
15 & Exterior Siding & 1 & Cood flooring \\
& & 2 & Metric Modular Brick \\
& & 3 & Cedar beval, 1/2, 6" \\
& & 4 & Stucco \\
& & 5 & Vinyl \\
& & 6 & Fiber Cement \\
& & 7 & Stucco (Top), Natural Stone (Bottom) \\
& & 8 & Stucco (Top), Concrete Brick (Bottom) \\
& & 1 & Finish \\
\hline
\end{tabular}


Appendix D: Partial Base IDF File 
!-Generator IDFEditor 1.43

!-Option OriginalOrderTop UseSpecialFormat

!-NOTE: All comments with '!-' are ignored by the IDFEditor and are generated automatically.

!-Use '!' comments if they need to be retained when using the IDFEditor.

Version,7.2;

SimulationControl,

$\begin{array}{ll}\begin{array}{l}\text { No, } \\ \text { No, }\end{array} & \text { !- Do Zone Sizing Calculation } \\ \text { No, } & \text { !- Do System Sizing Calculation } \\ \text { No, } & \text { !- Ro Plant Sizing Calculation } \\ \text { Yes; } & \text { !- Run Simulation for Sizing Periods } \\ & \\ \text { Building, } & \\ \text { UNT, } & \text { !- Name } \\ 0.0, & \text { !- North Axis }\{\mathrm{deg}\} \\ \text { City, } & \text { !- Terrain } \\ 0.04, & \text { !- Loads Convergence Tolerance Value } \\ 0.4, & \text { !- Temperature Convergence Tolerance Value } \\ \text { deltaC }\} & \text { !- Solar Distribution } \\ \text { MinimalShadowing, } \\ 25, & \text { !- Maximum Number of Warmup Days } \\ ; & \text { !- Minimum Number of Warmup Days }\end{array}$

SurfaceConvectionAlgorithm:Inside,TARP;

SurfaceConvectionAlgorithm:Outside,DOE-2;

HeatBalanceAlgorithm,ConductionTransferFunction,200,0.1,1000;

ZoneAirHeatBalanceAlgorithm,ThirdOrderBackwardDifference;

Timestep,4;

ConvergenceLimits,

$\begin{array}{ll}20, & \text { !- Minimum System Timestep }\{\text { minutes } \\ 2, & \text { !- Maximum HVAC Iterations } \\ 8 ; & \text { !- Minimum Plant Iterations } \\ & \text { !- Maximum Plant Iterations }\end{array}$

Site:Location, DFW,

32.9, !- Latitude $\{\mathrm{deg}\}$

-97.04, !- Longitude $\{\mathrm{deg}$

$-6.0, \quad$ !- Time Zone $\{\mathrm{hr}\}$

182; $\quad$ - Elevation $\{\mathrm{m}\}$

SizingPeriod:DesignDay,

Dallas Fort Worth Intl Ap Ann Htg 99\% Condns DB, !- Name

1, !- Month

21, !- Day of Month

WinterDesignDay, !- Day Type

-6.5, !- Maximum Dry-Bulb Temperature $\{\mathrm{C}\}$

$0, \quad$ !- Daily Dry-Bulb Temperature Range $\{$ deltaC

!- Dry-Bulb Temperature Range Modifier Type

!- Dry-Bulb Temperature Range Modifier

Schedule Name

WetBulb, !- Humidity Condition Type

-6.5, !- Wetbulb or DewPoint at Maximum Dry-Bulb

$\{\mathrm{C}\}$

!- Humidity Condition Day Schedule Name

, !- Humidity Ratio at Maximum Dry-Bulb

$\{\mathrm{kgWater} / \mathrm{kgDryAir}\}$

!- Enthalpy at Maximum Dry-Bulb $\{\mathrm{J} / \mathrm{kg}\}$

, $\quad$ !- Daily Wet-Bulb Temperature Range $\{$ deltaC $\}$

99158, !- Barometric Pressure $\{\mathrm{Pa}\}$

5.9, !- Wind Speed $\{\mathrm{m} / \mathrm{s}\}$

340; $\quad$ !- Wind Direction $\{$ deg $\}$

RunPeriod,

$\begin{array}{ll}\text { Period, } & \text { !- Name } \\ 10, & \text { !- Begin Month } \\ 28, & \text { !- Begin Day of Month } \\ 10, & \text { !- End Month }\end{array}$

$$
\begin{array}{ll}
27, & \text { !- End Day of Month } \\
\text { UseWeatherFile, } \quad \text { !- Day of Week for Start Day } \\
\begin{array}{ll}
\text { No, } & \text { !- Use Weather File Holidays and Special Days } \\
\text { Yes, } & \text { !- Use Weather File Daylight Saving Period } \\
\text { No, } & \text { !- Apply Weekend Holiday Rule } \\
\text { Yes, } & \text { !- Use Weather File Rain Indicators } \\
\text { Yes, } & \text { !- Use Weather File Snow Indicators } \\
\text { 1; } & \text { !- Number of Times Runperiod to be Repeated }
\end{array}
\end{array}
$$

RunPeriodControl:SpecialDays,

New Years Day, !- Name

January 1, !- Start Date

1, !- Duration \{days

Holiday; !- Special Day Type

RunPeriodControl:SpecialDays,

Veterans Day, !- Name

November 11, !- Start Date

1, !- Duration \{days

Holiday; !- Special Day Type

RunPeriodControl:SpecialDays,

Christmas, !- Name

December 25, !- Start Date

$1, \quad$ !- Duration \{days

Holiday; !- Special Day Type

RunPeriodControl:SpecialDays,

Independence Day, !- Name

July 4, !- Start Date

1, !- Duration \{days

Holiday; !- Special Day Type

RunPeriodControl:SpecialDays, MLK Day, !- Name 3rd Monday in January, !- Start Date

1, !- Duration \{days

Holiday; !- Special Day Type

RunPeriodControl:SpecialDays, Presidents Day, !- Name 3rd Monday in February, !- Start Date 1, !- Duration \{days

Holiday; !- Special Day Type

RunPeriodControl:SpecialDays,

Memorial Day, !- Name Last Monday in May, !- Start Date 1, !- Duration \{days

Holiday; !- Special Day Type

RunPeriodControl:SpecialDays, Labor Day, !- Name 1st Monday in September, !- Start Date $1, \quad$ !- Duration \{days

Holiday; !- Special Day Type

RunPeriodControl:SpecialDays, Columbus Day, !- Name 2nd Monday in October, !- Start Date

1, !- Duration \{days

Holiday; !- Special Day Type

RunPeriodControl:SpecialDays,

Thanksgiving, !- Name

4th Thursday in November,!- Start Date

1, !- Duration \{days

Holiday; !- Special Day Type

! Daylight Saving Period in US

RunPeriodControl:DaylightSavingTime, 2nd Sunday in March, !- Start Date 1st Sunday in November; !- End Date

Site:GroundTemperature:BuildingSurface, 20.03,20.03,20.13,20.30,20 $43,20.52,20.62,20.77,20.78,20.55,20.44,20.20$ 


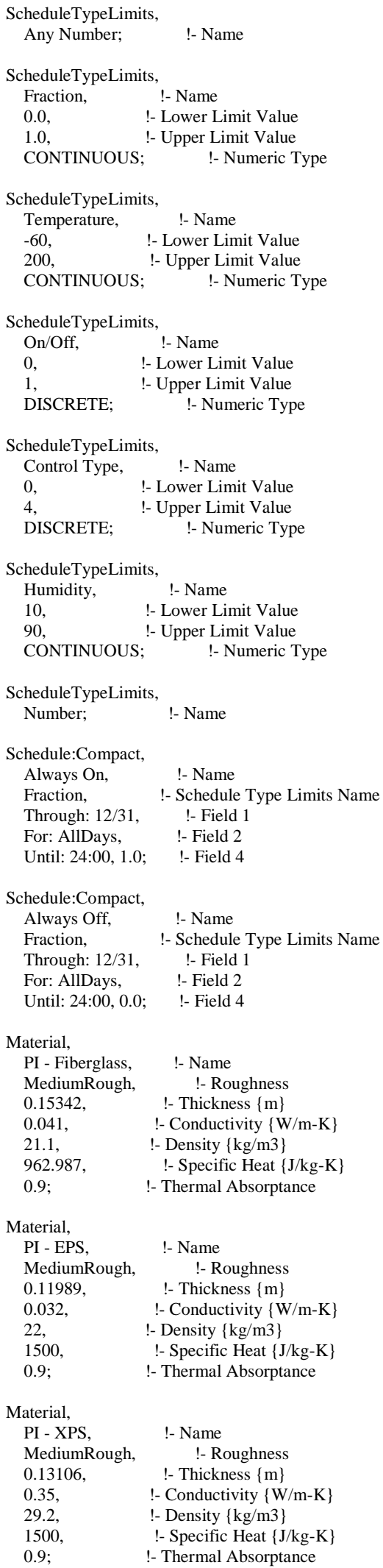

Material, PI - 30 Mil Mtl Stud 16 oc type C, !- Name Smooth, !- Roughness

Material,

PI - 3 5/8" Full Batt Insulation - Fiberglass, !- Name MediumRough, !- Roughness

Material, 


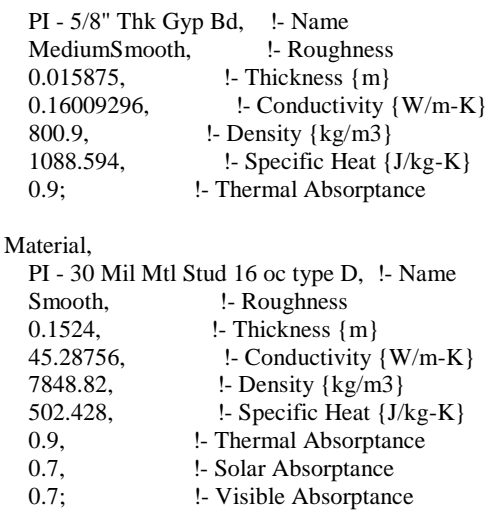

Material,

PI - 30 Mil Mtl Stud 16 oc type D, !- Name

Smooth, !- Roughness

0.1524, !- Thickness $\{\mathrm{m}\}$

45.28756, !- Conductivity $\{\mathrm{W} / \mathrm{m}-\mathrm{K}\}$

7848.82, !- Density $\{\mathrm{kg} / \mathrm{m} 3\}$

502.428, !- Specific Heat $\{\mathrm{J} / \mathrm{kg}-\mathrm{K}\}$

0.9, !- Thermal Absorptance

0.7, !- Solar Absorptance

0.7; !- Visible Absorptance

Material,

PI - 6" Full Batt Insulation - Fiberglass , !- Name

Smooth, !- Roughness

0.1524, !- Thickness $\{\mathrm{m}\}$

$0.04615292, \quad$ !- Conductivity $\{\mathrm{W} / \mathrm{m}-\mathrm{K}\}$

$84.8954, \quad$ !- Density $\{\mathrm{kg} / \mathrm{m} 3\}$

962.987; !- Specific Heat $\{\mathrm{J} / \mathrm{kg}-\mathrm{K}$

Material,

PI - Masonry Brick, !- Name

MediumRough, !- Roughnes

0.0762 , !- Thickness $\{\mathrm{m}\}$

0.865367334 , !- Conductivity $\{\mathrm{W} / \mathrm{m}-\mathrm{K}\}$

1922.16, !- Density $\{\mathrm{kg} / \mathrm{m} 3\}$

785.511; !- Specific Heat $\{\mathrm{J} / \mathrm{kg}-\mathrm{K}\}$

Material,

PI - 1/2" thk Sheating OSB, !- Name

Smooth, !- Roughness

0.0127, !- Thickness $\{\mathrm{m}\}$

0.12, !- Conductivity $\{\mathrm{W} / \mathrm{m}-\mathrm{K}\}$

660, !- Density $\{\mathrm{kg} / \mathrm{m} 3\}$

1300; !- Specific Heat $\{\mathrm{J} / \mathrm{kg}-\mathrm{K}\}$

Material,

PI - 43 Mil Mtl Stud 16 oc, !- Name

Smooth, !- Roughness

0.1524, !- Thickness $\{\mathrm{m}\}$

45.28756, !- Conductivity $\{\mathrm{W} / \mathrm{m}-\mathrm{K}\}$

7848.82, !- Density $\{\mathrm{kg} / \mathrm{m} 3\}$

502.428, !- Specific Heat $\{\mathrm{J} / \mathrm{kg}-\mathrm{K}\}$

0.9, !- Thermal Absorptance

0.7, !- Solar Absorptance

0.7; !- Visible Absorptance

Material,

PI - SIP OSB 7/16", !- Name

MediumSmooth, !- Roughness

0.0111125, !- Thickness $\{\mathrm{m}\}$

$0.12, \quad$ !- Conductivity $\{\mathrm{W} / \mathrm{m}-\mathrm{K}\}$

$660, \quad$ !- Density $\{\mathrm{kg} / \mathrm{m} 3\}$

1500, !- Specific Heat $\{\mathrm{J} / \mathrm{kg}-\mathrm{K}\}$

!- Thermal Absorptance

0.6; !- Solar Absorptance

Material,

PI - SIP Core-Expanded Polystyrene, !- Name

MediumRough, !- Roughness

$0.079375, \quad$ !- Thickness $\{\mathrm{m}\}$

0.037, !- Conductivity $\{\mathrm{W} / \mathrm{m}-\mathrm{K}\}$

22, !- Density $\{\mathrm{kg} / \mathrm{m} 3\}$

1300; !- Specific Heat $\{\mathrm{J} / \mathrm{kg}-\mathrm{K}\}$

Material,

PI - SIP 30 Mil Mtl Stud 16 oc, !- Name

Smooth, !- Roughness

0.041275, !- Thickness $\{\mathrm{m}\}$

45.28756, !- Conductivity $\{\mathrm{W} / \mathrm{m}-\mathrm{K}\}$

7848.82, !- Density $\{\mathrm{kg} / \mathrm{m} 3\}$

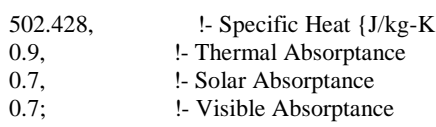

Material,

PI - Metal surface, !- Name

Smooth, !- Roughness

0.0008, !- Thickness $\{\mathrm{m}\}$

45.28, !- Conductivity $\{\mathrm{W} / \mathrm{m}-\mathrm{K}\}$

7824, !- Density $\{\mathrm{kg} / \mathrm{m} 3\}$

$500 ; \quad$ !- Specific Heat $\{\mathrm{J} / \mathrm{kg}-\mathrm{K}\}$

Material,

M11 100mm lightweight concrete, !- Name

MediumRough, !- Roughness

0.1016, !- Thickness $\{\mathrm{m}\}$

$0.53, \quad$ !- Conductivity $\{\mathrm{W} / \mathrm{m}-\mathrm{K}\}$

$1280, \quad$ !- Density $\{\mathrm{kg} / \mathrm{m} 3\}$

$840 ; \quad$ !- Specific Heat $\{\mathrm{J} / \mathrm{kg}-\mathrm{K}\}$

Material,

F16 Acoustic tile, !- Name

MediumSmooth, !- Roughness

0.0191, !- Thickness $\{\mathrm{m}\}$

$0.06, \quad$ !- Conductivity $\{\mathrm{W} / \mathrm{m}-\mathrm{K}$

$368, \quad$ !- Density $\{\mathrm{kg} / \mathrm{m} 3\}$

$590 ; \quad$ !- Specific Heat $\{\mathrm{J} / \mathrm{kg}-\mathrm{K}\}$

Material,

M01 100mm brick, !- Name

MediumRough, !- Roughness

$0.1016, \quad$ !- Thickness $\{\mathrm{m}\}$

0.89, !- Conductivity $\{\mathrm{W} / \mathrm{m}-\mathrm{K}\}$

1920, !- Density $\{\mathrm{kg} / \mathrm{m} 3\}$

$790 ; \quad$ !- Specific Heat $\{\mathrm{J} / \mathrm{kg}-\mathrm{K}\}$

Material,

M15 200mm heavyweight concrete, !- Name

MediumRough, !- Roughness

0.2032, !- Thickness $\{\mathrm{m}\}$

1.95, !- Conductivity $\{\mathrm{W} / \mathrm{m}-\mathrm{K}$

2240, !- Density $\{\mathrm{kg} / \mathrm{m} 3\}$

900; !- Specific Heat $\{\mathrm{J} / \mathrm{kg}-\mathrm{K}\}$

Material,

M05 200mm concrete block,!- Name

MediumRough, !- Roughness

0.2032, !- Thickness $\{\mathrm{m}\}$

$1.11, \quad !-$ Conductivity $\{\mathrm{W} / \mathrm{m}-\mathrm{K}\}$

$800, \quad$ !- Density $\{\mathrm{kg} / \mathrm{m} 3\}$

$920 ; \quad$ !- Specific Heat $\{\mathrm{J} / \mathrm{kg}-\mathrm{K}\}$

Material,

G05 25mm wood, !- Name

MediumSmooth, !- Roughness

0.0254, !- Thickness $\{\mathrm{m}\}$

$0.15, \quad$ !- Conductivity $\{\mathrm{W} / \mathrm{m}-\mathrm{K}\}$

608, !- Density $\{\mathrm{kg} / \mathrm{m} 3\}$

1630; !- Specific Heat $\{\mathrm{J} / \mathrm{kg}-\mathrm{K}\}$

Material,

CONCRETE - DRIED SAND AND GRAVEL 4 IN, !- Name

MediumRough, !- Roughness

$0.1000000, \quad$ !- Thickness $\{\mathrm{m}\}$

1.290000, !- Conductivity $\{\mathrm{W} / \mathrm{m}-\mathrm{K}\}$

2242.580, !- Density $\{\mathrm{kg} / \mathrm{m} 3\}$

$830.00000, \quad$ !- Specific Heat $\{\mathrm{J} / \mathrm{kg}-\mathrm{K}\}$

$0.9000000, \quad$ !- Thermal Absorptance

0.6000000, !- Solar Absorptance

0.6000000; !- Visible Absorptance

Material,

INS - EXPANDED EXT POLYSTYRENE R12 2 IN, !- Name

Rough,

!- Roughness

5.0000001E-02, !- Thickness $\{\mathrm{m}\}$

$2.0000000 \mathrm{E}-02, \quad$ !- Conductivity $\{\mathrm{W} / \mathrm{m}-\mathrm{K}\}$

$56.06000, \quad$ !- Density $\{\mathrm{kg} / \mathrm{m} 3\}$

1210.000, !- Specific Heat $\{\mathrm{J} / \mathrm{kg}-\mathrm{K}\}$ 


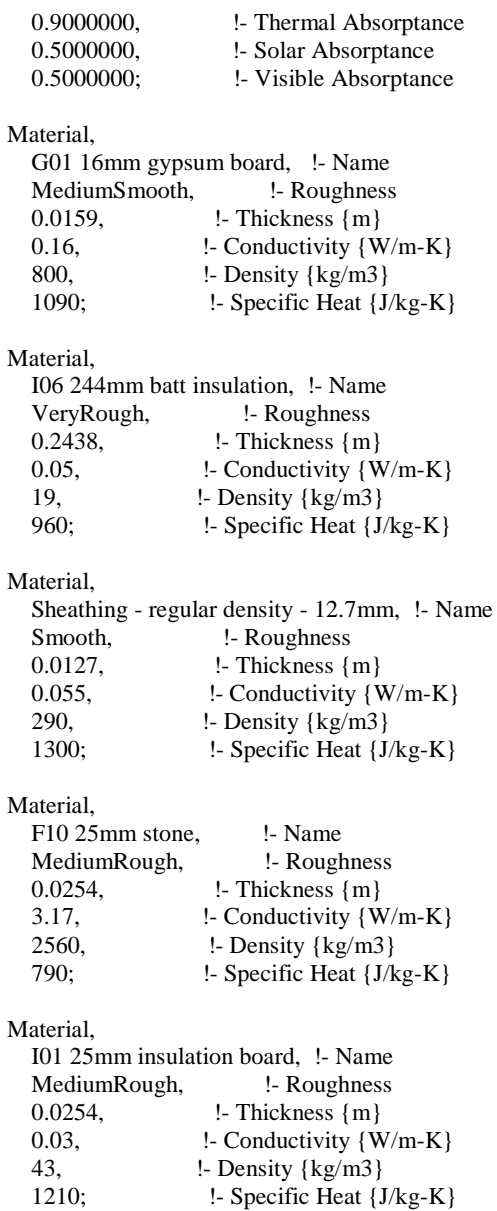

0.6000000; !- Visible Absorptance

Material,

Radiant Floor 4th Layer, !- Name

MediumRough, !- Roughnes

$0.0635, \quad$ !- Thickness $\{\mathrm{m}\}$

1.290000, !- Conductivity $\{\mathrm{W} / \mathrm{m}-\mathrm{K}$

2242.580, !- Density $\{\mathrm{kg} / \mathrm{m} 3\}$

$830.00000, \quad$ !- Specific Heat $\{\mathrm{J} / \mathrm{kg}-\mathrm{K}\}$

0.9000000, !- Thermal Absorptance

0.6000000, !- Solar Absorptance

0.6000000; !- Visible Absorptance

Material,

Radiant Floor Outside Layer, !- Name

MediumRough, !- Roughness

$0.025, \quad$ !- Thickness $\{\mathrm{m}\}$

$1.290000, \quad$ !- Conductivity $\{\mathrm{W} / \mathrm{m}-\mathrm{K}\}$

$2242.580, \quad$ !- Density $\{\mathrm{kg} / \mathrm{m} 3\}$

$830.00000, \quad$ !- Specific Heat $\{\mathrm{J} / \mathrm{kg}-\mathrm{K}\}$

0.9000000, !- Thermal Absorptance

0.6000000, !- Solar Absorptance

0.6000000; !- Visible Absorptance

Material:AirGap,

F04 Wall air space resistance, !- Name

0.15 !- Thermal Resistance $\{\mathrm{m} 2-\mathrm{K} / \mathrm{W}\}$

Material:AirGap,

F05 Ceiling air space resistance, !- Name

0.18 !- Thermal Resistance $\{\mathrm{m} 2-\mathrm{K} / \mathrm{W}\}$

WindowMaterial:Glazing,

PYR B CLEAR 3MM, !- Name

SpectralAverage, !- Optical Data Type

!- Window Glass Spectral Data Set Name

0.003, !- Thickness $\{\mathrm{m}\}$

$0.06, \quad$ !- Solar Transmittance at Normal Incidence

0.090, !- Front Side Solar Reflectance at Normal

Incidence

0.100, !- Back Side Solar Reflectance at Normal

0.820, !- Visible Transmittance at Normal Incidence

0.110, !- Front Side Visible Reflectance at Normal

0.120, !- Back Side Visible Reflectance at Normal

Incidence

0.0, !- Infrared Transmittance at Normal Incidence

0.84, !- Front Side Infrared Hemispherical Emissivity

0.20, !- Back Side Infrared Hemispherical Emissivity

0.9 !- Conductivity $\{\mathrm{W} / \mathrm{m}-\mathrm{K}\}$

WindowMaterial:Gas,

ARGON 13MM, !- Name

Argon, !- Gas Type

0.0127; !- Thickness $\{\mathrm{m}\}$

Construction,

PI - Floor Wood, !- Name

PI - Wood Flooring, !- Outside Layer

F05 Ceiling air space resistance, !- Layer 2

M11 100mm lightweight concrete; !- Layer 3

Construction,

PI - Floor Bamboo, !- Name

PI - Bamboo Flooring, !- Outside Layer

F05 Ceiling air space resistance, !- Layer 2

M11 100mm lightweight concrete; !- Layer 3

Construction,

Exterior Wall, !- Name

M01 100mm brick, !- Outside Layer

M15 200mm heavyweight concrete, !- Layer 2

I02 50mm insulation board, !- Layer 3

F04 Wall air space resistance, !- Layer 4

G01a 19mm gypsum board; !- Layer 5

Construction,

PI - Masonry Wall EPS， !- Name 
PI - Masonry Brick, !- Outside Layer PI - 1/2" thk Sheating OSB, !- Layer 2

F04 Wall air space resistance, !- Layer 3

PI - EPS, !- Layer 4

PI - 5/8" Thk Gyp Bd; !- Layer 5

Construction,

PI - Masonry Wall XPS, !- Name

PI - Masonry Brick, !- Outside Layer

PI - 1/2" thk Sheating OSB, !- Layer 2

F04 Wall air space resistance, !- Layer 3

PI - XPS, !- Layer 4

PI - 5/8" Thk Gyp Bd; !- Layer 5

Construction,

PI - Masonry Wall Rockwool, !- Name

PI - Masonry Brick, !- Outside Layer

PI - 1/2" thk Sheating OSB, !- Layer 2

F04 Wall air space resistance, !- Layer 3

PI - Rockwool, !- Layer 4

PI - 5/8" Thk Gyp Bd; !- Layer 5

Construction,

PI - Masonry Wall FG, !- Name

PI - Masonry Brick, !- Outside Layer

PI - 1/2" thk Sheating OSB, !- Layer 2

F04 Wall air space resistance, !- Layer 3

PI - Fiberglass, !- Layer 4

PI - 5/8" Thk Gyp Bd; !- Layer 5

Construction,

PI - Roof Clay Tiles, !- Name

M11 100mm lightweight concrete, !- Outside Layer

F05 Ceiling air space resistance, !- Layer 2

PI - Clay tile; !- Layer 3

Construction,

PI - Roof Concrete Tiles,!- Name

M11 100mm lightweight concrete, !- Outside Layer

F05 Ceiling air space resistance, !- Layer 2

PI - Concrete tile; !- Layer 3

Construction,

PI - Roof Organic Felt, !- Name

M11 100mm lightweight concrete, !- Outside Layer

F05 Ceiling air space resistance, !- Layer 2

PI - Organic Felt; !- Layer 3

Construction,

PI - Roof Steel Panel, !- Name

M11 100mm lightweight concrete, !- Outside Layer

F05 Ceiling air space resistance, !- Layer 2

PI - Roofing Steel Panel;!- Layer 3

Construction,

Exterior Floor, !- Name

I02 50mm insulation board, !- Outside Layer

M15 200mm heavyweight concrete; !- Layer 2

Construction,

Interior Floor, !- Name

F16 Acoustic tile, !- Outside Layer

F05 Ceiling air space resistance, !- Layer 2

M11 100mm lightweight concrete; !- Layer 3

Construction,

Interior Wall, !- Name

G01a 19mm gypsum board, !- Outside Layer

F04 Wall air space resistance, !- Layer 2

G01a 19mm gypsum board; !- Layer 3

Construction,

Exterior Roof, !- Name

M11 100mm lightweight concrete, !- Outside Layer

F05 Ceiling air space resistance, !- Layer 2

F16 Acoustic tile; !- Layer 3

Construction,

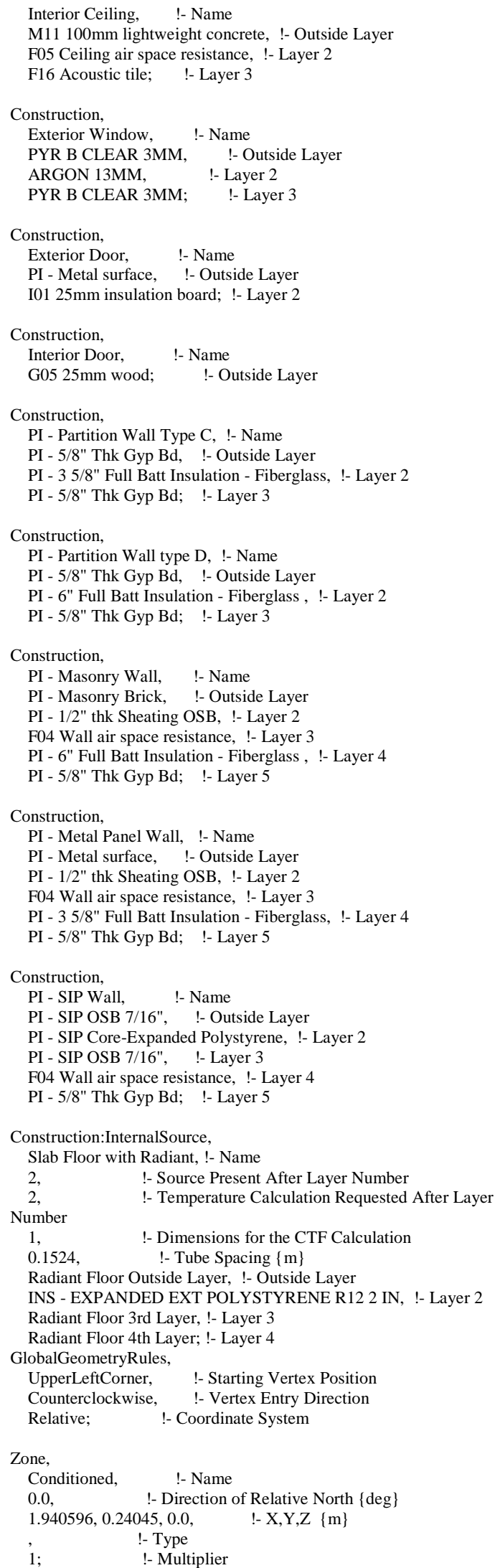




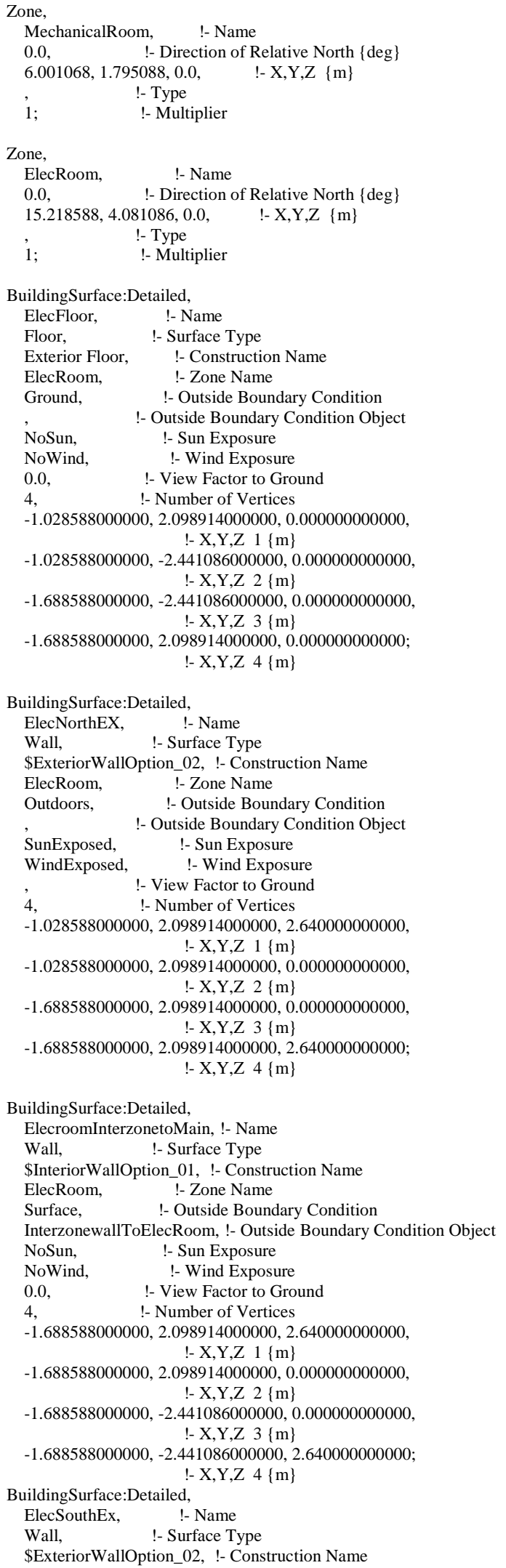

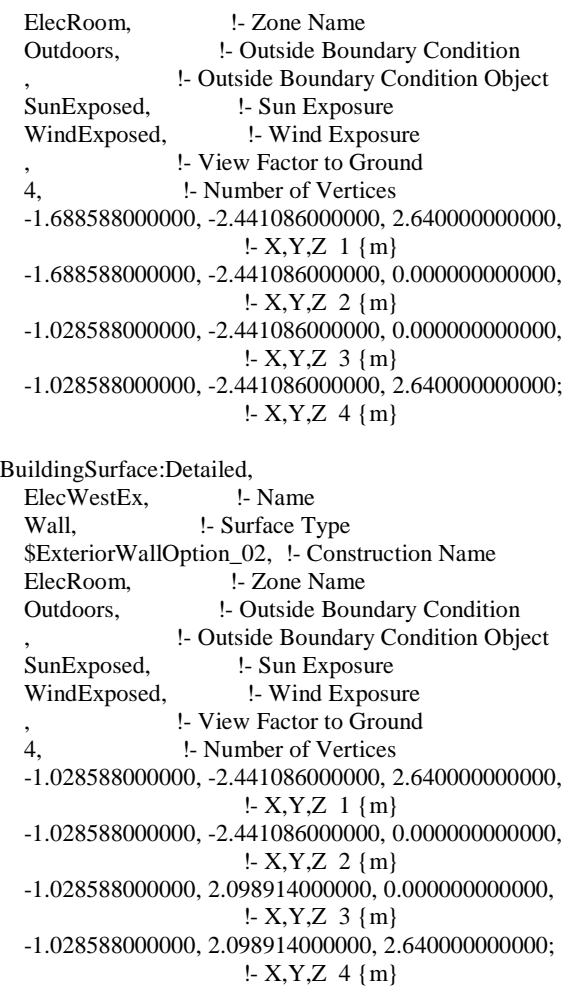


!- X,Y,Z $6\{\mathrm{~m}\}$

$-0.451068000000,2.114912000000,2.870000000000$;

!- X,Y,Z $7\{\mathrm{~m}\}$

BuildingSurface:Detailed,

MechWestExWall, !- Name

Wall, !- Surface Type

\$ExteriorWallOption_03, !- Construction Name

MechanicalRoom, !- Zone Name

Outdoors, !- Outside Boundary Condition

, !- Outside Boundary Condition Object

SunExposed, !- Sun Exposure

WindExposed, !- Wind Exposure

, !- View Factor to Ground

7, !- Number of Vertices

$-2.551068000000,6.534912000000,6.910000000000$ !- X,Y,Z $1\{\mathrm{~m}\}$

$-2.551068000000,6.534912000000,2.440000000000$, !- X,Y,Z $2\{\mathrm{~m}\}$

$-2.551068000000,6.024912000000,2.440000000000$ !- X,Y,Z $3\{\mathrm{~m}\}$

$-2.551068000000,6.024912000000,4.090000000000$ !- X,Y,Z $4\{\mathrm{~m}\}$

$-2.551068000000,2.114912000000,2.870000000000$, !- X,Y,Z $5\{\mathrm{~m}\}$

$-2.551068000000,-0.685088000000,3.743657289003$ !- X,Y,Z $6\{\mathrm{~m}\}$

$-2.551068000000,-0.685088000000,6.910000000000$; !- X,Y,Z $7\{\mathrm{~m}\}$

BuildingSurface:Detailed,

InterChimneytoMech, !- Name

Wall, !- Surface Type

\$InteriorWallOption_01, !- Construction Name

Conditioned, !- Zone Name

Surface, !- Outside Boundary Condition

InterMechtoChimney, !- Outside Boundary Condition Object

NoSun, !- Sun Exposure

NoWind, !- Wind Exposure

0.0, !- View Factor to Ground

6, !- Number of Vertices

1.509404000000, 0.869550000000, 6.910000000000, !- X,Y,Z $1\{\mathrm{~m}\}$

$1.509404000000,0.869550000000,2.440000000000$, !- X,Y,Z $2\{\mathrm{~m}\}$

2.699404000000, 0.869550000000, 2.440000000000, !- X,Y,Z $3\{\mathrm{~m}\}$

2.699404000000, 0.869550000000, 0.000000000000, !- X,Y,Z $4\{\mathrm{~m}\}$

3.609404000000, 0.869550000000, 0.000000000000, !- X,Y,Z $5\{\mathrm{~m}\}$

3.609404000000, 0.869550000000, 6.910000000000; !- X,Y,Z $6\{\mathrm{~m}\}$

BuildingSurface:Detailed,

Living left side wall, !- Name

Wall, !- Surface Type

\$ExteriorWallOption 01, !- Construction Name

Conditioned, !- Zone Name

Outdoors, !- Outside Boundary Condition

!- Outside Boundary Condition Object

SunExposed, !- Sun Exposure

WindExposed, !- Wind Exposure

!- View Factor to Ground

5, !- Number of Vertices

$-1.940596000000,7.579550000000,4.090000000000$, !- X,Y,Z $1\{\mathrm{~m}\}$

$-1.940596000000,7.579550000000,0.000000000000$ !- X,Y,Z $2\{\mathrm{~m}\}$

$-1.940596000000,-0.240450000000,0.000000000000$ !- X,Y,Z $3\{\mathrm{~m}\}$

$-1.940596000000,-0.240450000000,4.090000000000$ !- X,Y,Z $4\{\mathrm{~m}\}$

$-1.940596000000,3.669550000000,2.870000000000$

!- X,Y,Z $5\{\mathrm{~m}\}$

BuildingSurface:Detailed,

D502FE, !- Name
Wall, !- Surface Type

\$ExteriorWallOption_01, !- Construction Name

Conditioned, !- Zone Name

Outdoors, !- Outside Boundary Condition

!- Outside Boundary Condition Object

SunExposed, !- Sun Exposure

WindExposed, !- Wind Exposure

, !- View Factor to Ground

!- Number of Vertices

3.609404000000, 7.579550000000, 4.090000000000

!- X,Y,Z $1\{\mathrm{~m}\}$

3.609404000000, 7.579550000000, 0.000000000000,

!- X,Y,Z $2\{\mathrm{~m}\}$

11.589404000000, 7.579550000000, 0.000000000000, !- X,Y,Z $3\{\mathrm{~m}\}$

11.589404000000, 7.579550000000, 4.090000000000; !- X,Y,Z $4\{\mathrm{~m}\}$

BuildingSurface:Detailed,

NorthMasonaryToiletWall, !- Name

Wall, !- Surface Type

\$ExteriorWallOption_03, !- Construction Name

Conditioned, !- Zone Name

Outdoors, !- Outside Boundary Condition

!- Outside Boundary Condition Object

!- Sun Exposure

WindExposed, !- Wind Exposure

, !- View Factor to Ground

4, !- Number of Vertices

$3.609404000000,8.089550000000,2.440000000000$ !- X,Y,Z $1\{\mathrm{~m}\}$

3.609404000000, 8.089550000000, 0.000000000000 1- X,Y,Z $2\{\mathrm{~m}\}$

1.509404000000, 8.089550000000, 0.000000000000 !- X,Y,Z $3\{\mathrm{~m}\}$

1.509404000000, 8.089550000000, 2.440000000000

!- X,Y,Z $4\{\mathrm{~m}\}$

BuildingSurface:Detailed,

PartitionToilet, !- Name

Wall, !- Surface Type

\$ExteriorWallOption_03, !- Construction Name

Conditioned, !- Zone Name

Adiabatic, !- Outside Boundary Condition

NoSun, !- Outside Boundary Condition Object

- Sun Exposure

0.0, !- View Factor to Ground

4, !- Number of Vertices

$3.609404000000,5.519550000000,2.440000000000$

!- X,Y,Z $1\{\mathrm{~m}\}$

$3.609404000000,5.519550000000,0.000000000000$ !- X,Y,Z $2\{\mathrm{~m}\}$

$3.609404000000,7.579550000000,0.000000000000$ !- X,Y,Z $3\{\mathrm{~m}\}$

3.609404000000, 7.579550000000, 2.440000000000; !- X,Y,Z $4\{\mathrm{~m}\}$

BuildingSurface:Detailed,

ceilingtoMechRoom, !- Name

Ceiling, !- Surface Type

Interior Ceiling, !- Construction Name

Conditioned, !- Zone Name

Surface, !- Outside Boundary Condition

MechInterfloortoLiving, !- Outside Boundary Condition Object

NoSun, !- Sun Exposure

NoWind, !- Wind Exposure

!- View Factor to Ground

6, !- Number of Vertices

$1.509404000000,8.089550000000,2.440000000000$ !- X,Y,Z $1\{\mathrm{~m}\}$

$1.509404000000,0.869550000000,2.440000000000$ !- X,Y,Z $2\{\mathrm{~m}\}$

$2.699404000000,0.869550000000,2.440000000000$

!- X,Y,Z $3\{\mathrm{~m}\}$

2.699404000000, 5.519550000000, 2.440000000000 !- X,Y,Z $4\{\mathrm{~m}\}$

$3.609404000000,5.519550000000,2.440000000000$ 
!- X,Y,Z $5\{\mathrm{~m}\}$

3.609404000000, 8.089550000000, 2.440000000000;

!- X,Y,Z $6\{\mathrm{~m}\}$

BuildingSurface:Detailed,

InterKitchentoMech, !- Name

Wall, !- Surface Type

\$nteriorWallOption_01, !- Construction Name

Conditioned, !- Zone Name

Surface, !- Outside Boundary Condition

InterMechtoKitchen, !- Outside Boundary Condition Object

NoSun, !- Sun Exposure

NoWind, !- Wind Exposure

0.0, !- View Factor to Ground

4, !- Number of Vertices

2.699404000000, 0.869550000000, 2.440000000000, !- X,Y,Z $1\{\mathrm{~m}\}$

2.699404000000, 0.869550000000, 0.000000000000, !- X,Y,Z $2\{\mathrm{~m}\}$

$2.699404000000,5.519550000000,0.000000000000$ !- X,Y,Z $3\{\mathrm{~m}\}$

2.699404000000, 5.519550000000, 2.440000000000;

!- X,Y,Z $4\{\mathrm{~m}\}$

BuildingSurface:Detailed,

InterResttoMech, !- Name

Wall, !- Surface Type

\$InteriorWallOption_01, !- Construction Name

Conditioned, !- Zone Name

Surface, !- Outside Boundary Condition

InterMechtoRest, !- Outside Boundary Condition Object

NoSun, !- Sun Exposure

NoWind, !- Wind Exposure

0.0, !- View Factor to Ground

4, !- Number of Vertices

2.699404000000, 5.519550000000, 2.440000000000,

$$
\text { !- X,Y,Z } 1\{\mathrm{~m}\}
$$

2.699404000000, 5.519550000000, 0.000000000000, !- X,Y,Z $2\{\mathrm{~m}\}$

3.609404000000, 5.519550000000, 0.000000000000, !- X,Y,Z $3\{\mathrm{~m}\}$

3.609404000000, 5.519550000000, 2.440000000000; !- X,Y,Z $4\{\mathrm{~m}\}$

BuildingSurface:Detailed,

WestMasonaryToiletWall, !- Name

Wall, !- Surface Type

\$ExteriorWallOption_03, !- Construction Name

Conditioned, !- Zone Name

Outdoors, !- Outside Boundary Condition

!- Outside Boundary Condition Object

SunExposed, !- Sun Exposure

WindExposed, !- Wind Exposure

!- View Factor to Ground

4, !- Number of Vertices

1.509404000000, 8.089550000000, 2.440000000000, !- X,Y,Z $1\{\mathrm{~m}\}$

1.509404000000, 8.089550000000, 0.000000000000, !- X,Y,Z $2\{\mathrm{~m}\}$

1.509404000000, 7.579550000000, 0.000000000000, !- X,Y,Z $3\{\mathrm{~m}\}$

1.509404000000, 7.579550000000, 2.440000000000; !- X,Y,Z $4\{\mathrm{~m}\}$

BuildingSurface:Detailed,

EastChimneyWall, !- Name

Wall, !- Surface Type

\$ExteriorWallOption 01, !- Construction Name

Conditioned, !- Zone Name

Outdoors, !- Outside Boundary Condition

!- Outside Boundary Condition Object

SunExposed, !- Sun Exposure

WindExposed, !- Wind Exposure

6, !- Number of Vertices

3.609404000000, 0.869550000000, 6.910000000000, !- X,Y,Z $1\{\mathrm{~m}\}$

$3.609404000000,0.869550000000,3.743657289003$,
!- X,Y,Z $2\{\mathrm{~m}\}$

$3.609404000000,-0.240450000000,4.090000000000$ !- X,Y,Z $3\{\mathrm{~m}\}$

$3.609404000000,-0.240450000000,0.000000000000$ !- X,Y,Z $4\{\mathrm{~m}\}$

$3.609404000000,-0.750450000000,0.000000000000$ !- X,Y,Z $5\{\mathrm{~m}\}$

3.609404000000, -0.750450000000, 6.910000000000

!- X,Y,Z $6\{\mathrm{~m}\}$

BuildingSurface:Detailed,

SouthChimneyWall, !- Name

Wall, !- Surface Type

\$ExteriorWallOption_01, !- Construction Name

Conditioned, !- Zone Name

Outdoors, !- Outside Boundary Condition

!- Outside Boundary Condition Object

SunExposed, !- Sun Exposure

WindExposed, !- Wind Exposure

!- View Factor to Ground

4, !- Number of Vertices

3.609404000000, -0.750450000000, 6.910000000000,

!- X,Y,Z $1\{\mathrm{~m}\}$

3.609404000000, -0.750450000000, 0.000000000000,

!- X,Y,Z $2\{\mathrm{~m}\}$

$1.509404000000,-0.750450000000,0.000000000000$

!- X,Y,Z $3\{\mathrm{~m}\}$

1.509404000000, -0.750450000000, 6.910000000000 !- X,Y,Z $4\{\mathrm{~m}\}$

BuildingSurface:Detailed,

ChimneyRoof, !- Name

Roof, !- Surface Type

\$RoofingOption_01, !- Construction Name

Conditioned, !- Zone Name

Outdoors, !- Outside Boundary Condition

!- Outside Boundary Condition Object

SunExposed, !- Sun Exposure

WindExposed, !- Wind Exposure

0.0 !- View Factor to Ground

4, !- Number of Vertices

1.509404000000, 0.869550000000, 6.910000000000 !- X,Y,Z $1\{\mathrm{~m}\}$

$1.509404000000,-0.750450000000,6.910000000000$ !- X,Y,Z $2\{\mathrm{~m}\}$

3.609404000000, -0.750450000000, 6.910000000000

!- X,Y,Z $3\{\mathrm{~m}\}$

3.609404000000, 0.869550000000, 6.910000000000;

!- X,Y,Z $4\{\mathrm{~m}\}$

BuildingSurface:Detailed,

InterLivingtoMech, !- Name

Wall, !- Surface Type

\$InteriorWallOption_01, !- Construction Name

Conditioned, !- Zone Name

Surface, !- Outside Boundary Condition

InterMechtoLiving, !- Outside Boundary Condition Object

NoSun, !- Sun Exposure

NoWind, !- Wind Exposure

0.0, !- View Factor to Ground

$5 . \quad$ !- Number of Vertices

1.509404000000, 7.579550000000, 4.090000000000 !- X,Y,Z $1\{\mathrm{~m}\}$

$1.509404000000,7.579550000000,2.440000000000$

!- X,Y,Z $2\{\mathrm{~m}\}$

$1.509404000000,0.869550000000,2.440000000000$ !- X,Y,Z $3\{\mathrm{~m}\}$

$1.509404000000,0.869550000000,3.743657289003$ !- X,Y,Z $4\{\mathrm{~m}\}$

1.509404000000, 3.669550000000, 2.870000000000 ; !- X,Y,Z $5\{\mathrm{~m}\}$

BuildingSurface:Detailed,

SouthWindowFlameWallleft,!- Name

Wall, !- Surface Type

\$ExteriorWallOption_01, !- Construction Name

Conditioned, !- Zone Name

Outdoors, !- Outside Boundary Condition 


$$
\begin{aligned}
& \text { !- Outside Boundary Condition Object } \\
& \text { SunExposed, !- Sun Exposure } \\
& \text { WindExposed, !- Wind Exposure } \\
& \text { 4, !- Number of Vertices } \\
& \text { !- X,Y,Z } 4\{\mathrm{~m}\}
\end{aligned}
$$

BuildingSurface:Detailed,

NorthWindowFlameWallRight, !- Name

Wall, !- Surface Type

\$ExteriorWallOption_01, !- Construction Name

Conditioned, !- Zone Name

Outdoors, !- Outside Boundary Condition

, !- Outside Boundary Condition Object

SunExposed, !- Sun Exposure

WindExposed, !- Wind Exposure

!- View Factor to Ground

4, !- Number of Vertices

$-1.940596000000,7.579550000000,4.090000000000$ !- X,Y,Z $1\{\mathrm{~m}\}$

$-1.940596000000,7.579550000000,0.000000000000$, !- X,Y,Z $2\{\mathrm{~m}\}$

1.509404000000, 7.579550000000, 0.000000000000, !- X,Y,Z $3\{\mathrm{~m}\}$

1.509404000000, 7.579550000000, 4.090000000000; !- X,Y,Z $4\{\mathrm{~m}\}$

BuildingSurface:Detailed,

NorthWestRoof, !- Name

Roof, !- Surface Type

\$RoofingOption_01, !- Construction Name

Conditioned, !- Zone Name

Outdoors, !- Outside Boundary Condition

, !- Outside Boundary Condition Object

SunExposed, !- Sun Exposure

WindExposed, !- Wind Exposure

!- View Factor to Ground

4, !- Number of Vertices

$-1.940596000000,7.579550000000,4.090000000000$ !- X,Y,Z $1\{\mathrm{~m}\}$

$-1.940596000000,3.669550000000,2.870000000000$ !- X,Y,Z $2\{\mathrm{~m}\}$

$1.509404000000,3.669550000000,2.870000000000$, !- X,Y,Z $3\{\mathrm{~m}\}$

1.509404000000, 7.579550000000, 4.090000000000; !- X,Y,Z $4\{\mathrm{~m}\}$

BuildingSurface:Detailed,

SouthWestRoof, !- Name

Roof, !- Surface Type

\$RoofingOption 01, !- Construction Name

Conditioned, !- Zone Name

Outdoors, !- Outside Boundary Condition

!- Outside Boundary Condition Object

SunExposed, !- Sun Exposure

WindExposed, !- Wind Exposure

, !- View Factor to Ground

4, !- Number of Vertices

1.509404000000, -0.240450000000, 4.090000000000, !- X,Y,Z $1\{\mathrm{~m}\}$

$1.509404000000,3.669550000000,2.870000000000$, !- X,Y,Z $2\{\mathrm{~m}\}$

$-1.940596000000,3.669550000000,2.870000000000$ !- X,Y,Z $3\{\mathrm{~m}\}$

$-1.940596000000,-0.240450000000,4.090000000000$; !- X,Y,Z $4\{\mathrm{~m}\}$

BuildingSurface:Detailed,

WestChimneyWall, !- Name

Wall, !- Surface Type

\$ExteriorWallOption_01, !- Construction Name

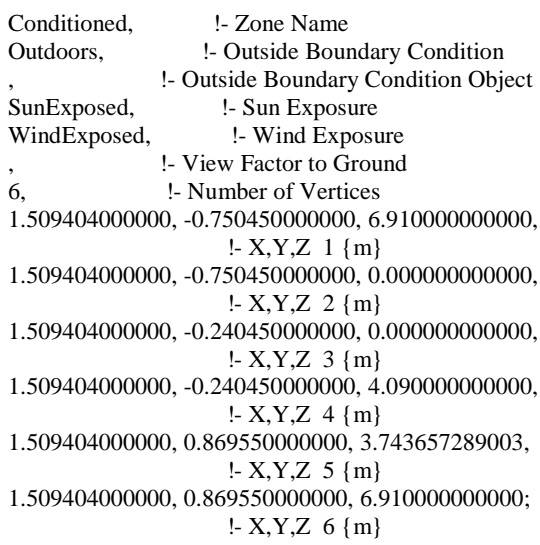




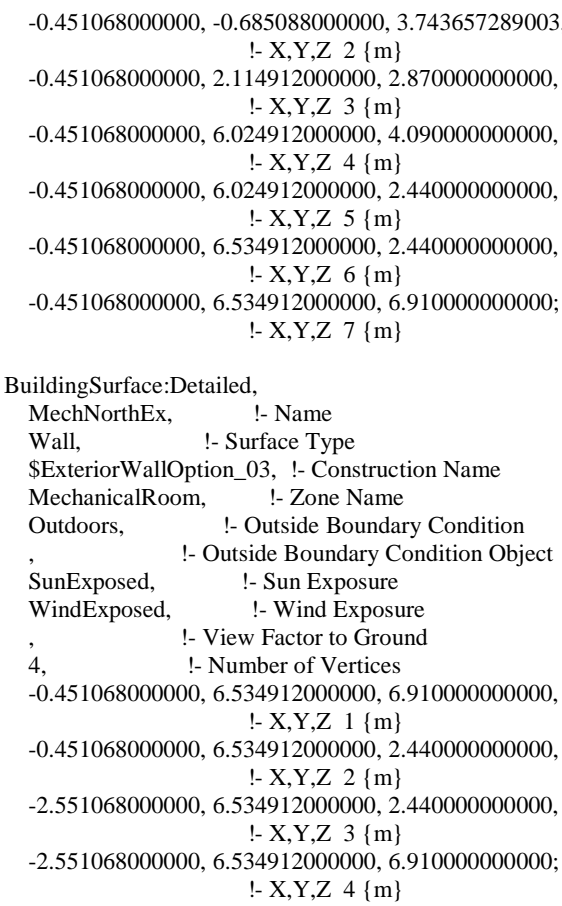

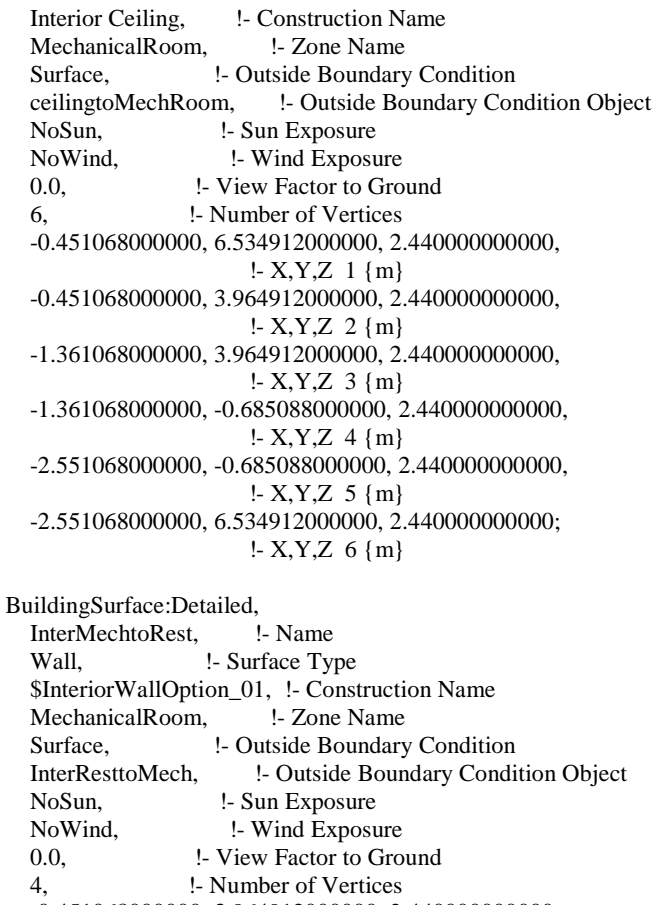


!- X,Y,Z $2\{\mathrm{~m}\}$

BuildingSurface:Detailed,

MainFloor, !- Name

Slab Floor with Radiant, !- Construction Name

Conditioned, !- Zone Name

Ground, !- Outside Boundary Condition

!- Outside Boundary Condition Object

NoSun, !- Sun Exposure

NoWind, !- Wind Exposure

0.0, !- View Factor to Ground

12, !- Number of Vertices

11.589404000000, 7.579550000000, 0.000000000000, !- X,Y,Z $1\{\mathrm{~m}\}$

$11.589404000000,-0.240450000000,0.000000000000$ !- X,Y,Z $2\{\mathrm{~m}\}$

3.609404000000, -0.240450000000, 0.000000000000, !- X,Y Z $3\{\mathrm{~m}\}$

3.609404000000, -0.750450000000, 0.000000000000 !- X,Y,Z $4\{\mathrm{~m}\}$

1.509404000000, -0.750450000000, 0.000000000000 !- X,Y,Z $5\{\mathrm{~m}\}$

1.509404000000, -0.240450000000, 0.000000000000, !- X,Y,Z $6\{\mathrm{~m}\}$

$-1.940596000000,-0.240450000000,0.000000000000$ !- X,Y,Z $7\{\mathrm{~m}\}$

$-1.940596000000,7.579550000000,0.000000000000$, !- X,Y,Z $8\{\mathrm{~m}\}$

1.509404000000, 7.579550000000, 0.000000000000, !- X,Y,Z $9\{\mathrm{~m}\}$

1.509404000000, 8.089550000000, 0.000000000000, !- X,Y,Z $10\{\mathrm{~m}\}$

3.609404000000, 8.089550000000, 0.000000000000, !- X,Y,Z $11\{\mathrm{~m}\}$

3.609404000000, 7.579550000000, 0.000000000000;

!- X,Y,Z $12\{\mathrm{~m}\}$

BuildingSurface:Detailed,

InterMaintoMech, !- Name

Wall, !- Surface Type

\$InteriorWallOption_01, !- Construction Name

Conditioned, !- Zone Name

Surface, !- Outside Boundary Condition

InterMechtoMain, !- Outside Boundary Condition Object

NoSun, !- Sun Exposure

NoWind, !- Wind Exposure

0.0, !- View Factor to Ground

7, !- Number of Vertices

3.609404000000, 0.869550000000, 3.743657289003,

!- X,Y,Z $1\{\mathrm{~m}\}$

3.609404000000, 0.869550000000, 0.000000000000, !- X,Y,Z $2\{\mathrm{~m}\}$

3.609404000000, 5.519550000000, 0.000000000000, !- X,Y,Z $3\{\mathrm{~m}\}$

3.609404000000, 5.519550000000, 2.440000000000, !- X,Y,Z $4\{\mathrm{~m}\}$

3.609404000000, 7.579550000000, 2.440000000000, !- X,Y,Z $5\{\mathrm{~m}\}$

3.609404000000, 7.579550000000, 4.090000000000, !- X,Y,Z $6\{\mathrm{~m}\}$

3.609404000000, 3.669550000000, 2.870000000000; !- X,Y,Z $7\{\mathrm{~m}\}$

BuildingSurface:Detailed,

NorthEastRoof, !- Name

Roof, !- Surface Type

\$RoofingOption_01, !- Construction Name

Conditioned, !- Zone Name

Outdoors, !- Outside Boundary Condition

!- Outside Boundary Condition Object

SunExposed, !- Sun Exposure

WindExposed, !- Wind Exposure

4, !- Number of Vertices

3.609404000000, 7.579550000000, 4.090000000000, !- X,Y,Z $1\{\mathrm{~m}\}$

3.609404000000, 3.669550000000, 2.870000000000,
$11.589404000000,3.669550000000,2.870000000000$,

!- X,Y,Z $3\{\mathrm{~m}\}$

11.589404000000, 7.579550000000, 4.090000000000;

!- X,Y,Z $4\{\mathrm{~m}\}$

BuildingSurface:Detailed,

SouthEastRoof, !- Name

Roof, !- Surface Type

\$RoofingOption_01, !- Construction Name

Conditioned, !- Zone Name

Outdoors, !- Outside Boundary Condition

!- Outside Boundary Condition Object

SunExposed, !- Sun Exposure

WindExposed, !- Wind Exposure

!- View Factor to Ground

4, !- Number of Vertices

11.589404000000, - -0.240450000000, 4.090000000000, !- X,Y,Z $1\{\mathrm{~m}\}$

11.589404000000, 3.669550000000, 2.870000000000, !- X,Y,Z $2\{\mathrm{~m}\}$

$3.609404000000,3.669550000000,2.870000000000$

!- X,Y,Z $3\{\mathrm{~m}\}$

3.609404000000, -0.240450000000, 4.090000000000

!- X,Y,Z $4\{\mathrm{~m}\}$

BuildingSurface:Detailed,

MechRoofEx, !- Name

Roof, !- Surface Type

\$RoofingOption 01, !- Construction Name

MechanicalRoom, !- Zone Name

Outdoors, !- Outside Boundary Condition

!- Outside Boundary Condition Object

SunExposed, !- Sun Exposure

WindExposed, !- Wind Exposure

!- View Factor to Ground

4 !- Number of Vertices

$-2.551068000000,6.534912000000,6.910000000000$, !- X,Y,Z $1\{\mathrm{~m}\}$

$-2.551068000000,-0.685088000000,6.910000000000$, !- X,Y,Z $2\{\mathrm{~m}\}$

$-0.451068000000,-0.685088000000,6.910000000000$, !- X,Y,Z $3\{\mathrm{~m}\}$

$-0.451068000000,6.534912000000,6.910000000000$ !- X,Y,Z $4\{\mathrm{~m}\}$

BuildingSurface:Detailed,

SouthWindowFlameWalllRightTop, !- Name

Wall, !- Surface Type

\$ExteriorWallOption_01, !- Construction Name

Conditioned, !- Zone Name

Outdoors, !- Outside Boundary Condition

!- Outside Boundary Condition Object

!- Sun Exposure

WindExposed, !- Wind Exposure

, !- View Factor to Ground

4 , !- Number of Vertices

$11.589404000000,-0.240450000000,4.090000000000$, !- X,Y,Z $1\{\mathrm{~m}\}$

$11.589404000000,-0.240450000000,0.000000000000$

!- X,Y,Z $2\{\mathrm{~m}\}$

3.609404000000, -0.240450000000, 0.000000000000, !- X,Y,Z $3\{\mathrm{~m}\}$

3.609404000000, -0.240450000000, 4.090000000000;

!- X,Y,Z $4\{\mathrm{~m}\}$

BuildingSurface:Detailed,

EastSolidWall, !- Name

Wall, !- Surface Type

\$ExteriorWallOption_01, !- Construction Name

Conditioned, !- Zone Name

Outdoors, !- Outside Boundary Condition

!- Outside Boundary Condition Object

SunExposed, !- Sun Exposure

WindExposed, !- Wind Exposure

!- View Factor to Ground

5, !- Number of Vertices

$11.589404000000,-0.240450000000,4.090000000000$ 
!- X,Y,Z $1\{\mathrm{~m}\}$

$11.589404000000,-0.240450000000,0.000000000000$, !- X,Y,Z $2\{\mathrm{~m}\}$

$11.589404000000,7.579550000000,0.000000000000$ !- X,Y,Z $3\{\mathrm{~m}\}$

$11.589404000000,7.579550000000,4.090000000000$ !- X,Y,Z $4\{\mathrm{~m}\}$

11.589404000000, 3.669550000000, 2.870000000000;

!- X,Y,Z $5\{\mathrm{~m}\}$

BuildingSurface:Detailed,

InterzonewallToElecRoom, !- Name

Wall, !- Surface Type

\$InteriorWallOption_01, !- Construction Name

Conditioned, !- Zone Name

Surface, !- Outside Boundary Condition

ElecroomInterzonetoMain, !- Outside Boundary Condition Object

NoSun, !- Sun Exposure

NoWind, !- Wind Exposure

0.0, !- View Factor to Ground

4, !- Number of Vertices

11.589404000000, 1.399550000000, 2.640000000000, !- X,Y,Z $1\{\mathrm{~m}\}$

11.589404000000, 1.399550000000, 0.000000000000 !- X,Y,Z $2\{\mathrm{~m}\}$

11.589404000000, 5.939550000000, 0.000000000000, !- X,Y,Z $3\{\mathrm{~m}\}$

11.589404000000, 5.939550000000, 2.640000000000 !- X,Y,Z $4\{\mathrm{~m}\}$

FenestrationSurface:Detailed,

Mechnical window left, !- Name

Window, !- Surface Type

Exterior Window, !- Construction Name

MechWestExWall, !- Building Surface Name

!- Outside Boundary Condition Object

!- View Factor to Ground

!- Shading Control Name

!- Frame and Divider Name

!- Multiplier

!- Number of Vertices

$-2.551068000000,6.433312000000,6.859200000000$ !- X,Y,Z $1\{\mathrm{~m}\}$

$-2.551068000000,6.433312000000,5.030400000000$ !- X,Y,Z $2\{\mathrm{~m}\}$

$-2.551068000000,4.477512000000,5.030400000000$ !- X,Y,Z $3\{\mathrm{~m}\}$

$-2.551068000000,4.477512000000,6.859200000000$; !- X,Y,Z $4\{\mathrm{~m}\}$

FenestrationSurface:Detailed,

Solar Chimney window left, !- Name

Window, !- Surface Type

Exterior Window, !- Construction Name

WestChimneyWall, !- Building Surface Name

, !- Outside Boundary Condition Object

!- View Factor to Ground

!- Shading Control Name

!- Frame and Divider Name

!- Multiplier

, !- Number of Vertices

1.509404000000, -0.648850000000, 6.859200000000 !- X,Y,Z $1\{\mathrm{~m}\}$

1.509404000000, $-0.648850000000,5.030400000000$ !- X,Y,Z $2\{\mathrm{~m}\}$

1.509404000000, 0.869550000000, 5.030400000000, !- X,Y,Z $3\{\mathrm{~m}\}$

1.509404000000, 0.869550000000, 6.859200000000; !- X,Y,Z $4\{\mathrm{~m}\}$

FenestrationSurface:Detailed,

Solar Chimney window front, !- Name

Window, !- Surface Type

Exterior Window, !- Construction Name

SouthChimneyWall, !- Building Surface Name

!- Outside Boundary Condition Object

!- View Factor to Ground

!- Shading Control Name

$$
\begin{aligned}
& \text {, !- Frame and Divider Name } \\
& \text { !- Multiplier } \\
& \text { 4, !- Number of Vertices }
\end{aligned}
$$

FenestrationSurface:Detailed,

Solar Chimney window right, !- Name

Window, !- Surface Type

Exterior Window, !- Construction Name

EastChimneyWall, !- Building Surface Name

, !- Outside Boundary Condition Object

!- View Factor to Ground

!- Shading Control Name

!- Frame and Divider Name

, !- Multiplier

3.609404000000, 0.869550000000, 6.859200000000 !- X,Y,Z $1\{\mathrm{~m}\}$

3.609404000000, 0.869550000000, 5.030400000000 !- X,Y,Z $2\{\mathrm{~m}\}$

3.609404000000, -0.648850000000, 5.030400000000 !- X,Y,Z $3\{\mathrm{~m}\}$

$3.609404000000,-0.648850000000,6.859200000000$; !- X,Y,Z $4\{\mathrm{~m}\}$

FenestrationSurface:Detailed,

Mechanical window left big, !- Name

Window, !- Surface Type

Exterior Window, !- Construction Name

MechEastEx, !- Building Surface Name

!- Outside Boundary Condition Object

!- View Factor to Ground

!- Shading Control Name

!- Frame and Divider Name

!- Multiplier

4, !- Number of Vertices

$-0.451068000000,4.477512000000,6.859200000000$ !- X,Y,Z $1\{\mathrm{~m}\}$

$-0.451068000000,4.477512000000,5.030400000000$

!- X,Y,Z $2\{\mathrm{~m}\}$

$-0.451068000000,6.433312000000,5.030400000000$ !- X,Y,Z $3\{\mathrm{~m}\}$

$-0.451068000000,6.433312000000,6.859200000000$ !- X,Y,Z $4\{\mathrm{~m}\}$

FenestrationSurface:Detailed,

Mechanical window back, !- Name

Window, !- Surface Type

Exterior Window, !- Construction Name

MechNorthEx, !- Building Surface Name

!- Outside Boundary Condition Object

!- View Factor to Ground

!- Shading Control Name

!- Frame and Divider Name

!- Multiplier

4, !- Number of Vertices

$-0.552668000000,6.534912000000,6.859200000000$ !- X,Y,Z $1\{\mathrm{~m}\}$

$-0.552668000000,6.534912000000,5.030400000000$ !- X,Y,Z $2\{\mathrm{~m}\}$

$-2.449468000000,6.534912000000,5.030400000000$ !- X,Y,Z $3\{\mathrm{~m}\}$

$-2.449468000000,6.534912000000,6.859200000000$ !- X,Y,Z $4\{\mathrm{~m}\}$

FenestrationSurface:Detailed,

Working door, !- Name

Door, !- Surface Type

Exterior Door, !- Construction Name

SouthWindowFlameWalliRightTop, !- Building Surface Name

!- Outside Boundary Condition Object 


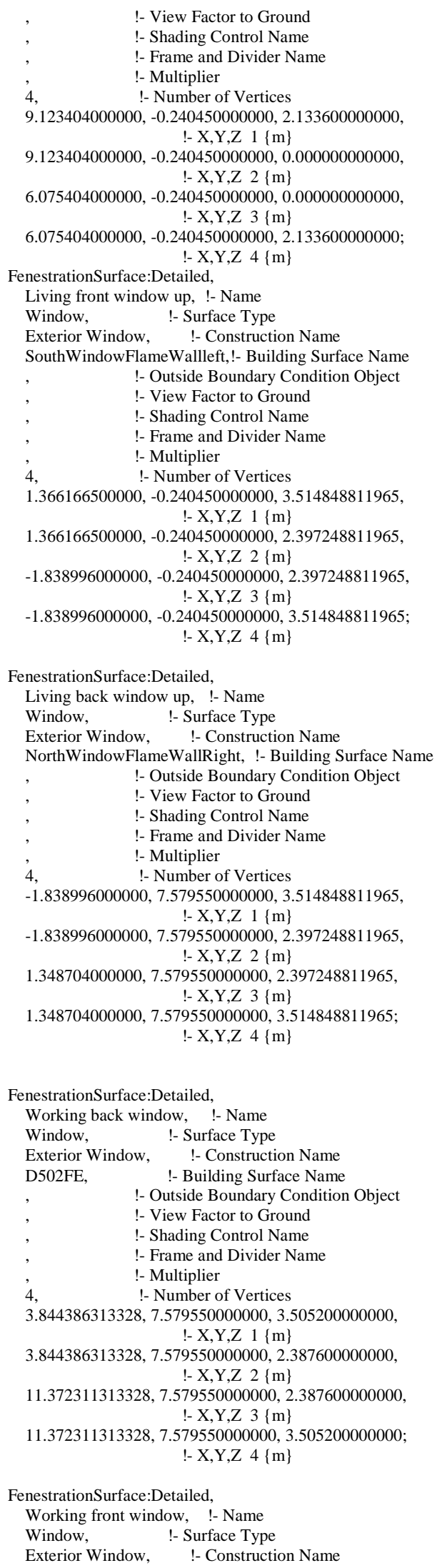

SouthWindowFlameWalllRightTop, !- Building Surface Name

!- Outside Boundary Condition Object

!- View Factor to Ground

!- Shading Control Name

!- Frame and Divider Name

!- Multiplier

4, !- Number of Vertices

$11.253328617860,-0.240450000000,3.505200000000$ !- X,Y,Z $1\{\mathrm{~m}\}$

$11.253328617860,-0.240450000000,2.387600000000$ !- X,Y,Z $2\{\mathrm{~m}\}$

$3.738103617860,-0.240450000000,2.387600000000$ !- X,Y,Z $3\{\mathrm{~m}\}$

$3.738103617860,-0.240450000000,3.505200000000$ !- X,Y,Z $4\{\mathrm{~m}\}$

FenestrationSurface:Detailed,

Living front window down,!- Name

Window, !- Surface Type

Exterior Window, !- Construction Name

SouthWindowFlameWallleft,!- Building Surface Name , !- Outside Boundary Condition Object

!- View Factor to Ground

!- Shading Control Name

, !- Shading Control Name

4, !- Multiplier

1.362991500000, -0.240450000000, 2.244848811965, !- X,Y,Z $1\{\mathrm{~m}\}$

$1.362991500000,-0.240450000000,0.073148811965$ !- X,Y,Z $2\{\mathrm{~m}\}$

$-1.838996000000,-0.240450000000,0.073148811965$, !- X,Y,Z $3\{\mathrm{~m}\}$

$-1.838996000000,-0.240450000000,2.244848811965$; !- X,Y,Z $4\{\mathrm{~m}\}$

FenestrationSurface:Detailed,

Living back window down, !- Name

Window, !- Surface Type

Exterior Window, !- Construction Name

NorthWindowFlameWallRight, !- Building Surface Name

, !- Outside Boundary Condition Object

!- View Factor to Ground

!- Shading Control Name

!- Frame and Divider Name

, !- Multiplier

-1.813596000000, 7.579550000000, 2.244848811965, !- X,Y,Z $1\{\mathrm{~m}\}$

$-1.813596000000,7.579550000000,0.111248811965$

!- X,Y,Z $2\{\mathrm{~m}\}$

1.348704000000, 7.579550000000, 0.111248811965, !- X,Y,Z $3\{\mathrm{~m}\}$

$1.348704000000,7.579550000000,2.244848811965$; !- X,Y,Z $4\{\mathrm{~m}\}$

FenestrationSurface:Detailed,

Living left window 1, !- Name

Window, !- Surface Type

Exterior Window, !- Construction Name

Living left side wall, !- Building Surface Name

!- Outside Boundary Condition Object

!- View Factor to Ground

!- Shading Control Name

!- Frame and Divider Name

!- Multiplier

4, !- Number of Vertices $-1.940596000000,7.463662500000,2.244848811965$
!- X,Y,Z $1\{\mathrm{~m}\}$

$-1.940596000000,7.463662500000,0.111248811965$, !- X,Y,Z $2\{\mathrm{~m}\}$

$-1.940596000000,5.939662500000,0.111248811965$ !- X,Y,Z $3\{\mathrm{~m}\}$

$-1.940596000000,5.939662500000,2.244848811965$ !- X,Y,Z $4\{\mathrm{~m}\}$

FenestrationSurface:Detailed,

Living left window 3, !- Name 


$$
\begin{aligned}
& \text { Window, !- Surface Type } \\
& \text { Exterior Window, !- Construction Name } \\
& \text { Living left side wall, !- Building Surface Name } \\
& \text {, !- Outside Boundary Condition Object } \\
& \text { !- View Factor to Ground } \\
& \text { !- Shading Control Name } \\
& \text { !- Frame and Divider Name } \\
& \text { !- Multiplier } \\
& \text { !- Number of Vertices } \\
& \text { FenestrationSurface:Detailed, } \\
& \text { Living door, !- Name } \\
& \text { Door, !- Surface Type } \\
& \text { Exterior Door, !- Construction Name } \\
& \text { Living left side wall, !- Building Surface Name } \\
& \text { !- Outside Boundary Condition Object } \\
& \text { !- View Factor to Ground } \\
& \text { !- Shading Control Name } \\
& \text { !- Frame and Divider Name } \\
& \text { 4, !- Multiplier }
\end{aligned}
$$

FenestrationSurface:Detailed,

Living left window 2, !- Name

Window, !- Surface Type

Exterior Window, !- Construction Name

Living left side wall, !- Building Surface Name

!- Outside Boundary Condition Object

!- View Factor to Ground

!- Shading Control Name

!- Frame and Divider Name

!- Multiplier

$4, \quad$ !- Number of Vertices
$-1.940596000000,1.195399817688,2$.

$$
\text { !- X,Y,Z } 1\{\mathrm{~m}\}
$$

$-1.940596000000,1.195399817688,0.063808822170$, !- X,Y,Z $2\{\mathrm{~m}\}$

$-1.940596000000,1.062049817688,0.063808822170$, !- X,Y,Z $3\{\mathrm{~m}\}$

$-1.940596000000,1.062049817688,2.232333822170$; !- X,Y,Z $4\{\mathrm{~m}\}$

FenestrationSurface:Detailed,

Living left window up 1, !- Name

Window, !- Surface Type

Exterior Window, !- Construction Name

Living left side wall, !- Building Surface Name

, !- Outside Boundary Condition Object

!- View Factor to Ground

!- Shading Control Name

!- Frame and Divider Name

!- Multiplier

4, !- Number of Vertices

$-1.940596000000,7.463662500000,2.828464534562$, !- X,Y,Z $1\{\mathrm{~m}\}$

$-1.940596000000,7.463662500000,2.439000000000$ !- X,Y,Z $2\{\mathrm{~m}\}$

$-1.940596000000,3.699242073884,2.439000000000$, !- X,Y,Z $3\{\mathrm{~m}\}$

-1.940596000000, 3.699242073884, 2.828464534562 ; !- X,Y,Z $4\{\mathrm{~m}\}$
FenestrationSurface:Detailed,

Living left window up 2, !- Name

Window, !- Surface Type

Exterior Window, !- Construction Name Living left side wall, !- Building Surface Name

!- Outside Boundary Condition Object

!- View Factor to Ground

!- Shading Control Name

!- Frame and Divider Name

!- Multiplier

4, !- Number of Vertices

$-1.940596000000,3.640566687729,2.828243386437$ !- X,Y,Z $1\{\mathrm{~m}\}$

$-1.940596000000,3.640566687729,2.439000000000$, !- X,Y,Z $2\{\mathrm{~m}\}$

$-1.940596000000,-0.138850000000,2.439000000000$, !- X,Y,Z $3\{\mathrm{~m}\}$

-1.940596000000, -0.138850000000, 2.828243386437; !- X,Y,Z $4\{\mathrm{~m}\}$

FenestrationSurface:Detailed,

75E66C, !- Name

Window, !- Surface Type

Exterior Window, !- Construction Name

Living left side wall, !- Building Surface Name

!- Outside Boundary Condition Object

!- View Factor to Ground

!- Shading Control Name

!- Frame and Divider Name

!- Multiplier

4, !- Number of Vertices

$-1.940596000000,7.416966472892,3.449033100849$ !- X,Y,Z $1\{\mathrm{~m}\}$

$-1.940596000000,7.416966472892,2.898170600849$ !- X,Y,Z $2\{\mathrm{~m}\}$

$-1.940596000000,5.754853972892,2.898170600849$, !- X,Y,Z $3\{\mathrm{~m}\}$

$-1.940596000000,5.754853972892,3.449033100849$; !- X,Y,Z $4\{\mathrm{~m}\}$

FenestrationSurface:Detailed,

A40630, !- Name

Window, !- Surface Type

Exterior Window, !- Construction Name

Living left side wall, !- Building Surface Name

, !- Outside Boundary Condition Object

!- View Factor to Ground

!- Shading Control Name

!- Frame and Divider Name

!- Multiplier

4, !- Number of Vertices

-1.940596000000, 5.640285501700, 3.349477701601, !- X,Y,Z $1\{\mathrm{~m}\}$

$-1.940596000000,5.640285501700,2.928790201601$ !- X,Y,Z $2\{\mathrm{~m}\}$

$-1.940596000000,5.333898001700,2.928790201601$, !- X,Y,Z $3\{\mathrm{~m}\}$

-1.940596000000, 5.333898001700, 3.349477701601; !- X,Y,Z $4\{\mathrm{~m}\}$

FenestrationSurface:Detailed,

6E2063, !- Name

Window, !- Surface Type

Exterior Window, !- Construction Name

Living left side wall, !- Building Surface Name

!- Outside Boundary Condition Object

!- View Factor to Ground

!- Shading Control Name

!- Frame and Divider Name

!- Multiplier

!- Number of Vertices

$4, \quad-1-$ Numbe

$-1.940596000000,5.196115258902,3.234606087084$ !- X,Y,Z $1\{\mathrm{~m}\}$

$-1.940596000000,5.196115258902,2.936156087084$ !- X,Y,Z $2\{\mathrm{~m}\}$

$-1.940596000000,4.897665258902,2.936156087084$ !- X,Y,Z $3\{\mathrm{~m}\}$

$-1.940596000000,4.897665258902,3.234606087084$ 


\section{!- X,Y,Z $4\{\mathrm{~m}\}$}

FenestrationSurface:Detailed,

802E3E, !- Name

Window, !- Surface Type

Exterior Window, !- Construction Name

Living left side wall, !- Building Surface Name

!- Outside Boundary Condition Object

!- View Factor to Ground

!- Shading Control Name

!- Frame and Divider Name

!- Multiplier

!- Number of Vertices

-1.940596000000, 7.378675934720, 3.831938482571, !- X,Y,Z $1\{\mathrm{~m}\}$

$-1.940596000000,7.378675934720,3.509675982571$, !- X,Y,Z $2\{\mathrm{~m}\}$

$-1.940596000000,6.950050934720,3.509675982571$ !- X,Y,Z $3\{\mathrm{~m}\}$

$-1.940596000000,6.950050934720,3.831938482571$. !- X,Y,Z $4\{\mathrm{~m}\}$

FenestrationSurface:Detailed,

D1B8FC, !- Name

Window, !- Surface Type

Exterior Window, !- Construction Name

Living left side wall, !- Building Surface Name

, !- Outside Boundary Condition Object

!- View Factor to Ground

!- Shading Control Name

!- Frame and Divider Name

!- Multiplier

$4, \quad$ !- Number of Vertices
$-1.940596000000,1.583129342773,3$.

$-1.940596000000,1.583129342773,3.447214125062$ !- X,Y,Z $1\{\mathrm{~m}\}$

$-1.940596000000,1.583129342773,2.956676625062$ !- X,Y,Z $2\{\mathrm{~m}\}$

$-1.940596000000,-0.125020657227,2.956676625062$ !- X,Y,Z $3\{\mathrm{~m}\}$

$-1.940596000000,-0.125020657227,3.447214125062$; !- X,Y,Z $4\{\mathrm{~m}\}$

FenestrationSurface:Detailed,

17DACE, !- Name

Window, !- Surface Type

Exterior Window, !- Construction Name

Living left side wall, !- Building Surface Name

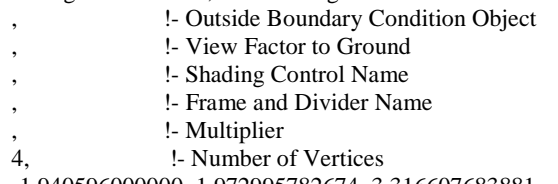

-1.940596000000, 1.972995782674, 3.316607683881, !- X,Y,Z $1\{\mathrm{~m}\}$

$-1.940596000000,1.972995782674,2.956245183881$ !- X,Y,Z $2\{\mathrm{~m}\}$

$-1.940596000000,1.720583282674,2.956245183881$ !- X,Y,Z $3\{\mathrm{~m}\}$

$-1.940596000000,1.720583282674,3.316607683881$; !- X,Y,Z $4\{\mathrm{~m}\}$

FenestrationSurface:Detailed,

CA26E4, !- Name

Window, !- Surface Type

Exterior Window, !- Construction Name

Living left side wall, !- Building Surface Name

!- Outside Boundary Condition Object

!- View Factor to Ground

!- Shading Control Name

!- Frame and Divider Name

!- Multiplier

4, !- Number of Vertices

$-1.940596000000,2.379180539237,3.194077961730$

!- X,Y,Z $1\{\mathrm{~m}\}$

-1.940596000000, 2.379180539237, 2.949602961730, !- X,Y,Z $2\{\mathrm{~m}\}$

$-1.940596000000,2.080730539237,2.949602961730$,
!- X,Y,Z $3\{\mathrm{~m}$

$-1.940596000000,2.080730539237,3.194077961730$ !- X,Y,Z $4\{\mathrm{~m}\}$

FenestrationSurface:Detailed,

6EC22E, !- Name

Window, !- Surface Type

Exterior Window, !- Construction Name

Living left side wall, !- Building Surface Name

!- Outside Boundary Condition Object

!- View Factor to Ground

!- Shading Control Name

!- Frame and Divider Name

!- Multiplier

4, !- Number of Vertices

$-1.940596000000,0.350391165676,3.837701590011$ !- X,Y,Z $1\{\mathrm{~m}\}$

$-1.940596000000,0.350391165676,3.523376590011$, !- X,Y,Z $2\{\mathrm{~m}\}$

$-1.940596000000,-0.102046334324,3.523376590011$, !- X,Y,Z $3\{\mathrm{~m}\}$

$-1.940596000000,-0.102046334324,3.837701590011$; !- X,Y,Z $4\{\mathrm{~m}\}$ 
Appendix D: XML Option File 


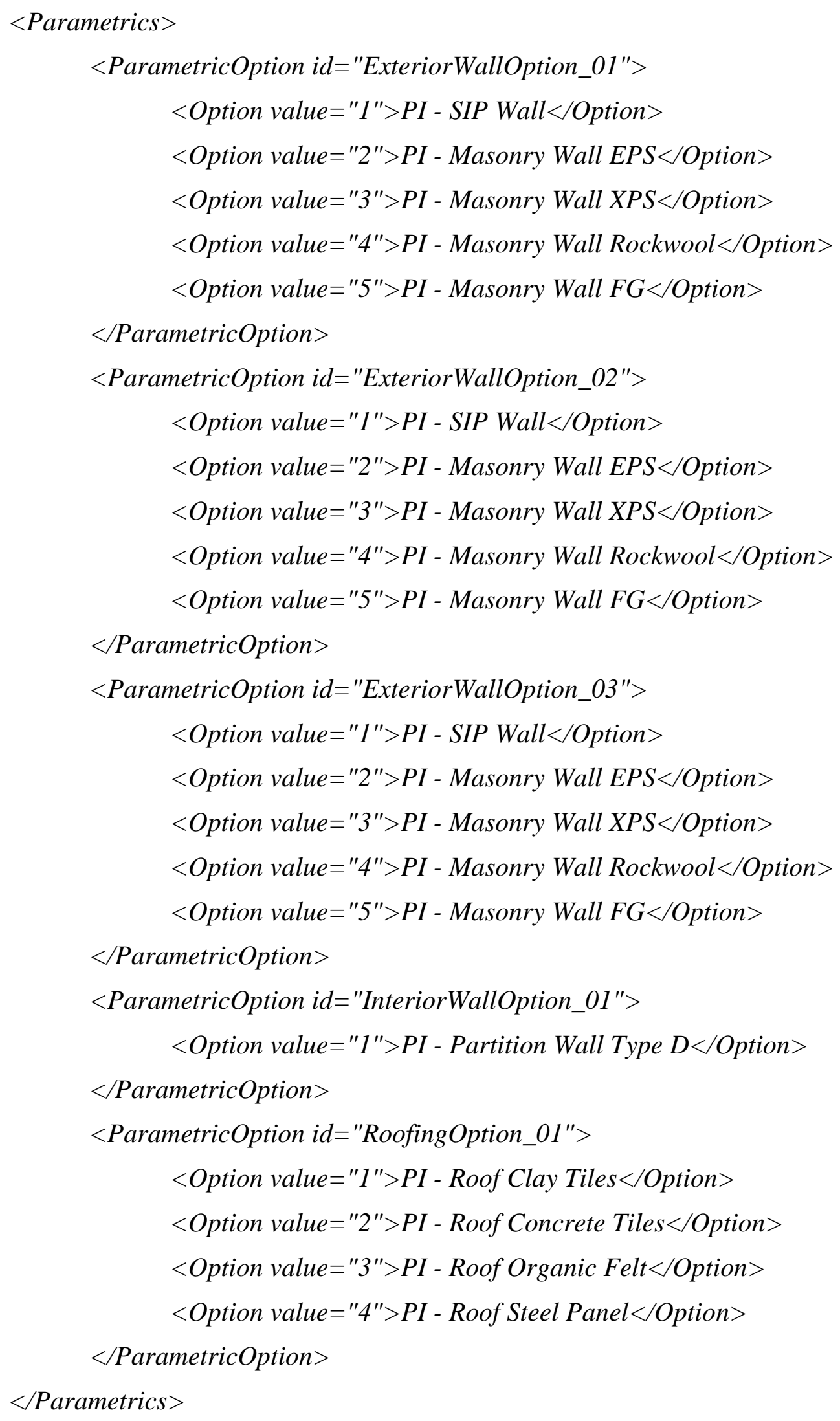




\section{PEERAYA INYIM}

Born, Phitsanulok, THAILAND

June 2003-May 2007

Mar 2006 - May 2006

May 2007 - May 2008

Aug 2009 - Dec 2010

March 2014

May 2014 - July 2014

Aug 2011 - Apr 2015
Bachelor of Engineering in Civil Engineering

Department of Civil Engineering

Chulalongkorn University,

Bangkok, THAILAND

Construction Management Engineer Intern

Unique Engineering and Construction Public Company

Limited

Bangkok, THAILAND

Structural Engineer and Social Coordinator for Graduate Development Organization (GDO)

WorleyParsons (Thailand) Limited, Thailand

Master of Science in Civil Engineering

Viterbi School of Engineering

University of Southern California (USC)

Los Angeles, CA USA

Elevator Pitches People's Choice Award

EPA P3 Competition and National Sustainable Design

Expo, the US Science and Engineering Festival (USA SEF)

Washington DC, USA

Dissertation Year Fellowship (DYF)

University Graduate School

Florida International University (FIU)

Miami, FL USA

Ph.D. Candidate

Department of Civil and Environmental Engineering

Florida International University (FIU)

Miami, FL

Graduate Assistant

OHL School of Construction, Miami, FL

Florida International University (FIU)

Miami, FL 
National Science Foundation (NSF)

Grant No. 1000136 ( PI: Yimin Zhu/Wallied Orabi)

April 2015

Provost Award

Scholarly Forum

Graduate Student Appreciation Week

University Graduate School

Florida International University (FIU)

\section{PUBLICATIONS}

Inyim, P., Rivera, J., \& Zhu, Y. (2014). Integration of Building Information Modeling and Economic and Environmental Impact Analysis to Support Sustainable Building Design. Journal of Management in Engineering, 31(1).

Inyim, P, Zhu, Y. (2014). Application of Monte Carlo Simulation and Optimization to Multiple Objectives Analysis of Sustainable Building Designs. Proceedings from Computing in Civil and Building Engineering, 2009-2016.

Inyim, P., Zhu, Y. (2014). Integration of Monte Carlo Simulation and Genetic Algorithms for Sustainable Designs Analysis. Proceedings from Construction Research Congress 2014, 699-708.

Inyim, P., Ha, H. Y., Phan, L., Zhu, Y., \& Chen, S. (2014). Integration of Video Image Processing and BIM-Based Energy Simulation for Analyzing the Impact of Dynamic User Patterns on Building Energy Consumption. Proceedings from International Conference on Construction \& Real Estate Management, 526-534.

Inyim, P., Zhu, Y. (2013). A Simulation-based Approach for Selecting Sustainable Building Designs. Proceedings from $C I B W 78,30^{\text {th }}$ International Conference on Applications of IT in the AEC Industry, Beijing, China

Inyim, P., Zhu, Y. (2013). A Framework for Integrated Analysis of Building Designs Using Life Cycle Assessment and Energy Simulation. Proceedings from International Conference on Construction \& Real Estate Management, 316-327.

Zhu, Y., Inyim, P., \& Rivera, J. (2012). SimulEICon: A Multi-objective Decision Support Tool for Sustainable Construction. Proceedings from International Conference on Construction \& Real Estate Management, 134-138. 